June 2003 - NREL/TP-550-33954

\title{
A Model for Ground-Coupled Heat and Moisture Transfer from Buildings
}

M. Deru, Ph.D.

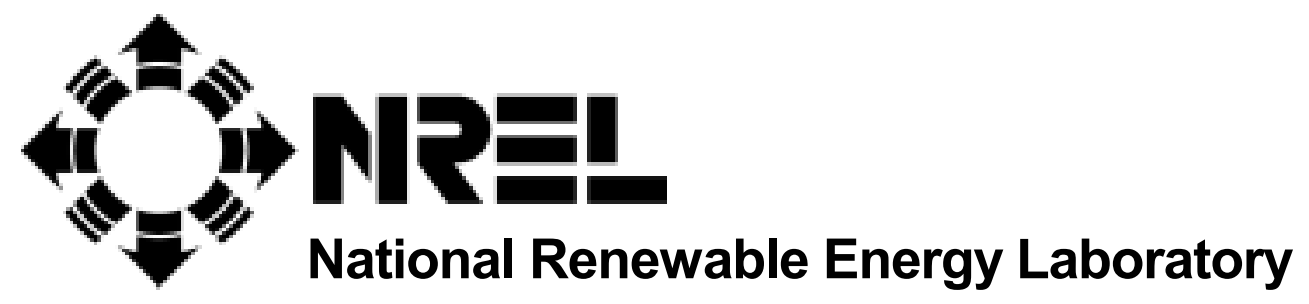

1617 Cole Boulevard

Golden, Colorado 80401-3393

NREL is a U.S. Department of Energy Laboratory

Operated by Midwest Research Institute $\bullet$ Battelle $\bullet$ Bechtel

Contract No. DE-AC36-99-G010337 


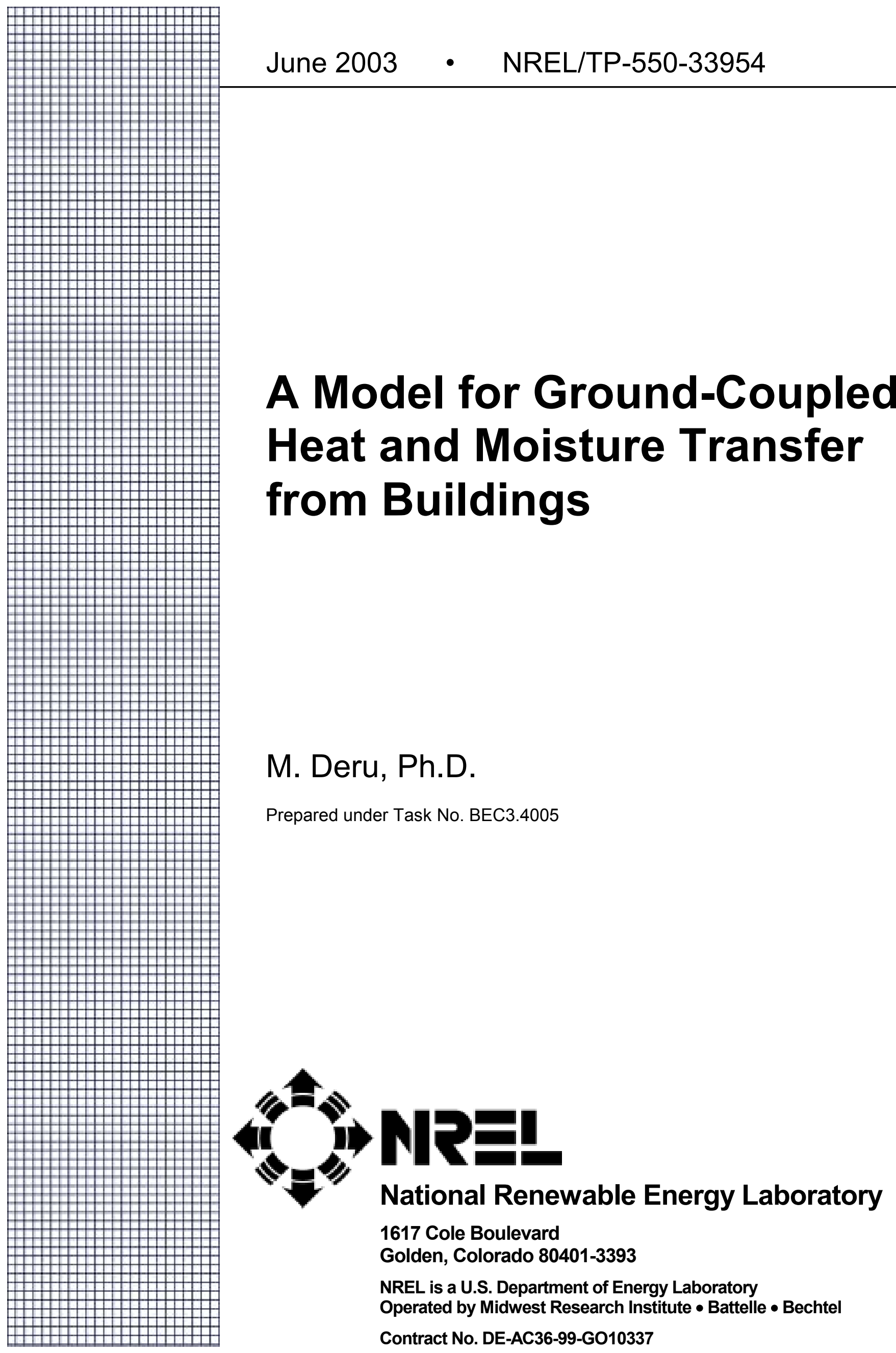




\section{NOTICE}

This report was prepared as an account of work sponsored by an agency of the United States government. Neither the United States government nor any agency thereof, nor any of their employees, makes any warranty, express or implied, or assumes any legal liability or responsibility for the accuracy, completeness, or usefulness of any information, apparatus, product, or process disclosed, or represents that its use would not infringe privately owned rights. Reference herein to any specific commercial product, process, or service by trade name, trademark, manufacturer, or otherwise does not necessarily constitute or imply its endorsement, recommendation, or favoring by the United States government or any agency thereof. The views and opinions of authors expressed herein do not necessarily state or reflect those of the United States government or any agency thereof.

Available electronically at http://www.osti.gov/bridge

Available for a processing fee to U.S. Department of Energy and its contractors, in paper, from:

U.S. Department of Energy

Office of Scientific and Technical Information

P.O. Box 62

Oak Ridge, TN 37831-0062

phone: 865.576 .8401

fax: 865.576.5728

email: reports@adonis.osti.gov

Available for sale to the public, in paper, from:

U.S. Department of Commerce

National Technical Information Service

5285 Port Royal Road

Springfield, VA 22161

phone: 800.553.6847

fax: 703.605.6900

email: orders@ntis.fedworld.gov

online ordering: http://www.ntis.gov/ordering.htm 


\section{Acknowledgments}

This work was made possible under the U.S. Department of Energy's (DOE's) Office of Energy Efficiency and Renewable Energy High Performance Building's Initiative. We appreciate the support and guidance of Dru Crawley, Program Manager for the High Performance Buildings Initiative, as well as the following people who reviewed this document prior to publication:

Brent Griffith, Paul Torcellini and Ron Judkoff (National Renewable Energy Laboratory) and a dissertation review panel at Colorado State University (Dr. Patrick Burns, Dr. Douglas Hittle, Dr. Erik Thompson, and Dr. Allan Kirkpatrick). 


\section{TABLE OF CONTENTS}

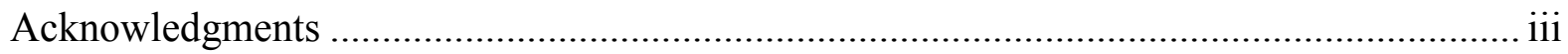

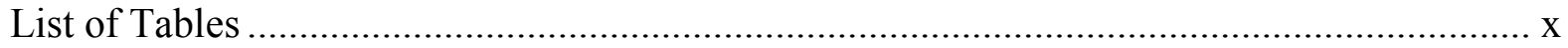

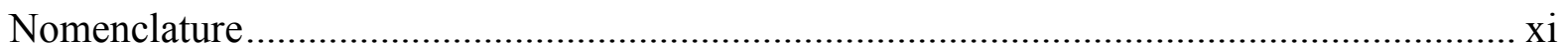

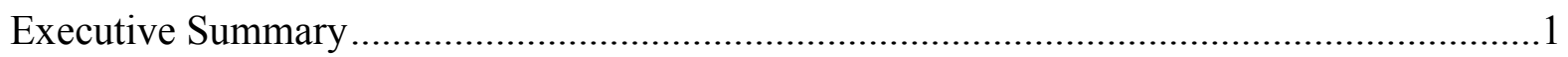

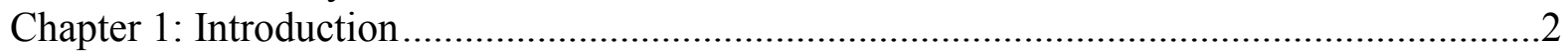

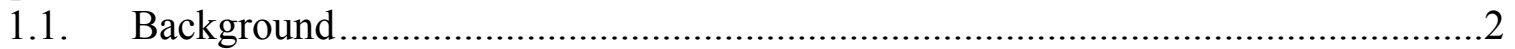

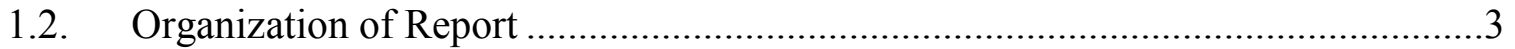

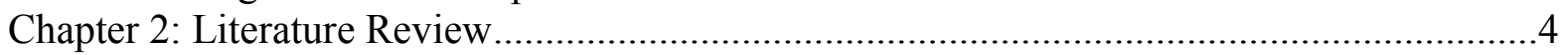

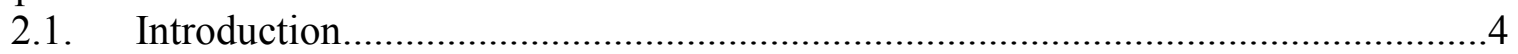

2.2. Experimental Work in Building Ground-Coupled Heat Transfer ............................

2.3. Analytic Solutions to Ground-Coupled Heat Transfer ..............................................5

2.4. Design Calculation Methods.........................................................................

2.5. Numerical Models of Building Ground-Coupled Heat Transfer ..............................

2.6. Effects of Ground Cover............................................................................11

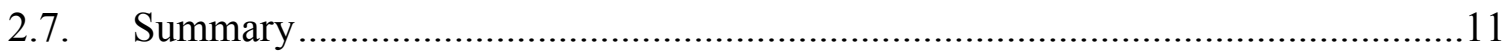

Chapter 3: Review of Soil Physics ...........................................................................13

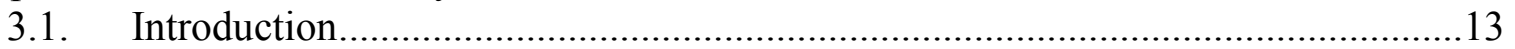

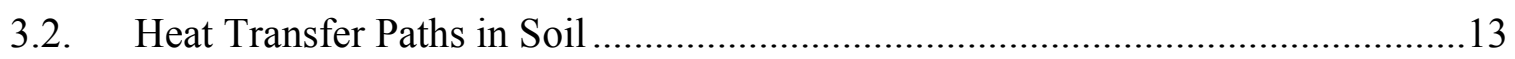

3.3. Hydraulic and Thermal Properties of Soil ........................................................15

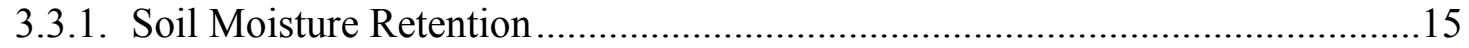

3.3.2. Hydraulic Conductivity ………...............................................................17

3.3.3. Temperature Effects on Hydraulic Properties ..................................................18

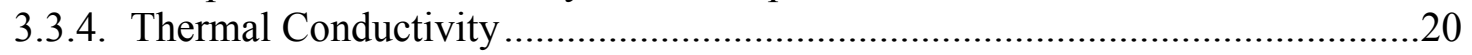

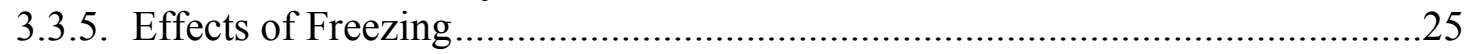

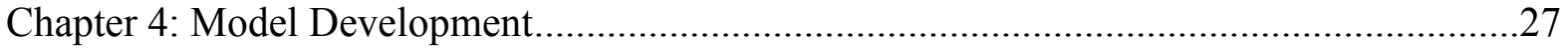

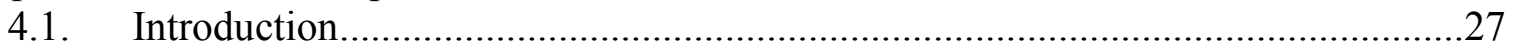

4.2. Coupled Heat and Moisture Transfer Model .......................................................22

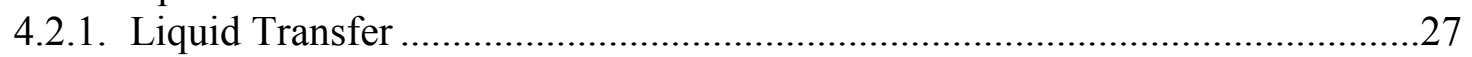

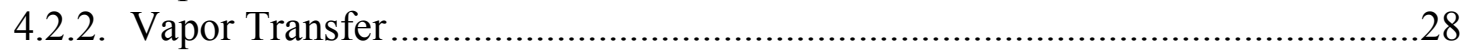

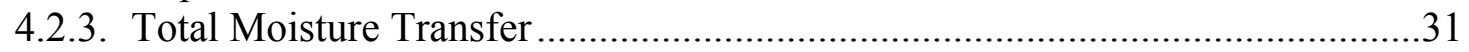

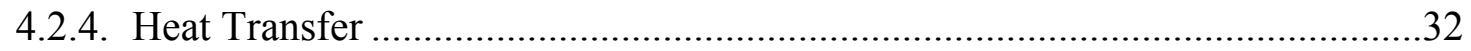

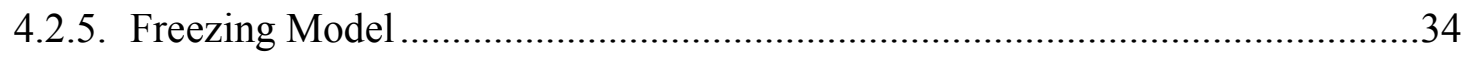

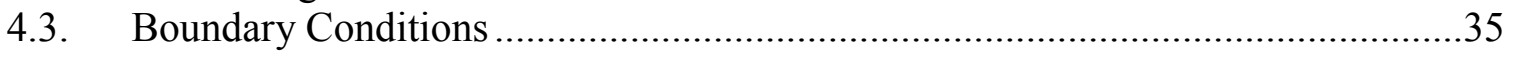

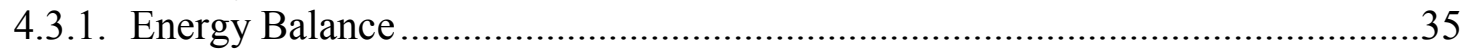

4.3.2. Moisture Balance ……………...................................................................4

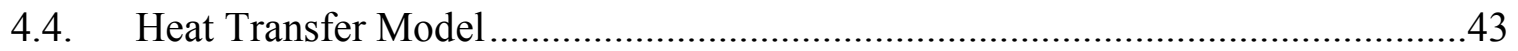

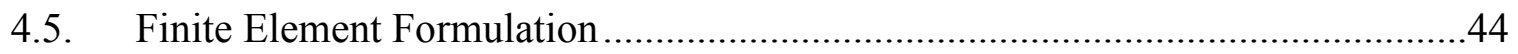

4.6. Spatial and Temporal Discretization .............................................................47

Chapter 5: Testing, Verification, and Validation..............................................................50

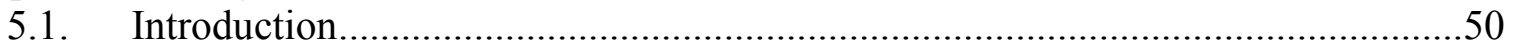

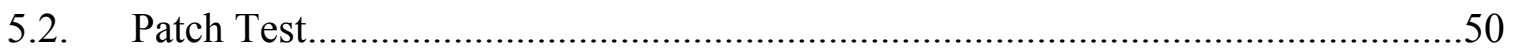

5.3. Two-Dimensional Heat Conduction Problem …………………........................51

5.4. One-Dimensional Isothermal Infiltration Problem ..............................................52

5.5. Comparison with Field Experimental Results .....................................................54

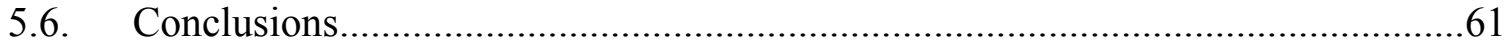




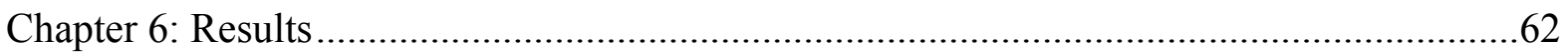

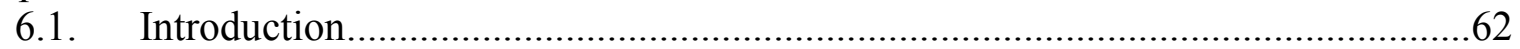

6.2. Comparison of Soil Heat Transfer Terms ........................................................62

6.3. Slab-on-Grade and Basement Heat-Transfer Simulation Parameters ....................66

6.4. Effect of Surface Moisture on Slab-on-Grade Heat Transfer ................................69

6.5. Effects of Surface Moisture on Basement Heat Transfer ........................................72

6.6. Effect of Groundwater Depth on Heat Transfer From a Basement ........................77

6.7. Effect of Buildings on the Soil Moisture Field...................................................79

6.8. Effect of Freezing on Heat Transfer From a Basement .........................................82

6.9. Comparison of the Heat and Moisture Transfer Model with a Heat

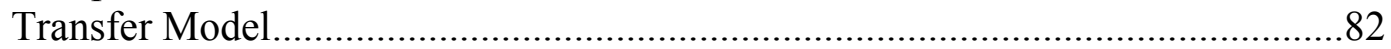

6.10. Comparison of the Heat Transfer Model with the Mitalas Method.........................87

6.11. Comparison of the Heat Transfer Model with the ASHRAE Method...................89

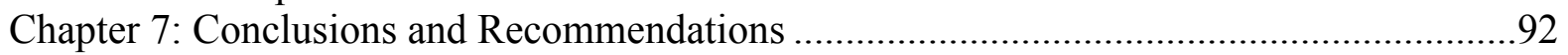

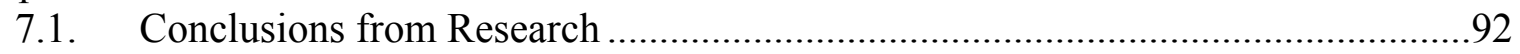

7.2. Recommendations for Further Work …………................................................94

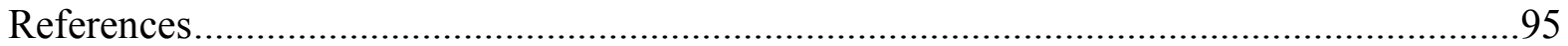

APPENDIX A: Derivation of the Heat-and-Moisture Transfer Equations ............................105

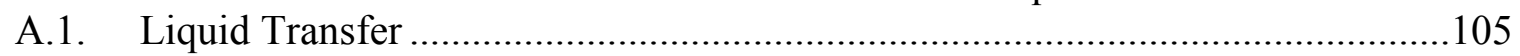

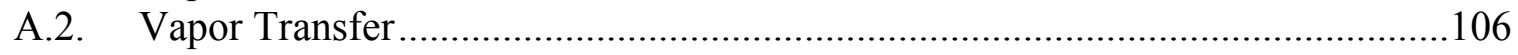

A.3. Total Moisture Transfer ..........................................................................111

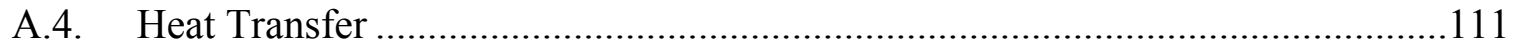

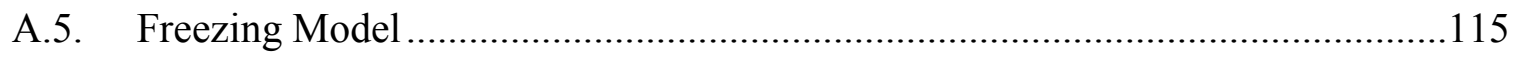

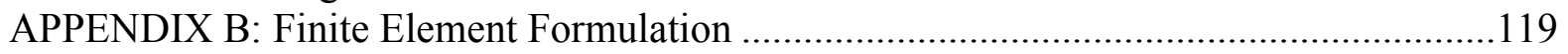

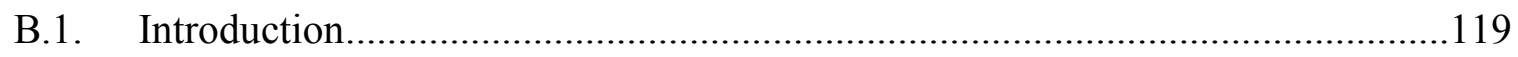

B.2. Application to the Heat-and-Moisture Transfer Equations .................................119

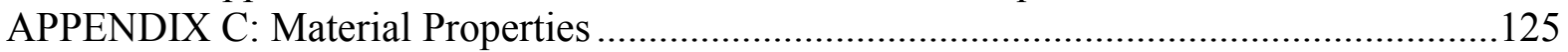

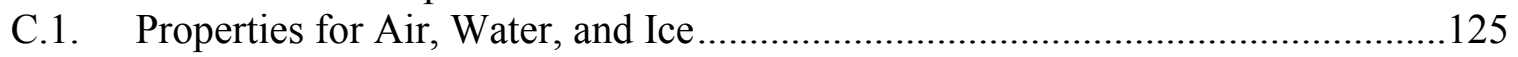

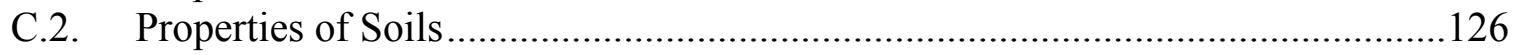

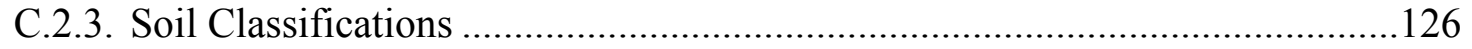

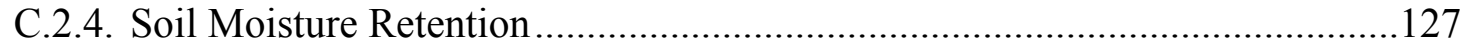

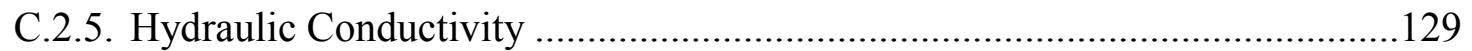

C.2.6. Hydraulic Conductivity of Frozen Soil...........................................................130

C.2.7. Temperature Dependency ............................................................................130

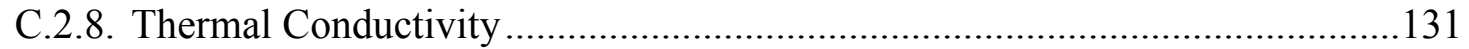

C.2.9. Thermal Conductivity of Frozen Soil .........................................................132

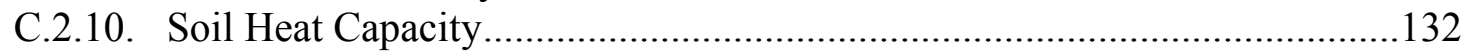

APPENDIX D: Analysis of the Convective Heat Transfer Coefficient ...............................133

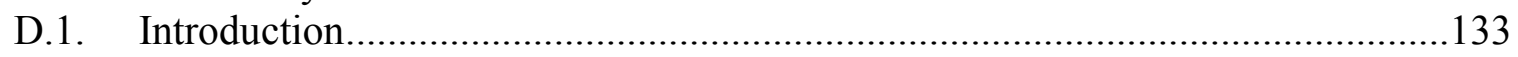

D.2. Models for the Convective Heat Transfer Coefficient .........................................133 


\section{List of Figures}

Figure 2.1. Geometry transformation used by Walton to reduce the three-dimensional problem to a two-dimensional problem.

Figure 3.1. Simplified diagram of the major heat transfer paths in soil.

Figure 3.2. Approximate soil moisture retention curves for a loamy sand (Noborio et al. 1996) and Yolo light clay (Moore 1939).

Figure 3.3. Approximations of the hydraulic conductivities of a loamy sand (Noborio et al. 1996) and Yolo light clay (Moore 1939).

Figure 3.4. Temperature correction factors for the matric potential and hydraulic conductivity correlations.

Figure 3.5. Relative humidity of soil moisture at a temperature of $10^{\circ} \mathrm{C}$.

Figure 3.6. The effective thermal conductivity of vapor distillation in the gas-filled pores as compared to that of water and air and the total effective thermal conductivity of Yolo light clay as calculated by the de Vries Method.

Figure 3.7. Effective thermal conductivity of Bighorn sandy loam as a function of moisture content with and without the vapor diffusion term.

Figure 3.8. Ratio of the thermal conductivities of frozen and unfrozen soil as approximated by the de Vries method and measured by Kersten (1949) for Fairbanks Silty Clay Loam and Dakota Sandy Loam.

Figure 4.1. Heat-capacity coefficients (a) and the heat-conductivity coefficients (b) for Yolo light clay as a function of moisture content at $293.15 \mathrm{~K}$

Figure 4.2. Isothermal soil freezing model with the unfrozen and frozen soil thermal

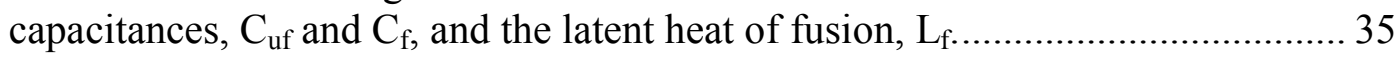

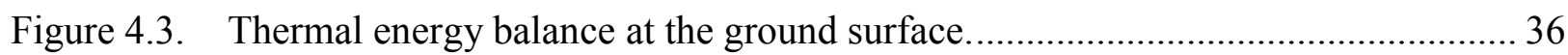

Figure 4.4. Moisture balance at the ground surface........................................................ 41

Figure 4.5. Errors in temperature, moisture, and total heat flux at the surface for quadrilateral elements

Figure 4.6. Errors in temperature, moisture, and total heat flux at the surface triangular elements

Figure 5.1. Patch test used to check GHAMT ............................................................... 51

Figure 5.2. Two-dimensional heat conduction problem................................................ 52

Figure 5.3. Temperature contours for the numerical and analytic solutions to a twodimensional heat-conduction problem.

Figure 5.4. Infiltration in a column of Yolo light clay as predicted by Philip's quasianalytic solution and GHAMT.

Figure 5.5. Ground temperature and weather data configuration....................................... 55

Figure 5.6. Weather conditions along with the measured and predicted surface temperatures for the period from January 10-30.

Figure 5.7. Weather conditions along with the measured and predicted surface temperatures for the period from April 27 to May 17. 
Figure 5.8. Measured and predicted surface temperatures for the period from April 27 to May 17 with cloudy skies during the rainy period.....

Figure 5.9. Measured and approximated temperatures and the error at $\mathrm{z}=-0.34 \mathrm{~m}$........... 60

Figure 5.10. Measured and approximated temperatures and the error at $\mathrm{z}=-0.65 \mathrm{~m}$............ 60

Figure 5.11. Measured and approximated temperatures and the error at $\mathrm{z}=-0.95 \mathrm{~m}$........... 61

Figure 6.1. Heat flux terms of conduction, vapor distillation driven by temperature, and liquid convection at $\mathrm{z}=-0.038 \mathrm{~m}$ for Solar Village clay.

Figure 6.2. Heat flux terms of conduction, vapor distillation driven by temperature, and liquid convection at $\mathrm{z}=-0.35 \mathrm{~m}$ for Solar Village clay

Figure 6.3. Heat flux terms of conduction, vapor distillation driven by temperature, and liquid convection at $\mathrm{z}=-0.95 \mathrm{~m}$ for Solar Village clay.

Figure 6.4. Heat flux terms of conduction, vapor distillation driven by temperature, and liquid convection at $\mathrm{z}=-0.038 \mathrm{~m}$ for Bighorn sandy loam.

Figure 6.5. Heat flux terms of conduction, vapor distillation driven by temperature, and liquid convection at $\mathrm{z}=-0.35 \mathrm{~m}$ for Bighorn sandy loam.

Figure 6.6. Mesh and boundary conditions used for the slab-on-grade simulations. 67

Figure 6.7. Mesh and boundary conditions used for the basement simulations. 68

Figure 6.8. Heat flux across the slab-on-grade floor at 12:00 on day 14 for the sandy loam soil and winter conditions.

Figure 6.9. Hourly total heat loss for summer conditions from the insulated slab-on-grade for a sandy loam and a Yolo light clay for dry conditions and with $25 \mathrm{~mm}$ of rain added on days 7 and 14 .

Figure 6.10. Hourly heat loss for summer conditions from the uninsulated slab-on-grade for a sandy loam and a Yolo light clay for dry conditions and with $25 \mathrm{~mm}$ of rain added on days 7 and 14 .

Figure 6.11. Hourly total heat loss for winter conditions from the uninsulated slab-on-grade with a sandy loam for the dry case and the case with $25 \mathrm{~mm}$ of rain added on days 7 and 14 .

Figure 6.12. Daily basement wall heat losses for summer conditions over 112 days. 73

Figure 6.13. Basement wall heat flux in the x-direction for the uninsulated wall and summer conditions on day 8 of the simulation.

Figure 6.14. Basement wall heat flux in the x-direction for the insulated wall and summer conditions on day 8 of the simulation.

Figure 6.15. Basement wall heat flux in the z-direction for the uninsulated wall and summer conditions on day 8 of the simulation. 76

Figure 6.16. Basement wall heat flux in the z-direction for the insulated wall and summer conditions on day 8 of the simulation.

Figure 6.17. Average daily basement wall heat loss as a function of groundwater depth below the basement floor. 78

Figure 6.18. Average daily basement floor heat loss as a function of groundwater depth below the basement floor. 78 
Figure 6.19. Temperature contours $\left({ }^{\circ} \mathrm{C}\right)$ for uninsulated basements on day 46 of simulations with winter conditions, sandy loam soil, and ground water depths of $-10 \mathrm{~m},-5$ $\mathrm{m}$, and $-3 \mathrm{~m}$......

Figure 6.20. Contours of the effective thermal conductivity $(\mathrm{W} / \mathrm{m} \cdot \mathrm{K})$ for an uninsulated basement on day 46 of simulations with winter conditions, sandy loam soil, and ground water depths of $-10 \mathrm{~m},-5 \mathrm{~m}$, and $-3 \mathrm{~m}$.

Figure 6.21. Contours of the soil volumetric moisture content for an uninsulated basement. ... 82

Figure 6.22. Daily basement-wall heat loss predicted by GHAMT and GHT2D. .................... 85

Figure 6.23. Daily basement-floor heat loss predicted by GHAMT and GHT2D...................... 86

Figure 6.24. Daily total basement heat loss predicted by GHAMT and GHT2D....................... 86

Figure 6.25. Daily average floor heat loss for a basement with an insulated wall from the Mitalas method and GHT2D. 88

Figure 6.26. Daily average wall heat loss for a basement with an insulated wall from the Mitalas method and GHT2D. .

Figure 6.27. Daily average total heat loss for a basement with an insulated wall from the Mitalas method and GHT2D.

Figure 6.28. Monthly basement heat loss predicted by the ASHRAE method and by GHT2D for Fort Collins weather data.

Figure 6.29. Monthly basement-wall heat loss predicted by the ASHRAE method and by GHT2D for Fort Collins weather data.

Figure 6.30. Monthly basement-floor heat loss predicted by the ASHRAE method and by GHT2D for Fort Collins weather data.

Figure A.1. Fixed control volume of soil used for the liquid moisture balance.

Figure A.2. Temperature gradient coefficient terms for the vapor diffusion equation (Eq. (A.23)) at $30.0^{\circ} \mathrm{C}$.

Figure A.3. Fixed-shape control volume and energy transfers............................................ 112

Figure A.4. Model of the isothermal soil-freezing process............................................... 116

Figure A.5. Model approximation of isothermal (a) freezing and (b) thawing of soil............ 116

Figure B.1. Three- and four-node isoperimetric parent elements, shape functions, and points and weights used for Gaussian quadrature (Zienkiewicz and Taylor 1989).

Figure C.1. Soil moisture retention data and approximation curves for Solar Village clay (data Hampton 1989) and Yolo light clay (data Moore 1939).

Figure C.2. Approximate soil moisture retention curves for the soils included in this work.. 128

Figure C.3. Approximations of the hydraulic conductivity of the soils included in this work.

Figure C.4. Approximations for the thermal conductivity of the soils at $20^{\circ} \mathrm{C}$ included in this work.

Figure D.1. Effect of ground surface/ambient air temperature difference on the convective heat transfer coefficient $u_{\mathrm{w}}=5.0 \mathrm{~m} / \mathrm{s}, \mathrm{z}_{\mathrm{veg}}=0.05 \mathrm{~m}$. 
Figure D.2. Effect of surface roughness height on the convective heat transfer coefficient for a stable temperature gradient $\left(\mathrm{T}_{\mathrm{amb}}-\mathrm{T}_{\mathrm{s}}\right)=+10.0 \mathrm{C}, \mathrm{u}_{\mathrm{w}}=5.0 \mathrm{~m} / \mathrm{s} \ldots \ldots \ldots \ldots \ldots . .136$

Figure D.3. Effect of wind speed on the convective heat transfer coefficient for a stable

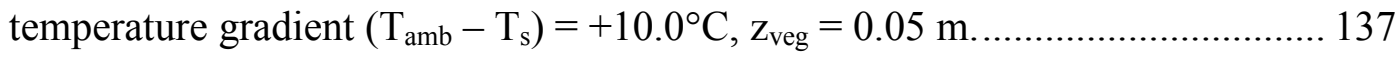

Figure D.4. Effect of wind speed on the convective heat transfer coefficient for an unstable temperature gradient $\left(\mathrm{T}_{\mathrm{amb}}-\mathrm{T}_{\mathrm{s}}\right)=-10.0^{\circ} \mathrm{C}, \mathrm{z}_{\mathrm{veg}}=0.05 \mathrm{~m}$.

Figure D.5. Combined forced and natural convective heat transfer coefficients. The forced convection coefficient is calculated using the Jensen model. 138 


\section{List of Tables}

Table 4.1. Terrain Parameters for Wind (Sherman and Grimsrud 1980) ................................4 40

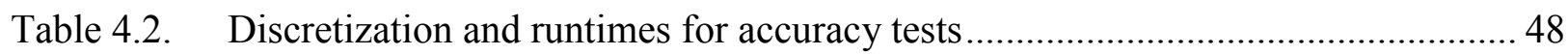

Table 6.1. Material Properties Used for Ground-Heat-Transfer Simulations............................66 66

Table 6.2. Weather Parameters Used for Ground Heat Transfer Simulations. .......................... 69

Table 6.3 Cases to Show the Effects of Surface Moisture on Ground-Coupled Heat

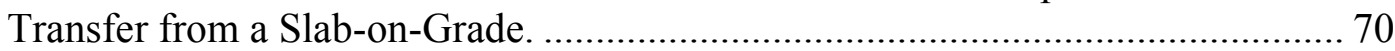

Table 6.4 Cases to Show Effects of Surface Moisture on Ground-Coupled Heat Transfer

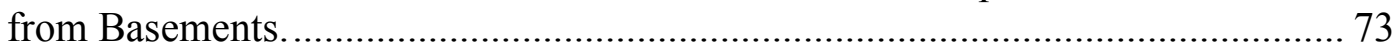

Table 6.5. Annual Heat Loss for a Half-Width Basement from GHAMT and GHT2D per Unit Length of Perimeter...................................................................................... 84

Table 6.6. Annual Heat Loss for a Half-Width Basement from the Mitalas Method and

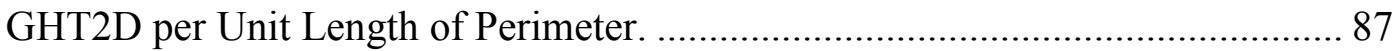

Table C.1. Physical and thermal properties of air, water, and ice. ..................................... 125

Table C.2. Classification and properties of soils included in this work............................... 126

Table C.3. Parameters from the van Genuchten Method for the Matric Potential and Hydraulic Conductivity Correlations. ............................................................... 128

Table C.4. Physical and thermal properties of soil constituents ........................................... 131 


\section{Nomenclature}

\begin{tabular}{|c|c|}
\hline A & area $\left[\mathrm{m}^{3}\right]$ \\
\hline $\mathrm{a}$ & volumetric air content $\left[\mathrm{m}^{3} / \mathrm{m}^{3}\right]$ \\
\hline CMD & capacitance minus diffusivity \\
\hline CPD & capacitance plus diffusivity \\
\hline $\mathrm{C}_{\mathrm{P}}$ & specific heat capacity $[\mathrm{J} / \mathrm{kg} \cdot \mathrm{K}]$ \\
\hline $\mathrm{C}_{\mathrm{T} \ell}, \mathrm{C}_{\psi \ell}$ & thermal and matric liquid capacitance terms $\left[\mathrm{K}^{-1}, \mathrm{~m}^{-1}\right]$ \\
\hline $\mathrm{C}_{\mathrm{Tm}}, \mathrm{C}_{\psi \mathrm{m}}$ & thermal and matric moisture capacitance terms $\left[\mathrm{K}^{-1}, \mathrm{~m}^{-1}\right]$ \\
\hline $\mathrm{C}_{\mathrm{TT}}, \mathrm{C}_{\mathrm{T} \psi}$ & thermal and matric heat capacitance terms $\left[\mathrm{J} \cdot \mathrm{s} / \mathrm{m}^{4}, \mathrm{~J} / \mathrm{m}^{3} \cdot \mathrm{K}\right]$ \\
\hline $\mathrm{C}_{\mathrm{Tv}}, \mathrm{C}_{\psi \mathrm{v}}$ & thermal and matric vapor capacitance terms $\left[\mathrm{K}^{-1}, \mathrm{~m}^{-1}\right]$ \\
\hline $\mathrm{D}$ & wet-bulb depression $\left(\mathrm{T}-\mathrm{T}_{\mathrm{wb}}\right)[\mathrm{K}]$ \\
\hline $\mathrm{D}_{\mathrm{a}}$ & molecular diffusivity of water vapor in air $\left[\mathrm{m}^{2} / \mathrm{s}\right]$ \\
\hline $\mathrm{D}_{\mathrm{h}}$ & heat diffusivity in air \\
\hline $\mathrm{D}_{\mathrm{v}}$ & vapor diffusivity in air \\
\hline $\mathrm{D}_{\mathrm{m}}$ & neutral stability momentum transfer coefficient $[\mathrm{m} / \mathrm{s}]$ \\
\hline $\mathrm{D}_{\mathrm{Tm}}, \mathrm{D}_{\psi \mathrm{m}}$ & thermal and matric moisture diffusivities $\left[\mathrm{m}^{2} / \mathrm{s} \cdot \mathrm{K}, \mathrm{m} / \mathrm{s}\right]$ \\
\hline $\mathrm{D}_{\mathrm{Tv}}, \mathrm{D}_{\psi \mathrm{v}}$ & thermal and matric vapor diffusivities $\left[\mathrm{m} / \mathrm{s}, \mathrm{m}^{2} / \mathrm{s} \cdot \mathrm{K}\right]$ \\
\hline $\mathrm{D}_{\psi \mathrm{T}}$ & matric potential heat diffusivity $\left[\mathrm{W} / \mathrm{m}^{2}\right]$ \\
\hline $\mathrm{E}$ & internally stored energy \\
\hline $\mathrm{E}$ & evaporation rate $\left[\mathrm{s}^{-1}\right]$ \\
\hline $\mathrm{e}$ & specific internally stored energy \\
\hline $\mathrm{f}$ & vapor diffusion correction factor \\
\hline$\Delta \mathrm{f}_{\mathrm{v}}, \Delta \mathrm{f}_{\ell}$ & free energy of the soil water vapor and liquid phases $[\mathrm{J} / \mathrm{mole}]$ \\
\hline G & global solar horizontal radiation $\left[\mathrm{Wh} / \mathrm{m}^{2}\right]$ \\
\hline g & acceleration due to gravity $\left[\mathrm{m} / \mathrm{s}^{2}\right]$ \\
\hline $\mathrm{g}_{\mathrm{a}, \mathrm{b}, \mathrm{c}}$ & geometry weighting factors used in estimating soil thermal conductivity \\
\hline $\mathrm{H}$ & height $[\mathrm{m}]$ \\
\hline $\mathrm{h}$ & convective heat transfer coefficient $\left[\mathrm{W} / \mathrm{m}^{2} \cdot \mathrm{K}\right]$ \\
\hline $\mathrm{h}_{\mathrm{fg}}$ & latent heat of vaporization of water $[\mathrm{J} / \mathrm{kg}]$ \\
\hline$I^{15}$ & solar radiation $\left[\mathrm{W} / \mathrm{m}^{2}\right]$ \\
\hline $\mathrm{k}$ & thermal conductivity $[\mathrm{W} / \mathrm{m} \cdot \mathrm{K}]$ \\
\hline $\mathrm{k}^{*}$ & thermal conductivity of soil with no moisture movement $[\mathrm{W} / \mathrm{m} \cdot \mathrm{K}]$ \\
\hline K & soil hydraulic conductivity $[\mathrm{m} / \mathrm{s}]$ \\
\hline $\mathrm{K}_{\text {evap }}$ & evapotranspiration ration \\
\hline $\mathrm{L}$ & latent heat of fusion $[\mathrm{J} / \mathrm{kg}]$ \\
\hline $\mathrm{L}$ & characteristic length $[\mathrm{m}]$ \\
\hline MO & Monin-Obukhov length \\
\hline$\dot{\mathrm{m}}$ & mass-flow rate $\left[\mathrm{kg} / \mathrm{m}^{2} \cdot \mathrm{S}\right]$ \\
\hline $\mathrm{N}$ & shape factor \\
\hline $\mathrm{Nu}$ & Nusselt number \\
\hline $\mathrm{P}$ & total gas pressure in pores, assumed equal to atmospheric pressure $[\mathrm{Pa}]$ \\
\hline $\operatorname{Pr}$ & Prandtl number \\
\hline $\mathrm{P}_{\mathrm{v}}$ & partial pressure of water vapor in pores $[\mathrm{Pa}]$ \\
\hline $\mathrm{P}_{\mathrm{vs}}$ & partial pressure of saturated water vapor in pores $[\mathrm{Pa}]$ \\
\hline
\end{tabular}




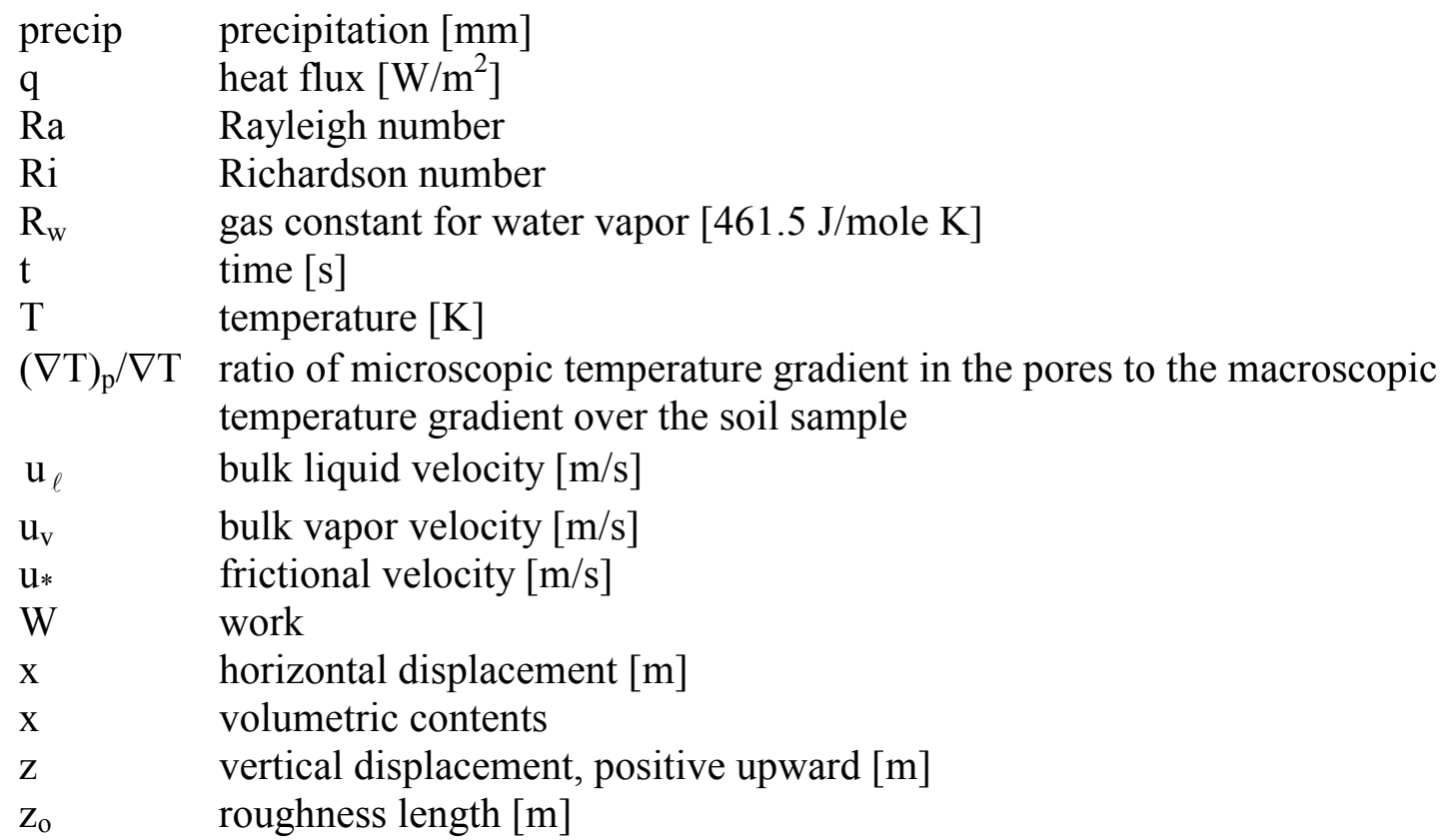

\section{Greek Letters}

$\alpha \quad$ tortuosity factor and thermal diffusivity $\left[\mathrm{m}^{2} / \mathrm{s}\right]$

$\beta \quad$ time weighting factor used in the transient solution

$\Delta \quad$ derivative of saturated water vapor pressure with temperature $\left[\mathrm{kg} / \mathrm{m} \cdot \mathrm{s}^{2} \cdot \mathrm{K}\right]$

$\varepsilon \quad$ emissivity

$\varepsilon_{0} \quad$ clear sky emissivity

$\varphi \quad$ relative humidity

$\Phi \quad$ total soil potential for liquid flow [m]

$\gamma \quad$ psychrometric constant $\left[\mathrm{kg} / \mathrm{m} \cdot \mathrm{s}^{2} \cdot \mathrm{K}\right]$

$\Gamma \quad$ cloud temperature correction factor

$\eta \quad$ soil porosity

$\kappa \quad$ von Karman's constant

$\mu \quad$ liquid water dynamic viscosity $[\mathrm{kg} / \mathrm{m} \cdot \mathrm{s}]$

u mass-flow factor

u water kinematic viscosity $\left[\mathrm{s} / \mathrm{m}^{2}\right]$

$\rho \quad$ density $\left[\mathrm{kg} / \mathrm{m}^{3}\right]$

$\rho_{\mathrm{vs}} \quad$ saturated soil water vapor density $\left[\mathrm{kg} / \mathrm{m}^{3}\right]$

$\Theta \quad$ degree of saturation

$\theta_{\ell} \quad$ volumetric liquid content $\left[\mathrm{m}^{3} / \mathrm{m}^{3}\right]$

$\theta_{\mathrm{k}} \quad$ critical moisture content below which liquid water is no longer continuous

$\theta_{\text {dry }} \quad$ moisture content below which air is the continuous medium

$\sigma \quad$ surface tension of water $[\mathrm{N} / \mathrm{m}]$

$\sigma \quad$ Stefan-Boltzmann constant $\left[5.6686 \times 10^{-8} \mathrm{~W} / \mathrm{m}^{2} \cdot \mathrm{K}\right]$

$\xi$ temperature gradient ratio term used in the calculation of soil thermal conductivity

$\psi \quad$ matric liquid potential $[\mathrm{m}]$ 


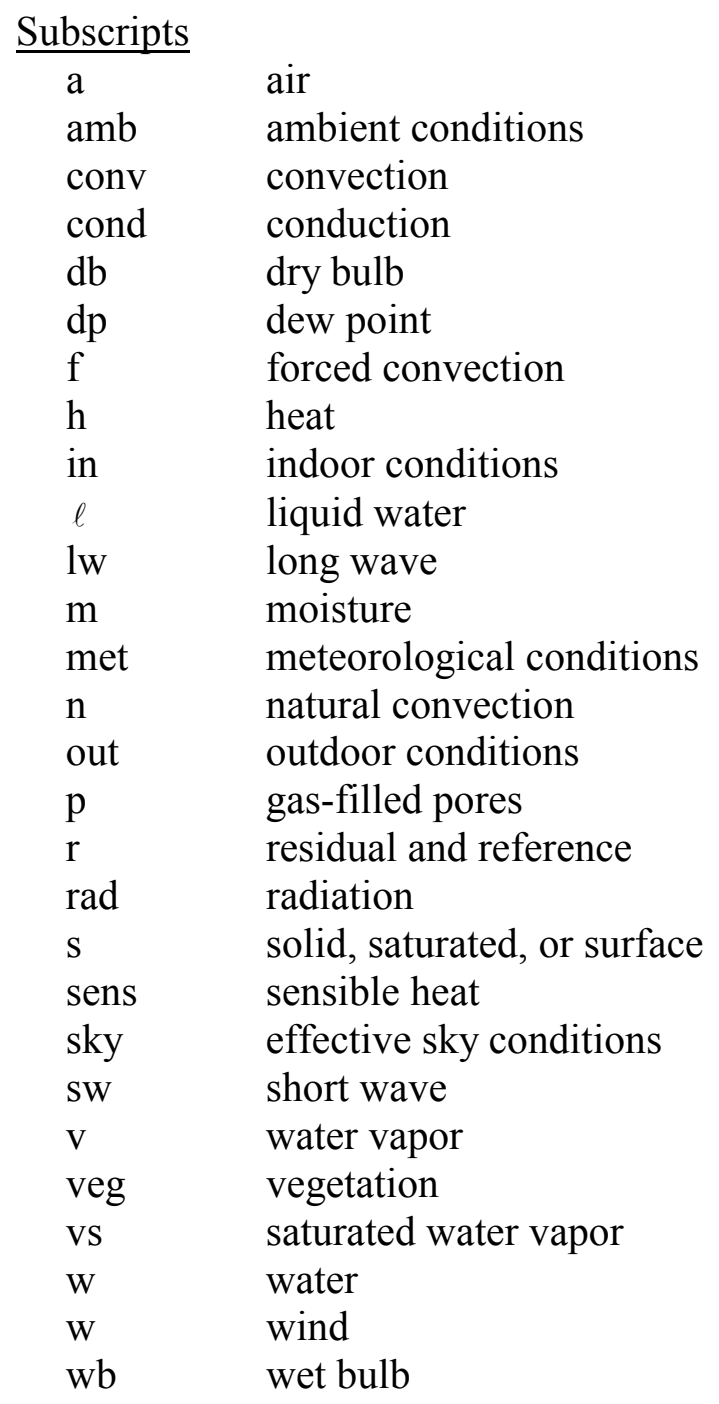




\section{Executive Summary}

\section{Introduction}

Although most buildings have some form of thermal coupling to the ground, there is normally very little thought put into the consequences of this thermal connection. Today, a well-built house is so energy efficient above ground that the ground-coupled heat losses can account for $30 \%$ to $50 \%$ of the total heat loss, showing the importance of a detailed analysis of groundcoupled heat transfer. Despite the potential magnitude of this heat transfer term, the thermal modeling is often over simplified. Ground-coupled heat transfer calculations in building-energysimulation programs are usually one-dimensional, with corrections from the results of detailed numerical analysis to approximate the two- and three-dimensional effects. This approach can produce reasonable results by a knowledgeable user with a building similar to the cases examined in the original detailed numerical analysis. However, predictions between models can vary by a factor of more than two.

An important factor in soil heat transfer that is often over looked is the effect of moisture, which can vary the effective thermal conductivity by a factor of ten. The objective of this research was to investigate the ground-coupled heat and moisture transfer from buildings, and to develop results and tools to improve energy simulation of ground-coupled heat transfer.

\section{Approach}

A two-dimensional, finite-element, heat-and-moisture transfer computer program and a companion two-dimensional heat-transfer computer program were developed to study the ground-coupled heat transfer from buildings. Soil thermal conductivity is a strong function of the soil moisture; therefore, accurate analysis of the ground-coupled heat transfer requires knowledge of the soil's moisture content. The moisture-transfer model developed in this work is based on a mechanistic approach with temperature and matric potential as the independent variables. The model includes a detailed treatment of the ground-surface heat and moisture balances and includes a simple model for soil freezing. The finite element formulation uses the Galerkin weighted residual method. The nonlinear equations are solved using a modified Picard iteration technique.

\section{Results}

We investigated the effects of moisture added to the ground surface and the effects of water-table depth on the heat transfer from a slab-on-grade and a basement. The effect of moisture added to the surface is largest in the summer and larger for uninsulated floors and basements. Basement walls are sensitive to the conditions at the surface and are the most affected by surface moisture. Basement floors are relatively unaffected by short-term variations at the surface, but they are closely tied with the deep ground conditions, such as groundwater.

Comparing annual simulations from the heat-and-moisture-transfer model and the heat-transfer model produced agreeable results when an appropriate value for soil thermal conductivity and evapotranspiration were chosen. Using seasonal values of soil thermal conductivity for heatconduction models can distort the daily results even though the annual results may appear to be correct. 


\section{Chapter 1: Introduction}

\subsection{Background}

Although most buildings have some form of thermal coupling to the ground, there is normally very little thought put into the consequences of this thermal connection. There are numerous examples throughout history of intelligent use of the earth to moderate the daily and seasonal temperature swings in buildings. The cliff dwellings at Mesa Verde National Park are one of the best-known examples in the United States. Other examples include houses burrowed into the sides of mountains in Tunisia (Cole 1981), multiple family houses carved into rock in Turkey (Flint 1981), and buildings cooled with air drawn through tunnels in Italy (Fanchiotti and Scudo 1981). While ground coupling provided relief in these cases, the indoor climate was surely uncomfortable by today's standards.

For most buildings in the United States today, the earth acts as a constant heat sink-slowly and constantly absorbing heat from buildings. It was estimated that in the early 1970s, earth-contact heat losses accounted for approximately $10 \%$ of the annual heat losses of the average home in the US (Labs et al. 1988). Rising energy prices in the 1970s forced an increase in conservation, and houses were built to be more energy efficient by reducing the infiltration, adding more insulation, and installing better windows. Today, a well-built house is so energy efficient above ground that the ground-coupled heat losses can account for 30 to $50 \%$ of the total heat loss (calculations by the author, Claesson and Hagentoft 1991a, and Labs et al. 1988), showing the importance of a detailed analysis of ground-coupled heat transfer.

The increased energy costs in the 1970s also spurred developments in the analysis of the energy use in buildings, and many building-energy-simulation programs were created in the 1970s and 1980s. Again, most of the effort was directed towards the aboveground portion of the building. Design analysis of ground-coupled heat transfer has mainly been confined to using correlationbased methods such as those found in the ASHRAE Handbook of Fundamentals (1997). Groundcoupled heat transfer calculations in building-energy-simulation programs are usually onedimensional, with corrections from the results of detailed numerical analysis to approximate the two- and three-dimensional effects. This approach can produce reasonable results by a knowledgeable user with a building similar to the cases examined in the original detailed numerical analysis.

The use of detailed numerical analysis of ground-coupled heat transfer has been limited to a few researchers and rarely applied outside of their work. The main reason for the limited use is that the computation time required for three-dimensional numerical solutions is much greater than that required for analyzing the above ground portion of the building. As the speed of computers continues to rise (and the price drops), using detailed analysis of ground-coupled heat transfer becomes more feasible.

The original objective of this research was to develop two- and three-dimensional heatconduction models suitable for use with hourly building-energy-simulation programs. In the early stages of the project, it became clear that there was a real need to study the coupled heatand moisture transfer in soils around buildings. Soil heat and moisture transfer is tightly coupled, and soil thermal properties are strong functions of the moisture content. Therefore, accurate 
knowledge of soil heat transfer must include moisture transfer analysis. Soil Physicists, Agricultural Engineers, and Civil Engineers have studied soil heat and moisture transfer for many years and have had detailed solutions since the 1950s (Philip and de Vries 1957). A detailed numerical analysis of the heat and moisture transfer in soils next to buildings has only been applied in a limited case (Shen 1986). This is because the problem is very complex, and the computing power needed to solve the coupled heat-and-moisture transfer equations is at least two orders of magnitude greater than that needed to solve the heat-conduction equation alone. So, why go to the trouble of developing a detailed model? With a detailed model, the inputs can be closely examined to determine which ones are important and need closer attention. A detailed model can also be used to create a benchmark for simple models and bound the solution between extremes.

Therefore, the focus of this research evolved into analyzing the coupled heat and moisture transfer in soils to determine the important terms and parameters. To accomplish this, a twodimensional, ground-coupled, heat-and-moisture transfer model and a two-dimensional, groundcoupled heat-transfer model were created. The models followed a mechanistic approach, using finite element analysis to solve the governing equations. After validating and verifying the models, they were used to study the effects of moisture and freezing on the ground-coupled heat transfer from slab floors and basements.

\subsection{Organization of Report}

This report begins by briefly reviewing the history of building ground-coupled heat transfer research and analysis in Chapter 2. Chapter 3 presents an overview of the physics of heat and moisture transfer in soils and the methods used to determine the soil thermal and hydraulic properties. The development of the heat and moisture transfer model is presented in Chapter 4, along with the surface moisture and energy balances and the numerical solution method. Testing, verification, and validation of the model are covered in Chapter 5. Application of the model to the heat transfer from a slab-on-grade floor and basement geometry are included in Chapter 6 . Appendices A through $\mathrm{D}$ include a detailed derivation of the governing equations, the finite element formulation, correlations used for the thermal and hydraulic properties, and a comparison of correlations for the convective heat-transfer coefficient for the ground surface. 


\section{Chapter 2: Literature Review}

\subsection{Introduction}

There have been many approaches to analyzing ground-coupled heat transfer from buildings, including steady-state analytic models, correlation-based models, transient analytic models, combined analytic and numeric models, and full numeric models. Each of these approaches can produce useful information if they are used correctly within the bounds of the simplifying assumptions, but they can produce extremely inaccurate results if used improperly (Bahnfleth 1989 and MacDonald et al. 1985). A summary of some of these models is presented here. Extensive reviews have also been completed by Claridge (1988), Labs (1989), Adjali et al. (1998a), and Krarti (1999).

\subsection{Experimental Work in Building Ground-Coupled Heat Transfer}

Some of the earliest detailed heat transfer measurements from a basement were performed by Houghten et al. (1942). They measured soil temperatures and wall and floor heat fluxes for a buried structure over a period of one year. These measurements proved that the simple conduction calculations used at that time vastly over-predicted the heat loss. Bareither et al. (1948) measured temperatures and heat loss from nine slab-on-grade constructions and showed the existence of two-dimensional flow for a 3-foot strip along the edge and one-dimensional flow for the central region of the floor. They also derived two methods to estimate the heat loss, q (W) from slab-on-grade floors based on heat-loss factors, $\mathrm{F}_{1}$ and $\mathrm{F}_{2}$.

$$
\begin{aligned}
& \mathrm{q}=\mathrm{F}_{1} \mathrm{P}\left(\mathrm{T}_{\text {in }}-\mathrm{T}_{\text {out }}\right)+2\left(\mathrm{~A}_{\text {totalfloor }}-\mathrm{A}_{\text {perimeter }}\right) \\
& \mathrm{q}=\mathrm{F}_{2} \mathrm{P}\left(\mathrm{T}_{\text {in }}-\mathrm{T}_{\text {out }}\right)
\end{aligned}
$$

The perimeter of the floor is $\mathrm{P}(\mathrm{m})$, the indoor-outdoor air temperature difference is $\left(\mathrm{T}_{\text {in }}-\mathrm{T}_{\text {out }}\right)$ (C), and $\mathrm{A}_{\text {perimeter }}\left(\mathrm{m}^{2}\right)$ is the floor area of a 3-foot border along the exposed edge. Bareither et al. believed that Eq. (2.1) would provide better estimates of floor heat loss for all constructions, especially for floors with an $\mathrm{A} / \mathrm{P}$ ratio greater than $12 \mathrm{~m}$. The values for the $\mathrm{F}_{2}$ heat loss factor from this research were used in the ASHRAE Handbook of Fundamentals for many years until they were replaced by numerically derived values.

For his Ph.D. thesis, Shipp (1979) compiled experimental data on a large, earth-sheltered building on the University of Minnesota campus. Wall heat fluxes, soil temperatures, and moisture contents were measured to depths of $9.3 \mathrm{~m}$ in grass-covered, asphalt-covered, and concrete-covered areas around the building. On the north side of the building, three different soil types were used as backfill. The ground surface conditions were determined to be the most important factor controlling the heat transfer between the building and the ground. The boundary conditions at the surface affect not only the heat flow into the ground but also the moisture content of the soil, which affects the soil thermal properties. This suggests that a detailed treatment of the ground surface moisture and energy balances is important.

Bligh et al. (1982) and Bligh and Knoth (1983) completed detailed measurements of the soil and structure temperatures, heat flows, energy use, and indoor and outdoor conditions for an earth- 
sheltered house near Boston, Massachusetts. They demonstrated that the heat-flow paths from the buried walls change from the surface in the winter to the deep ground in the spring. They also showed that ground surface temperatures under damp grass were as much as $20^{\circ} \mathrm{C}$ cooler than the temperatures of bare ground, showing the importance of ground cover.

Yoshino et al. (1992) completed a 5-year study of the thermal performance of a semiunderground test house in Sendai, Japan. The house was divided into identical sides, C and D, except that $\mathrm{D}$ also included horizontal insulation $0.3 \mathrm{~m}$ beneath the ground surface around the perimeter extending out $1.35 \mathrm{~m}$ from the building. They measured soil and inside air temperatures and heating energy consumption for the two sides. The side with horizontal insulation had slightly lower temperature variations and slightly lower heating loads. The use of horizontal insulation was only moderately effective in this case.

Trethowen and Delsante (1998) measured heat flows, temperatures, and soil thermal conductivities for two houses over a 4-year period in New Zealand. Both houses used uninsulated slab-on-grade construction and were occupied throughout the experiment. The water-table depth for the houses varied between $0.4 \mathrm{~m}$ and $1.0 \mathrm{~m}$ and maintained a high soil moisture content throughout the year. One significant result of the work is that it took approximately 2 years for the perimeter regions to reach a quasi-steady state and 3 years for the core region to reach a quasi-steady state. In addition, the presence of the houses did not seem to affect the depths of the water tables. Trethowen and Delsante calculated whole-floor R-values and compared these with calculations from simple methods from the ASHRAE (1997) and CIBSE Handbooks (1986), Delsante (1990), and Davies (1993). The calculated values were off by as much as $+50 \%$ for one house and $-25 \%$ for the other house. The disagreements in these comparisons were caused by underestimating the soil thermal conductivity and by not including the width of the exterior wall. They estimate that approximately $10 \%$ of the floor heat loss could be through vertical conduction to the masonry exterior wall above the floor.

Thomas and Rees (1999) completed a one-and-a-half-year study of floor heat flows, soil temperature, and moisture levels of a new building at the Cardiff School of Engineering. The experiments showed that a lightweight concrete floor performed better thermally, with an overall thermal transmittance of $0.20 \mathrm{~W} / \mathrm{m}^{2} \cdot \mathrm{K}$, when compared to $0.26 \mathrm{~W} / \mathrm{m}^{2} \mathrm{~K}$ for a normal-weight concrete floor. The measurements also showed that, for an uninsulated floor, approximately $60 \%$ of the winter floor heat loss to the ground occurs in a 1.5-m-wide strip around the perimeter of the building. Soil moisture levels in the first $2 \mathrm{~m}$ beneath the slab were relatively constant, but a rising water table did increase the moisture at a depth of $3 \mathrm{~m}$. The soil moisture levels measured $1 \mathrm{~m}$ outside of the building foundation showed significant seasonal variation, suggesting strong effects of coupled heat and moisture transfer.

\subsection{Analytic Solutions to Ground-Coupled Heat Transfer}

The first analytic two-dimensional model of ground-heat transfer to be widely recognized was developed by Macey (1949), who considered the problem of an infinitely long floor with correction factors for rectangular floors and wall thickness. This method is still used as the basis for heat-loss calculations in the CIBSE Guide (1986). The first well-known transient solution method was developed by Lachenbruch (1957), who solved the differential heat-conduction equation using Green's functions. Lachenbruch used this method to study the three-dimensional 
heat conduction in permafrost beneath heated buildings and found that it takes 3 years for the temperature field to reach an annual steady periodic behavior. This solution method was later used as the basis of a computer program to calculate monthly heat loss values and ground temperature data used by the building energy simulation programs DOE-2 and BLAST (Kusuda et al. 1982 and Kusuda and Bean 1984). Both of these models assume uniform and constant thermal properties.

Fourier series solutions to the ground-heat-conduction equation were developed by Muncey and Spencer (1978), Shen and Ramsey (1983), and Delsante and Stokes (1983). Muncey and Spencer studied the shape of the slab floor and found that there is a linear relationship between a resistance parameter defined as thermal resistance of a slab shape/thermal resistance of a square of equal perimeter, and an area parameter defined as area/(perimeter $/ 4)^{2}$. Shen and Ramsey developed a transient thermal-analysis program for earth-sheltered buildings based on their solution method. Delsante was able to derive a closed-form solution to the two-dimensional heat conduction problem and an approximate solution to the three-dimensional problem. This model was later extended to approximate the heat loss through core and perimeter regions of insulated floors (Delsante 1988 and 1989), which was shown to compare well with measured data (Delsante 1990).

Claesson and Hagentoft (1991a and 1991b) applied superposition and dimensional analysis to combine numerical and analytical solutions of the problem of heat loss from slab-on-grade floors. The heat-conduction equation is solved for a steady state problem, for a periodic outdoor temperature, and for a unit step in outdoor temperature. The three solutions are combined by superposition to obtain the final solutions for specific problems. They discovered that the effects of groundwater are small unless the water level is high, that the effects of freezing are small, and that the insulating effects of snow cover should be considered. Hagentoft (1996a and 1996b) later investigated using a constant-temperature water table as a lower boundary condition. The effect of the water table depends on the heat-conduction ratio through the soil to the convection of heat carried away by the groundwater.

Krarti uses a clever approach called the Interzone Temperature Profile Estimation (ITPE) technique, which combines numerical and analytical approaches to solve the heat-conduction problem (Krarti et al. 1988a, 1988b, 1990, and 1994). If steady-periodic conditions are assumed, the transient heat-conduction equation can be transformed into a time-independent Helmholtztype equation. The temperature is represented by a mean value, amplitude, frequency, and a phase shift. The ITPE technique divides the problem domain into zones, where the heatconduction equation can be easily solved, and requires estimates of the temperature profile along the surfaces between the zones. Two- and three-dimensional models were developed that compare favorably with the results of Mitalas and Bahnfleth (Krarti 1995b) in predicting annual heat-loss values. One important conclusion from this work is the fact that the heat transfer from a slab floor can be divided into one-, two-, and three-dimensional regions (Krarti 1990). A frequency-response analysis of this problem by Krarti, Claridge, and Kreider (1995a) showed that uninsulated slab floors and basement walls respond to ground-surface temperature variations in a few hours and insulated floors and walls respond to temperature variations in a few days. Limitations of this model include the need to know (or estimate) the temperature profiles between zones, constant soil properties, and a simplified treatment of the ground-surface boundary condition. 


\subsection{Design Calculation Methods}

There are many simple methods available to determine the seasonal or annual ground-coupled heat loss from buildings. Most of these methods are based on the results of massive amounts of numerical simulations. While they can provide guidelines, the potential errors are large. MacDonald et al. (1985) found that the predictions between models could vary by more than a factor of two.

Probably the most widely used methods are presented in the ASHRAE Handbook of Fundamentals (1997) for slab-on-grade floors and basements. The heat conduction from a slabon-grade floor is approximated as a function of a heat-loss coefficient, $\mathrm{F}_{2}$, the slab perimeter, and the temperature difference between the indoor and outdoor air as given in Eq. (2.2). The heatloss coefficients were determined using the results of a two-dimensional, finite-element program for four foundation types with and without insulation in three climates (Wang 1979). As pointed out by Bahnfleth (1989), this method neglects the heat transfer from the core region of the floor, which can be important for medium or large buildings. The method for basements, based on the work of Latta and Boileau (1969), assumes circular heat-conduction paths from the basement walls and floor to the ground surface. The walls are divided into strips at different depths with effective path lengths through the soil to the ground surface. This method does not take into account the vertical heat flow in the walls, which can be dramatically altered by insulation configurations and surface conditions. In addition, this model does not directly account for heat transfer to the deep ground, which can be significant when the surface is warm or when there is high groundwater. Both of these methods were based on calculations that assumed a single soil thermal conductivity and, they are limited in the geometries that can be modeled.

Another well-known method derived by Mitalas (1982 and 1987) is based on the results of hundreds of two- and three-dimensional simulations with a finite element method (FEM) code. This method uses shape factors called Basement Heat Loss Factors (BHLF) to estimate the monthly heat loss values for various geometries, insulation configurations, and soil thermal properties. Corner allowance factors for the three-dimensional corner effects were derived from the three-dimensional model. This simplified method is limited to a few specified geometries, insulation configurations, soil thermal conductivities, and heating degree days. In addition, no information is given on the ground surface boundary conditions used in the numerical simulations. Other methods are presented by Yard et al. (1984), the CIBSE guide (1986), Bahnfleth (1989), and Krarti and Choi (1996).

Changes were made to the DOE-2 building energy simulation program to improve its groundcoupled heat transfer calculations (Huang et al. 1988 and Shen et al. 1988). Shen et al. completed an annual numerical analysis of the ground-coupled heat transfer for 88 configurations of deep basements, shallow basements, crawl spaces, and slabs-on-grade in 13 U.S. cities. Using superposition of a steady-state solution and a periodic solution, they showed that the periodic solution could be completed once and then scaled to any climate. Many simplifying assumptions had to be made, such as neglecting the solar input and using a fixed heat-transfer coefficient at the ground surface. Huang et al. combined these results with DOE-2.1C to complete wholebuilding simulations and to provide guidance on insulation placement and amounts, which were published in the Builder's Foundation Handbook (Carmody et al. 1991). Winkelmann (1998) 
used these results to develop a simplified method of modeling underground surfaces using DOE2.1E.

\subsection{Numerical Models of Building Ground-Coupled Heat Transfer}

Using fully numeric solutions has been limited mainly to the researchers who developed them to perform parametric analysis and to develop correlation-based methods (e.g., the Mitalas method). The main reason for their limited use is the large amount of computer time and memory required to run them; they also tend to be complex programs. However, personal computers are now becoming fast enough, and the speed will continue to rise rapidly, making full numerical models practical. Most of the methods use either the finite-difference method (FDM) or the FEM method.

One of the earliest models was a three-dimensional FDM developed by Kusuda and Achenbach (1963). The program was used to study the temperature and humidity conditions in fallout shelters. One significant feature of this work is that they used different values of soil thermal conductivity for summer and winter to account for the seasonal changes in soil moisture content.

Wang (1979) developed a two-dimensional FEM model, which, as mentioned above, is the basis for the present $\mathrm{F}_{2}$ coefficients in the ASHRAE Handbook of Fundamentals (1997). This program includes the effects of the soil freezing and thawing. The results were reported as the heat loss per linear foot of the floor cross-section and not for the entire floor. The translation of these results to real floor geometry was not reported.

Speltz (1980) developed a complete program for the energy simulation of underground structures that includes a two-dimensional FEM routine for ground-coupled heat transfer. The most notable feature of this work is the detailed energy balance for the ground-surface-boundary condition. The model includes short- and long-wave radiation exchange, conduction to the ground, convection, and evapotranspiration.

One of the most thorough works in this area was completed by Mitalas $(1982,1987)$, who completed hundreds of computer runs for slab-on-grade floors, shallow basements, and deep basements using two- and three-dimensional FEM codes. Mitalas noted that the heat loss can be significantly affected by groundwater, changes in soil thermal conductivity caused by moisture and temperature variation, and variations in ground surface temperature caused by solar radiation, adjacent buildings, and snow cover. This work was used as the basis for another twodimensional program called BASECALC that simulates the three-dimensional heat transfer at the corners with the corner correction method (Beausoleil-Morrison et al. 1995). The corner factor is defined as

$$
\mathrm{F}_{\mathrm{C}}=\frac{\mathrm{q}_{\text {corner zones }} / \mathrm{P}_{\text {corner zones }}}{\mathrm{q}_{\text {centralzone }} / \mathrm{P}_{\text {central zone }}}
$$

The heat loss is $\mathrm{q}$ and the zone perimeter is P. A total of 1512 corner factors were determined for different combinations of the insulation placement, insulation resistance, basement depth, basement width, soil thermal conductivity, and water table depth. The heat loss for the central 
zone is calculated by BASECALC using two-dimensional calculations. The total heat loss is then determined by

$$
\mathrm{q}_{\text {total }}=\mathrm{q}_{\text {central zone }}\left(1+\mathrm{F}_{\mathrm{C}} \frac{\mathrm{P}_{\text {corner zones }}}{\mathrm{P}_{\text {centralzone }}}\right)
$$

Bligh and Willard (1985) used the FEM thermal analysis program ADINAT to study the thermal performance of earth-sheltered buildings. This model used hourly weather data and included the effects of snow cover, cloud cover, and soil moisture phase changes from liquid to vapor and from liquid to solid. The most significant result of this work is that the heat loss varied nearly linearly with soil conductivity. Also, the solution took nearly 3 years to reach a quasi-steady state when initialized at zero and only a month when using a more realistic initialization from the results of a 3-year run, confirming the results of Lachenbruch.

Walton (1987) investigated the possibility of using two-dimensional calculations to approximate the three-dimensional heat flow to reduce the computation time. He transformed rectangularshaped floors into rectangles with round ends, keeping the area and the perimeter the same as shown in Figure 2.1. The heat transfer is then calculated using two-dimensional Cartesian coordinates for the center section and two-dimensional cylindrical coordinates for the end sections. This method, called the "rounded rectangle" or RR method, estimates the steady-state heat transfer from various simple basement and slab-on-grade floor geometries to within $1.5 \%$ and $1.7 \%$ of the results from the three-dimensional model. Year-long transient calculations also produced similar results. This shows the possibility of reducing the computation time by using two-dimensional calculations; however, the RR technique is limited to simple slab-on-grade geometries where axis-symmetric conditions exist.

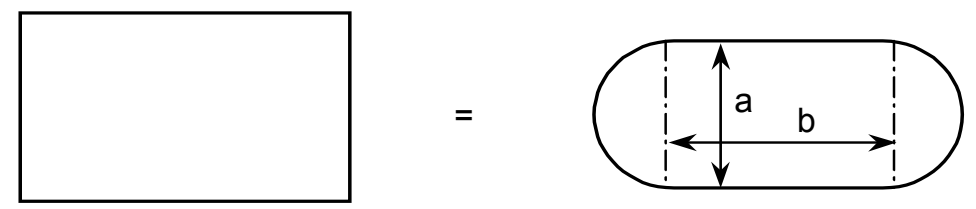

Same area, $A$ and perimeter $P$

$$
\begin{aligned}
& \mathrm{a}=\left(\mathrm{P}-\sqrt{\mathrm{P}^{2}-4 \pi \mathrm{A}}\right) / \pi \\
& \mathrm{b}=(\mathrm{P}-\pi \mathrm{a}) / 2
\end{aligned}
$$

Figure 2.1. Geometry transformation used by Walton to reduce the threedimensional problem to a two-dimensional problem.

Another comprehensive model is presented by Bahnfleth (1989) and Bahnfleth and Pedersen (1990). He developed a detailed three-dimensional FDM model for heat conduction from slabon-grade floors. Significant features of this model include the detailed ground-surface energy balance that handles everything the Speltz model does plus the ground-shading effects. Bahnfleth 
performed many parametric runs to study the dominant influences on ground-heat loss. $\mathrm{He}$ determined that the primary factors in determining the heat loss are the weather conditions affecting the ground-surface temperatures, the floor-area-to-perimeter ratio, soil thermal conductivity, and the insulation configuration. He showed that when the annual mean heat loss, $\mathrm{q}$, is plotted against the floor area-to-perimeter ratio, $\mathrm{A} / \mathrm{P}$, the data can be approximated by

$$
\mathrm{q}=\mathrm{c}(\mathrm{A} / \mathrm{P})^{\mathrm{d}}
$$

The parameters $\mathrm{c}$ and $\mathrm{d}$ are functions of the annual average indoor-outdoor temperature difference, soil properties, domain geometry, foundation design, and other factors. A parametric study of soil thermal conductivity and diffusivity showed that a factor of four increase in conductivity produced a three-fold increase in annual mean heat loss, while the diffusivity had very little effect on the mean or periodic heat loss. The ground-surface temperature was also shown to have a large influence on heat loss; therefore, it is not surprising that evapotranspiration and shading can significantly affect the ground-heat transfer. Runs with potential (maximum) evapotranspiration reduced the annual mean heat loss by $18.7 \%$ in Minneapolis and by $170 \%$ in Phoenix. The real effect of this will be less because the maximum evapotranspiration rarely occurs. The shading of the building on the ground decreased the annual mean heat loss by $27 \%$ in Phoenix.

Despite the thoroughness of the model, there are some weaknesses. One shortcoming is the assumption of constant soil thermal properties, which does not allow for different soil layers, moisture effects, or freezing and thawing. Another limitation is that partial insulation of the slab and footing walls, which are common methods of construction, cannot be modeled. Bahnfleth et al. (1998) extended this work to a three-dimensional model for the heat loss from basements. This new model is more flexible with the insulation configurations, and the temperature of an unconditioned basement can be calculated to simulate interior conditions more accurately.

One glaring omission from the area of building ground-coupled heat transfer models is the lack of validation with experimental data. This is because of the size, complexity, and length of time required to monitor ground-coupled heat and moisture transfer. Rees et al. (1995) and Rees and Thomas (1997) compared the results of an FEM program with long-term experimental data. Some of the comparisons are very good, while others are not. Rees attributes this to the estimation of the soil properties. It could also be caused by the approximation of the surface boundary conditions and by the fact that the soil properties were kept constant.

Adjali et al. (1998b) compared results from a finite volume ground heat transfer model added to the building energy simulation code, APACHE, with experimental data on a partial underground test room at the University of Minnesota. The results compared favorably for the summer, but not very well in the winter. They concluded that neglecting the effects of snow cover and rain can significantly affect the predicted temperatures. A sensitivity study showed that the soil thermal conductivity is the most important parameter and that the simulated results are more sensitive in the winter than the summer.

The only researcher found by the author to model the coupled heat and moisture transfer in soils around buildings was Shen (1986), who developed a two-dimensional fully implicit FDM program to analyze soil heat and moisture transfer. Shen validated the model well with published 
analytic solutions and with experimental data from heat and moisture transfer in a 1-m cylinder of Mississippi River sand. This model was then used to study the effects of rain on the heat transfer from a basement wall with both a clay soil and a sandy soil (Shen 1986; Shen and Ramsey 1988). The simulations were completed with the heat and moisture equations coupled and uncoupled. In the uncoupled simulation, the heat transfer by moisture movement was not considered; however, the soil's thermal properties were calculated as a function of the moisture content from the moisture transfer solution. The sandy soil showed a $9 \%$ increase in heat transfer for winter conditions and a $40 \%$ increase for summer conditions when the equations were coupled. The differences were much smaller for the clay soil. These results must be regarded with care because uncoupling the equations increases the thermal resistance since the heat flow by moisture transfer is not included. The main effect of moisture on the heat transfer in soils is on the thermal conductivity, which was not tested by this case.

\subsection{Effects of Ground Cover}

Gold (1967) measured the ground temperatures under two parking lots. One was cleared of snow in the winter, and the other was a grass-covered area. He estimated that for the grass-covered area in the summer, about $48 \%$ of the net solar radiation was dissipated by evapotranspiration, $42 \%$ by long-wave radiation, $7 \%$ by convection, and $3 \%$ by conduction into the ground. For the parking lot areas, the net solar radiation was split between convection and long-wave radiation losses with about $50 \%$ for each. Apparently, the conduction to the ground was very small. The snow-covered parking lot maintained an average surface temperature approximately $10^{\circ} \mathrm{C}$ warmer than the coldest monthly average air temperature.

Kusuda (1975) investigated the effect of ground surface cover by measuring the temperatures under black asphalt, asphalt painted white, bare dirt, short grass, and long grass. He found that the average monthly temperatures near the surface under the black asphalt were about $15^{\circ} \mathrm{F}$ hotter than under the long grass, even at a depth of one foot. In the winter, all of the temperatures at one foot were similar. At a depth of 30 feet, the soil temperatures under the black asphalt were higher in the winter, but similar to the others in the summer.

Gilpin and Wong (1976) discussed the "heat-valve" effect of snow cover. They argued that prolonged snow cover in the winter acts as an insulating layer and can raise the annual mean ground-surface temperatures. They also showed that a phase change in the ground amplifies this effect.

\subsection{Summary}

Ground-coupled heat transfer is an important term in a building's energy balance; however, the tools for detailed analyses of the problem are not available. The most widely used analysis methods are quite crude and can easily produce inaccurate results. Most models are severely limited in the geometries, insulation configurations, boundary conditions, and the soil properties that can be analyzed. For a first approximation, these models can produce reasonable results; however, answers that are more accurate are difficult to come by. Questions such as the distribution of soil moisture around buildings, the interaction of the ground surface with the atmosphere, and the effects of phase change on ground-coupled heat transfer have not been answered with enough detail to provide good design advice. The behavior of heated floors and 
basements is also not well understood. Using the ground for cooling in warm climates has not been mentioned, but is also a very important topic. The aim of this research was to gain some insight into these issues and provide the necessary tools for further research. 


\section{Chapter 3: Review of Soil Physics}

\subsection{Introduction}

One of the major difficulties in modeling heat-and-moisture transfer in soils is estimating the thermal and hydraulic properties. Soils consist of minerals, organic material, water (as vapor, liquid, and solid), solutes, air, and other gases, each of which affect the physical behavior of the soil. Soils are nonhomogeneous and nonisotropic, and many of the properties are strong functions of moisture content and, to a lesser degree, temperature. Measuring the properties in the field or in the lab is difficult, and the process of measuring can strongly affect the value obtained. Measured values are only valid for the conditions at the time of the measurement; therefore, correlations based on physical models and empirical observations of soil behavior are used to model soil behavior. The model for heat-and-moisture transfer developed in this work requires correlations for the thermal conductivity, soil water retention, and hydraulic conductivity. A brief introduction to the soil physics of these correlations and the effects of phase changes is presented in this chapter.

Reasonable approximations of soil behavior depend strongly on the simplifying assumptions used. For the purposes of this work, soils are considered homogenous and isotropic within each defined soil type. The soil matrix is assumed nondeformable, and hysteresis of the properties is neglected, as are the effects of solutes.

\subsection{Heat Transfer Paths in Soil}

Heat transfer in soil occurs through many different paths, including conduction through the soil grains, liquid, and gases; latent heat transfer through evaporation-condensation cycles; sensible heat transfer by vapor and liquid diffusion and convection; and radiation in the gas-filled pores. The relative magnitudes of the heat-transfer terms depend on the soil composition, structure, temperature, and moisture content. Simply adding the heat-transfer terms is not strictly correct because they are not uniformly distributed throughout the soil. A simplified diagram of the main heat-transfer paths examined in this work is shown in Figure 3.1. 


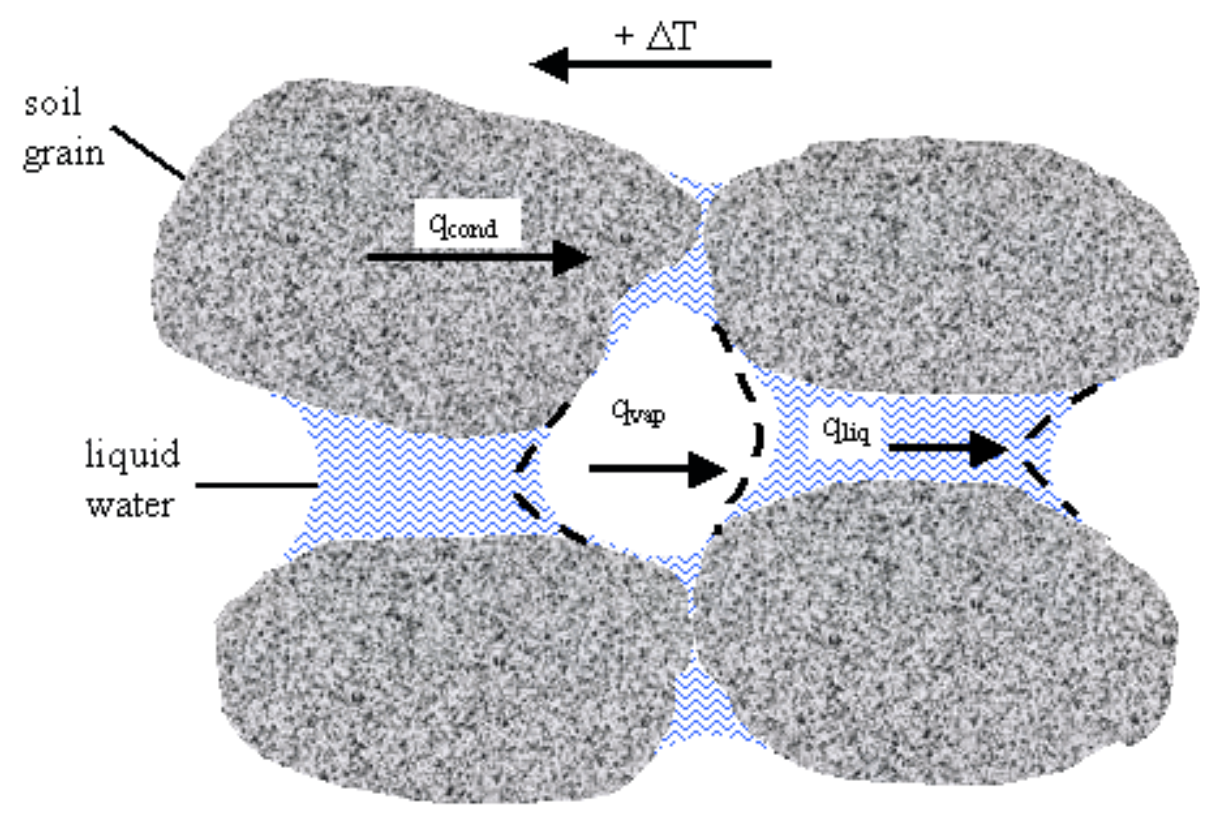

Figure 3.1. Simplified diagram of the major heat transfer paths in soil.

Conduction through the solid soil particles is the dominant heat-transfer mode under most circumstances (de Vries 1958). The contact resistance between the soil grains is the limiting factor; therefore, anything that reduces this resistance increases the thermal conductivity. Increasing the dry density promotes better contact between soil grains, and adding colloidal clay particles to a coarse soil can reduce the contact resistance by filling in the voids as long as the larger grains are not pushed apart. Adding moisture to a dry soil forms liquid islands around the contact points, which provides another path for heat flow (Farouki 1981). When moisture levels approach saturation, the lower thermally conductive gases are replaced with higher thermally conductive moisture.

In the gas-filled pores of unsaturated soils, liquid water evaporates on the warm side, absorbing the latent heat of vaporization and reducing the radius of the meniscus (dotted lines in Figure 3.1). Diffusion occurs because of the vapor pressure gradient, and the vapor condenses on the other side of the pore, releasing the latent heat of vaporization and increasing the meniscus radius. The sensible heat carried by the vapor is negligible because of the vapor's low volumetric heat capacity. At steady state, the imbalance in menisci radii induces capillary liquid flow between the soil grains to balance the vapor flow (Philip and de Vries 1957). This process is significant to the overall thermal conductivity because the effective thermal conductivity of the vapor distillation cycles is larger than the thermal conductivity of the gas-filled pores alone (deVries 1958).

Forced convection arises from potential gradients. One example of forced convection in soils is the infiltration of liquid at the ground surface, which can be significant for a short time after a large rain or irrigation. This heat transfer mode is included in this model. Groundwater flow, which is usually parallel to the ground surface, affects the vertical heat transfer by entraining moisture and by dispersion effects. This is only significant in coarse sands and gravel (Farouki 
1981) and is not considered in this analysis. The presence of groundwater does affect soil heat transfer by providing a large heat sink and a source of moisture, which can be adsorbed by the soil above. This effect is included in this analysis.

The following three heat transfer modes are small for the soils and the conditions encountered in the ground around buildings. Free convection arising from temperature gradients is only significant in soils having particle sizes larger than $8 \mathrm{~mm}$ (Farouki 1981). Sensible heat transfer by vapor convection or diffusion is negligible because of the vapor's low volumetric heat capacity. Radiation heat transfer contributes less than $1 \%$ of the total heat transfer in sands at normal atmospheric temperatures and is much less in finer-grained soils (Farouki 1981).

\subsection{Hydraulic and Thermal Properties of Soil}

\subsubsection{Soil Moisture Retention}

The movement of water in soil is determined by the water's relative potential energy state. Hillel (1998) defines soil water potential "as the difference in partial specific free energy between soil water and standard water." Standard water is water at a free surface, which is exposed to atmospheric pressure at a specified height. Water in saturated soil under hydrostatic pressure greater than atmospheric pressure has a positive potential energy. Water in unsaturated soil is at pressures less than atmospheric and has a negative potential energy. To extract water from an unsaturated soil, the capillary and adsorptive forces holding on to the water must be overcome. The attractive force of the capillary and adsorptive actions of the soil matrix is called the soil matric potential. The total potential is assumed to be the gravitational and matric potentials as presented in Eq. (3.1), where $\mathrm{z}$ is taken as positive upwards. Osmotic potential arises from solute concentration gradients and is usually much smaller than the gravitational and matric potentials, and is neglected in this work. The potential is often expressed as an equivalent head of water and, therefore, has the dimension of length.

$$
\Phi=\psi+\mathrm{z}
$$

In the absence of osmotic forces, the matric potential can be used to determine the soil's moisture content. The relationship between the matric potential and the soil moisture is shown graphically by the soil-moisture-retention curve (also called the soil water characteristic curve). Figure 3.2 shows an approximation of the soil-moisture-retention curve for loamy sand reported by Noborio et al. (1996) and Yolo light clay (Moore 1939). The flatness of the sandy soil curve shows that the moisture drains quickly and the steeper slope for the clay shows that this soil has a higher attraction to moisture. 


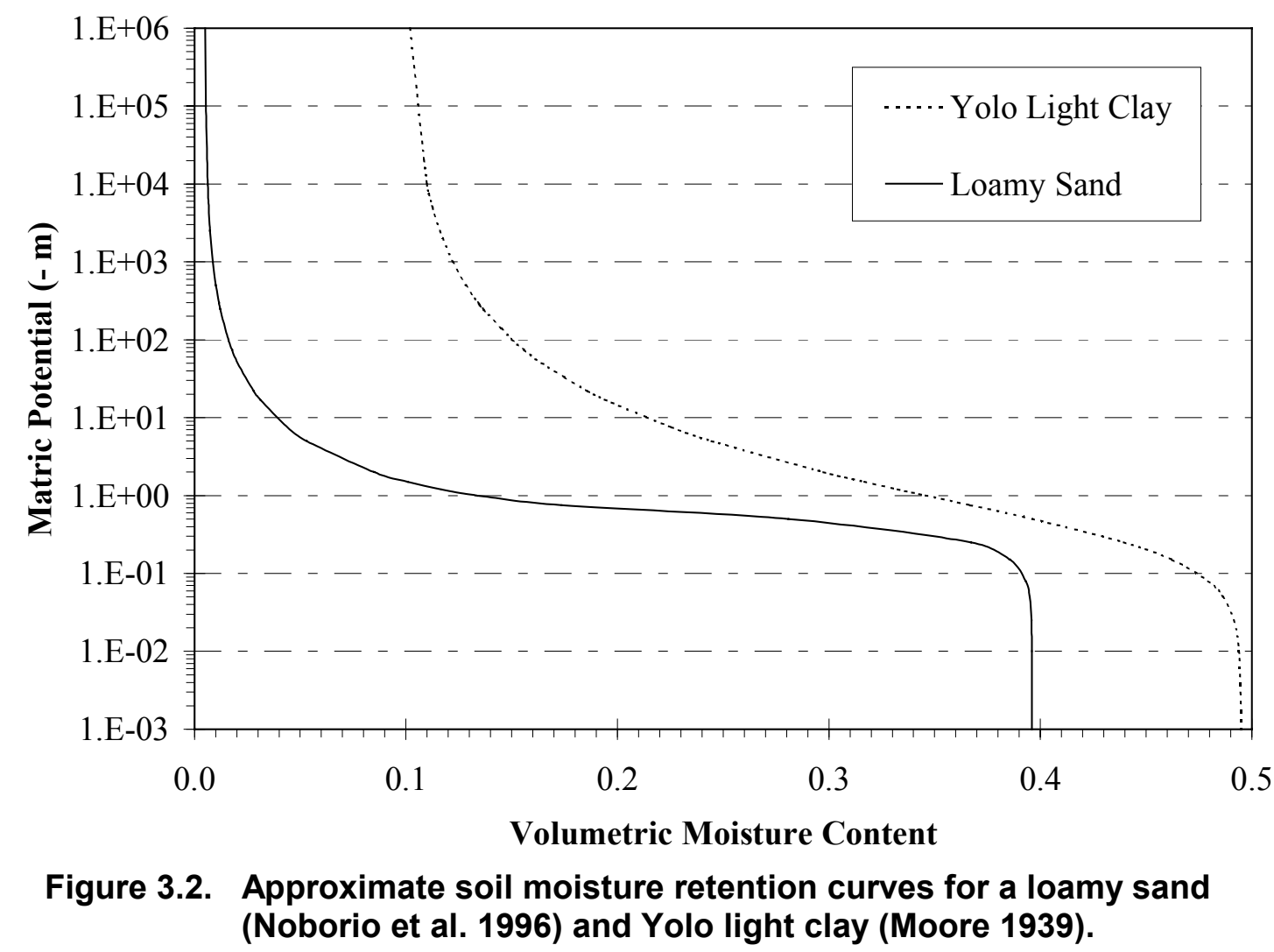

The behavior of the soil moisture retention typically exhibits a hysteresis between wetting and drying. The process of drying a moist soil (desorption) takes more energy than is released during the wetting (adsorption) process; therefore, the drying curve is usually higher than the wetting curve (Case 1994). This hysteresis is not modeled in this work, and the soil moisture retention curves are based on the drying behavior because this was the measurement method used for the soils in this research.

To simulate the soil moisture transfer in a soil, a continuous or piece-wise continuous correlation for the matric potential must be obtained. One of the most widely accepted methods for doing this is presented by van Genuchten (1980). The form of the correlation is

$$
\begin{aligned}
& \Theta=\left(\frac{1}{1+|\alpha \psi|^{\mathrm{n}}}\right)^{\mathrm{m}} \\
& \Theta \equiv \frac{\theta-\theta_{\mathrm{r}}}{\theta_{\mathrm{s}}-\theta_{\mathrm{r}}}
\end{aligned}
$$

The degree of saturation is $\Theta ; \theta_{\mathrm{r}}$ and $\theta_{\mathrm{s}}$ are the residual and saturated water contents; $\alpha, \mathrm{m}$, and $\mathrm{n}$ are parameters set to fit the measured data; and $m=1-1 / \mathrm{n}$. Van Genuchten presents a graphical method of determining these parameters to fit the measured data. The values used for each of the soils modeled in this work are included in Appendix C. 


\subsubsection{Hydraulic Conductivity}

The flow of water through unsaturated soil can be approximated by Richards' version of Darcy's law relating the flow to the gradient of the hydraulic head or the total potential (Hillel 1998). The parameter relating the flow to the pressure gradient is the hydraulic conductivity, $\mathrm{K}(\mathrm{m} / \mathrm{s})$.

$$
\mathrm{u}_{\ell}=-\mathrm{K}(\psi) \nabla \Phi
$$

The hydraulic conductivity in unsaturated soil is a function of soil and fluid properties, moisture content, and temperature. The soil liquid is assumed to be relatively pure water; therefore, the effects of the liquid on the hydraulic conductivity are neglected. If measured data are known for the range of moisture contents under consideration, a good approximation can be fitted to the data by a least-squares technique (Haverkamp et al. 1977). If hydraulic conductivity values are not known over the range of moisture contents, a satisfactory approximation can be developed using the hydraulic conductivity at saturation and the same parameters as determined from the soil-moisture-retention curve using van Genuchten's method (1980).

$$
\mathrm{K}(\Theta)=\mathrm{K}_{\mathrm{sat}} \Theta^{1 / 2}\left[1-\left(1-\Theta^{1 / \mathrm{m}}\right)^{\mathrm{m}}\right]^{2}
$$

or in terms of the matric potential

$$
\mathrm{K}(\psi)=\mathrm{K}_{\text {sat }} \frac{\left\{1-|\alpha \psi|^{\mathrm{n}-1}\left[1+|\alpha \psi|^{\mathrm{n}}\right]^{-\mathrm{m}}\right\}^{2}}{\left[1+|\alpha \psi|^{\mathrm{n}}\right]^{\mathrm{m} / 2}}
$$

The hydraulic conductivity curves of a loamy sand (Norborio et al. 1996) and of Yolo light clay using van Genuchten's method are shown in Figure 3.3.

If only pore ice exists in partially frozen soil, the movement of the unfrozen water content can be approximated by a Darcy's Law approach similar to that used in unfrozen soil (Kay and Perfect 1988). The hydraulic conductivity of partially frozen soil is a function of the unfrozen water content, which is a function of the temperature (Hoekstra 1966 and Harlan 1973). Measurements show that the hydraulic conductivity falls from values in the range of $10^{-8} \mathrm{~m} / \mathrm{s}$ to between $10^{-12}$ $\mathrm{m} / \mathrm{s}$ and $10^{-14} \mathrm{~m} / \mathrm{s}$ over the temperature range from 0.0 to $-1.0^{\circ} \mathrm{C}$ (Horiguchi and Miller 1983). Because no correlations for the hydraulic conductivity of frozen soil were found, it is assumed to follow the unfrozen relation using the unfrozen water content and corresponding matric potential. A small amount of water corresponding to the residual water content from the soilmoisture-retention curve remains unfrozen below the freezing point, but is not allowed to move once the soil temperature is below $0.0^{\circ} \mathrm{C}$. 


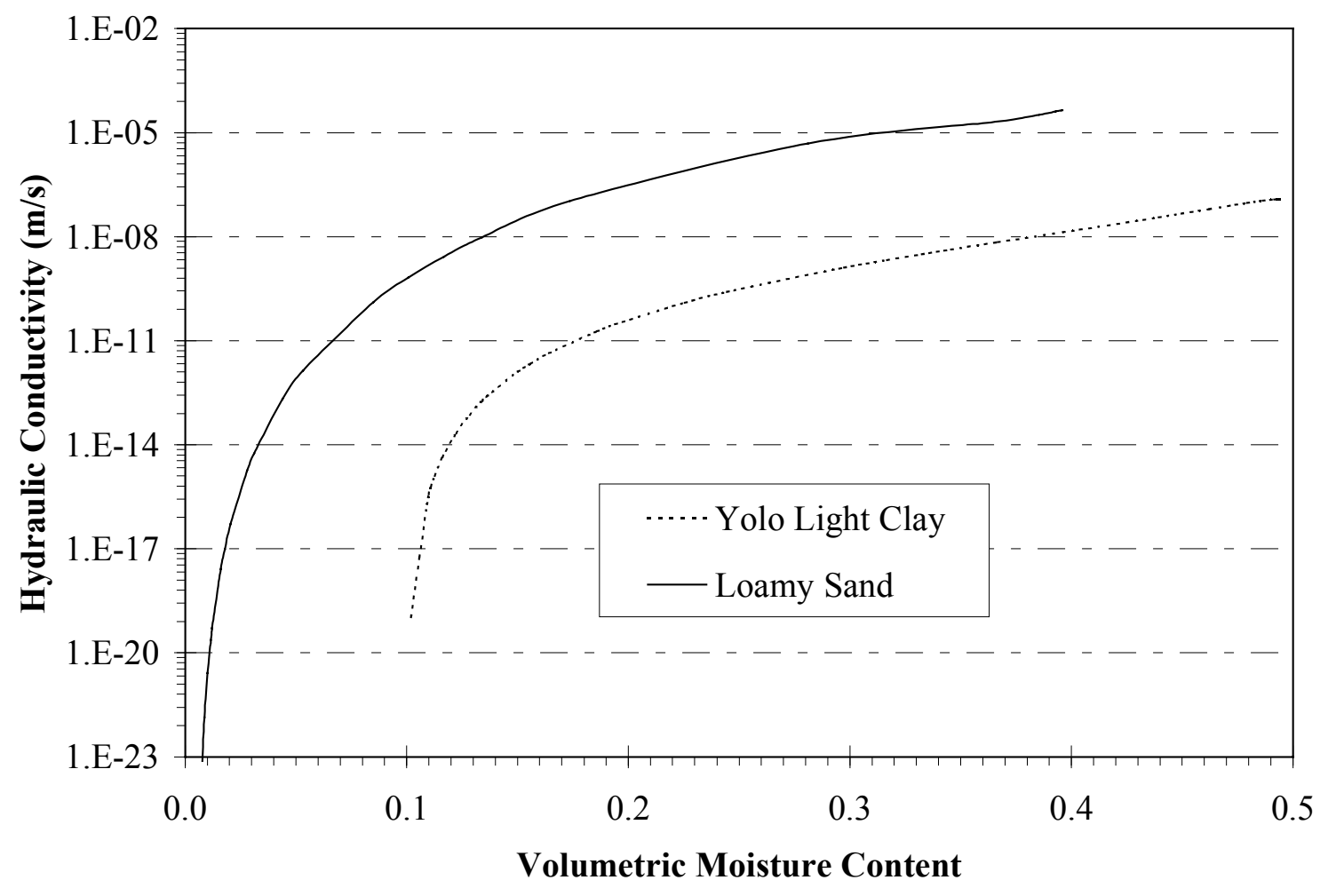

Figure 3.3. Approximations of the hydraulic conductivities of a loamy sand (Noborio et al. 1996) and Yolo light clay (Moore 1939).

\subsubsection{Temperature Effects on Hydraulic Properties}

The correlations presented for the matric potential and the hydraulic conductivity are based on measurements taken in the lab at a constant temperature; however, soil temperatures in the field are constantly changing, which affects the values of these properties. This temperature effect is much smaller than that of moisture and is often neglected. For hydraulic conductivity, the viscous flow model of Miller and Miller (1956) points to a correction by the ratio of the kinematic viscosities of water at the reference temperature $T_{r}$ and the actual temperature $T$. This method is generally accepted to produce accurate results (Milly 1982 from Eagleson 1970).

$$
\mathrm{K}\left(\mathrm{T}, \theta_{\ell}\right)=\frac{v\left(\mathrm{~T}_{\mathrm{r}}\right)}{v(\mathrm{~T})} \mathrm{K}\left(\mathrm{T}_{\mathrm{r}}, \theta_{\ell}\right)
$$

A temperature correction for the matric potential relationship can be derived by noting that the equilibrium of the air-water interface in a soil pore requires (Milly 1982)

$$
\psi=\frac{2 \sigma}{\rho_{\ell} g r_{c}}
$$

The harmonic mean radius is $r_{c}$, and the surface tension of the liquid is $\sigma$. From this, a temperature correction can be formed as 


$$
\psi(\theta, \mathrm{T})=\psi\left(\theta, \mathrm{T}_{\mathrm{r}}\right) \frac{\sigma(\mathrm{T})}{\sigma\left(\mathrm{T}_{\mathrm{r}}\right)} \frac{\rho_{\ell}\left(\mathrm{T}_{\mathrm{r}}\right)}{\rho_{\ell}(\mathrm{T})}
$$

The density ratio is usually dropped from this equation. Using these temperature corrections from Eqs. (3.7) and (3.9) is often called the surface-tension viscous-flow (STVF) approach. Milly (1984 from Milly and Eagleson 1980) suggests another formulation for the matric potential

$$
\psi(\theta, T)=\psi\left(\theta, \mathrm{T}_{\mathrm{r}}\right) \mathrm{e}^{-\mathrm{C}_{\psi}\left(\mathrm{T}-\mathrm{T}_{\mathrm{r}}\right)}
$$

where

$$
\mathrm{C}_{\psi}=\left.\frac{1}{\psi} \frac{\partial \psi}{\partial \mathrm{T}}\right|_{\theta}
$$

is taken as a constant, $\mathrm{C}_{\psi}=0.0068 \mathrm{~K}^{-1}$.

Another approach is the gain factor method from Nimmo and Miller (1986). The gain factor G for the matric potential relationship is defined as

$$
\mathrm{G}_{\psi}(\theta)=\frac{\psi(\mathrm{T}, \theta) / \psi\left(\mathrm{T}_{\mathrm{r}}, \theta\right)-1}{\sigma(\mathrm{T}) / \sigma\left(\mathrm{T}_{\mathrm{r}}\right)-1}
$$

This method requires knowledge of the matric potential at two temperatures to determine the gain factor. Giakoumakis and Tsakiris (1991) showed that the gain-factor method works better than the STVF method for fine-textured soils, but the STVF method works well for coarsetextured soils.

The temperature correction factors with $\mathrm{T}_{\mathrm{r}}=20.0^{\circ} \mathrm{C}$ for the STVF method and the MillyEagleson method are shown in Figure 3.4. Notice that the surface-tension model with the density ratio is very similar to the value without the density ratio. Because the STVF model is the most widely used, it was chosen for this work. 


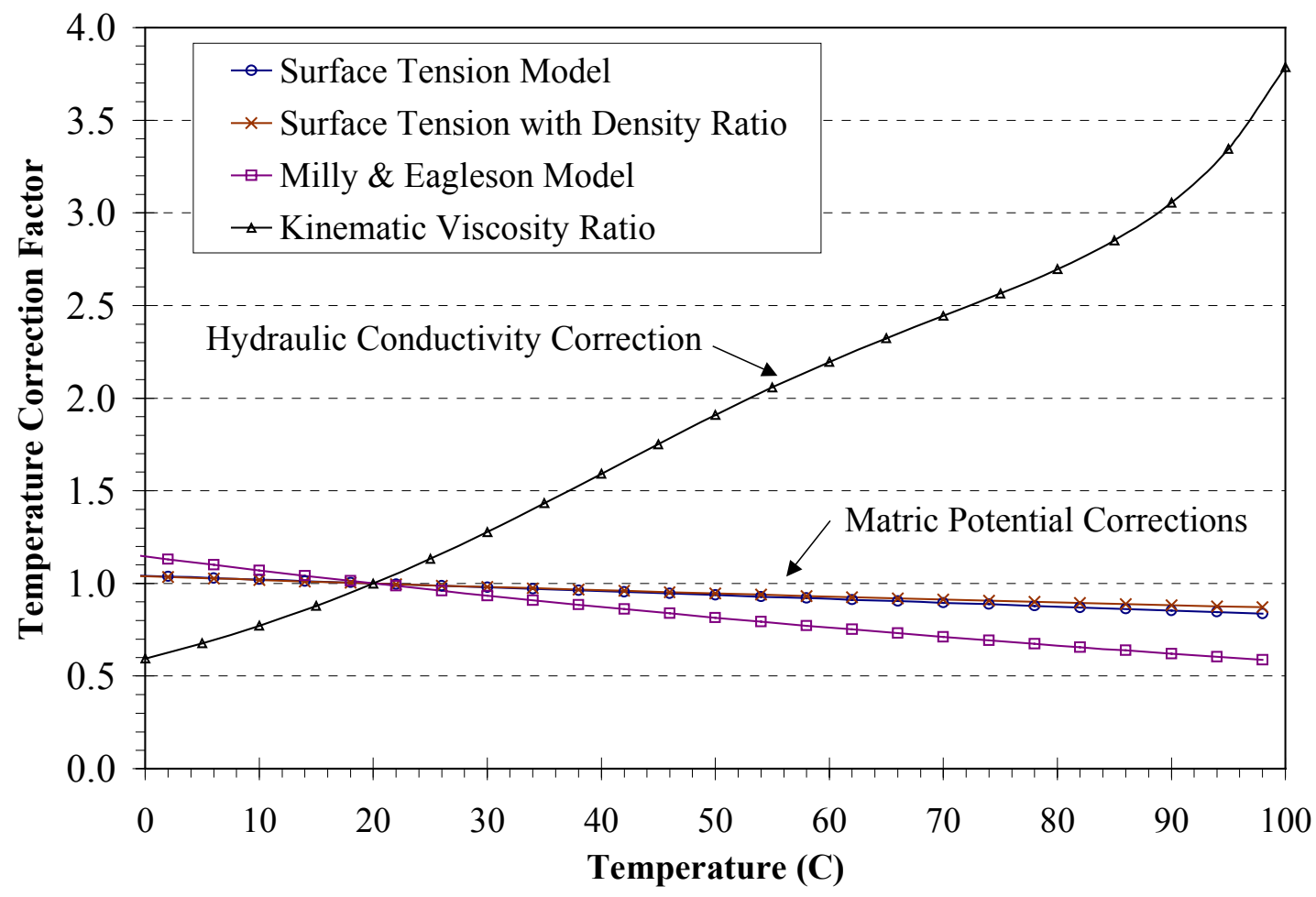

Figure 3.4. Temperature correction factors for the matric potential and hydraulic conductivity correlations.

\subsubsection{Thermal Conductivity}

Soil thermal conductivity can be defined as "the rate at which heat energy flows across a unit area of soil due to a unit temperature gradient" (Farouki 1981). It is a function of the moisture content; temperature; and the size, shape, orientation, packing, and type of grains that make up the soil matrix. The moisture content has the largest effect; it can change the thermal conductivity by more than a factor of 10 . For most ground-coupled heat transfer work, a fixed value of the thermal conductivity is assumed, which could lead to large errors. Some researchers have used seasonal values of thermal conductivity to account for changing moisture content (Kusuda and Achenbach 1963; McBride et al. 1979; Bligh and Willard 1985). The ASHRAE Handbook of Fundamentals (1997) suggests bounding the results with low and high values of thermal conductivities and presents ranges based on the work of Salomone and Marlowe (1989).

There are several methods available to approximate soil thermal conductivity based on empirical observations or on a combination of theoretical and empirical results (Farouki 1981 and Shen 1986). The method used in this research was developed by de Vries (1966) and has been shown to compare well with experimental data. In this model, we assume the soil consists of a continuous medium with an even distribution of ellipsoidal grains. The thermal conductivity is then estimated by Eq. (3.13). Water is considered to be the continuous medium except at very low moisture contents where air is used, and the result from this equation is multiplied by a correction factor of 1.25 . 


$$
\mathrm{k}=\frac{\mathrm{x}_{\mathrm{w}} \mathrm{k}_{\mathrm{w}}+\xi_{\mathrm{p}} \mathrm{x}_{\mathrm{p}} \mathrm{k}_{\mathrm{p}}+\sum_{\mathrm{i}=1}^{\mathrm{n}} \xi_{\mathrm{i}} \mathrm{x}_{\mathrm{i}} \mathrm{k}_{\mathrm{i}}}{\mathrm{x}_{\mathrm{w}}+\xi_{\mathrm{p}} \mathrm{x}_{\mathrm{p}}+\sum_{\mathrm{i}=1}^{\mathrm{n}} \xi_{\mathrm{i}} \mathrm{x}_{\mathrm{i}}}
$$

This equation represents an average of the thermal conductivities of water $w$, pores $p$, and $n$ types of soil grains weighted by the volumetric contents $\mathrm{x}$ and the ratio of the average temperature gradient in the constituent and the average temperature gradient of the medium $\xi$. The latter term is a function of the thermal conductivity ratios and the size, shape, and packing of the soil grains. For randomly oriented ellipsoidal grains with axes a, b, and c, an approximation to this term is

$$
\xi_{\mathrm{i}}=\frac{1}{3} \sum_{\mathrm{j}=\mathrm{a}, \mathrm{b}, \mathrm{c}}\left[1+\left(\frac{\mathrm{k}_{\mathrm{i}}}{\mathrm{k}_{\mathrm{w}}}-1\right) \mathrm{g}_{\mathrm{j}}\right]^{-1}
$$

The values of $g_{a}, g_{b}$, and $g_{c}$ depend upon the ratios of the grain axes, and they sum to unity. For a spheroid with axes $\mathrm{a}=\mathrm{b}=\mathrm{mc}$, the value of $\mathrm{g}_{\mathrm{a}}=\mathrm{g}_{\mathrm{b}}$ can be read from a graph in de Vries (1966). For example, the value of $g_{a}$ for the quartz grains is taken to be 0.144 , which corresponds to a value of $m \cong 4$.

As discussed above, the latent heat transfer of the evaporation-condensation cycles significantly increases the thermal conductivity of the gas-filled pores. The main driving force for the vapor diffusion is the vapor density gradients brought about by the presence of temperature gradients. Because temperature is the main driving force, this heat transfer can be treated as an effective heat conduction, and the thermal conductivity of the gas-filled pores can be estimated as the sum of the thermal conductivity of the air $\mathrm{k}_{\mathrm{a}}$ and the effective thermal conductivity of the vapor diffusion $\mathrm{k}_{\mathrm{v}}$.

$$
\mathrm{k}_{\mathrm{p}}=\mathrm{k}_{\mathrm{a}}+\mathrm{k}_{\mathrm{v}}
$$

The effective thermal conductivity of vapor distillation cycles for saturated conditions is derived in Chapter 4 and presented here for a single pore as

$$
\mathrm{k}_{\mathrm{v}, \mathrm{sat}}=\mathrm{h}_{\mathrm{fg}} \mathrm{D}_{\mathrm{a}} \frac{\mathrm{d} \rho_{\mathrm{vs}}}{\mathrm{dT}}
$$

The latent heat of vaporization is $\mathrm{h}_{\mathrm{fg}}(\mathrm{J} / \mathrm{kg}), \mathrm{D}_{\mathrm{a}}\left(\mathrm{m}^{2} / \mathrm{s}\right)$ is the vapor diffusion coefficient in air, and $\rho_{\mathrm{vs}}\left(\mathrm{kg} / \mathrm{m}^{3}\right)$ is the saturated vapor density. When the gas-filled pores are not saturated, the effective thermal conductivity is proportional to the relative humidity, $\varphi$ (Philip and de Vries 1957).

$$
\mathrm{k}_{\mathrm{v}}=\varphi \mathrm{k}_{\mathrm{v}, \mathrm{sat}}
$$

The behavior of the gas-filled pores varies with the moisture content, and therefore the method used to determine the value of $g_{a, p}$ for the gas-filled pores also changes. De Vries (1966) divides the calculation into three ranges of moisture content. In the first range, the relative humidity in the pores remains very close to unity and the effective thermal conductivity of the gas-filled pores is equal to $\mathrm{k}_{\mathrm{a}}+\mathrm{k}_{\mathrm{v} \text {,sat }}$. This range lies between saturation, $\theta_{\mathrm{s}}$, and a critical moisture content, 
$\theta_{\mathrm{k}}$. Below this critical moisture content, continuity of the liquid water no longer exists, the relative humidity reduces quickly from unity, and the thermal conductivity decreases rapidly. A discussion on how to determine the value of $\theta_{\mathrm{k}}$ is included at the end of this section.

As the moisture content approaches saturation, it is assumed that the small air pockets are nearly spherical and the value of $g_{a, p}$ approaches $1 / 3$. At the lower end of this first range, de Vries estimates that the value of $g_{a, p}$ approaches 0.035 , assuming that $g_{a}=0.144$ for the soil grains. The value of $g_{a, p}$ is assumed to vary linearly with moisture content between $\theta_{\mathrm{s}}$, and $\theta_{\mathrm{k}}$.

$$
\begin{aligned}
\mathrm{g}_{\mathrm{a}, \mathrm{p}} & =0.035+(0.333-0.035) \frac{\theta_{\ell}}{\theta_{\mathrm{s}}} \\
& =0.035+0.298 \frac{\theta_{\ell}}{\theta_{\mathrm{s}}}
\end{aligned}
$$

The second region is bounded by $\theta_{\mathrm{k}}$ and $\theta_{\text {dry }}$. The effective thermal conductivity of the vapor diffusion is considered to vary linearly between $\mathrm{k}_{\mathrm{v}, \mathrm{sat}}$ at $\theta_{\mathrm{k}}$ and 0 at $\theta_{\ell}=0$. Therefore, the thermal conductivity of the gas-filled pores is approximated as

$$
\mathrm{k}_{\mathrm{p}}=\mathrm{k}_{\mathrm{a}}+\mathrm{k}_{\mathrm{v}, \mathrm{s}}\left(\theta_{\mathrm{k}}\right) \frac{\theta_{\ell}}{\theta_{\mathrm{k}}}
$$

The value of $\mathrm{g}_{\mathrm{a}, \mathrm{p}}$ is also assumed to vary linearly between the value determined from Eq. (3.18) at $\theta_{\mathrm{k}}$ and $\mathrm{g}_{\mathrm{a}}=0.013$ corresponding to $\theta_{\ell}=0$.

$$
\mathrm{g}_{\mathrm{a}, \mathrm{p}}=0.013+\mathrm{g}_{\mathrm{a}, \mathrm{p}}\left(\text { eqn.(3.18) at } \theta_{\mathrm{k}}\right) \frac{\theta_{\ell}}{\theta_{\mathrm{k}}}
$$

The value of $\theta_{\text {dry }}$ is the lowest moisture content where water can be considered the continuous medium. Below $\theta_{\text {dry }}$, de Vries suggests that the soil thermal conductivity be determined by graphical interpolation between $\mathrm{k}\left(\theta_{\ell}=\theta_{\text {dry }}\right)$ and $\mathrm{k}\left(\theta_{\ell}=0\right)$. Graphical interpolation is taken here to be linear interpolation. The value of $\theta_{\text {dry }}$ is taken as 0.03 for coarse grain soils and between 0.05 and 0.1 for fine grain soils (de Vries, 1966). The thermal conductivity of dry soil is calculated from Eq. (3.13) with $\theta_{\ell}=0, \theta_{\mathrm{a}}=\eta$, and $\xi_{\mathrm{a}}=1$, and the result is multiplied by 1.25 .

There are several suggested modifications to the de Vries method created by researchers to fit their experimental data (Shen, 1986). Shen compares the de Vries method and a modified version by Kimball et al. (1976) with experimental data for four soil types. The Kimball et al. modification performs better for coarse grain soils, but the de Vries method produced better results for a finer-grained, silty soil. De Vries (1966) reported excellent results for a wide range of soil types; therefore, the original method developed by de Vries is used in this work.

There is no definite method used to determine the value of the critical moisture content, $\theta_{\mathrm{k}}$. If reliable experimental data for the thermal conductivity are available, the value can be used as a parameter to fit the data; otherwise, it must be estimated. De Vries claims that for coarse-grained soils, it is approximately equal to the field capacity, which is very close to the wilting point for 
these soils. Shen (1986) reviews methods to estimate the critical moisture content from the curvature of the soil moisture-retention curve. These methods are subjective and tend to give values higher than those of de Vries. An easier method is to look at the relative humidity of the gas-filled pores and determine the point where it begins to decrease from unity. If the soil liquid and vapor are in thermodynamic equilibrium, and in the absence of solutes, the relative humidity of the soil moisture may be written as (Edlefsen and Anderson 1943)

$$
\varphi=\exp \left(\frac{\psi g}{\mathrm{R}_{\mathrm{w}} \mathrm{T}}\right)
$$

The acceleration of gravity is $\mathrm{g}$, and the gas constant for water vapor is $\mathrm{R}_{\mathrm{w}}$. Figure 3.5 shows a graph of this equation as a function of the matric potential at $10^{\circ} \mathrm{C}$. Varying the temperature between $0^{\circ} \mathrm{C}$ and $50^{\circ} \mathrm{C}$ has very little effect on this curve, especially on the point of departure from unity.

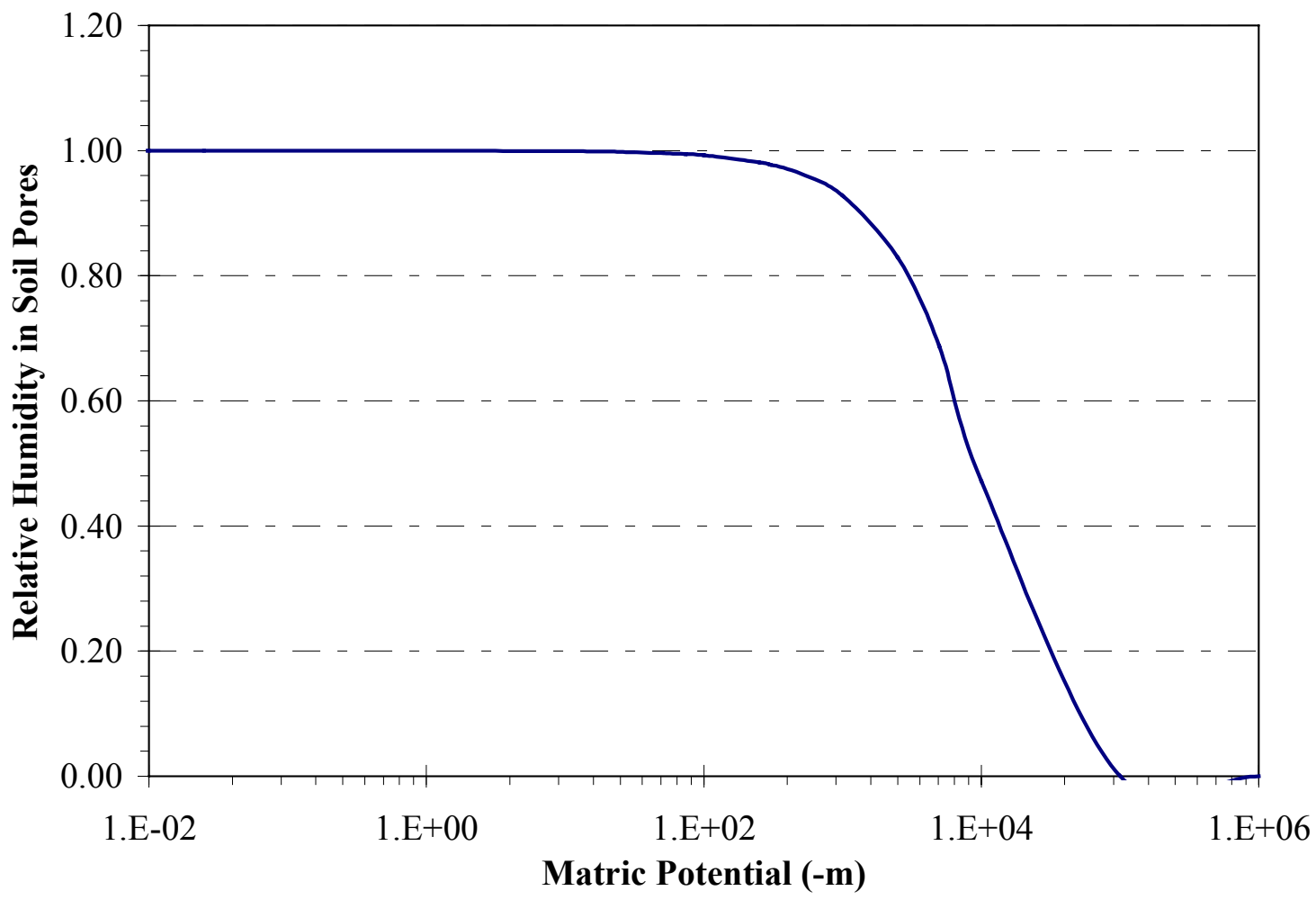

Figure 3.5. Relative humidity of soil moisture at a temperature of $10^{\circ} \mathrm{C}$.

At a matric potential of $-100 \mathrm{~m}$, the relative humidity $\varphi=0.9925$, and at $\psi=-50 \mathrm{~m}, \varphi=0.9963$. From the soil moisture-retention curve in Figure 3.2 with a value of $\psi=-50 \mathrm{~m}$, the critical moisture contents for the loamy sand and Yolo light clay are approximately 0.02 and 0.16 . This is by no means an exact method, but it does give some physical basis and a good starting point. The actual values used for the soils in this research are listed in Table C.3 in Appendix C.

Figure 3.6 shows the effective thermal conductivity of saturated vapor distillation cycles from Eq. (3.16) as compared with the thermal conductivity of water and air. It must be remembered 
that vapor distillation occurs only in the gas-filled pores and that the effective thermal conductivity from this cannot be directly compared to the thermal conductivity calculated for the soil. This graph also shows the effective thermal conductivity of Yolo light clay (Moore 1939) for three moisture contents as calculated by the de Vries method. The nonlinear behavior of the curves is mainly caused by the heat transfer of vapor distillation. This effect is most important at low moisture contents as can be seen in Figure 3.7, which shows the thermal conductivity for a sandy loam calculated with and without the vapor diffusion term in Eq. (3.15).

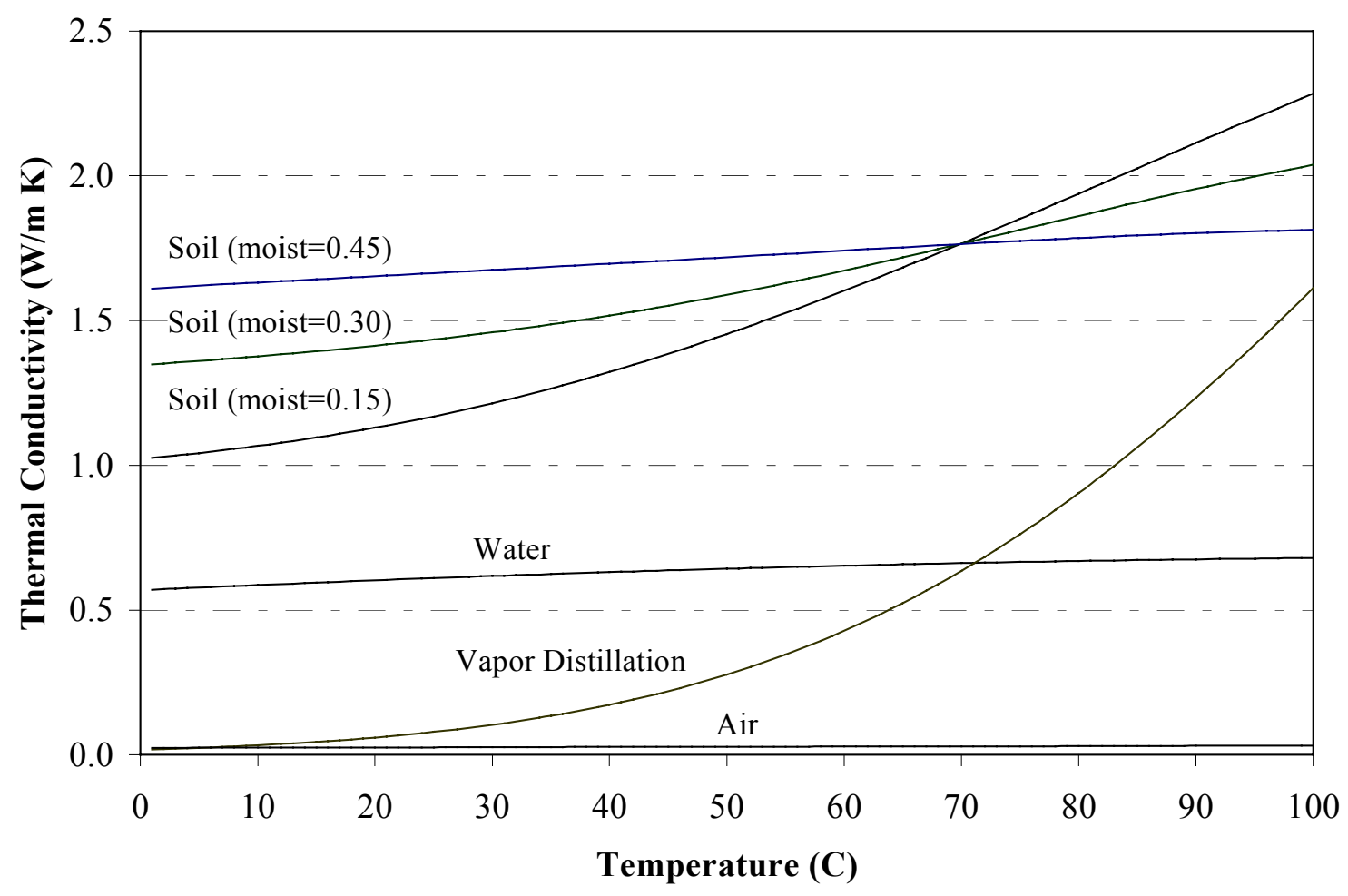

Figure 3.6. The effective thermal conductivity of vapor distillation in the gasfilled pores as compared to that of water and air and the total effective thermal conductivity of Yolo light clay as calculated by the de Vries Method. 


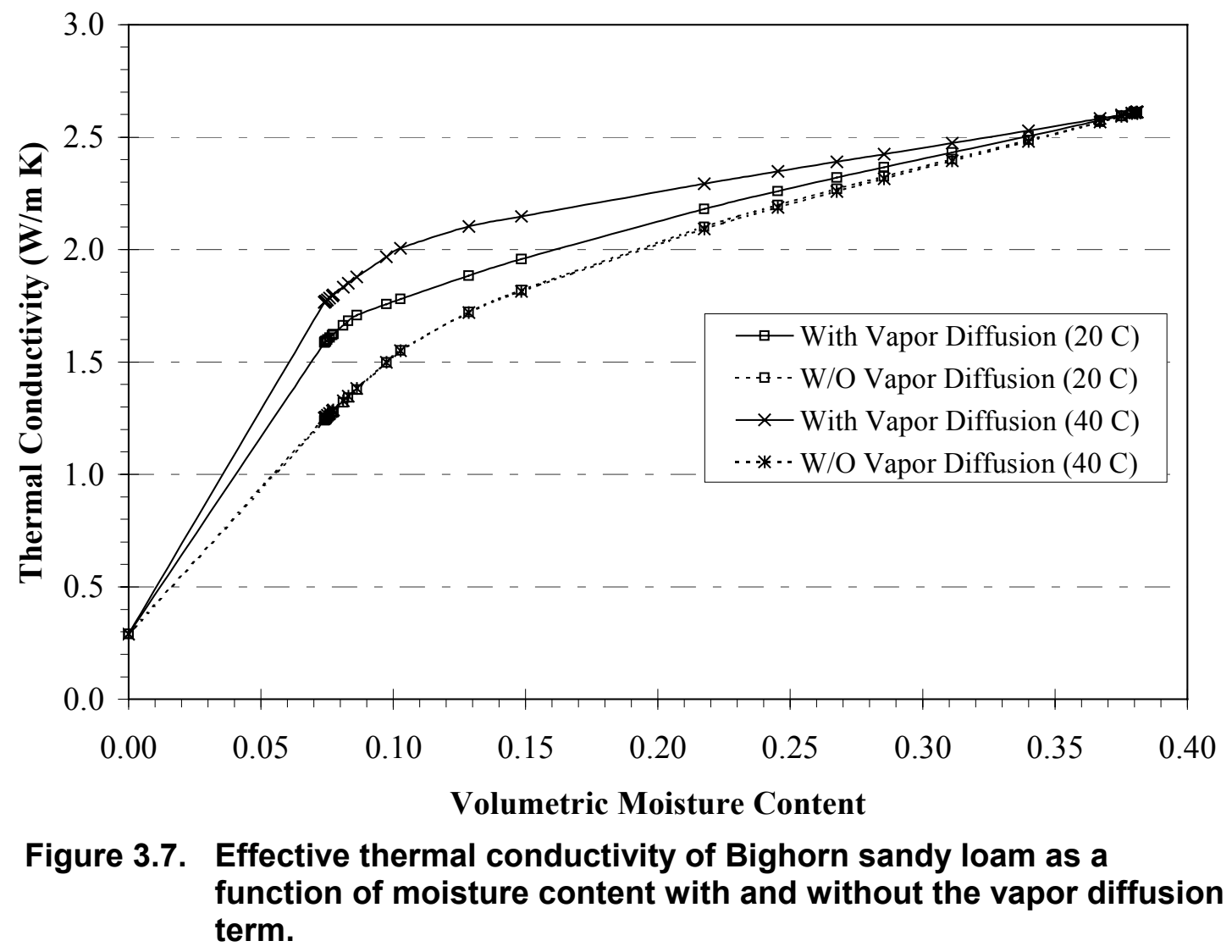

\subsubsection{Effects of Freezing}

The effect of freezing on the thermal and hydraulic performance of soil is not well understood. Kersten (1949) completed the most extensive experimental work concerning the effects of freezing on the thermal properties of soil by measuring the thermal conductivity of 19 soils at different temperatures, densities, and moisture contents. The results showed that as a soil freezes, the thermal conductivity decreases for low moisture contents and increases for high moisture contents. For all of the experiments, the soils were frozen quickly, so it was not expected that ice lenses had time to form, which would alter the results.

One way to approximate the thermal conductivity of frozen soil is to use the de Vries method, treating ice as another soil constituent. Harlan (1973) used this method but simplified it so the ratios of the temperature gradients were set to one for all soil particles. The de Vries method, without Harlan's simplification, was compared with Kersten's results (1949). Kersten presented graphs of the thermal conductivity ratio of soil at $25^{\circ} \mathrm{F}\left(-4^{\circ} \mathrm{C}\right)$ and $40^{\circ} \mathrm{F}\left(4.4^{\circ} \mathrm{C}\right)$. He also measured the thermal conductivity of the soils at $-20^{\circ} \mathrm{F}\left(-28.9^{\circ} \mathrm{C}\right)$, which was similar to the results at $25^{\circ} \mathrm{F}$. Comparisons of the de Vries method and Kersten's measured values for Fairbanks silty clay loam, which is similar to Yolo light clay, and Dakota sandy loam are shown in Figure 3.8. The approximated values follow the general trend of the measured values, especially for the Fairbanks silty clay loam. 

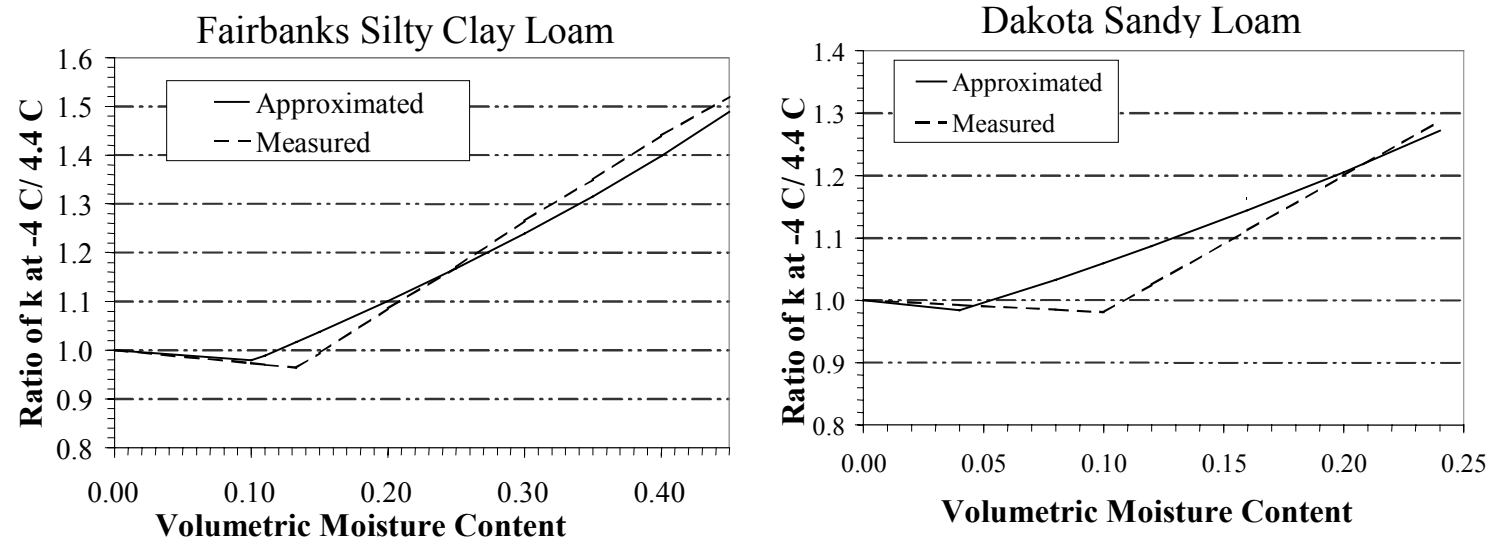

Figure 3.8. Ratio of the thermal conductivities of frozen and unfrozen soil as approximated by the de Vries method and measured by Kersten (1949) for Fairbanks Silty Clay Loam and Dakota Sandy Loam. 


\section{Chapter 4: Model Development}

\subsection{Introduction}

Modeling ground-coupled heat transfer is complicated by the many unknowns and the complex physical processes involved. In most cases, the heat transfer is tightly coupled with the moisture transfer in the soil; therefore, an accurate model must solve both problems simultaneously. This chapter outlines the development of a model directed towards ground-coupled heat-and-moisture transfer around buildings. A more complete derivation is included in Appendix A. The twodimensional, ground-coupled, heat-and-moisture transfer equations were coded in a Fortran 90 computer program called GHAMT. A two-dimensional heat-conduction program was also created called GHT2D.

\subsection{Coupled Heat and Moisture Transfer Model}

There are two macroscopic approaches to the heat-and-moisture-transfer problem in soils. One uses irreversible thermodynamics to describe the interactions of the forces and fluxes involved (Cary and Taylor 1962a and 1962b and Jury 1973). The other method is a mechanistic approach based on physical models of the phenomenological processes that occur in the soil (Philips and de Vries 1957, de Vries 1958, and Jury 1973). The second approach is better at addressing the vapor phase change, the vapor diffusion process, and the interaction of the heat transfer in the soil matrix and soil pore system (de Vries 1975). Because of these strengths, the mechanistic approach was chosen for this work.

The moisture-transfer equations can be cast in terms of the moisture content ( $\theta$-based equations) or in terms of the matric potential ( $\psi$-based equations). The $\theta$-based approach is slightly simpler and avoids problems with mass convergence, but the diffusivity is undefined at saturation and is discontinuous at the interface between soil types. The $\psi$-based equations can handle saturation and is continuous for layered soils (Hillel 1998). Because of the ability to handle saturated soil, the $\psi$-based approach is used in this work.

As stated in Chapter 3, the main simplifying assumptions made in the derivations are as follows: the soil is homogenous and isotropic within each defined unit of soil; the soil matrix is nondeformable, and therefore, swelling and frost heaving are not modeled; the effects of solutes are neglected; and hysteresis of soil properties is not modeled. Other assumptions are stated as appropriate in the descriptions below.

\subsubsection{Liquid Transfer}

Darcy's law can be used to approximate the flow of water through saturated soil by relating the flow, $\mathbf{u}_{\ell}(\mathrm{m} / \mathrm{s})$, to the gradient of the hydraulic head. When the soil is unsaturated, the water pressure is less than ambient and is referred to as the soil suction or soil water matric potential, $\psi$ $(\mathrm{m})$. Richards extended Darcy's law to unsaturated soil by using the gradient of the total potential, $\Phi$, and defining the hydraulic conductivity, $\mathrm{K}(\mathrm{m} / \mathrm{s})$, as a function of the soil water matric potential (Hillel 1998). 


$$
\mathbf{u}_{\ell}=-\mathrm{K}(\psi) \nabla \Phi
$$

As described in Chapter 3, the total potential is taken as the sum of the matric and gravitational potentials as presented in Eq. (4.2), where $\mathrm{z}$ is taken as positive upwards. The potential is often expressed as an equivalent head of water and therefore has the dimension of length.

$$
\Phi=\psi+\mathrm{z}
$$

Substitution of Eq. (4.2) into Eq. (4.1) yields

$$
\mathbf{u}_{\ell}=-\mathrm{K} \nabla \psi-\mathrm{K} \hat{\mathrm{k}}
$$

By applying the continuity equation to the liquid moisture content of a control volume of soil, the conservation of liquid can be written as

$$
\frac{\partial \theta_{\ell}}{\partial \mathrm{t}}=-\nabla \cdot \mathbf{u}_{\ell}-\mathrm{E}
$$

The volumetric liquid moisture content is $\theta_{\ell}\left(\mathrm{m}^{3} / \mathrm{m}^{3}\right)$ and the evaporation from the liquid to the vapor phase in the soil pores is $\mathrm{E}\left(\mathrm{s}^{-1}\right)$. The liquid content is a function of the matric potential and temperature; therefore, the time derivative of the liquid content can be expanded by the chain rule to give

$$
\frac{\partial \theta_{\ell}}{\partial \mathrm{t}}=\left(\frac{\partial \theta_{\ell}}{\partial \psi}\right)_{\mathrm{T}} \frac{\partial \psi}{\partial \mathrm{t}}+\left(\frac{\partial \theta_{\ell}}{\partial \mathrm{T}}\right)_{\psi} \frac{\partial \mathrm{T}}{\partial \mathrm{t}}
$$

Substitution of Eqs. (4.3) and (4.5) into (4.4) gives the governing equation for liquid transfer:

$$
\mathrm{C}_{\psi \ell} \frac{\partial \psi}{\partial \mathrm{t}}+\mathrm{C}_{\mathrm{T} \ell} \frac{\partial \mathrm{T}}{\partial \mathrm{t}}=\nabla \cdot[\mathrm{K} \nabla \psi]+\frac{\partial \mathrm{K}}{\partial \mathrm{z}}-\mathrm{E}
$$

where the matric and thermal liquid capacitances are defined as

$$
\begin{aligned}
\mathrm{C}_{\psi \ell} & =\left(\frac{\partial \theta_{\ell}}{\partial \psi}\right)_{\mathrm{T}}\left[\mathrm{m}^{-1}\right] \\
\mathrm{C}_{\mathrm{T} \ell} & =\left(\frac{\partial \theta_{\ell}}{\partial \mathrm{T}}\right)_{\psi}\left[\mathrm{K}^{-1}\right]
\end{aligned}
$$

\subsubsection{Vapor Transfer}

The vapor diffusion in a gas-filled pore can be approximated by modifying Fick's law of diffusion, assuming a uniform and constant total pressure, P (Pa) (de Vries 1975 and Nakano and Miyazaki 1979).

$$
\dot{\mathbf{m}}_{\mathrm{v}}=-\frac{\mathrm{D}_{\mathrm{a}}}{\mathrm{R}_{\mathrm{w}} \mathrm{T}} \frac{\mathrm{P}}{\mathrm{P}-\mathrm{P}_{\mathrm{v}}} \nabla \mathrm{P}_{\mathrm{v}}
$$


The molecular diffusivity of water vapor in air is $D_{a}\left(\mathrm{~m}^{2} / \mathrm{s}\right), \mathrm{R}_{\mathrm{w}}(=461.5 \mathrm{~J} / \mathrm{kg} \mathrm{K})$ is the gas constant for water vapor, $T(K)$ is the absolute temperature, and $P_{v}$ is the partial pressure of the water vapor. The mass-flow factor as defined in Eq. (4.10) is nearly unity for all conditions in the soil around buildings and is therefore not included in the equations after this point. The molecular diffusivity of water vapor in air is $\mathrm{D}_{\mathrm{a}}$ and can be determined by Eq. (4.11) (deVries 1975).

$$
\begin{aligned}
& v=\frac{P}{P-P_{v}} \\
& D_{a}=c\left(\frac{P_{o}}{P}\right)\left(\frac{T}{T_{o}}\right)^{n}
\end{aligned}
$$

The reference pressure is $\mathrm{P}_{\mathrm{o}}=1.01325 \times 10^{5} \mathrm{~Pa}$, the reference temperature is $\mathrm{T}_{\mathrm{o}}=273.15 \mathrm{~K}, \mathrm{c}=$ $2.17 \times 10^{-5} \mathrm{~m}^{2} / \mathrm{s}$, and $\mathrm{n}=1.88$.

Assuming the vapor behaves as an ideal gas, the vapor diffusion equation can be written in terms of the vapor density as

$$
\dot{\mathbf{m}}_{\mathrm{v}}=-\mathrm{D}_{\mathrm{a}}\left(\nabla \rho_{\mathrm{v}}+\frac{\rho_{\mathrm{v}}}{\mathrm{T}}(\nabla \mathrm{T})_{\mathrm{p}}\right)
$$

The term $(\nabla \mathrm{T})_{\mathrm{p}}$ is the temperature gradient across a single gas-filled pore. The vapor density in the pores can be expressed as the product of the relative humidity, $\varphi$, and the saturated vapor density, $\rho_{\mathrm{vs}}$ (Edlefsen and Anderson 1943).

$$
\rho_{\mathrm{v}}=\rho_{\mathrm{vs}} \varphi
$$

If the soil liquid and vapor are in thermodynamic equilibrium, and in the absence of solutes, the relative humidity of the soil moisture may be written as (Edlefsen and Anderson 1943)

$$
\varphi=\exp \left(\frac{\psi g}{\mathrm{R}_{\mathrm{w}} \mathrm{T}}\right)
$$

The acceleration of gravity is $g$, and the gas constant for water vapor is $R_{w}$. From Eqs. (4.13) and (4.14), the vapor density gradient can be expanded, and the vapor diffusion equation can be written as

$$
\dot{\mathbf{m}}_{\mathrm{v}}=-\mathrm{D}_{\mathrm{a}} \varphi \rho_{\mathrm{vs}}\left[\frac{\mathrm{g}}{\mathrm{R}_{\mathrm{w}} \mathrm{T}} \nabla \psi+\left(\frac{1}{\rho_{\mathrm{vs}}} \frac{\partial \rho_{\mathrm{vs}}}{\partial \mathrm{T}}+\frac{1}{\mathrm{~T}}-\frac{\psi \mathrm{g}}{\mathrm{R}_{\mathrm{w}} \mathrm{T}^{2}}+\left.\frac{\mathrm{g}}{\mathrm{R}_{\mathrm{w}} \mathrm{T}} \frac{\partial \psi}{\partial \mathrm{T}}\right|_{\theta}\right)(\nabla \mathrm{T})_{\mathrm{p}}\right]
$$

The four coefficient terms of the temperature gradient are plotted as a function of the matric potential in Figure A.2. From this graph, it is easy to see that the second and third terms are negligible for $\psi>-10^{4} \mathrm{~m}$ and quickly become the dominant terms below this point. Only in extreme dry conditions is the matric potential less than $-10^{4} \mathrm{~m}$. However, since these terms 
become large very quickly, they are included for $\psi<-10^{4} \mathrm{~m}$. The term $(1 / \mathrm{T})$ is considered negligible and dropped from the calculations.

The vapor mass flux presented in Eq. (4.15) is for a single pore and must be altered when extending it to a porous soil system. The effects of the reduced cross section for diffusion, the tortuosity, and the interactions between the vapor and liquid phases must be addressed. A vapor diffusion correction factor, $\mathrm{f}\left(\theta_{\ell}\right)$, is added to account for these effects. In addition, the temperature gradients across the gas-filled pores are higher than those across the system because of the lower thermal conductivity of the gas-filled pores. The temperature gradient term is multiplied by the ratio of the average temperature gradient across the pores and by the temperature gradient across the system. The vapor diffusion correction factor as defined by de Vries (1958) is

$$
\begin{array}{ll}
\mathrm{f}\left(\theta_{\ell}\right)=\eta, & \text { for } \theta_{\ell} \leq \theta_{\mathrm{k}} \\
\mathrm{f}\left(\theta_{\ell}\right)=\theta_{\mathrm{a}}+\theta_{\mathrm{a}} \theta_{\ell} /\left(\eta-\theta_{\mathrm{k}}\right), & \text { for } \theta_{\ell}>\theta_{\mathrm{k}}
\end{array}
$$

The soil porosity is $\eta$, and $\theta_{\mathrm{k}}$ is a critical moisture content, below which the hydraulic conductivity falls to a value much lower than its value at saturation (Philip and de Vries 1957). This value of critical moisture content is not strictly the same as the value defined in Chapter 3 in the discussion of the thermal conductivity, but is taken as the same value in this work.

With these additions, the vapor mass flux of Eq. (4.15) divided by the liquid density for consistency with the liquid transfer equation can be written for the soil system as

$$
\frac{\dot{\mathbf{m}}_{\mathrm{v}}}{\rho_{\ell}}=-\mathrm{D}_{\psi \mathrm{v}} \nabla \psi-\mathrm{D}_{\mathrm{Tv}} \nabla \mathrm{T}
$$

where the matric and thermal vapor diffusivities are

$$
\begin{aligned}
& \mathrm{D}_{\psi \mathrm{v}}=\mathrm{f}\left(\theta_{\ell}\right) \mathrm{D}_{\mathrm{a}} \frac{\rho_{\mathrm{vs}}}{\rho_{\ell}} \frac{\varphi \mathrm{g}}{\mathrm{R}_{\mathrm{w}} \mathrm{T}} \\
& \mathrm{D}_{\mathrm{Tv}}=\mathrm{f}\left(\theta_{\ell}\right) \mathrm{D}_{\mathrm{a}} \varphi \frac{\rho_{\mathrm{vs}}}{\rho_{\ell}}\left(\frac{1}{\rho_{\mathrm{vs}}} \frac{\partial \rho_{\mathrm{vs}}}{\partial \mathrm{T}}-\frac{\psi \mathrm{g}}{\mathrm{R}_{\mathrm{w}} \mathrm{T}^{2}}+\left.\frac{\mathrm{g}}{\mathrm{R}_{\mathrm{w}} \mathrm{T}} \frac{\partial \psi}{\partial \mathrm{T}}\right|_{\theta}\right) \frac{(\nabla \mathrm{T})_{\mathrm{p}}}{(\nabla \mathrm{T})}
\end{aligned}
$$

An expression for the ratio of the temperature gradients follows from the de Vries method of approximating the thermal conductivity (Chapter 3 and Appendix C) and can be calculated as

$$
\frac{(\nabla \mathrm{T})_{\mathrm{p}}}{(\nabla \mathrm{T})}=\frac{\xi_{\mathrm{p}}}{\mathrm{x}_{\mathrm{w}}+\xi_{\mathrm{p}} \mathrm{x}_{\mathrm{p}}+\sum_{\mathrm{i}=1}^{\mathrm{n}} \xi_{\mathrm{i}} \mathrm{x}_{\mathrm{i}}}
$$

The vapor content is expressed as an equivalent liquid content, and assuming thermodynamic equilibrium between the liquid and vapor, we can write 


$$
\theta_{\mathrm{v}}=\frac{\left(\eta-\theta_{\ell}\right) \rho_{\mathrm{v}}}{\rho_{\ell}}
$$

Expanding $\left(\partial \theta_{\mathrm{v}} / \partial \mathrm{t}\right)$ yields

$$
\frac{\partial \theta_{\mathrm{v}}}{\partial \mathrm{t}}=-\frac{\varphi \rho_{\mathrm{vs}}}{\rho_{\mathrm{v}}} \frac{\partial \theta_{\ell}}{\partial \mathrm{t}}+\frac{\varphi\left(\eta-\theta_{\ell}\right)}{\rho_{\mathrm{v}}} \frac{\partial \rho_{\mathrm{vs}}}{\partial \mathrm{t}}+\frac{\left(\eta-\theta_{\ell}\right) \rho_{\mathrm{vs}}}{\rho_{\mathrm{v}}} \frac{\partial \varphi}{\partial \mathrm{t}}
$$

Substituting Eq. (4.5) into Eq. (4.22) and expanding the other time derivatives in terms of $\psi$ and T yields

$$
\frac{\partial \theta_{v}}{\partial \mathrm{t}}=\mathrm{C}_{\psi \mathrm{v}} \frac{\partial \psi}{\partial \mathrm{t}}+\mathrm{C}_{\mathrm{Tv}} \frac{\partial \mathrm{T}}{\partial \mathrm{t}}
$$

where the matric and thermal vapor capacitances are

$$
\begin{aligned}
& \mathrm{C}_{\psi \mathrm{v}}=\frac{\rho_{\mathrm{vs}} \varphi}{\rho_{\ell}}\left[\frac{\left(\eta-\theta_{\ell}\right) \mathrm{g}}{\mathrm{R}_{\mathrm{w}} \mathrm{T}}-\left(\frac{\partial \theta_{\ell}}{\partial \psi}\right)_{\mathrm{T}}\right] \\
& \mathrm{C}_{\mathrm{Tv}}=\frac{\rho_{\mathrm{vs}} \varphi}{\rho_{\ell}}\left[\frac{\left(\eta-\theta_{\ell}\right)}{\rho_{\mathrm{vs}}}\left(\frac{\partial \rho_{\mathrm{vs}}}{\partial \mathrm{T}}\right)-\left(\frac{\partial \theta_{\ell}}{\partial \mathrm{T}}\right)_{\psi}\right]
\end{aligned}
$$

The conservation of vapor content can be written as

$$
\frac{\partial \theta_{\mathrm{v}}}{\partial \mathrm{t}}=-\nabla \cdot\left(\dot{\mathbf{m}}_{\mathrm{v}} / \rho_{\ell}\right)+\mathrm{E}
$$

The governing equation for vapor transfer can now be derived by substituting Eqs. (4.17) and (4.23) into (4.26).

$$
\mathrm{C}_{\psi \mathrm{v}} \frac{\partial \psi}{\partial \mathrm{t}}+\mathrm{C}_{\mathrm{Tv}} \frac{\partial \mathrm{T}}{\partial \mathrm{t}}=\nabla \cdot\left[\mathrm{D}_{\psi \mathrm{v}} \nabla \psi\right]+\nabla \cdot\left[\mathrm{D}_{\mathrm{Tv}} \nabla \mathrm{T}\right]+\mathrm{E}
$$

\subsubsection{Total Moisture Transfer}

The moisture transfer equation is then found by combining the equations for liquid and vapor transport, Eqs. (4.6) and (4.27):

$$
\mathrm{C}_{\psi \mathrm{m}} \frac{\partial \psi}{\partial \mathrm{t}}+\mathrm{C}_{\mathrm{Tm}} \frac{\partial \mathrm{T}}{\partial \mathrm{t}}=\nabla \cdot\left[\mathrm{D}_{\psi \mathrm{m}} \nabla \psi\right]+\nabla \cdot\left[\mathrm{D}_{\mathrm{Tm}} \nabla \mathrm{T}\right]+\frac{\partial \mathrm{K}}{\partial \mathrm{z}}
$$

where the matric and thermal moisture capacitances are

$$
\begin{aligned}
& \mathrm{C}_{\psi \mathrm{m}}=\mathrm{C}_{\psi \ell}+\mathrm{C}_{\psi \mathrm{v}}[\mathrm{m}] \\
& \mathrm{C}_{\mathrm{Tm}}=\mathrm{C}_{\mathrm{T} \ell}+\mathrm{C}_{\mathrm{Tv}}[\mathrm{K}]
\end{aligned}
$$


and the matric and thermal moisture diffusivities are

$$
\begin{aligned}
& \mathrm{D}_{\psi \mathrm{m}}=\mathrm{K}+\mathrm{D}_{\psi \mathrm{v}}[\mathrm{m} / \mathrm{s}] \\
& \mathrm{D}_{\mathrm{Tm}}=\mathrm{D}_{\mathrm{Tv}}\left[\mathrm{m}^{2} / \mathrm{s} \mathrm{K}\right]
\end{aligned}
$$

\subsubsection{Heat Transfer}

Heat transfer in soil occurs by conduction, convection, and latent heat transfer by vapor distillation cycles, sensible heat transfer by vapor and liquid movement, and by radiation. According to de Vries (1958), the heat transfer in unsaturated soil is dominated by pure conduction, with a small addition by latent heat transfer of vapor movement. The sensible heat transfer by bulk liquid movement is only important for a few days after a large rainfall or other moisture at the surface. For most cases, the sensible heat transfer by vapor movement and by radiation is negligible.

By applying the conservation of energy on the soil system we can write

$$
\frac{\partial(\rho \mathrm{e})}{\partial \mathrm{t}}=-\nabla \cdot \mathbf{q}+\mathrm{q}^{\prime \prime \prime}
$$

The thermal internal energy is e $(\mathrm{J} / \mathrm{kg})$ and is defined in Eq. (4.34), the heat flux in the soil system is $\mathbf{q}\left(\mathrm{W} / \mathrm{m}^{2}\right)$ and is defined in Eq. (4.35), and the heat generation is $\mathrm{q}^{\prime \prime \prime}\left(\mathrm{W} / \mathrm{m}^{3}\right)$. The soil system is considered composed of solid soil grains, liquid water, water vapor, and air (with other gases). Neglecting the heat capacity of the air, the thermal energy of the soil system relative to an arbitrary reference temperature, $\mathrm{T}_{\mathrm{o}}$, can be written as (Jury 1973)

$$
\begin{aligned}
\rho e & =\rho_{\mathrm{s}}(1-\eta) \mathrm{C}_{\mathrm{p}, \mathrm{s}}\left(\mathrm{T}-\mathrm{T}_{\mathrm{o}}\right)+\rho_{\ell} \theta_{\ell} \mathrm{C}_{\mathrm{p}, \ell}\left(\mathrm{T}-\mathrm{T}_{\mathrm{o}}\right) \\
& +\rho_{\ell} \theta_{\mathrm{v}} \mathrm{C}_{\mathrm{p}, \mathrm{v}}\left(\mathrm{T}-\mathrm{T}_{\mathrm{o}}\right)+\rho_{\ell} \theta_{\mathrm{v}} \mathrm{h}_{\mathrm{fg}}\left(\mathrm{T}_{0}\right)-\rho_{\ell} \int_{0}^{\theta_{\ell}} \mathrm{W}(\theta) \mathrm{d} \theta
\end{aligned}
$$

The subscript s refers to the solid soil particles, $\ell$ to the liquid moisture phase, and $\mathrm{v}$ to the vapor phase. The specific heat capacities are denoted by $\mathrm{C}_{\mathrm{p}}(\mathrm{J} / \mathrm{kg} \mathrm{K})$, the latent heat of vaporization is $\mathrm{h}_{\mathrm{fg}}(\mathrm{J} / \mathrm{kg})$, and $\theta_{\mathrm{v}}$ is defined as an effective liquid volumetric content. The heat of wetting, $\mathrm{W}$, is the energy released when the water molecules adsorb on the surface of the soil grains. It is a function of the initial moisture content and surface area (Hillel 1998). It is only significant for wetting dry clay soils and is neglected in this work. Implicit in Eq. (4.35) is the assumption that the thermal sources and sinks are uniformly distributed throughout the soil system.

The heat flux in the soil consists of conduction, convection, and radiation. The conduction term is dominant, and the radiation term is negligible except at very high temperatures. With this in mind, the heat flux in the soil can be represented by:

$$
\mathbf{q}=-\mathrm{k}^{*} \nabla \mathrm{T}+\mathrm{h}_{\mathrm{fg}}\left(\mathrm{T}_{\mathrm{o}}\right) \dot{\mathbf{m}}_{\mathrm{v}}+\mathrm{C}_{\mathrm{p}, \ell}\left(\mathrm{T}-\mathrm{T}_{\mathrm{o}}\right) \dot{\mathbf{m}}_{\ell}+\mathrm{C}_{\mathrm{p}, \mathrm{v}}\left(\mathrm{T}-\mathrm{T}_{\mathrm{o}}\right) \dot{\mathbf{m}}_{\mathrm{v}}
$$

Note that the heat fluxes are not strictly additive as this equation indicates. The various heat transfers occur along different paths through the soil (de Vries 1958). However, a complete treatment of this would require a microscopic model of the processes occurring on a soil pore 
level. The thermal conductivity $\mathrm{k}^{*}$ represents the pure heat conduction through the soil system with no moisture movement. Note that this is different from the thermal conductivity $\mathrm{k}$ measured in a soil system and calculated by the de Vries method (Chapter 3 and Appendix C) that includes the effect of latent heat transfer by vapor distillation.

Substituting Eqs. (4.34) and (4.35) along with the liquid and vapor mass fluxes from Eqs. (4.3) and (4.17) into Eq. (4.33) yields

$$
\begin{aligned}
& \rho_{\mathrm{s}}(1-\eta) \mathrm{C}_{\mathrm{p}, \mathrm{s}} \frac{\partial \mathrm{T}}{\partial \mathrm{t}}+\rho_{\ell} \theta_{\ell} \mathrm{C}_{\mathrm{p}, \ell} \frac{\partial \mathrm{T}}{\partial \mathrm{t}}+\rho_{\ell} \mathrm{C}_{\mathrm{p}, \ell}\left(\mathrm{T}-\mathrm{T}_{\mathrm{o}}\right) \frac{\partial \theta_{\ell}}{\partial \mathrm{t}} \\
& +\rho_{\ell} \mathrm{h}_{\mathrm{fg}}\left(\mathrm{T}_{0}\right) \frac{\partial \theta_{\mathrm{v}}}{\partial \mathrm{t}}+\rho_{\ell} \theta_{\mathrm{v}} \mathrm{C}_{\mathrm{p}, \mathrm{v}} \frac{\partial \mathrm{T}}{\partial \mathrm{t}}+\rho_{\ell} \mathrm{C}_{\mathrm{p}, \mathrm{v}}\left(\mathrm{T}-\mathrm{T}_{\mathrm{o}}\right) \frac{\partial \theta_{\mathrm{v}}}{\partial \mathrm{t}} \\
& \quad=\nabla \cdot\left(\mathrm{k}^{*} \nabla \mathrm{T}\right)-\mathrm{h}_{\mathrm{fg}}\left(\mathrm{T}_{0}\right) \nabla \cdot \dot{\mathbf{m}}_{\mathrm{v}}-\mathrm{C}_{\mathrm{p}, \ell}\left(\mathrm{T}-\mathrm{T}_{\mathrm{o}}\right) \nabla \cdot \dot{\mathbf{m}}_{\ell} \\
& -\mathrm{C}_{\mathrm{p}, \ell} \dot{\mathbf{m}}_{\ell} \cdot \nabla \mathrm{T}-\mathrm{C}_{\mathrm{p}, \mathrm{v}}\left(\mathrm{T}-\mathrm{T}_{\mathrm{o}}\right) \nabla \cdot \dot{\mathbf{m}}_{\mathrm{v}}-\mathrm{C}_{\mathrm{p}, \mathrm{v}} \overrightarrow{\mathrm{q}}_{\mathrm{v}} \cdot \nabla \mathrm{T}+\mathrm{q}^{\prime \prime \prime}
\end{aligned}
$$

The total volumetric heat capacity of the soil system and the latent heat of vaporization at temperature $\mathrm{T}$ can be defined as

$$
\begin{aligned}
& \mathrm{C}=(1-\eta) \rho_{\mathrm{s}} \mathrm{C}_{\mathrm{p}, \mathrm{s}}+\theta_{\ell} \rho_{\ell} \mathrm{C}_{\mathrm{p}, \ell}+\theta_{\mathrm{v}} \rho_{\ell} \mathrm{C}_{\mathrm{p}, \mathrm{v}}\left[\mathrm{J} / \mathrm{m}^{3} \cdot \mathrm{K}\right] \\
& \mathrm{h}_{\mathrm{fg}}(\mathrm{T})=\mathrm{h}_{\mathrm{fg}}\left(\mathrm{T}_{\mathrm{o}}\right)-\mathrm{C}_{\mathrm{p} \ell}\left(\mathrm{T}-\mathrm{T}_{\mathrm{o}}\right)+\mathrm{C}_{\mathrm{pv}}\left(\mathrm{T}-\mathrm{T}_{\mathrm{o}}\right)[\mathrm{J} / \mathrm{kg}]
\end{aligned}
$$

The latent heat (enthalpy) of vaporization, $\mathrm{h}_{\mathrm{fg}}(\mathrm{T})$, is approximately a linear function of temperature and can be represented by Eq. (4.39). Standard steam tables use a reference temperature of $0.01^{\circ} \mathrm{C}$ for the enthalpy (ASHRAE 1997); however, it is assumed to be $0.0^{\circ} \mathrm{C}$ in this work.

$$
\mathrm{h}_{\mathrm{fg}}(\mathrm{T})=2501-2.405(\mathrm{~T}-273.15) \quad[\mathrm{kJ} / \mathrm{kg}]
$$

With the substitution of Eqs. (4.37) and (4.38) and substitutions for the liquid and vapor mass fluxes, Eq. (4.36) becomes the final version of the governing equation for soil heat transfer.

$$
\mathrm{C}_{\mathrm{TT}} \frac{\partial \mathrm{T}}{\partial \mathrm{t}}+\mathrm{C}_{\psi \mathrm{T}} \frac{\partial \psi}{\partial \mathrm{t}}=\nabla \cdot(\mathrm{k} \nabla \mathrm{T})+\nabla \cdot\left(\mathrm{D}_{\psi \mathrm{T}} \nabla \psi\right)+\mathrm{C}_{\mathrm{p}, \ell} \dot{\mathbf{m}}_{\ell} \cdot \nabla \mathrm{T}+\mathrm{q}^{\prime \prime \prime}
$$

where the thermal and matric heat capacitances are

$$
\begin{aligned}
& \mathrm{C}_{\mathrm{TT}}=\mathrm{C}+\rho_{\ell} \mathrm{h}_{\mathrm{fg}} \mathrm{C}_{\mathrm{Tv}} \quad\left[\mathrm{J} / \mathrm{m}^{3} \mathrm{~K}\right] \\
& \mathrm{C}_{\psi \mathrm{T}}=\rho_{\ell} \mathrm{h}_{\mathrm{fg}} \mathrm{C}_{\psi \mathrm{v}} \quad\left[\mathrm{J} / \mathrm{m}^{4}\right]
\end{aligned}
$$

and the matric heat conductivity is

$$
\mathrm{D}_{\psi \mathrm{T}}=\rho_{\ell} \mathrm{h}_{\mathrm{fg}} \mathrm{D}_{\psi \mathrm{v}}\left[\mathrm{W} / \mathrm{m}^{2}\right]
$$

The first term on the right hand side of Eq. (4.40) represents the Fourier heat conduction defined by the thermal conductivity $\mathrm{k}^{*}$ and the effective heat conduction by thermally driven vapor diffusion. The effective thermal conductivity, $\mathrm{k}$, is the value calculated by the de Vries method 
(1966) and described in Chapter 3 and Appendix 3. The second term is the heat transfer by moisture diffusion caused by the matric potential gradient, which corresponds to the moisture gradient. This term is much smaller than the first term, which is evident from Figure 4.1(b). The third term is the sensible heat transfer by bulk liquid flow. In unsaturated soil, this term is only significant for a short period after a large influx of moisture such as rainfall or irrigation. The final term is a heat generation term. A comparison of the magnitudes of the heat transfer terms is presented in Chapter 6.

The first term on the left hand side of Eq. (4.40) relates the change in the thermal energy stored to changes in temperature, and the second term relates the change in thermal energy stored to changes in the matric potential. The temperature term dominates the heat storage as can be seen in Figure 4.1(a), which shows the two-capacitance coefficients as a function of moisture content for Yolo light clay. When comparing the two-capacitance coefficients, it must be kept in mind that they are multiplied by the time rate of change of the temperature and the time rate of change of the matric potential respectively.

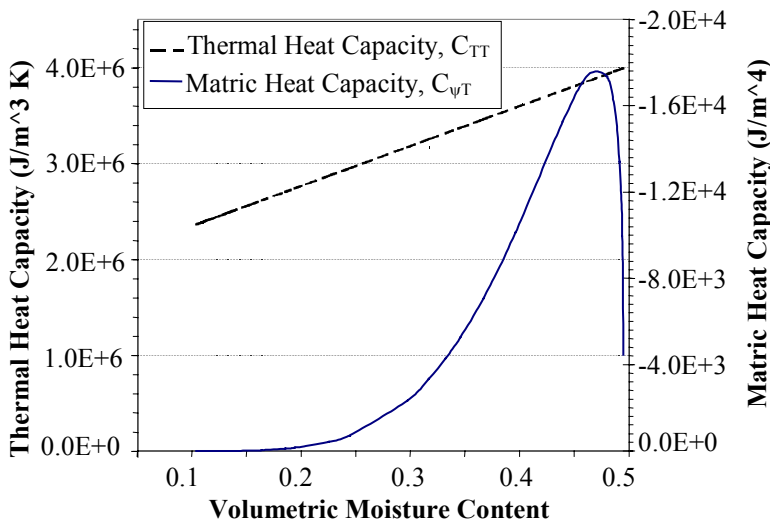

(a)

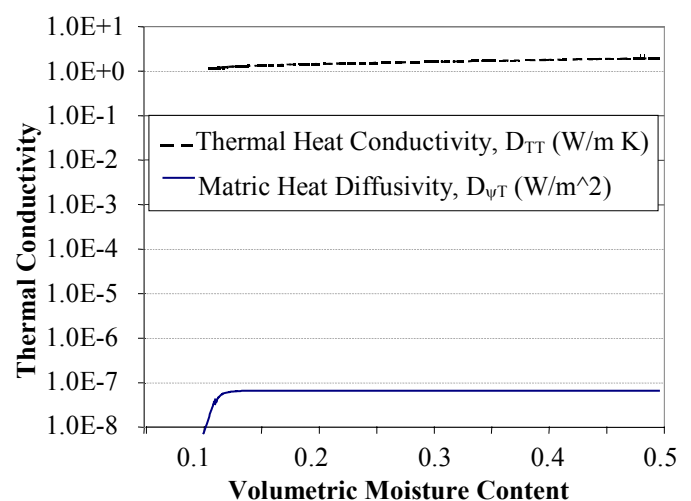

(b)

Figure 4.1. Heat-capacity coefficients (a) and the heat-conductivity coefficients (b) for Yolo light clay as a function of moisture content at $293.15 \mathrm{~K}$.

\subsubsection{Freezing Model}

Freezing the soil affects the heat transfer, not only through the release and adsorption of the latent heat of fusion, but also through changes in the thermal and hydraulic properties. The thermal conductivity of frozen soil can be more or less than that of unfrozen soil depending on the moisture content (Kersten 1949). The most obvious effect of freezing on the moisture transfer is the moisture's immobility in the completely frozen state. The not-so-obvious detail is that the phase change is not isothermal; in fact, a very small amount of liquid water remains even at temperatures near liquid nitrogen (Harlan 1973). However, most of the liquid-to-solid phase change occurs between $0.0^{\circ} \mathrm{C}$ and $-0.2^{\circ} \mathrm{C}$, depending on the soil type (Horiguchi and Miller 1983). The remaining unfrozen water content exists in thin films adsorbed on the soil grains. The presence of solutes lowers the freezing point and can cause pockets of unfrozen moisture as the solute becomes concentrated ahead of the freezing front (Kay and Perfect 1988). 
The purpose of this model is to capture the main effects of freezing on the heat transfer. The most important effects are the latent heat of fusion, the change in thermal conductivity, and the loss of mobility of the moisture. This can all be accomplished with an isothermal freezing model, shown in Figure 4.2. The effects of solutes and the expansion and contraction of the soil matrix (frost heaving) are neglected. The equations used in the model are included in Appendix A.

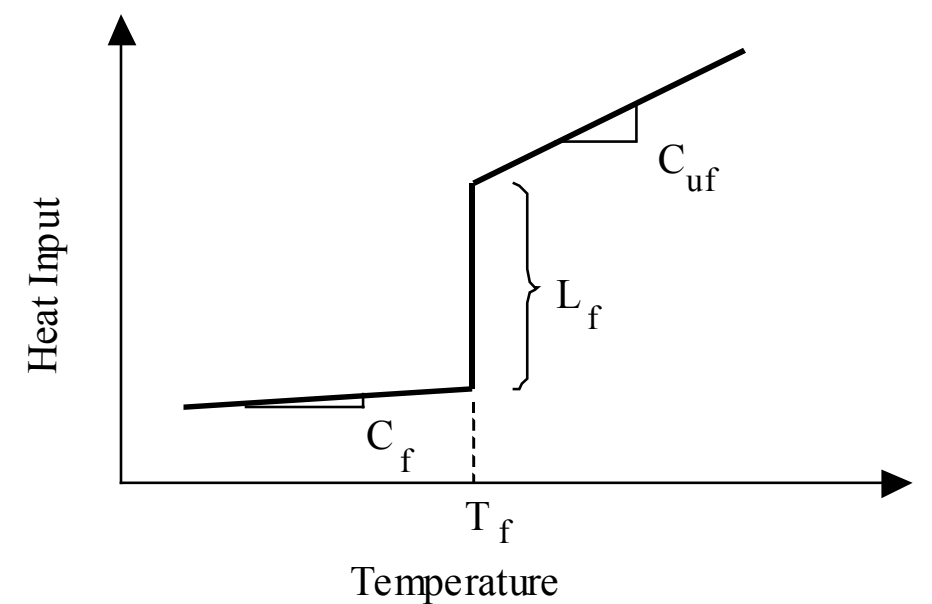

Figure 4.2. Isothermal soil freezing model with the unfrozen and frozen soil thermal capacitances, $C_{u f}$ and $C_{f}$, and the latent heat of fusion, $L_{f}$.

\subsection{Boundary Conditions}

The most relevant and interesting boundary is that exposed to the ambient conditions; all other boundaries are a subset of this. Shipp (1979) showed that the treatment of the ground surface has the largest impact on the local values of the underground-wall heat fluxes. The energy and moisture balances at the ground surface are examined in this section.

\subsubsection{Energy Balance}

A thermal energy balance at the surface can be viewed as that shown in Figure 4.3. The constant temperature condition is defined in Eq. (4.44), and the flux boundary condition is defined by Eq. (4.45); all heat flows are taken positive into the control surface. Because of this definition, the evaporation term is positive for moisture addition.

$$
\begin{aligned}
& \mathrm{T}=\mathrm{T}_{\mathrm{s}} \quad[\mathrm{K}] \\
& \mathrm{q}_{\mathrm{g}}+\mathrm{q}_{\text {sens }}+\mathrm{q}_{\text {rad }}+\mathrm{q}_{\text {conv }}+\mathrm{q}_{\mathrm{v}}=0 \quad\left[\mathrm{~W} / \mathrm{m}^{2}\right]
\end{aligned}
$$

The first term in Eq. (4.45) represents heat conduction in the ground caused by gradients normal to the surface of temperature and matric potential.

$$
\mathrm{q}_{\mathrm{g}}=-\mathrm{D}_{\mathrm{TT}} \frac{\partial \mathrm{T}}{\partial \mathrm{n}}-\mathrm{D}_{\psi \mathrm{T}} \frac{\partial \psi}{\partial \mathrm{n}}
$$




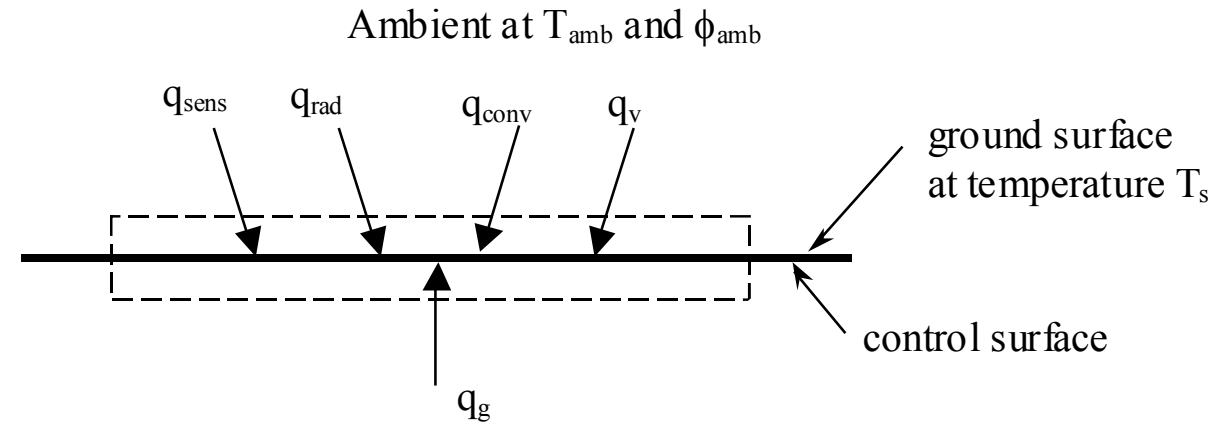

Figure 4.3. Thermal energy balance at the ground surface.

The sensible heat, $\mathrm{q}_{\mathrm{sens}}$, is divided into two sources: that caused by bulk liquid transfer across the boundary $\mathrm{q}_{\ell}$ and another term $\mathrm{q}_{\mathrm{h}}$ to account for all other miscellaneous heat transfer sources. Only the liquid transfer at the surface caused by precipitation or irrigation is considered in this paper; other sources can be treated in a similar manner. The details of this liquid transfer are presented in Section 4.3.2. The heat transfer caused by the bulk liquid flow across a boundary is calculated relative to a reference temperature $\mathrm{T}_{\mathrm{o}}$, as shown in Eq. (4.48). The temperature of liquid $\mathrm{T}_{\ell}$ at the atmospheric boundary is assumed equal to the ambient dry-bulb temperature. The reference temperature is taken to be $0.0^{\circ} \mathrm{C}$, because this is the reference temperature used for the enthalpy of vaporization (see Eq. (4.39).

$$
\begin{aligned}
& \mathrm{q}_{\text {sens }}=\mathrm{q}_{\ell}+\mathrm{q}_{\mathrm{h}} \\
& \mathrm{q}_{\ell}=\mathrm{U}_{\ell} \rho_{\ell} \mathrm{C}_{\mathrm{p}}\left(\mathrm{T}_{\ell}-\mathrm{T}_{\mathrm{o}}\right)
\end{aligned}
$$

The radiation term $\mathrm{q}_{\mathrm{rad}}$ can be divided into absorbed shortwave radiation from the sun $\mathrm{q}_{\mathrm{sw}}$ and the long-wave radiation exchange between the ground and the atmosphere $\mathrm{q}_{\mathrm{lw}}$. The shortwave radiation, shown in Eq. (4.50), consists of the direct normal and diffuse components. The amount of the shortwave radiation that is absorbed depends on the ground albedo or reflectivity, which ranges from 0.05 for blacktop to 0.98 for fresh snow (Geiger et al. 1995).

$$
\begin{aligned}
& \mathrm{q}_{\mathrm{rad}}=\mathrm{q}_{\mathrm{sw}}+\mathrm{q}_{\mathrm{lw}} \\
& \mathrm{q}_{\mathrm{sw}}=\left(1-\rho_{\mathrm{g}}\right)\left(\mathrm{I}_{\mathrm{dn}}+\mathrm{I}_{\mathrm{df}}\right)
\end{aligned}
$$

The long-wave radiation exchange between the ground and the sky is modeled by Eq. (4.51), which assumes that the ground behaves as a gray body and that the infrared emissivity, $\varepsilon_{\mathrm{s}}$, and absorptivity are equal (Martin 1989).

$$
\mathrm{q}_{\mathrm{lw}}=\varepsilon_{\mathrm{s}} \sigma\left(\mathrm{T}_{\mathrm{s}}^{4}-\mathrm{T}_{\text {sky }}^{4}\right)
$$

The Stefan-Boltzmann constant is $\sigma\left(=5.6686 \times 10^{-8} \mathrm{~W} / \mathrm{m}^{2} \mathrm{~K}\right)$, the ground surface temperature is $\mathrm{T}_{\mathrm{s}}(\mathrm{K})$, and $\mathrm{T}_{\text {sky }}$ is the temperature of a blackbody emitting the same amount of radiation as the 
sky. Martin and Berdahl (1984) linearized Eq. (4.51) by introducing a sky-temperature depression, $\Delta \mathrm{T}_{\mathrm{sky}}=\mathrm{T}_{\mathrm{amb}}-\mathrm{T}_{\mathrm{sky}}$, and a surface-temperature depression, $\Delta \mathrm{T}_{\mathrm{s}}=\mathrm{T}_{\mathrm{amb}}-\mathrm{T}_{\mathrm{s}}$.

$$
\begin{aligned}
\mathrm{q}_{\mathrm{lw}} & =4 \varepsilon_{\mathrm{s}} \sigma \mathrm{T}_{\mathrm{amb}}^{3}\left(\Delta \mathrm{T}_{\text {sky }}-\Delta \mathrm{T}_{\mathrm{s}}\right) \\
& =4 \varepsilon_{\mathrm{s}} \sigma \mathrm{T}_{\mathrm{amb}}^{3}\left(\mathrm{~T}_{\mathrm{s}}-\mathrm{T}_{\mathrm{sky}}\right) \\
& =\mathrm{h}_{\mathrm{r}}\left(\mathrm{T}_{\mathrm{s}}-\mathrm{T}_{\text {sky }}\right)
\end{aligned}
$$

The sky temperature is calculated by

$$
\mathrm{T}_{\mathrm{sky}}=\varepsilon_{\mathrm{sky}}^{1 / 4} \mathrm{~T}_{\mathrm{amb}}
$$

Martin and Berdahl calculated the clear-sky emissivity as a function of the dew point temperature $\mathrm{T}_{\mathrm{dp}}\left({ }^{\circ} \mathrm{C}\right)$ and made adjustments for the time of day $\mathrm{t}(\mathrm{hr})$ and the elevation by the location pressure $\mathrm{P}(\mathrm{Pa})$.

$$
\begin{aligned}
\varepsilon_{\mathrm{o}} & =0.711+0.0056 \mathrm{~T}_{\mathrm{dp}}+7.3 \times 10^{-5} \mathrm{~T}_{\mathrm{dp}}^{2} \\
& +0.013 \cos \left(\frac{2 \pi \mathrm{t}}{24}\right)+1.2 \times 10^{-6}(\mathrm{P}-101325)
\end{aligned}
$$

The correction for several cloud layers $\mathrm{i}$ is

$$
\varepsilon_{\text {sky }}=\varepsilon_{\mathrm{o}}+\left(1-\varepsilon_{\mathrm{o}}\right) \sum_{\mathrm{i}} \mathrm{n}_{\mathrm{i}} \varepsilon_{\mathrm{c}, \mathrm{i}} \Gamma_{\mathrm{i}}
$$

The fractional area of the sky covered by each cloud layer as seen by an observer on the ground is $n_{i}$, which must equal one. The hemispherical cloud emissivity is $\varepsilon_{\mathrm{c}, \mathrm{I}}$, and $\Gamma_{\mathrm{i}}$ is a factor that accounts for the cloud-base temperature. Low- and mid-level clouds tend to be opaque and are assumed to emit as a blackbody $\left(\varepsilon_{\mathrm{c}} \cong 1.0\right)$, while the emissivity of high-level clouds varies. Martin and Berdahl assume an emissivity of 0.4 for high-level cirrus clouds. The cloud temperature factor, $\Gamma$, is small for high cold clouds and approaches unity for low opaque clouds. Because cloud base temperatures are usually not available, Martin and Berdahl approximated $\Gamma$ as a function of the cloud base height, $\mathrm{h}(\mathrm{m})$, and $\mathrm{h}_{\mathrm{o}}=8200 \mathrm{~m}$.

$$
\Gamma=\exp \left(\frac{-\mathrm{h}}{\mathrm{h}_{\mathrm{o}}}\right)
$$

Information on the cloud cover and the cloud base height is available in the Typical Meteorological Year 2 (TMY2) data files as total sky cover, opaque sky cover, and ceiling height (NREL 2003). TMY2 files contain weather information for 248 locations throughout the United States. For this model, the cloud cover is divided into low-level opaque clouds and high-level cirrus clouds. The high-level cloud cover is the total sky cover-opaque sky cover. If there is lowlevel cloud cover, the height is read from the file as the ceiling height and is assumed to be 2,000 $\mathrm{m}$ if no information is available. The height of the high-level clouds is assumed to be $8,000 \mathrm{~m}$ or the ceiling height if the opaque sky cover is zero. 
The governing equations for $\mathrm{q}_{\mathrm{conv}}$ and $\mathrm{q}_{\mathrm{v}}$ have a similar form because the heat and mass transfer processes from the ground to the air behave similarly. Convection and evaporation depend on the wind speed, the surface conditions, and the gradients of temperature and vapor density. The basic equations for convective heat and vapor transfer are

$$
\begin{aligned}
\mathrm{q}_{\text {conv }} & =\mathrm{h}\left(\mathrm{T}_{\mathrm{amb}}-\mathrm{T}_{\mathrm{s}}\right) \\
& =\rho_{\mathrm{a}} \mathrm{C}_{\mathrm{P}, \mathrm{a}} \mathrm{D}_{\mathrm{h}}\left(\mathrm{T}_{\mathrm{amb}}-\mathrm{T}_{\mathrm{s}}\right) \\
\mathrm{q}_{\mathrm{v}}= & \mathrm{h}_{\mathrm{fg}} \mathrm{D}_{\mathrm{v}}\left(\rho_{\mathrm{v}, \mathrm{amb}}-\rho_{\mathrm{v}, \mathrm{s}}\right)
\end{aligned}
$$

The convection heat transfer coefficient is $\mathrm{h}\left(\mathrm{W} / \mathrm{m}^{2} \mathrm{~K}\right)$, the heat and mass diffusivities in air are $D_{h}(m / s)$ and $D_{v}(m / s)$, and the vapor densities at the ambient and surface conditions are $\rho_{v \text {,amb }}$ and $\rho_{\mathrm{v}, \mathrm{s}}$.

The wind speed and air temperatures have been verified by experiments to be approximately linear with the log of height above the ground. The non-dimensional velocity profile can be approximated by (Plate 1971)

$$
\frac{\mathrm{u}}{\mathrm{u}_{*}}=\frac{1}{\kappa} \ln \left(\frac{\mathrm{z}}{\mathrm{z}_{\mathrm{o}}}\right)
$$

The frictional velocity $\mathrm{u}_{*}$ is defined as $(\tau / \rho)^{1 / 2}, \kappa$ is von Karman's constant (usually taken as $0.4), \mathrm{z}$ is the height above the ground, and $\mathrm{z}_{\mathrm{o}}$ is the roughness height. The roughness height is a characteristic of the surface and may be interpreted as the size of the smallest turbulent eddy (Businger 1975). An approximate value as a function of the vegetation height, $\mathrm{z}_{\mathrm{veg}}$, averaged for different vegetation types is (Plate 1971)

$$
\mathrm{z}_{\mathrm{o}}=0.15 \mathrm{z}_{\mathrm{veg}}
$$

The stability of the air mass above the ground can be estimated by the Richardson number, which relates the buoyancy and frictional forces. The air mass tends to be stable for positive values of the Richardson number and unstable for negative values (Sellers 1965). The

Richardson number is shown in Eq. (4.61), where $\theta\left(=\mathrm{T}+\mathrm{gz} / \mathrm{C}_{\mathrm{p}}\right)$ is the potential temperature (Businger 1975).

$$
\mathrm{Ri}=\frac{\mathrm{g}}{\theta} \frac{\partial \theta / \partial \mathrm{z}}{(\partial \mathrm{u} / \partial \mathrm{z})^{2}}
$$

The derivatives in this equation can be approximated by (Paulson 1970)

$$
\begin{aligned}
& \frac{\partial \mathrm{T}}{\partial \mathrm{z}} \approx \frac{\mathrm{T}_{\mathrm{amb}}-\mathrm{T}_{\mathrm{s}}}{\left(\mathrm{z}_{\mathrm{o}} \mathrm{z}\right)^{1 / 2}} \ln \left(\mathrm{z} / \mathrm{z}_{\mathrm{o}}\right) \\
& \frac{\partial \mathrm{u}}{\partial \mathrm{z}} \approx \frac{\mathrm{u}_{\mathrm{w}}}{\left(\mathrm{z}_{\mathrm{o}} \mathrm{z}\right)^{1 / 2}} \ln \left(\mathrm{z} / \mathrm{z}_{\mathrm{o}}\right)
\end{aligned}
$$


Therefore, an approximation to the Richardson number, replacing the potential temperature with the absolute temperature is

$$
\mathrm{Ri} \approx \frac{\mathrm{g}\left(\mathrm{T}_{\mathrm{amb}}-\mathrm{T}_{\mathrm{s}}\right)}{\mathrm{u}_{\mathrm{w}}^{2}} \frac{\left(\mathrm{z}_{\mathrm{o}} \mathrm{z}\right)^{1 / 2}}{\ln \left(\mathrm{z} / \mathrm{z}_{\mathrm{o}}\right)}
$$

Notice that this definition of the Richardson number goes to infinity as the wind speed goes to zero; therefore, this relationship is not valid for small wind-speed values.

The complex interactions of the plant cover, such as the canopy density, root distribution, and physiological responses to water stress, also play an important role in the heat-and-mass-transfer process (Hillel 1998), but are beyond the scope of this work. Plant cover effects are assumed to be approximated by averages over a large area and over long periods.

There are numerous eddy-diffusivity models to approximate the heat-transfer coefficients (Jensen 1973, van Bavel and Hillel 1976, Sellers 1965, and Camillo and Gurney 1986). These models are compared in Appendix D, and the Jensen model was chosen as the best fit for this research.

For neutrally stable conditions, the momentum-transfer coefficient can be calculated as

$$
\mathrm{D}_{\mathrm{m}}=\frac{\kappa^{2} \mathrm{u}_{\mathrm{w}}}{\left[\ln \left(\mathrm{z}_{\mathrm{w}} / \mathrm{z}_{\mathrm{o}}\right)\right]^{2}}[\mathrm{~m} / \mathrm{s}]
$$

Here, $\kappa$ is the von Karman constant, $u_{w}(\mathrm{~m} / \mathrm{s})$ is the local wind speed, $z_{w}(m)$ is the height of the wind speed measurement, and $z_{o}(m)$ is the roughness height of the ground surface. The heatdiffusivity coefficient is determined by using the following stability-correction relationships:

$$
\begin{array}{ll}
D_{h}=D_{m}(1-16 R i)^{0.75} & , \text { for Ri } \leq 0 \\
D_{h}=D_{m}(1+10 R i)^{-1} & , \text { for Ri }>0
\end{array}
$$

The wind speed, as taken from weather data files, is usually measured in an open area at a height of $10 \mathrm{~m}$ and must be adjusted to the local conditions. This adjustment accounts for terrain and height differences between the measurement location and location of interest. One method of adjusting this is (Sherman and Grimsrud 1980)

$$
\mathrm{u}_{\mathrm{w}}=\mathrm{u}_{\mathrm{w}, \mathrm{met}} \alpha\left(\frac{\mathrm{H}}{\mathrm{H}_{\mathrm{met}}}\right)^{\gamma}
$$

The subscript met refers to the meteorological conditions, and $\alpha$ and $\gamma$ are terrain-dependent parameters given in Table 4.1 . 
Table 4.1.Terrain Parameters for Wind (Sherman and Grimsrud 1980)

\begin{tabular}{|l|l|l|l|}
\hline \multicolumn{1}{|c|}{ Class } & $\gamma$ & $\alpha$ & \multicolumn{1}{c|}{ Description } \\
\hline \hline I & 0.10 & 1.30 & $\begin{array}{l}\text { Ocean or other open body of water with at least 5 km of } \\
\text { unrestricted expanse }\end{array}$ \\
\hline II & 0.15 & 1.00 & $\begin{array}{l}\text { Flat terrain with some isolated obstacles } \\
\text { (buildings or trees are separated) }\end{array}$ \\
\hline III & 0.20 & 0.85 & Rural areas with low buildings, trees, etc. \\
\hline IV & 0.25 & 0.67 & Urban, industrial, or forest areas \\
\hline V & 0.35 & 0.47 & Center of large city \\
\hline
\end{tabular}

Air stability is difficult to model when there is a very low wind speed. In this region, natural convection takes over and the forced convection models fail. The transition between forced and natural convection is modeled by blending the two coefficients. For transverse flows over a horizontal plate, the forced and natural convection terms can be combined by Eq. (4.68) (Incropera and DeWitt 1985). Note that the length scales are slightly different in the forced and natural convection values of $\mathrm{Nu}_{\mathrm{L}}$; therefore Eq. (4.69) does not derive exactly from the $\mathrm{Nu}$ correlation. The characteristic length for the forced convection from a horizontal surface is the length of the surface, and for natural convection, it is the area/perimeter ratio, which is L/4 for a square surface.

$$
\begin{aligned}
& \mathrm{Nu}^{4}=\mathrm{Nu}_{\mathrm{f}}^{4}+\mathrm{Nu}_{\mathrm{n}}^{4} \\
& \mathrm{~h}^{4}=\mathrm{h}_{\mathrm{f}}^{4}+\mathrm{h}_{\mathrm{n}}^{4}
\end{aligned}
$$

Natural convection from a horizontal flat plate can be estimated by (Incropera and DeWitt 1985)

$$
\begin{array}{ll}
\bar{N} u_{L}=0.54 \mathrm{Ra}_{\mathrm{L}}^{1 / 4}, & \text { for } 10^{4} \leq \mathrm{Ra}_{\mathrm{L}} \leq 10^{7} \\
\overline{\mathrm{N}} \mathrm{u}_{\mathrm{L}}=0.15 \mathrm{Ra}_{\mathrm{L}}^{1 / 3}, & \text { for } 10^{7} \leq \mathrm{Ra}_{\mathrm{L}} \leq 10^{11}
\end{array}
$$

The Rayleigh number is defined as

$$
\mathrm{Ra}_{\mathrm{L}}=\frac{\mathrm{g} \beta\left(\mathrm{T}_{\mathrm{s}}-\mathrm{T}_{\mathrm{amb}}\right) \mathrm{L}^{3}}{v \alpha}
$$

For the conditions encountered for natural convection from the ground surface, it can easily be shown that $\mathrm{Ra}_{\mathrm{L}}>10^{7}$; therefore the second relation in Eq. (4.70) is used and the natural convection heat transfer coefficient can be approximated by

$$
\overline{\mathrm{h}}_{\mathrm{n}}=0.15 \mathrm{k}\left(\frac{\mathrm{g}\left(\mathrm{T}_{\mathrm{s}}-\mathrm{T}_{\mathrm{amb})}\right.}{\mathrm{T}_{\mathrm{f}} v \alpha}\right)^{1 / 3}
$$

The film temperature, $\mathrm{T}_{\mathrm{f}}$, is the average of the ambient and surface temperatures. 


\subsubsection{Moisture Balance}

The moisture balance at the ground surface is shown in Figure 4.4, and the constant moisture and flux boundary conditions are defined in Eqs. (4.73) and (4.74). Moisture transfers into the control surface are taken as positive.

$$
\begin{aligned}
& \psi_{\mathrm{s}}=\psi[\mathrm{m}] \\
& \dot{\mathbf{m}}_{\mathrm{m}, \mathrm{g}}+\dot{\mathbf{m}}_{\ell}+\dot{\mathbf{m}}_{\mathrm{v}}=0 \quad\left[\mathrm{~kg} / \mathrm{m}^{2} \mathrm{~S}\right]
\end{aligned}
$$

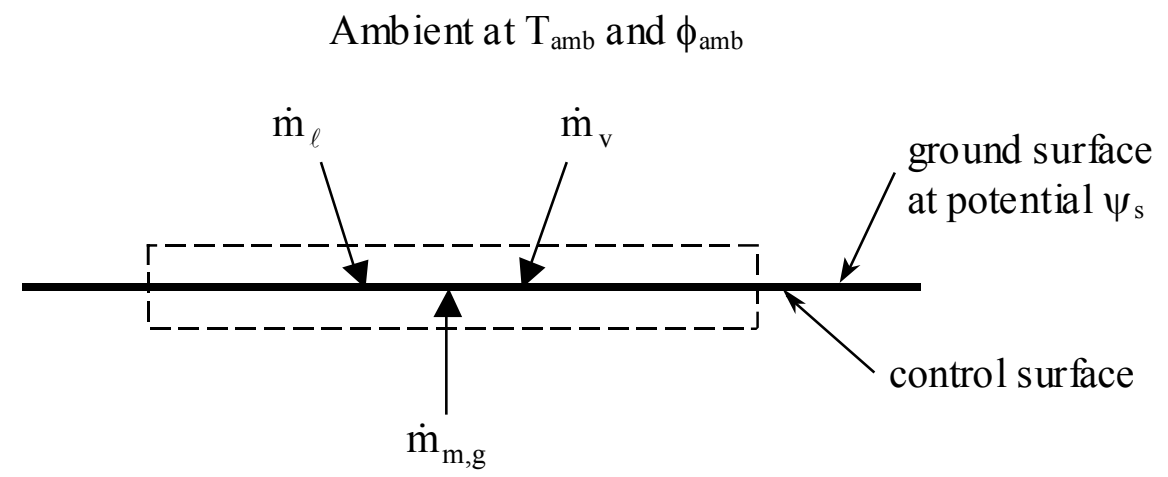

Figure 4.4. Moisture balance at the ground surface.

The moisture transfer in the ground is represented by Eq. (4.75). This term includes the liquid transfer caused by the gradient of the total potential, $\Phi$, and vapor transfer caused by gradients of the matric potential and temperature. This equation is used to include the natural boundary conditions in the finite-element analysis equations (Appendix D).

$$
\frac{\dot{\mathrm{m}}_{\mathrm{m}, \mathrm{g}}}{\rho_{\ell}}=-\mathrm{K} \frac{\partial \Phi}{\partial \mathrm{n}}-\mathrm{D}_{\psi \mathrm{v}} \frac{\partial \psi}{\partial \mathrm{n}}-\mathrm{D}_{\mathrm{Tm}} \frac{\partial \mathrm{T}}{\partial \mathrm{n}}
$$

The liquid transfer at the surface is assumed to be in the form of precipitation or irrigation measured in $(\mathrm{mm} / \mathrm{hr})$. The amount of moisture absorbed by the soil depends not only on how dry the soil is but also on the surface texture. A rougher surface has more surface area and may have cracks that allow the moisture to penetrate quickly into the soil. Modeling these surface effects can become very complicated and is not considered in this model. The moisture is added to the surface node up to the point of saturation, and any additional moisture during the time step is assumed to run off. The volume available to absorb the moisture is the node volume, $\mathrm{V}_{\mathrm{n}}$, times the difference between the porosity, $\eta$, and the volumetric moisture content, $\theta_{\ell}$. The volume of moisture available is the amount of precipitation, $d_{p}(m / s)$ times the node surface area, $A_{s}$. The amount of liquid crossing the boundary in $\left(\mathrm{kg} / \mathrm{m}^{2} \mathrm{~s}\right)$ is then:

$$
\dot{\mathrm{m}}_{\ell}=\rho_{\ell} \operatorname{MIN}\left[\left(\left(\eta-\theta_{\ell}\right) * \mathrm{~V}_{\mathrm{n}}\right),\left(\mathrm{d}_{\mathrm{p}} * \mathrm{~A}_{\mathrm{s}}\right)\right] /\left(\mathrm{A}_{\mathrm{s}} \Delta \mathrm{t}\right)
$$

This simple model will not work well for soils that are compacted, where most of the water runs off or for soils with large cracks. Also, it will not work well for terrain that pools the water, 
allowing it to be absorbed at a later time, or a terrain that is sloped so that very little of the water is absorbed.

The vapor transfer, $\dot{\mathrm{m}}_{\mathrm{v}}\left(\mathrm{kg} / \mathrm{m}^{2} \mathrm{~s}\right)$, is defined as an equivalent liquid transfer rate by multiplying the actual vapor transfer rate by the density ratio $\left(\rho_{\mathrm{v}} / \rho_{\ell}\right)$. Vapor is transferred mainly by evaporation from the surface.

$$
\dot{\mathrm{m}}_{\mathrm{v}}=\mathrm{D}_{\mathrm{v}}\left(\rho_{\mathrm{v}, \mathrm{amb}}-\rho_{\mathrm{v}, \mathrm{s}}\right)
$$

Penman (1948) describes three approaches to calculating the evaporation: sink strength, or aerodynamic energy, and a combination of the first two, which eliminates the need to know the surface temperature. The aerodynamic approach, as shown in Eq. (4.76), is the most common. The vapor diffusion coefficient, $\mathrm{D}_{\mathrm{v}}$, is often approximated as being equal to the thermal diffusion coefficient, $\mathrm{D}_{\mathrm{h}}$. A more rigorous approach is obtained by noting the similarity between the heatand-mass transfer phenomena. Because the equations governing heat-and-mass transfer are analogous, the dimensionless parameters from these equations can be related. The transfer coefficients can be related as shown in Eq. (4.78) (Incropera and De Witt 1985).

$$
\frac{\mathrm{Nu}}{\operatorname{Pr}^{\mathrm{n}}}=\frac{\mathrm{Sh}}{\mathrm{Sc}^{\mathrm{n}}}
$$

Substituting the definitions of $\mathrm{Nu}$ and $\mathrm{Sh}$ :

$$
\frac{\mathrm{hL} / \mathrm{k}}{\operatorname{Pr}^{\mathrm{n}}}=\frac{\mathrm{D}_{\mathrm{v}} \mathrm{L} / \mathrm{D}_{\mathrm{a}}}{\mathrm{Sc}^{\mathrm{n}}}
$$

which can be rearranged to give

$$
\mathrm{D}_{\mathrm{v}}=\frac{\mathrm{h}}{\rho_{\mathrm{a}} \mathrm{C}_{\mathrm{P}, \mathrm{a}}}\left(\frac{\mathrm{D}_{\mathrm{a}}}{\alpha}\right)^{1-\mathrm{n}}=\mathrm{D}_{\mathrm{h}}\left(\frac{\mathrm{D}_{\mathrm{a}}}{\alpha_{\mathrm{a}}}\right)^{1-\mathrm{n}}
$$

According to Incropera and De Witt, $n=1 / 3$ works well for most cases.

Using aerodynamic resistance alone has been shown to over-predict the evaporation from bare soil (Camillo and Gurney 1986) and from plant canopies (Shuttleworth 1993); therefore, a surface resistance is added in series. This term accounts for the resistance of the path from the vapor source to just outside the surface. Camillo and Gurney found from their experiments in Phoenix that this surface resistance behaves as a linear function of the moisture content at the surface. Their correlation, shown in Eq. (4.81), increases as the soil surface dries out and approaches zero as the volumetric moisture content approaches 0.2 . This correlation was empirically derived from their experiments, and extending it to other situations without testing is questionable; however, it is used, with caution, in this paper for lack of a better alternative.

$$
\mathrm{r}_{\mathrm{s}}=\operatorname{MAX}\left(810-4140 \theta_{\mathrm{s}}, 0\right)
$$

Now the evaporation equation, with $r_{a}=1 / D_{v}$, becomes 


$$
\dot{\mathrm{m}}_{\mathrm{v}}=\frac{\left(\rho_{\mathrm{v}, \mathrm{s}}-\rho_{\mathrm{v}, \mathrm{amb}}\right)}{\left(\mathrm{r}_{\mathrm{a}}+\mathrm{r}_{\mathrm{s}}\right)}
$$

\subsection{Heat Transfer Model}

A heat transfer only model was also developed in order to compare with the heat-and-moisture transfer model. This model is much simpler and is based on the standard transient heat conduction equation shown in Eq. (4.83).

$$
\rho \mathrm{C}_{\mathrm{P}} \frac{\partial \mathrm{T}}{\partial \mathrm{t}}=\nabla \cdot(\mathrm{k} \nabla \mathrm{T})+\mathrm{q}^{\prime \prime \prime}
$$

The boundary conditions are the same as the energy balance used in the heat-and-moisture transfer model as described in Section 4.3.1, except for the heat transfer associated with evapotranspiration. Because the moisture at the surface is not modeled, a different approach to this heat flow must be taken. Jensen (1973) presents a detailed derivation of an evapotranspiration model with three components, shown in Eqs. (4.84) to (4.86). The first component in Eq. (4.84) is the portion of the incoming heat energy from solar radiation and conduction from the ground that is converted directly to latent heat. The ratio $\Delta /(\Delta+\gamma)$ is the fraction of the energy added to the surface used for evaporation. The term, $\Delta$, is the derivative of the saturated water vapor pressure with temperature and $\gamma$ is sometimes called the psychrometric constant and defined in Eq. (4.87). A constant value of $66 \mathrm{~Pa} / \mathrm{K}$ is often used for this constant. The second evapotranspiration component in Eq. (4.85) represents the energy removed from the air and supplied for evaporation at the surface. The difference between the ambient temperature and the wet-bulb temperature at height $\mathrm{z},\left(\mathrm{T}_{\mathrm{amb}}-\mathrm{T}_{\mathrm{wb}}\right)$, is called the wet-bulb depression $\mathrm{D}$. The final term in Eq. (4.86) is the latent energy released by condensation at the surface when the vapor pressure is less than the saturation vapor pressure. Combining all three terms results in Eq. (4.88), where the surface wet-bulb depression $\left(T_{s}-T_{w b, s}\right)$ is denoted by $D_{s}$ and the negative sign in front of the equation is a result of the direction of positive heat flux defined in Figure 4.3.

$$
\begin{aligned}
& \mathrm{h}_{\mathrm{fg}} \mathrm{E}_{1}=\frac{\Delta}{\Delta+\gamma}\left(\mathrm{q}_{\mathrm{rad}}+\mathrm{q}_{\mathrm{g}}\right) \\
& \mathrm{h}_{\mathrm{fg}} \mathrm{E}_{2}=\rho_{\mathrm{a}} \mathrm{C}_{\mathrm{Pa}} \mathrm{D}_{\mathrm{v}}\left(\mathrm{T}_{\mathrm{amb}}-\mathrm{T}_{\mathrm{wb}}\right) \\
& -\mathrm{h}_{\mathrm{fg}} \mathrm{E}_{3}=\rho_{\mathrm{a}} \mathrm{C}_{\mathrm{Pa}} \mathrm{D}_{\mathrm{v}}\left(\mathrm{T}_{\mathrm{s}}-\mathrm{T}_{\mathrm{wb}, \mathrm{s}}\right) \\
& \gamma=\frac{\rho_{\mathrm{a}} \mathrm{C}_{\mathrm{Pa}} \mathrm{R}_{\mathrm{w}} \mathrm{T}}{\mathrm{h}_{\mathrm{fg}}} \\
& \mathrm{q}_{\mathrm{v}}=-\left[\frac{\Delta}{\Delta+\gamma}\left(\mathrm{q}_{\mathrm{rad}}+\mathrm{q}_{\mathrm{g}}\right)+\rho_{\mathrm{a}} \mathrm{C}_{\mathrm{Pa}} \mathrm{D}_{\mathrm{v}}\left(\mathrm{D}-\mathrm{D}_{\mathrm{s}}\right)\right]
\end{aligned}
$$

A more useful form of Eq. (4.88) can be derived by rearranging Eq. (4.45) and substituting into the first term of Eq. (4.88) as shown in Eq. (4.89). 


$$
\mathrm{q}_{\mathrm{v}}=\frac{\Delta}{\gamma}\left(\mathrm{q}_{\mathrm{g}}+\mathrm{q}_{\text {sens }}\right)-\frac{\Delta+\gamma}{\gamma} \rho_{\mathrm{a}} \mathrm{C}_{\mathrm{Pa}} \mathrm{D}_{\mathrm{v}}\left(\mathrm{D}-\mathrm{D}_{\mathrm{s}}\right)
$$

One difficulty with using Eq. (4.89) in the heat conduction model, is that the wet-bulb temperature at the surface, $T_{w b, s}$, is not known. If the vapor pressure at the surface is equal to the saturated value, then the wet-bulb depression at the surface $\mathrm{D}_{\mathrm{s}}$ is zero. When this is true, and when water is not the limiting factor, evapotranspiration occurs at the maximum rate, which is called potential evapotranspiration. Evapotranspiration rarely occurs at the potential value or at zero; therefore, it is up to the researcher to make educated assumptions about the appropriate level to use. A useful method is to bracket the results with an evapotranspiration ratio, $\mathrm{K}_{\text {evap}}$, which is defined as the ratio of the actual evapotranspiration and the potential evapotranspiration. With this ratio, the evapotranspiration for the heat transfer model can be expressed as Eq. (4.90), where $h_{v}$ represents an evapotranspiration heat transfer coefficient.

$$
\mathrm{q}_{\mathrm{v}}=\mathrm{K}_{\text {evap }} \frac{\Delta}{\gamma}\left(\mathrm{q}_{\mathrm{g}}+\mathrm{q}_{\text {sens }}\right)-\mathrm{K}_{\text {evap }} \frac{\Delta+\gamma}{\gamma} \mathrm{h}_{\mathrm{v}}\left(\mathrm{T}_{\text {amb }}-\mathrm{T}_{\mathrm{wb}}\right)
$$

By combining all of the equations in the energy balance at the surface, Eq.'s (4.50), (4.52), and (4.57), the energy balance can be written as Eq. (4.91). The surface temperatures, $\mathrm{T}_{\mathrm{s}}$, are unknown and are solved for as part of the system of equations.

$$
\begin{aligned}
-\mathrm{q}_{\mathrm{g}} & =\left(1-\rho_{\text {grd }}\right)\left(\mathrm{I}_{\mathrm{dn}}+\mathrm{I}_{\mathrm{df}}\right)+\mathrm{h}_{\mathrm{r}}\left(\mathrm{T}_{\text {sky }}-\mathrm{T}_{\mathrm{s}}\right)+\mathrm{h}\left(\mathrm{T}_{\mathrm{amb}}-\mathrm{T}_{\mathrm{s}}\right)+\mathrm{K}_{\text {evap }} \frac{\Delta}{\gamma} \mathrm{h}\left(\mathrm{T}_{\mathrm{amb}}-\mathrm{T}_{\mathrm{s}}\right) \\
& +\mathrm{K}_{\text {evap }} \frac{\Delta}{\gamma} \mathrm{q}_{\text {sens }}-\mathrm{K}_{\text {evap }} \frac{\Delta+\gamma}{\gamma} \mathrm{h}_{\mathrm{v}}\left(\mathrm{T}_{\mathrm{amb}}-\mathrm{T}_{\mathrm{wb}}\right)
\end{aligned}
$$

\subsection{Finite Element Formulation}

Because of the complexity and nonlinearity of the heat-and-moisture transfer equations, an analytic solution would be extremely difficult to obtain. Therefore, a numerical approach, such as the FDM or the FEM, is usually used to solve the problem. The main advantage of the FDM is that it easy to understand and code, and it is faster than the FEM for many applications. In addition, the FDM produces a better moisture balance with no oscillations for the problem of infiltration into an initially dry soil (Celia et al. 1990). The main disadvantage is that it is not as flexible as the FEM in accepting domain geometries.

The FEM is more complicated and harder to program than the FDM; however, once coded, it is much more flexible. The FEM easily models complex domain geometries, and accepts mesh refinement or expansion with little effort. The FEM is also flexible with boundary conditions and material properties. The problem of mass conservation and oscillations can be overcome by diagonalizing or lumping the mass matrix (Celia et al. 1990), which will be discussed later.

In the FEM, the problem domain is divided into elements with three or more nodes for two dimensions and four or more nodes for three dimensions. The dependent variables, in this case $\mathrm{T}$ 
and $\psi$, are approximated with piecewise continuous functions over the elements. These approximations over each element are of the form (Zienkiewicz and Taylor 1989)

$$
\begin{aligned}
& \mathrm{T}(\mathrm{x}, \mathrm{y}, \mathrm{z}) \approx \hat{\mathrm{T}}(\mathrm{x}, \mathrm{y}, \mathrm{z})=\sum_{\mathrm{i}=1}^{\mathrm{n}} \mathrm{N}_{\mathrm{i}}(\mathrm{x}, \mathrm{y}, \mathrm{z}) \mathrm{T}_{\mathrm{i}} \\
& \psi(\mathrm{x}, \mathrm{y}, \mathrm{z}) \approx \hat{\psi}(\mathrm{x}, \mathrm{y}, \mathrm{z})=\sum_{\mathrm{i}=1}^{\mathrm{n}} \mathrm{N}_{\mathrm{i}}(\mathrm{x}, \mathrm{y}, \mathrm{z}) \psi_{\mathrm{i}}
\end{aligned}
$$

where $T_{i}$ and $\psi_{i}$ are the element nodal point values of temperature and matric potential, $N_{i}$ are shape functions, and $\mathrm{n}$ is the number of nodes per element.

For three- or four-node, two-dimensional elements, the shape functions are linear. Higher order approximations can be used with elements having more nodes. A single FEM mesh may contain elements of different node numbers as long as they are compatible at the adjoining boundaries. However, this adds complexity to the program when forming the global matrices. The programs written for this research allow only three- or four-node elements, and only one type may be used for each mesh. The programs are based on the FEM program, TRANS, developed by Thompson (1999). It is a two-dimensional transient FEM program using isoperimetric elements and written in Fortran 90. The algorithm was developed using the Galerkin weighted-residual method.

The heat transfer equation, Eq. (4.40), and the moisture transfer equation, Eq. (4.28), are transformed into the following equations for the FEM. The details of the transformation are included in Appendix D.

$$
\begin{aligned}
& \mathbf{D}_{\mathrm{TT}} \mathbf{T}+\mathbf{D}_{\psi \mathrm{T}} \boldsymbol{\psi}+\mathbf{C}_{\mathrm{TT}} \dot{\mathbf{T}}+\mathbf{C}_{\psi \mathrm{T}} \dot{\boldsymbol{\psi}}+\mathbf{f}_{\mathrm{T}}=0 \\
& \mathbf{D}_{\mathrm{Tm}} \mathbf{T}+\mathbf{D}_{\psi \mathrm{m}} \boldsymbol{\psi}+\mathbf{C}_{\mathrm{Tm}} \dot{\mathbf{T}}+\mathbf{C}_{\psi \mathrm{m}} \dot{\boldsymbol{\psi}}+\mathbf{f}_{\psi}=0
\end{aligned}
$$

The conductance matrices are denoted by D's, and the capacitance matrices by C's. The two sets of Eqs. (4.93) and (4.94) can be combined into one system assembled by alternating equations for $\mathrm{T}$ and $\psi$ for each node as shown below.

$$
\mathbf{D U}+\mathbf{C} \dot{\mathbf{U}}+\mathbf{f}=0
$$

A single-step algorithm for the transient analysis is presented in Eq. (4.96), where k denotes the time step and $\beta$ is a time-weighting function, which determines whether the method is explicit or implicit (Zienkiewicz and Taylor 1989). All the analyses completed in this work applied a timeweighting function of 0.5 , which is analogous to the Crank-Nicolson implicit routine used in finite differences. Equation (4.97) represents Eq. (4.96) with [CPD] for C plus D and [CMD] for $\mathbf{C}$ minus $\mathbf{D}$. The forcing function is averaged assuming a linear variation in time as in Eq. (4.98).

$$
\begin{aligned}
& {[\mathbf{C}+\beta \Delta \mathrm{tD}] \mathbf{U}_{\mathrm{k}+1}=[\mathbf{C}-(1-\beta) \Delta \mathrm{t} \mathbf{D}] \mathbf{U}_{\mathrm{k}}-\Delta \mathrm{t} \overline{\mathbf{f}}} \\
& {[\mathbf{C P D}] \mathbf{U}_{\mathrm{k}+1}=[\mathbf{C M D}] \mathbf{U}_{\mathrm{k}}-\Delta \mathrm{t} \overline{\mathbf{f}}} \\
& \overline{\mathbf{f}}=\mathbf{f}_{\mathrm{k}}+\beta\left(\mathbf{f}_{\mathrm{k}+1}-\mathbf{f}_{\mathrm{k}}\right)
\end{aligned}
$$

Equation (4.96) is nonlinear because the coefficient matrices are functions of the dependent variables. The solution of the moisture-transfer equation is also subject to mass balance errors caused by the highly nonlinear relationship between the moisture content and the matric potential 
(Milly 1985 and Celia et al. 1990). This is especially a problem with the infiltration into an initially dry soil. According to Celia et al., diagonalizing or lumping the capacitance matrix is necessary to ensure a non-oscillatory and mass conservative solution. Diagonalization has also been shown to reduce the number of iterations to convergence. Diagonalization is accomplished by summing the total capacitance for the element and employing a scaled distribution of this capacitance to the diagonal nodes.

Solution methods of the nonlinear equations include the Picard iteration, the Newton-Raphson method, and the Predictor-Corrector methods (Istok 1989, Celia et al. 1990, and Hampton 1989). The Newton-Raphson method produces a non-symmetric tangent conductance matrix, which is computationally difficult and time consuming to deal with. The Predictor-Corrector method is used successfully by Hampton, but it was not selected for this work. The Picard iteration can introduce convergence problems for equations where the coefficients are sensitive to changes in the dependent variables; therefore, a modified Picard iteration is often used for soil-moisture transfer problems (Istok 1989). Both the Picard and the modified Picard iteration were tried in GHAMT and only the modified Picard iteration was successful. The Picard iteration is essentially a substitution method, using the values calculated from the previous iteration as an estimation in the present iteration until convergence is reached. In the modified Picard method, a residual vector is calculated as

$$
\mathbf{R}_{\mathrm{k}}^{\mathrm{i}-1}=[\mathbf{C M D}] \mathbf{U}_{\mathrm{k}}^{\mathrm{i}-1}-\Delta t \overline{\mathbf{f}}-[\mathbf{C P D}] \mathbf{U}_{\mathrm{k}}^{\mathrm{i}-1}
$$

Then the following system of equations is solved for $\Delta \mathbf{U}_{\mathrm{k}}^{\mathrm{i}}$.

$$
[\mathbf{C P D}] \Delta \mathbf{U}_{\mathrm{k}}^{\mathrm{i}}=\mathbf{R}_{\mathrm{k}}^{\mathrm{i}-1}
$$

The new values of $\mathrm{U}$ for time step $\mathrm{k}$ and iteration $\mathrm{i}$ are then calculated as

$$
\mathbf{U}_{\mathrm{k}}^{\mathrm{i}}=\mathbf{U}_{\mathrm{k}}^{\mathrm{i}-1}+\varpi \Delta \mathbf{U}_{\mathrm{k}}^{\mathrm{i}}
$$

The value of the relaxation factor $\varpi$ is determined by experience. For this work, a relaxation factor of $\varpi=1.0$ worked best. For the first iteration at time step k, the values for $\mathbf{U}_{\mathrm{k}}^{\mathrm{i}-1}$ are taken from the previous time step. Convergence is defined as

$$
\operatorname{MAX}\left|\frac{\Delta \mathbf{U}}{\mathbf{U}}\right|<\varepsilon
$$

The convergence criteria, $\varepsilon$, is typically set at 0.001 . If convergence is not reached, new coefficient matrices are assembled, a new residual is determined by Eq. (4.99), and the process is repeated. The maximum number of iterations must be set by the user; for most of the simulations in this work, only 20 iterations were allowed.

The conductance and capacitance matrices are sparse, but the exact form is dependent on the mesh and the numbering of the elemental nodes. A modified skyline storage technique is used to reduce the storage requirements. The solution of Eq. (4.101) is carried out using a Gaussian elimination routine written to take advantage of the matrix structures. The mesh may be generated by hand or by any of several mesh-generation packages available. For the work here, 
GEOMPACK90 (Joe 1999) and a program based on MESH.F from Thompson (1999) were used. To reduce the bandwidth, a program based on NEWNUM.F from Thompson (1999) was used.

\subsection{Spatial and Temporal Discretization}

The errors associated with the finite element and time approximations depend on the spatial and temporal discretizations used for the solutions. As the fineness of the mesh is improved and the time step is reduced, the errors diminish and the approximation approaches the true answer; however, as the discretizations are reduced, the computation time increases. The mathematical stability of the solution is also related to the time step. The implicit solution method is inherently numerically stable; however, the solution can become mathematically unstable by the propagation of errors brought about by an integration time step that is too large.

The required discretization depends on the problem being modeled and the type of boundary conditions. In regions with steady or slowly varying conditions, the mesh can be coarser than in regions with large gradients and rapidly changing conditions. For the ground-heat-transfer problems, the mesh must be finer near the ground surface and the building; away from these areas, it can be coarse. To the appropriate discretization, the program was run numerous times, refining the mesh until the solution was independent of the mesh size or until the desired accuracy was obtained.

Simulations were carried out with a $0.1-\mathrm{m}$-wide by $1.0-\mathrm{m}$-tall column of Bighorn sandy loam for 400 hours. The region was initialized with $\mathrm{T}=10^{\circ} \mathrm{C}$ and $\psi=-3.0 \mathrm{~m}$. The side boundary conditions were zero heat and moisture fluxes; the bottom boundary was $\mathrm{T}=10^{\circ} \mathrm{C}$ and $\psi=-3.0$ $\mathrm{m}$; the top boundary conditions were $\mathrm{T}_{\mathrm{db}}=25^{\circ} \mathrm{C}, \mathrm{T}_{\mathrm{dp}}=22^{\circ} \mathrm{C}, \mathrm{u}_{\text {wind }}=2.0 \mathrm{~m} / \mathrm{s}, \mathrm{G}=0.0 \mathrm{~W} / \mathrm{m}^{2 ;}$ and $25 \mathrm{~mm}$ of rain was added to the surface during hour 200. The solution is most sensitive to the addition of moisture; therefore, these results may be conservative for other cases. Meshes of quadrilateral and triangular elements were used with a fixed width of $5 \mathrm{~cm}$ and a height varying from $0.25 \mathrm{~cm}$ to $50 \mathrm{~cm}$. The triangular elements were formed by dividing the quadrilateral elements by a diagonal line. The maximum size of the time step that produces accurate and stable results depends on the mesh size; the finer the mesh, the smaller the time step must be. The time step used during the period when rain is added must be smaller than values used during steady-state or slowly varying conditions. The time steps used and the computer run times using a $600 \mathrm{Mhz}$ personal computer are listed in Table 4.2.

The steady-state errors for each case was extremely small: less than $1 \%$ for temperatures and only slightly exceeding $1 \%$ for the moisture with $\Delta \mathrm{z}=50 \mathrm{~cm}$. The discretization errors, when compared to the case with $\Delta \mathrm{z}=0.025 \mathrm{~cm}$ in the total heat transfer, temperature, and moisture at the surface as a function of the z-discretization are shown in Figures 4.5 and 4.6. The temperature error is small for all cases. The errors associated with the triangular elements are lower than the quadrilateral elements. From this, starting with a spatial discretization near the surface of less than $5 \mathrm{~cm}$ and less than or equal to $50 \mathrm{~cm}$ near the bottom boundary is recommended. The proper time step can be determined from Table 4.2. 
Table 4.2. Discretization and runtimes for accuracy tests

\begin{tabular}{|r|r|r|r|r|r|r|r|r|r|}
\hline \multirow{2}{*}{$\begin{array}{c}\Delta \mathbf{Z} \\
(\mathbf{c m})\end{array}$} & \multirow{2}{*}{ Nodes } & \multicolumn{5}{|c|}{ Quadrilaterals } & \multicolumn{4}{|c|}{ Triangles } \\
\cline { 3 - 10 } & & Elem's & $\begin{array}{c}\Delta \mathbf{t}_{\text {ss }} \\
(\mathbf{s e c})\end{array}$ & $\begin{array}{c}\Delta \mathbf{t}_{\text {rain }} \\
(\mathbf{s e c})\end{array}$ & $\begin{array}{c}\text { Runtime } \\
(\mathbf{s e c})\end{array}$ & Elem's & $\begin{array}{c}\Delta \mathbf{t}_{\text {ss }} \\
(\mathbf{s e c})\end{array}$ & $\begin{array}{c}\Delta \mathbf{t}_{\text {rain }} \\
(\mathbf{s e c})\end{array}$ & $\begin{array}{c}\text { Runtime } \\
(\mathbf{s e c})\end{array}$ \\
\hline 0.25 & 1,203 & 800 & 300 & 15 & 2,936 & 1,600 & 300 & 15 & 3,044 \\
\hline 0.5 & 603 & 400 & 300 & 30 & 870 & 800 & 600 & 30 & 534 \\
\hline 1.0 & 303 & 200 & 600 & 60 & 177 & 400 & 900 & 60 & 137 \\
\hline 2.0 & 153 & 100 & 600 & 60 & 65 & 200 & 900 & 60 & 55 \\
\hline 5.0 & 63 & 40 & 900 & 60 & 17 & 80 & 1,200 & 60 & 16 \\
\hline 10.0 & 33 & 20 & 1,800 & 60 & 5.4 & 40 & 1,800 & 60 & 6 \\
\hline 20.0 & 18 & 10 & 1,800 & 60 & 3.2 & 20 & 1,800 & 60 & 2.9 \\
\hline 50.0 & 9 & 4 & 1,800 & 120 & 1.1 & 8 & 3,600 & 120 & 0.9 \\
\hline
\end{tabular}

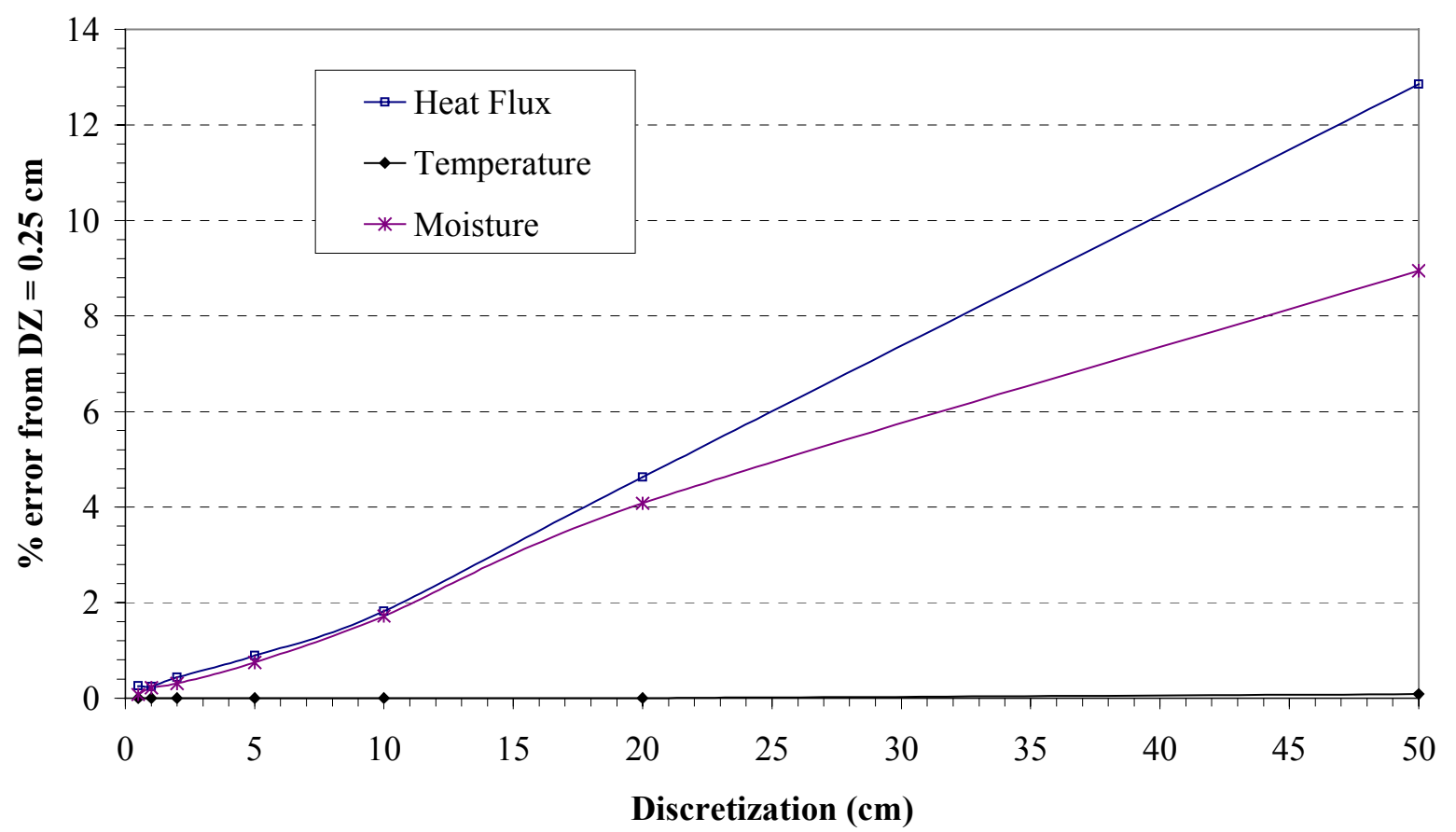

Figure 4.5. Errors in temperature, moisture, and total heat flux at the surface for quadrilateral elements 


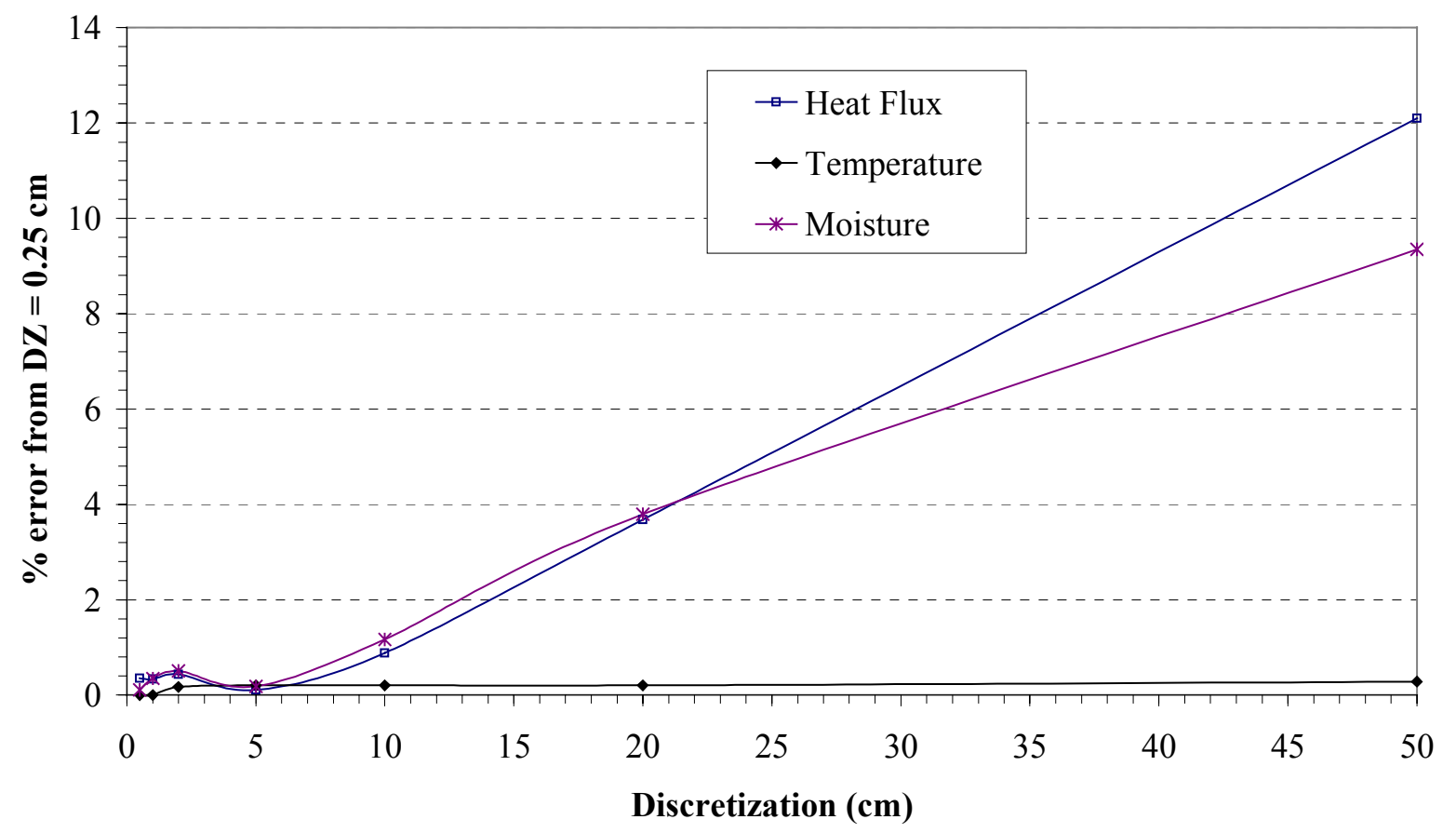

Figure 4.6. Errors in temperature, moisture, and total heat flux at the surface triangular elements 


\section{Chapter 5: Testing, Verification, and Validation}

\subsection{Introduction}

Ensuring that algorithms and computer programs produce the expected results is often quite difficult, especially for complicated programs. Programs are first tested for errors, ensuring that each procedure operates in the expected manner. This is usually accomplished by "unit testing" each procedure and module. Then, the program as a whole must be checked to ensure that it produces correct results under specific conditions - often called verification and validation (McConnell 1993).

In software development, verification is the process of checking that the program is built correctly, and validation is the process of checking that it is the correct program (Sommerville 1995). A slightly different definition, taken from the International Energy Agency Building Energy Simulation Test (BESTEST) diagnostic method (Judkoff and Neymark 1995), is used here. The BESTEST process involves three testing methods:

1. Analytical verification - the output from the program or subroutine is compared to a known analytical solution for isolated physical mechanisms with simple boundary conditions.

2. Empirical validation - results from the program or subroutines are compared with experimental results from a real structure, test cell, or laboratory experiment.

3. Comparative testing - the program is compared to itself or to other programs.

Each technique has advantages and disadvantages, and each brings out different problems with computer models. Analytical verification tests correct coding of the algorithms with no uncertainty in the input; however, the method does not fully test the model and is limited to situations in which analytical solutions exist. Empirical validation tests the model against a known solution within experimental accuracy, but the detailed measurements required are often time consuming and expensive, and there are a limited number of good data sets. Comparative testing is quick, allows any portion of the program to be tested, and the uncertainty in the input is small, but the accuracy standard is questionable. All of the above methods are used in various capacities to confirm the performance of GHAMT.

\subsection{Patch Test}

The patch test is a simple test of finite element programs and consists of testing the program using a known solution to a small patch of elements. According to Zienkiewicz and Taylor (1994), it is the most important check for finite element codes. It can be a method for assessing the convergence, a check of how robust the code is, and a check for correct programming. A diagram of the patch test used for this program is shown in Figure 5.1. 


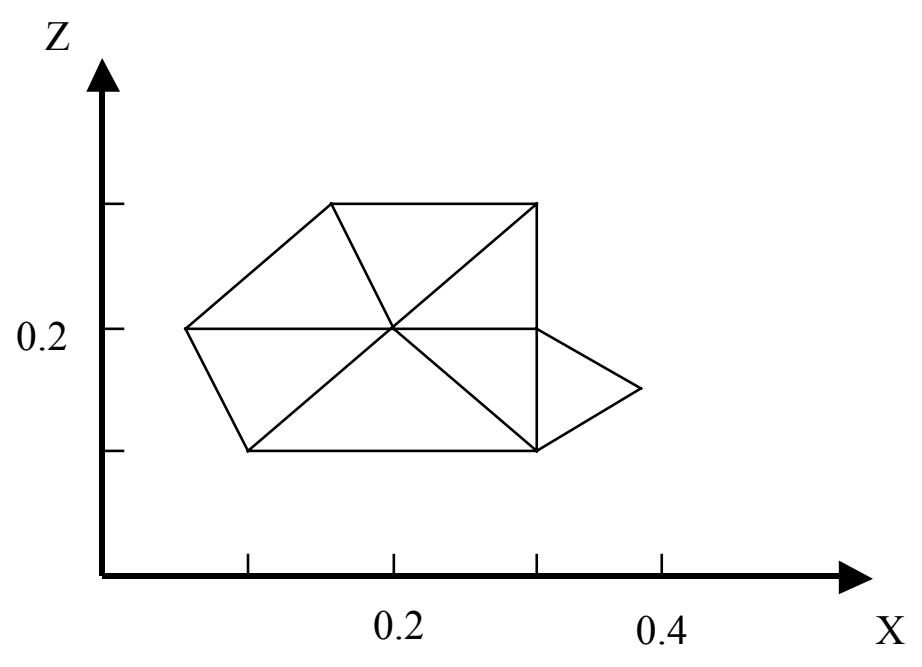

Figure 5.1. Patch test used to check GHAMT

The nodes were initialized with a matric potential of -1E5 $\mathrm{m}$ and a temperature of $300 \mathrm{~K}$. The matric potential was maintained at $-1 \mathrm{E} 5 \mathrm{~m}$, and the linear temperature profile of Eq. (5.1) was applied at the boundary nodes. This temperature profile results in a temperature of $292.0 \mathrm{~K}$ at the center node. The program was run with a time step of 1 hour. The test was completed using concrete (no moisture interaction), Solar Village clay, and Bighorn sandy loam. With the nonporous concrete, the temperature at the middle node converged to $292.0 \mathrm{~K}$ in 12 time steps. With the Solar Village clay, the center node temperature converged to $292.013 \mathrm{~K}$ in 58 steps; and with the sandy loam, it converged to $292.014 \mathrm{~K}$ in 39 steps. The thermal diffusivity of the soils at this low moisture content is about one-third that of the concrete, which explains the faster response. The nonlinear behavior of the coupled heat-and-moisture transfer produced the slight variation in the temperature at the center node for the soils.

$$
\mathrm{T}(\mathrm{x}, \mathrm{z})=20 \mathrm{x}+40 \mathrm{z}+280
$$

\subsection{Two-Dimensional Heat Conduction Problem}

For the two-dimensional temperature diffusion problem shown in Figure 5.2, an analytic solution is easily obtained by using variable separation to solve the steady-state heat conduction equation.

$$
\frac{\partial^{2} \mathrm{~T}}{\partial \mathrm{X}^{2}}+\frac{\partial^{2} \mathrm{~T}}{\partial \mathrm{Z}^{2}}=0
$$

The solution to this is shown in Eq. (5.3), where $\mathrm{x}_{1}=1.0, \mathrm{z}_{1}=2.0$, and $\mathrm{T}_{1}=100$.

$$
T(x, z)=\sum_{n=1}^{\infty} \frac{2 T_{1}\left(1-(-1)^{n}\right)}{n \pi \sinh \left(n \pi z_{1} / x_{1}\right)} \sin \left(n \pi x / x_{1}\right) \sinh \left(n \pi z / x_{1}\right)
$$




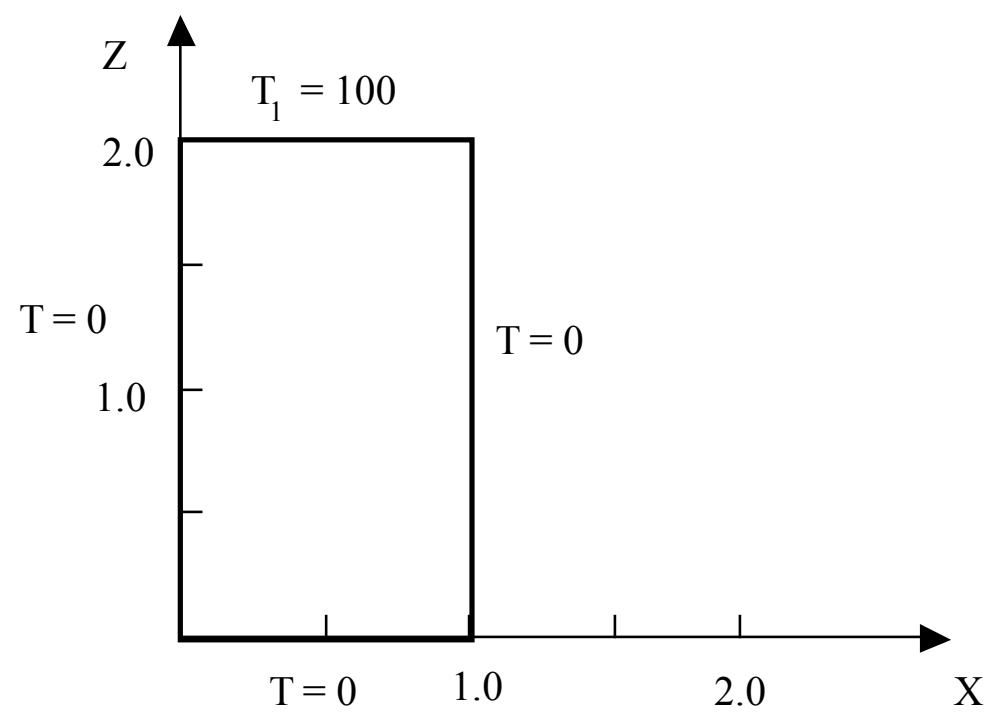

Figure 5.2. Two-dimensional heat conduction problem.

Both GHAMT and GHT2D were verified using this problem. GHAMT has the option of modeling non-porous materials adjacent to porous materials, such as a concrete slab on soil. For this test case, only a non-porous material was modeled. The problem was initialized with $\mathrm{T}=$ $0.0^{\circ} \mathrm{C}$, and then the boundary condition of $\mathrm{T}=100^{\circ} \mathrm{C}$ was applied at $\mathrm{z}=2.0$.

The numerical solution from GHAMT is compared with the analytic solution in Figure 5.3. The numerical solution is nearly identical to the analytic solution after 240 hours with a time step of 1 hour.

\subsection{One-Dimensional Isothermal Infiltration Problem}

Philip (1957) developed a quasi-analytic solution to the problem of one-dimensional isothermal moisture infiltration in a vertical soil column. The governing equation for moisture infiltration in terms of the matric potential is

$$
\left(\frac{\partial \theta}{\partial \psi}\right) \frac{\partial \psi}{\partial \mathrm{t}}=\frac{\partial}{\partial \mathrm{z}}\left(\mathrm{K}(\psi) \frac{\partial \psi}{\partial \mathrm{z}}\right)+\frac{\partial \mathrm{K}}{\partial \mathrm{z}}
$$




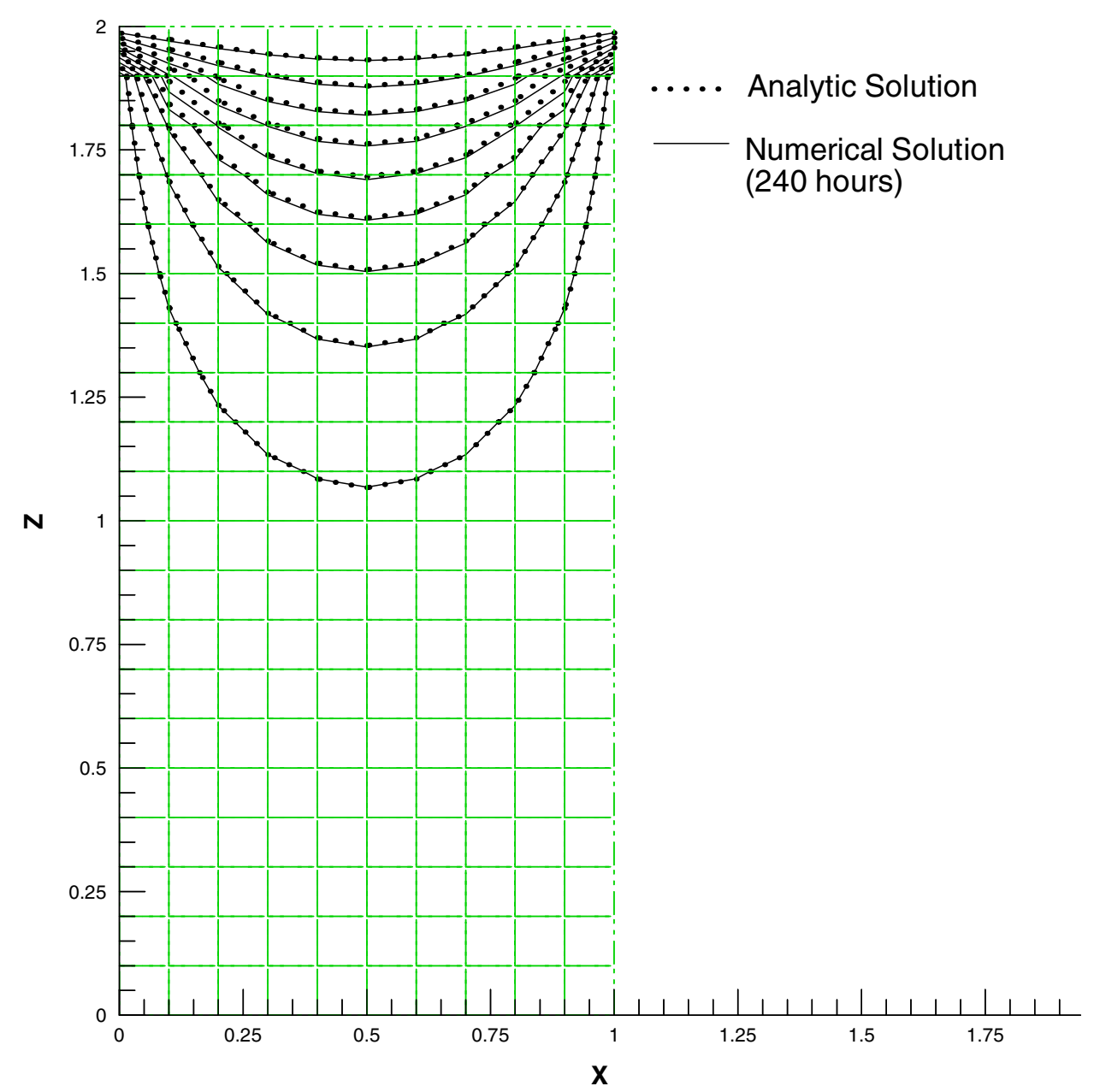

Figure 5.3. Temperature contours for the numerical and analytic solutions to a two-dimensional heat-conduction problem.

Philip assumed a semi-infinite medium with uniform initial conditions and constant boundary conditions. The solution is a power series in $\mathrm{t}^{1 / 2}$. Haverkamp et al. (1977) published the solution for the problem of vertical infiltration into a column of Yolo light clay in tabular form using Philip's method. The initial conditions were $\psi=-6.0 \mathrm{~m}(\theta=0.2367)$ and $\mathrm{T}=30.0^{\circ} \mathrm{C}$. The temperature was chosen to match the temperature at which Moore (1939) measured the soil moisture characteristic curve; therefore, there is no correction for temperature in the matric potential or the hydraulic conductivity relationships. The boundary conditions were zero moisture and heat fluxes on the sides, $\mathrm{T}=30.0^{\circ} \mathrm{C}$ on the top and bottom, and $\psi=-6.0 \mathrm{~m}$ on the bottom and $0.0 \mathrm{~m}$ on the top. A $2.5-\mathrm{m}$ column height was used to simulate the semi-infinite medium assumed by Philip. The numerical solution was run with a time step of $10 \mathrm{sec}$ for the first $1,000 \mathrm{sec}$, then increased to $1,000 \mathrm{sec}$ for the remainder of the run. The moisture content as a function of depth is plotted for three times against the quasi-analytic solution in Figure 5.4. The solution compares very well for each of the times. 


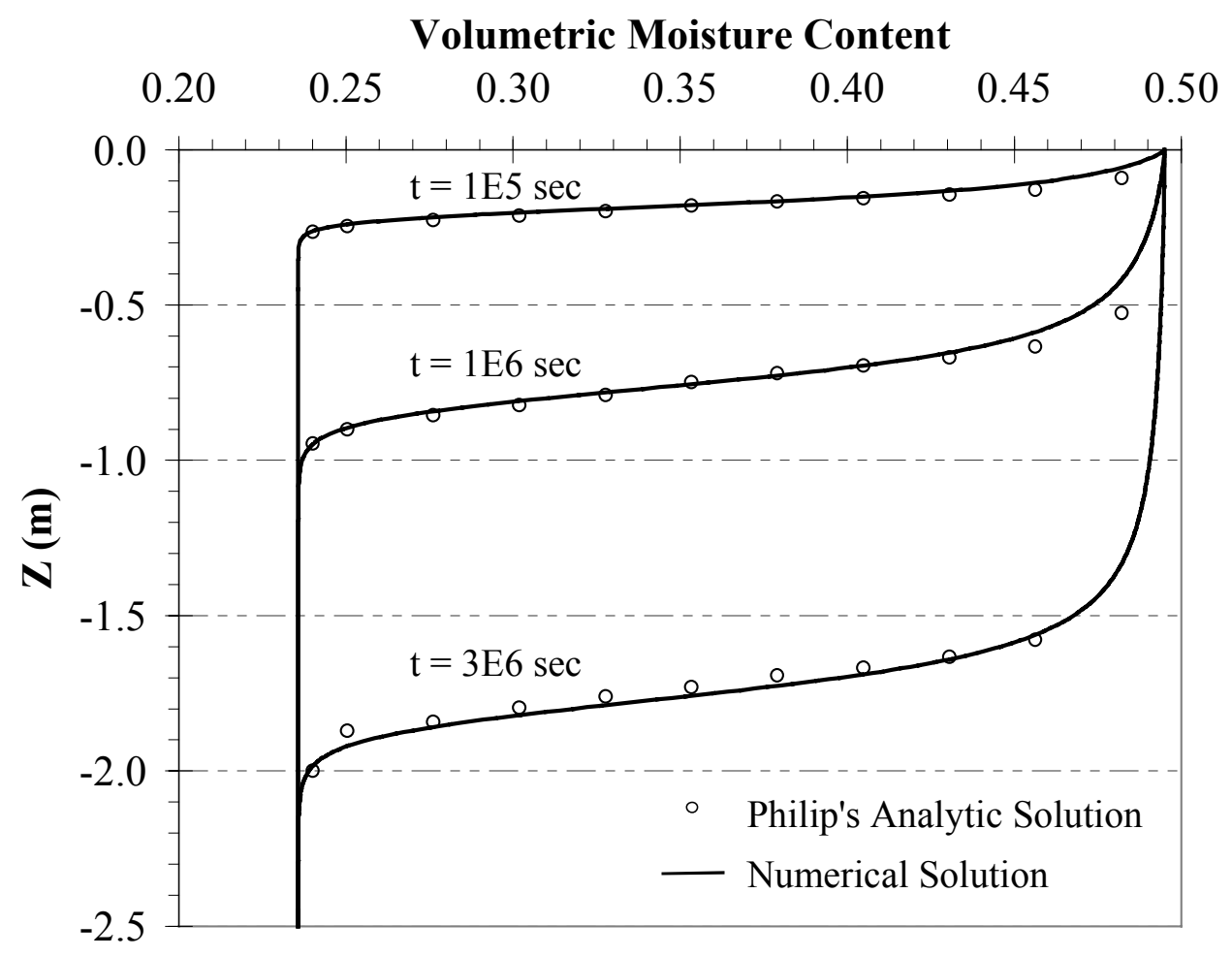

Figure 5.4. Infiltration in a column of Yolo light clay as predicted by Philip's quasi-analytic solution and GHAMT.

\subsection{Comparison with Field Experimental Results}

To test the heat-and-moisture transfer and the atmospheric boundary condition models, GHAMT was compared with experimental data taken at the Solar Energy Applications Laboratory at Colorado State University. A data-acquisition system was set up in an open field $10 \mathrm{~m}$ away from the only building in the area. The ground was covered with patchy wild grasses, which were matted down from occasional snowfall. The ground cover was estimated to be $10 \mathrm{~cm}$ high. Weather data and ground temperatures at the depths shown in Figure 5.5 were measured from October 29, 1998, to June 7, 1999. The copper-constantan thermocouples were inserted a minimum of $10 \mathrm{~cm}$ horizontally into the undisturbed soil of the hole's wall, which was then refilled and packed. The data were scanned every minute, and average values were recorded every 15 minutes. Because of problems with logging the solar radiation, this data was not reliable; therefore, the solar data, along with the precipitation data, were taken from a weather station located approximately $1 \mathrm{~km}$ from the site. For the period from April 8 to April 24, the data-logging system was down and no data were recorded. To keep a continuous simulation, the complete set of weather data was taken from the adjacent station during this period. 


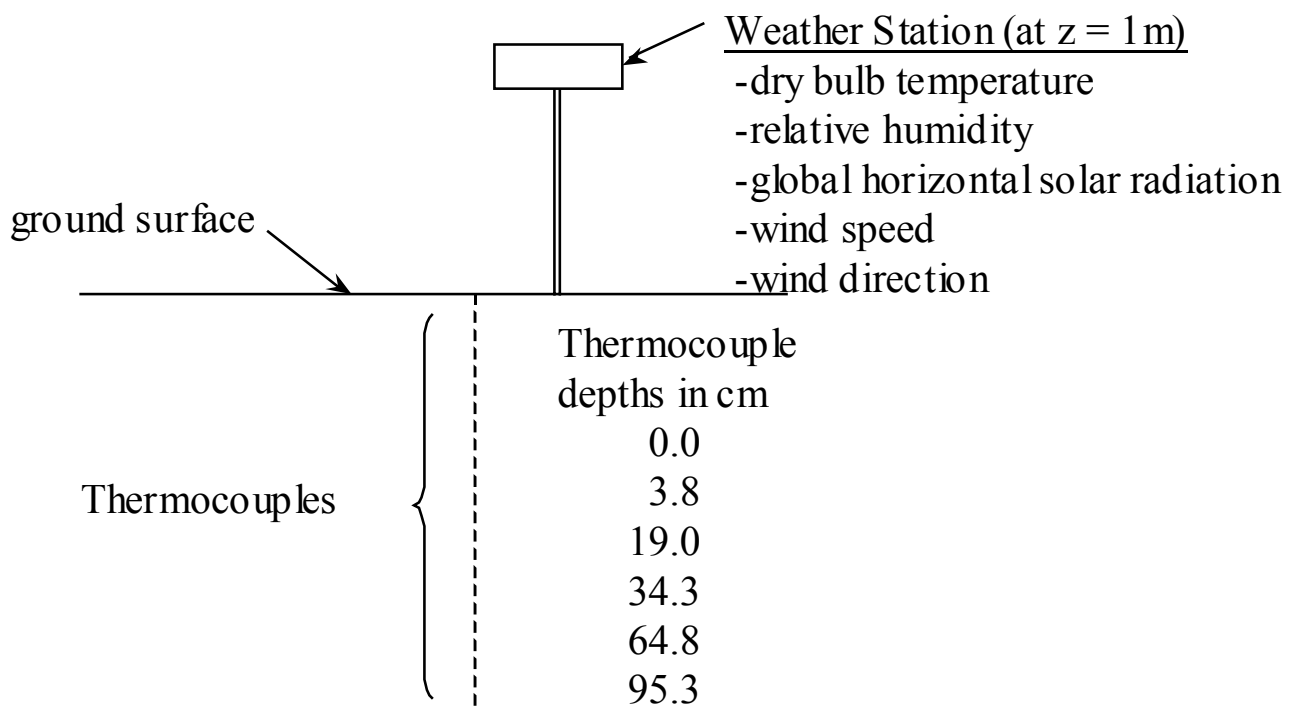

Figure 5.5. Ground temperature and weather data configuration.

Hampton (1989) measured the soil's thermal, hydraulic, and physical properties in this area and named it "Solar Village clay." The soil is composed of $15.8 \%$ sand, $40.0 \%$ silt, and $44.2 \%$ clay. The porosity and bulk density were taken from Hampton's experiments as 0.55 and $1,260 \mathrm{~kg} / \mathrm{m}^{3}$. The thermal conductivity and thermal heat capacity were estimated using the methods developed by de Vries (1966), assuming that the sand content was quartz minerals and that the other soil grains had the properties given by de Vries for "other" soil minerals. The soil water retention curve and the hydraulic conductivity were approximated using van Genuchten's (1980) method, matching Hampton's measured data as outlined in Appendix C.

A simulation was conducted using a 0.2 -m-wide by 3.0-m-deep column of Solar Village clay with GHAMT. The simulation was conducted from December 28, 1998, to June 8, 1999. This represented a period with good data and minor snow cover. The initial conditions for temperature were set to match the measured temperatures and linearly interpolated between the thermocouples to match the node positions. In this experiment, the moisture was not measured in this experiment and therefore had to be approximated. Prior to December 28, a large snowfall had just melted, and it was assumed the ground was very wet. The initial condition for the matric potential was set at $\psi(\mathrm{z})=-0.1+\mathrm{z}^{*} 0.05$ to simulate near-saturated soil. The boundary conditions along the sides were zero heat and moisture fluxes. The lower boundary condition was set with $\mathrm{T}$ $=10^{\circ} \mathrm{C}$ and $\psi=-0.25 \mathrm{~m}$. These were considered good representations for this location and soil over this time period. The upper boundary was modeled using the measured weather data.

Assumptions about the surface conditions were ground cover height $=0.1 \mathrm{~m}$, ground infrared emissivity $=0.9$, and ground albedo $($ solar reflectance $)=0.23$, which is representative of average crop cover (Shuttleworth 1993). Because of the evaporation and convection terms and the small element size at the surface $(0.74 \mathrm{~cm})$, the model is very sensitive to variations in the weather variables; therefore, a time step of $60 \mathrm{sec}$ was used to avoid instabilities. 
The weather conditions, along with the measured and predicted surface temperatures for two periods, are shown in Figures 5.6 and 5.7. Predicting the surface temperature is very sensitive to the atmospheric boundary conditions and is usually too high or too low. The over-predicted surface temperatures during the day seem to be caused by a combination of the incident solar radiation term and the convection term. Because there was no information on cloud cover, the long-wave radiation exchange with the atmosphere was modeled assuming a clear sky. The negative effects of this are clearly seen for the periods with substantial precipitation (and hence opaque cloud cover) between 1/21 and 1/27 in Figure 5.6 and from 4/28 to 5/2 in Figure 5.7. Between $4 / 28$ to $5 / 2,12.8 \mathrm{~cm}$ of precipitation was measured at the weather station. To see the effects of the clouds, the same run was completed with low $(\mathrm{h}=2,000 \mathrm{~m})$ opaque clouds for 1 hour before, during, and 2 hours after any precipitation. The results for the period between 4/27 and 5/17 are shown in Figure 5.8. The predicted temperature is much closer to the measured temperature during the period of heavy rainfall from $4 / 28$ to $5 / 2$. One variable that is not modeled is snow cover. There was snow cover insulating the ground between 1/21 and 1/27 evidenced by the nearly constant surface temperature. The presence of snow cover for short periods of time will have little effect on temperatures below $20 \mathrm{~cm}$; however, persistent snow cover is an important factor for deep ground temperatures as discussed by Gilpin and Wong (1976). 

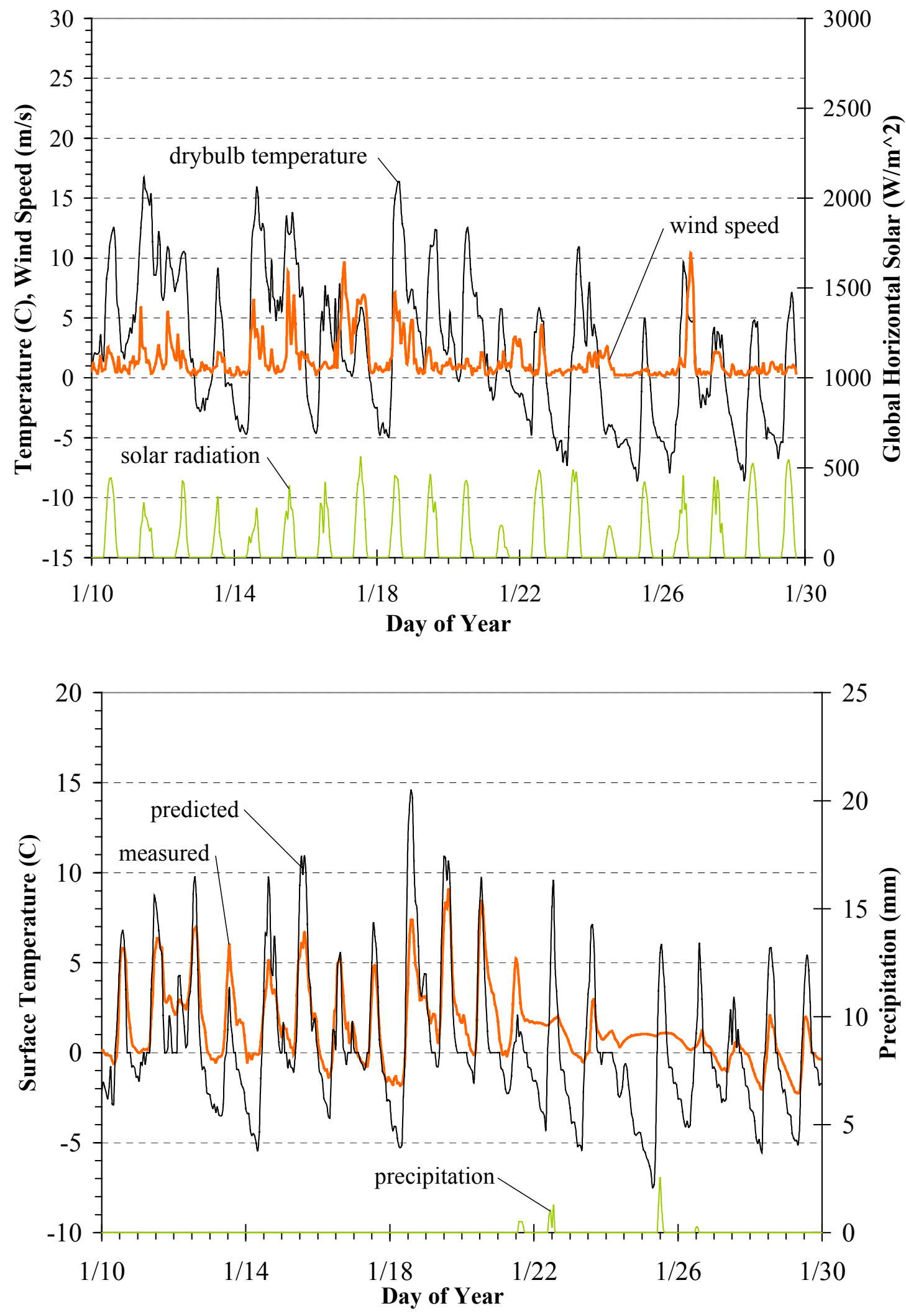

Figure 5.6. Weather conditions along with the measured and predicted surface temperatures for the period from January 10-30. 

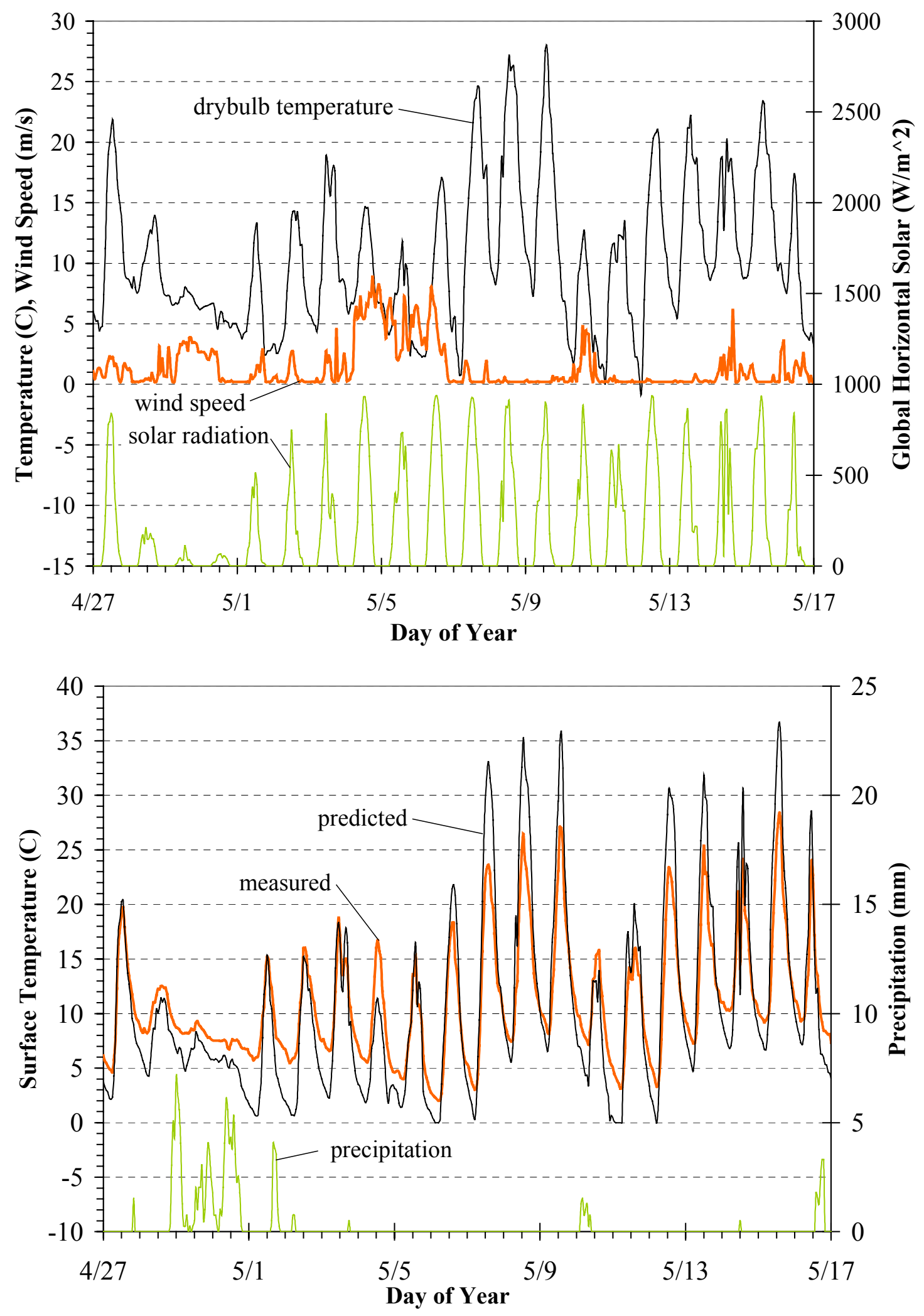

Figure 5.7. Weather conditions along with the measured and predicted surface temperatures for the period from April 27 to May 17. 


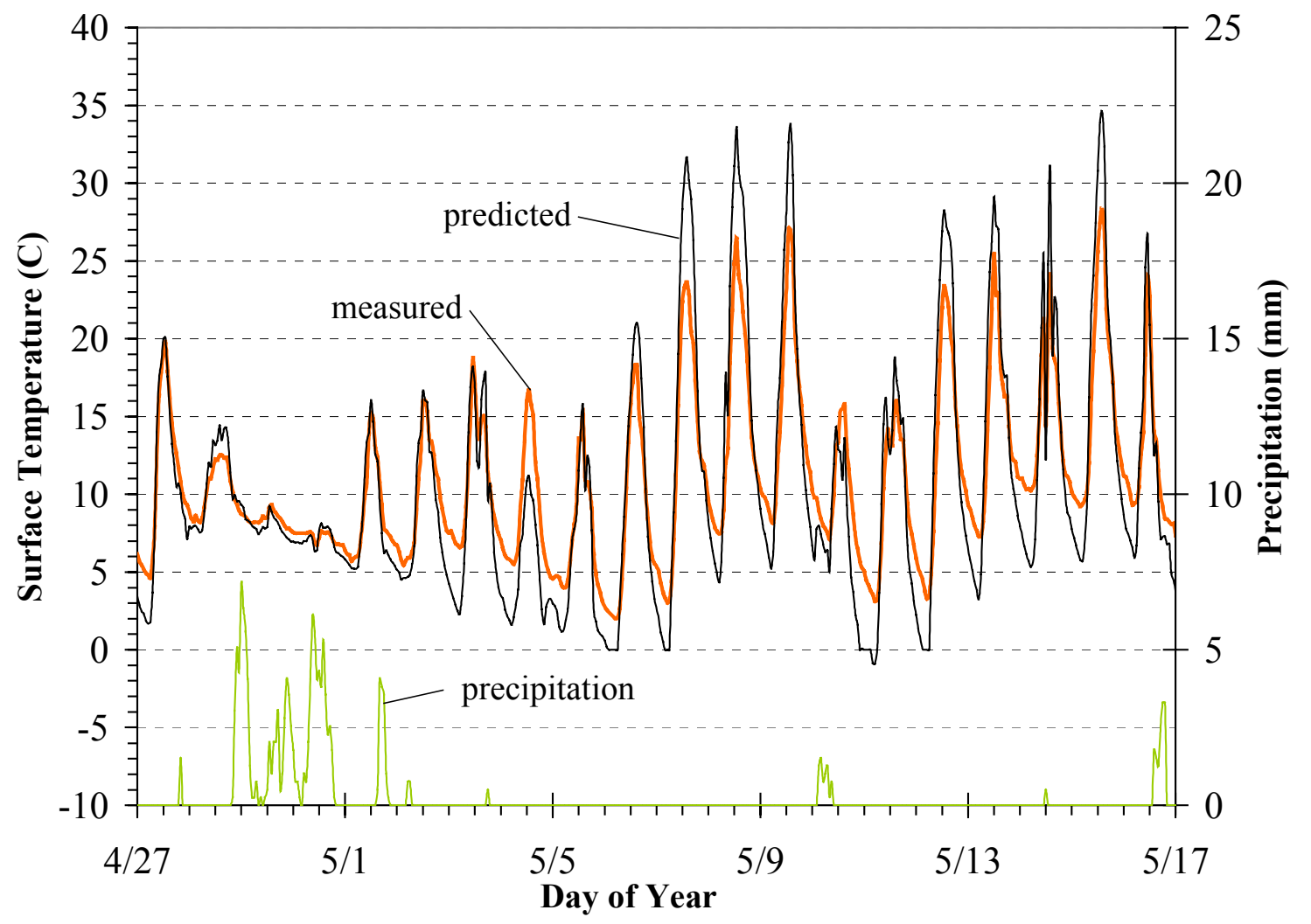

Figure 5.8. Measured and predicted surface temperatures for the period from April 27 to May 17 with cloudy skies during the rainy period.

Figures 5.9 to 5.11 show the measured and predicted temperatures along with the root-meansquare error at depths of $-0.34 \mathrm{~m},-0.65 \mathrm{~m}$, and $-0.95 \mathrm{~m}$. The predicted values at $-0.34 \mathrm{~m}$ and $0.65 \mathrm{~m}$ are very close to the measured temperatures with the root-mean-square error less than $1.0^{\circ} \mathrm{C}$. The values at $-0.95 \mathrm{~m}$ are also good, but the error is slightly larger. The growth in the error with depth is believed to be caused by inaccurate modeling of the thermal conductivity of the frozen soil and not modeling the effect of the snow cover (see Figure 5.6). Another cause may be incorrectly estimating the initial conditions for the moisture content. As the ambient temperature warms up and the moisture content has time to come to equilibrium, the temperature predictions become more accurate. 


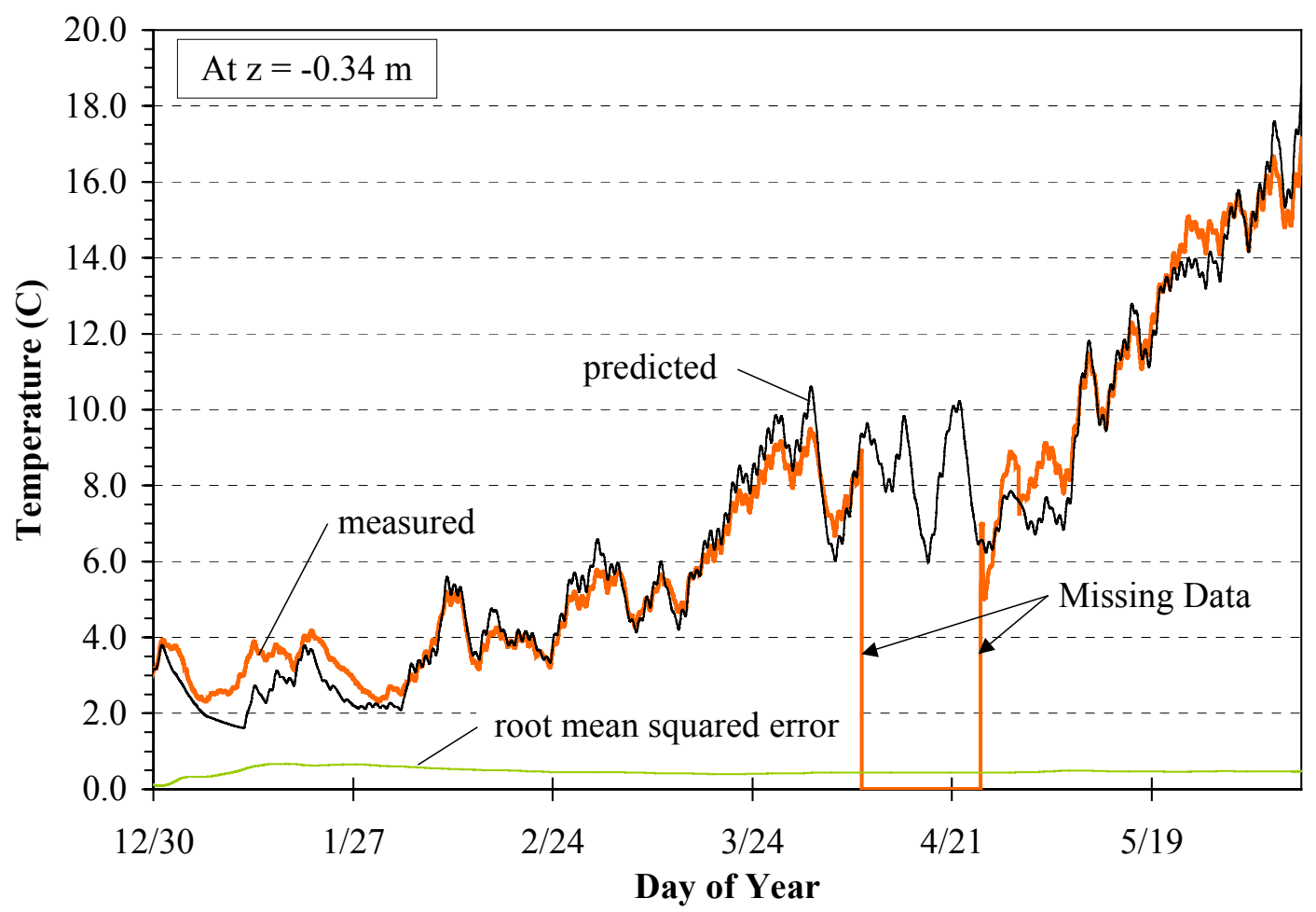

Figure 5.9. Measured and approximated temperatures and the error at $z=-$ $0.34 \mathrm{~m}$.

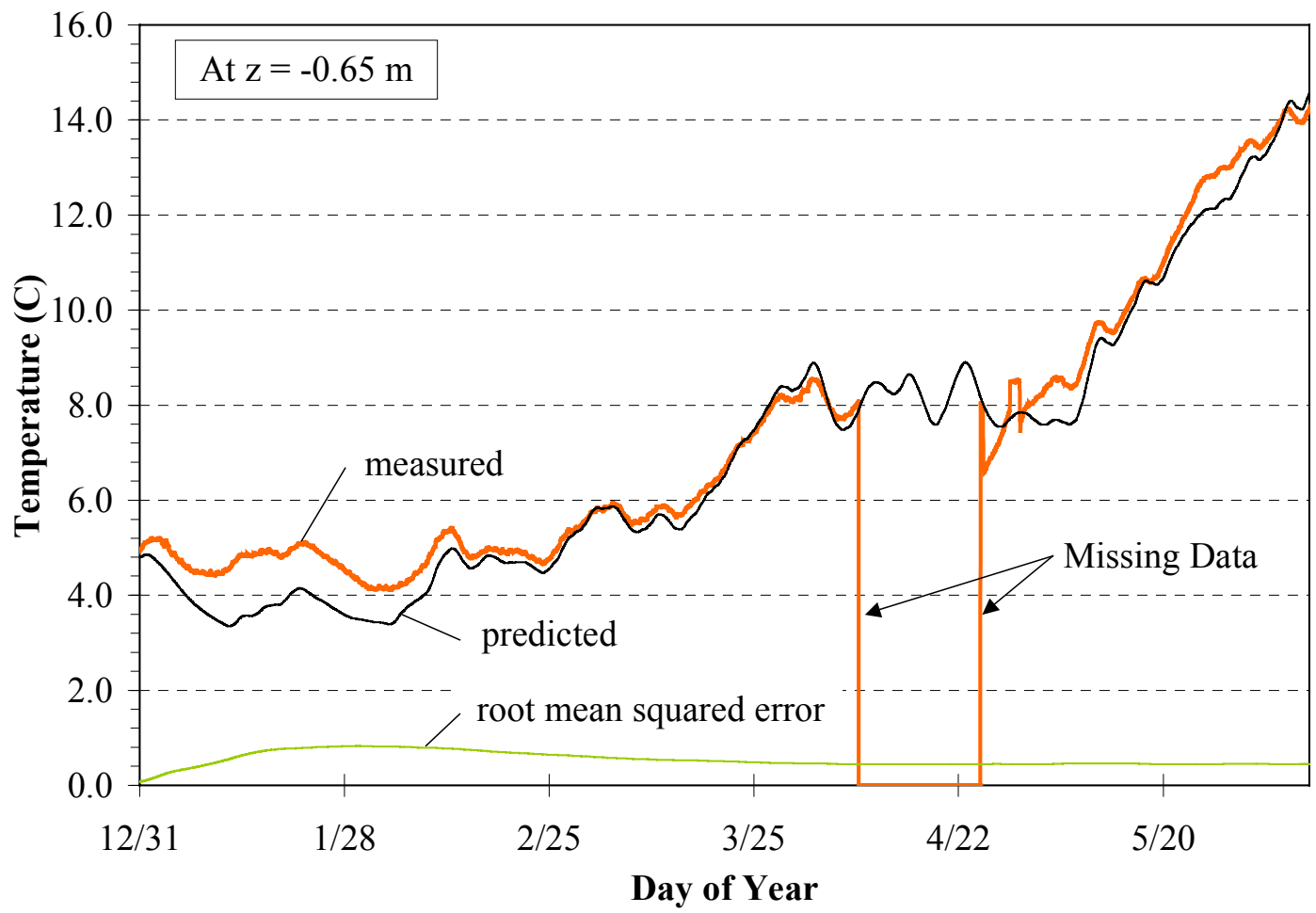

Figure 5.10. Measured and approximated temperatures and the error at $z=-$ $0.65 \mathrm{~m}$. 


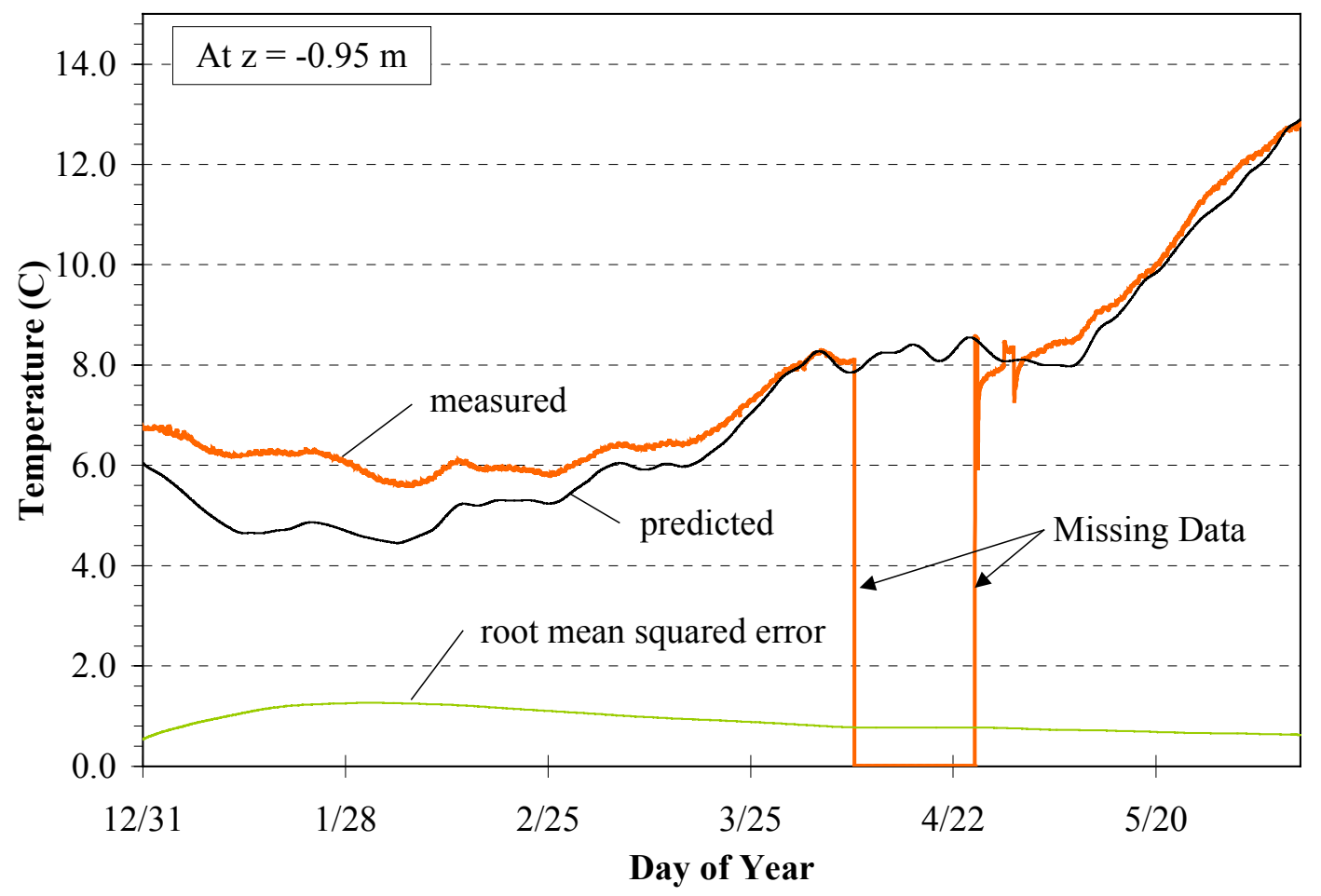

Figure 5.11. Measured and approximated temperatures and the error at $z=$ $0.95 \mathrm{~m}$.

\subsection{Conclusions}

The GHAMT program compares well with analytic solutions for heat conduction and isothermal infiltration and with experimental data. Unfortunately, moisture data were not measured during the field experiment, which would have been a more decisive validation. These tests are by no means conclusive as to the model's accuracy in all situations. As with all numerical models, caution is advised when using them to avoid erroneous results. It is advised to check the results against expected behavior and with hand calculations or proven solutions.

Comparison with the experimental data shows the sensitivity of the results at the surface to the atmospheric conditions. Short-term variations in the atmospheric conditions have little effect on the predicted soil temperatures below $0.2 \mathrm{~m}$; however, if small inaccuracies at the surface persist, the predictions slowly diverge from the actual behavior for simulations longer than a few weeks. An example of this was discovered when the model was run without the precipitation input. The results at all depths slowly diverged from the measured data because of the slow drying of the soil. Another long-term condition that could potentially alter the results is the presence of persistent snow cover. Gilpin and Wong (1980) showed how seasonal snow cover acts as a "heat valve" with significant effects in cold regions. Ground shading, which is not included in the present model, could also substantially affect the solution as shown by Bahnfleth (1989) and discussed in Chapter 2. 


\section{Chapter 6: Results}

\subsection{Introduction}

This chapter begins with an analysis of the magnitudes of the heat flux terms for a simple onedimensional case using GHAMT. Then the effects of moisture, freezing, and water-table depth on the heat transfer from a slab-on-grade floor and a basement are studied. An annual simulation is completed with hourly data to compare the heat-and-moisture-transfer model with the heattransfer model and with the results from a hand calculation method.

\subsection{Comparison of Soil Heat Transfer Terms}

The GHAMT program was verified against experimentally measured ground temperatures in a one-dimensional case in Chapter 5. The values of the four heat flux terms from the heat transfer equation were also calculated for this case. These heat transfer terms are the following: (1) heat conduction, $\mathrm{q}_{\text {cond }}$; (2) latent heat of vapor distillation driven by temperature gradients, $\mathrm{q}_{\mathrm{v}, \Delta \mathrm{T}}$; (3) latent heat of vapor distillation driven by matric potential gradients, $\mathrm{q}_{\mathrm{v}, \Delta \Psi}$; and (4) liquid convection by matric potential gradients and gravity, $\mathrm{q}_{\ell}$. The heat flux values were calculated in the z-direction by Eqs. (6.1) to (6.4) after the governing equations were solved.

$$
\begin{aligned}
& \mathrm{q}_{\text {cond }}=-\mathrm{k}\left\lfloor\frac{\partial \mathrm{N}}{\partial \mathrm{z}}\right\rfloor\{\mathrm{T}\} \\
& \mathrm{q}_{\mathrm{v}, \Delta \mathrm{T}}=-\rho_{\ell} \mathrm{h}_{\mathrm{fg}} \mathrm{D}_{\mathrm{Tv}}\left\lfloor\frac{\partial \mathrm{N}}{\partial \mathrm{z}}\right\rfloor\{\mathrm{T}\} \\
& \mathrm{q}_{\mathrm{v}, \Delta \psi}=-\rho_{\ell} \mathrm{h}_{\mathrm{fg}} \mathrm{D}_{\psi \mathrm{v}}\left\lfloor\frac{\partial \mathrm{N}}{\partial \mathrm{z}}\right\rfloor\{\psi\} \\
& \mathrm{q}_{\ell}=-\rho_{\ell} \mathrm{C}_{\mathrm{p}, \ell} \mathrm{K}\left(\left\lfloor\frac{\partial \mathrm{N}}{\partial \mathrm{z}}\right\rfloor\{\psi\}+1\right)\left(\mathrm{T}-\mathrm{T}_{\mathrm{o}}\right)
\end{aligned}
$$

The thermal conductivity $\mathrm{k}$ in Eq. (6.1) is calculated using the de Vries method, which includes the effect of the latent heat transfer of vapor distillation. The shape factors $\mathrm{N}$ and the coefficients were evaluated at the element centroids. The temperatures and matric potentials are the nodal point values, and the reference temperature is $\mathrm{T}_{\mathrm{o}}=0.0^{\circ} \mathrm{C}$, following the definition of the latent heat of vaporization in Eqs. (4.38) and (4.39).

Figures 6.1 to 6.3 show the heat flux values at $\mathrm{z}=-0.038 \mathrm{~m},-0.35 \mathrm{~m}$, and $-0.95 \mathrm{~m}$ with positive denoting heat flow into the ground. The heat flux of the latent heat of vapor distillation driven by matric potential gradients, $\mathrm{q}_{\mathrm{v}, \Delta \Psi}$, was extremely small for all cases and is not included in the graphs. The conduction heat transfer is usually the dominant term, except after the large 12.8-cm rainfall from $4 / 28$ to $5 / 2$ (see Figure 5.7). Normally, the heat flux by liquid convection is very small; however, the large influx of water causes this term to increase to levels that are comparable to, or larger than, the conduction term. The heat transfer by vapor distillation cycles driven by temperature gradients is very small, which is expected because of the high moisture 
content and the clay soil. This term becomes more important at lower moisture contents, as can be seen in the graph of thermal conductivity for the sandy loam in Figure 3.7.

Because of the variation in solar gain, the conduction term in Figure 6.1 exhibits sharp peaks during the day, and at night, the curves are shallow because the conditions are relatively constant. At the lower depths in Figures 6.2 and 6.3, the diurnal variations are damped out and the moisture-influx effect occurs later and lasts longer.

Figures 6.4 and 6.5 show the same heat flux terms using Bighorn sandy loam instead of the Solar Village clay for depths of $-0.038 \mathrm{~m}$ and $-0.35 \mathrm{~m}$. The thermal conductivity of the sandy loam is higher, also the heat conduction values are higher. The biggest difference between the two soils is in the hydraulic conductivity, which is evident in the magnitude of the liquid convection heat transfer. The saturated hydraulic conductivity of the Solar Village clay is $1.5 \times 10^{-6} \mathrm{~m} / \mathrm{s}$, and the value for the Bighorn sandy loam is $5.0 \times 10^{-5} \mathrm{~m} / \mathrm{s}$. For the run times not shown in these graphs, the liquid convection term is very small.

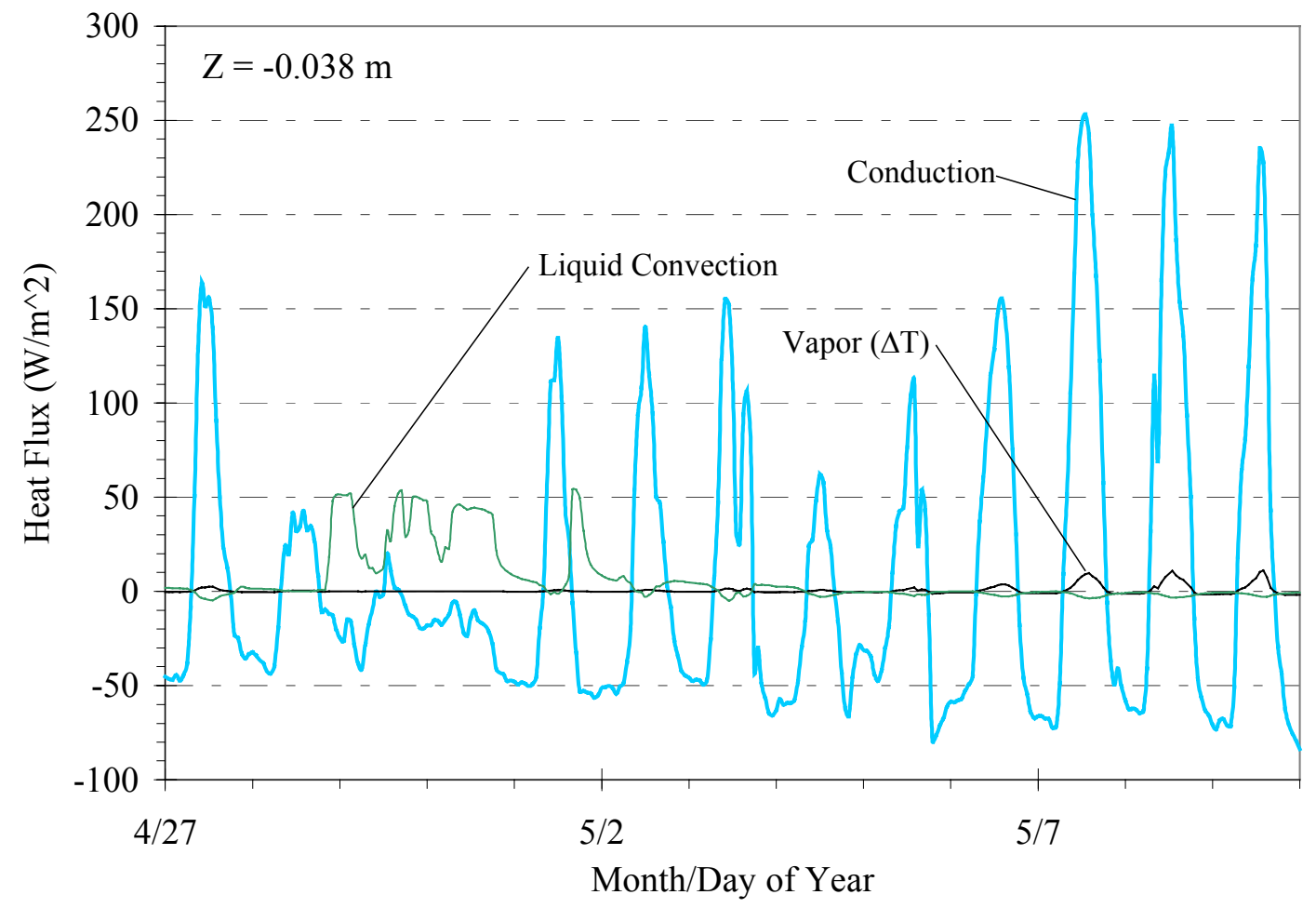

Figure 6.1. Heat flux terms of conduction, vapor distillation driven by temperature, and liquid convection at $\mathrm{z}=\mathbf{- 0 . 0 3 8} \mathrm{m}$ for Solar Village clay. 


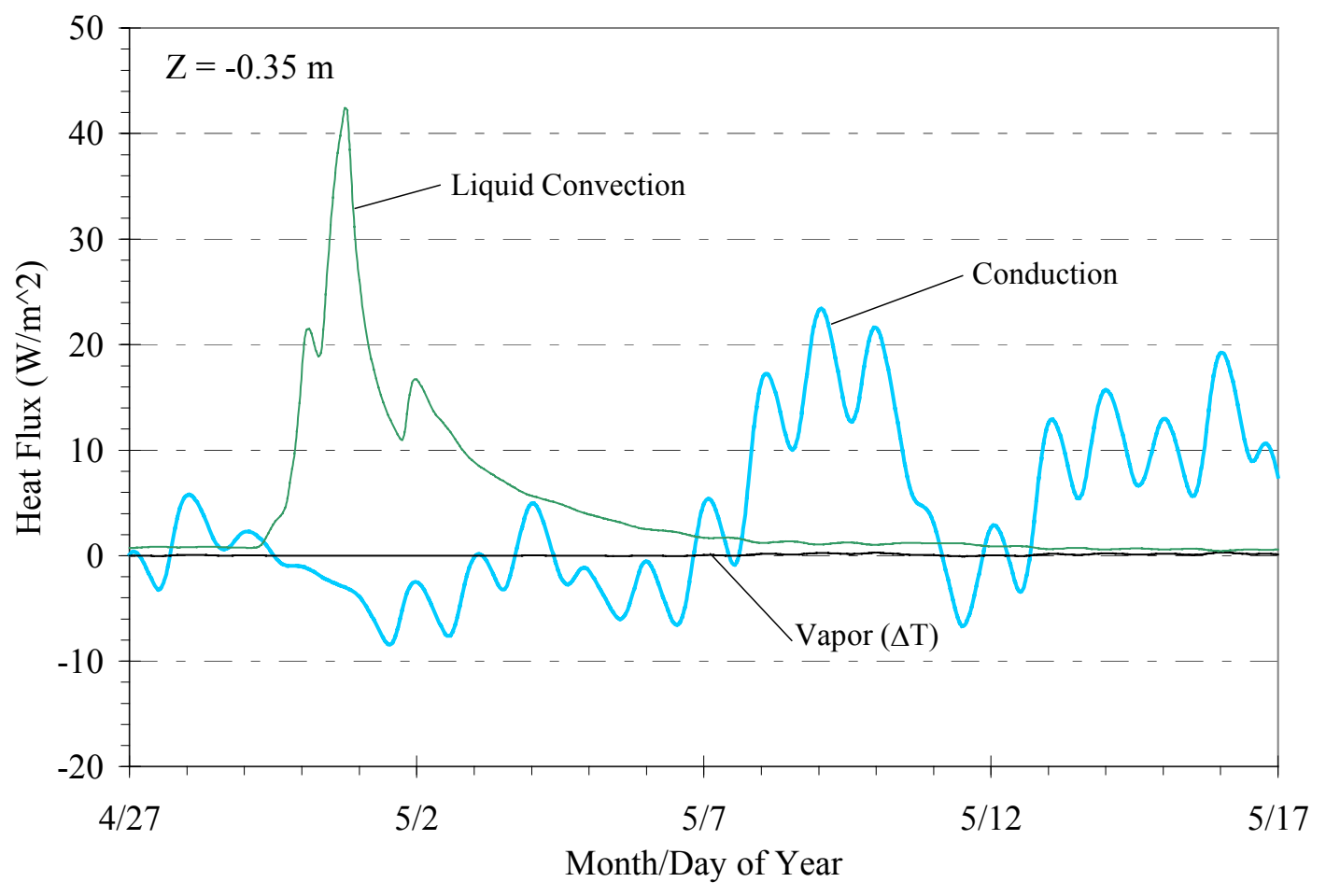

Figure 6.2. Heat flux terms of conduction, vapor distillation driven by temperature, and liquid convection at $z=-0.35 \mathrm{~m}$ for Solar Village clay

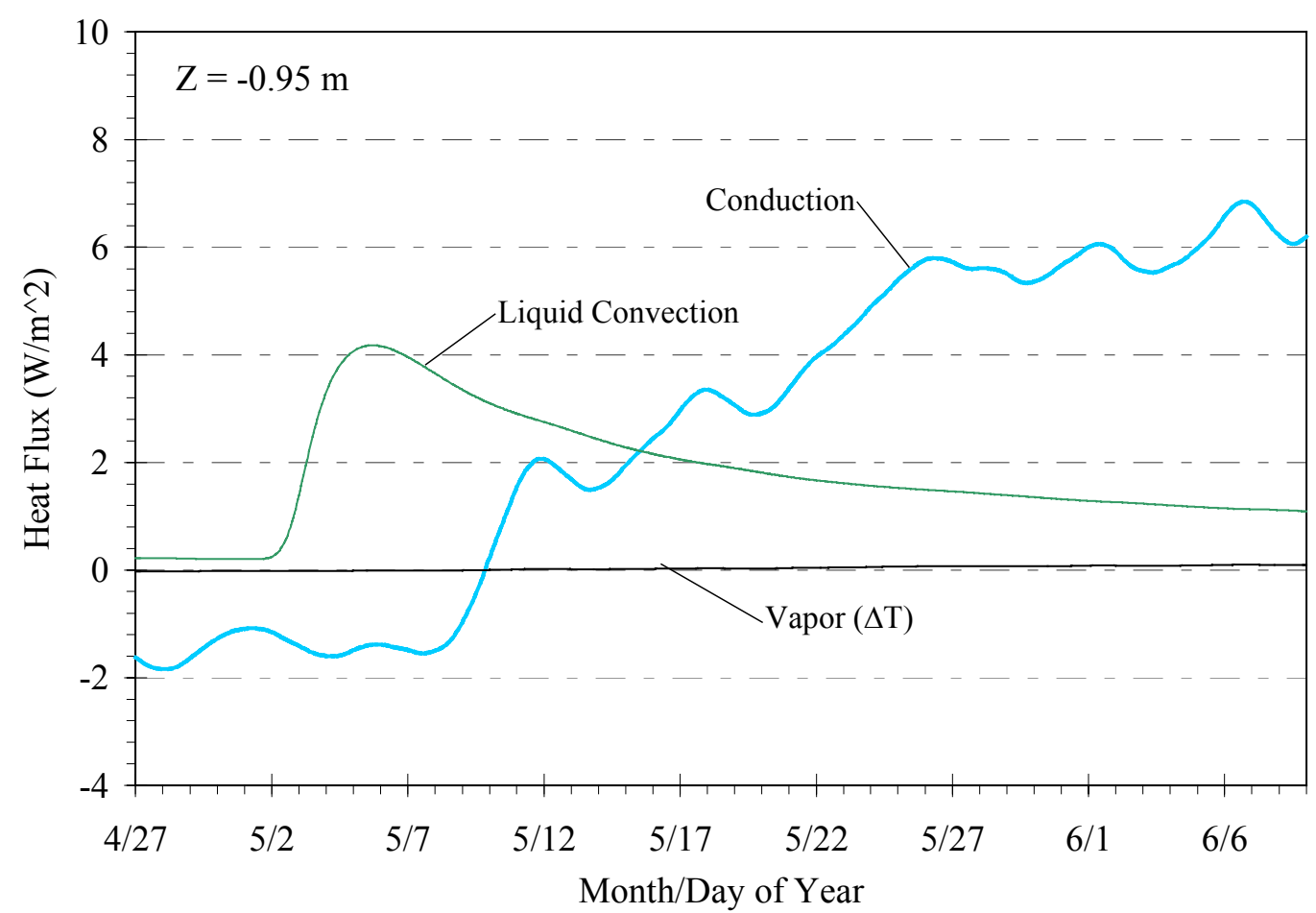

Figure 6.3. Heat flux terms of conduction, vapor distillation driven by

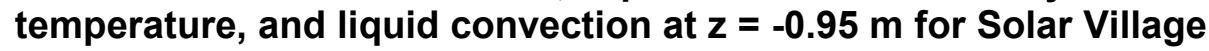
clay. 


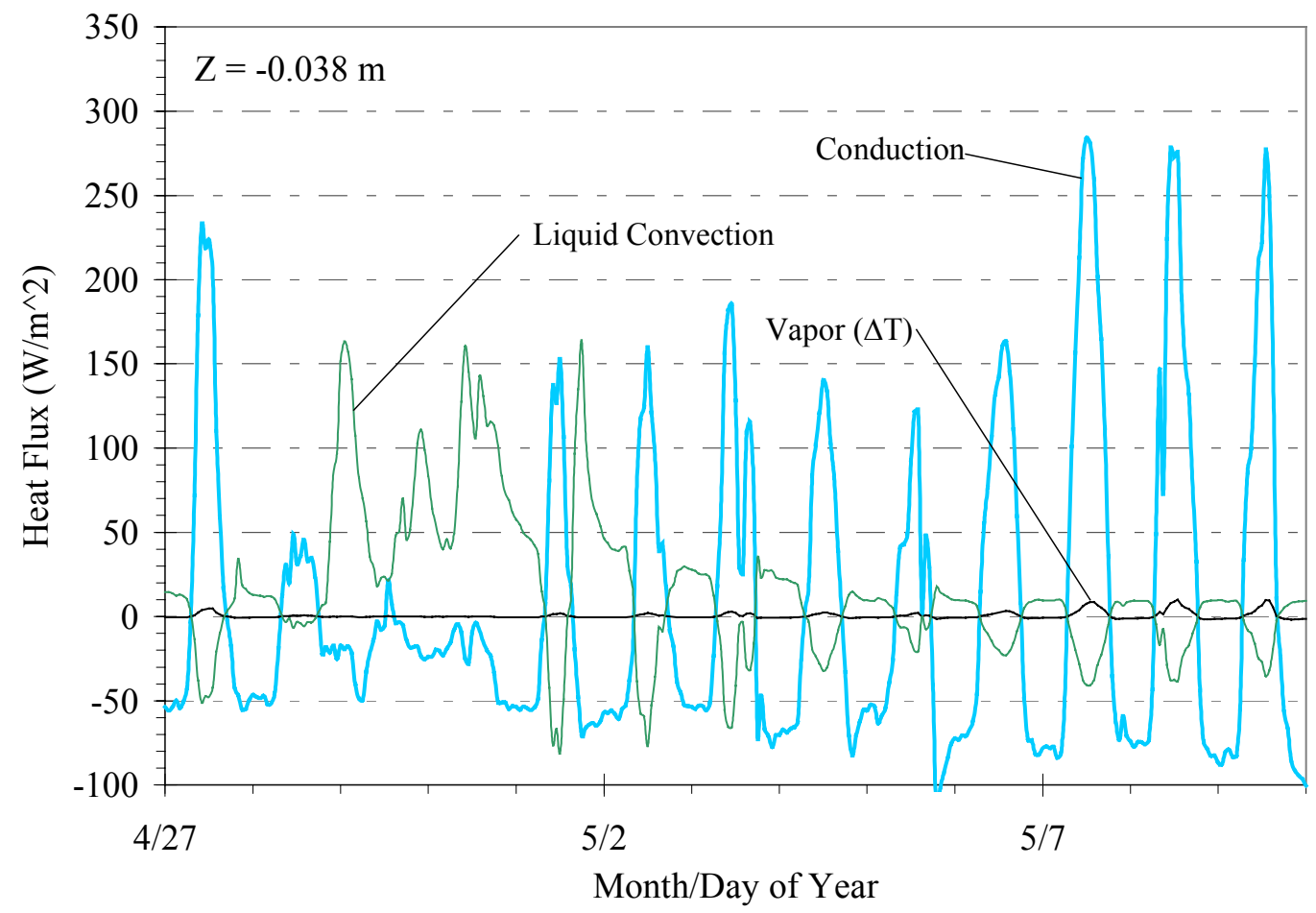

Figure 6.4. Heat flux terms of conduction, vapor distillation driven by temperature, and liquid convection at $\mathbf{z}=\mathbf{- 0 . 0 3 8} \mathrm{m}$ for Bighorn sandy loam.

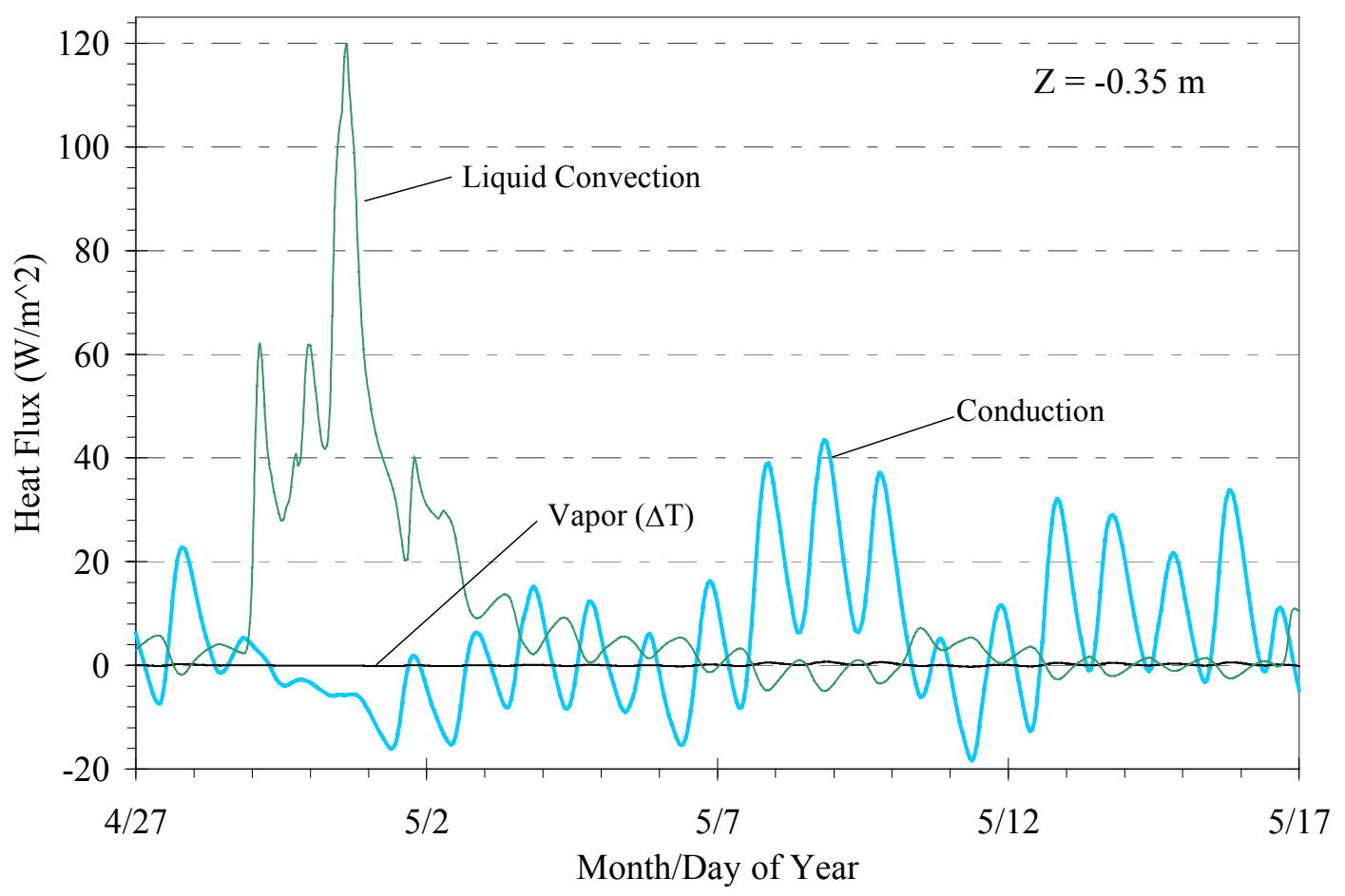

Figure 6.5. Heat flux terms of conduction, vapor distillation driven by temperature, and liquid convection at $\mathrm{z}=\mathbf{- 0 . 3 5} \mathrm{m}$ for Bighorn sandy loam. 


\subsection{Slab-on-Grade and Basement Heat-Transfer Simulation Parameters}

To determine the effect of moisture added to the ground surface on ground-coupled heat transfer from a slab-on-grade and basement, two sets of simulations were conducted. The simulations were identical in every way except that one included rain added to the soil surface during the simulation. This was completed for a half-width slab-on-grade floor and a half-width basement. Simulations were completed with summer and winter conditions, with insulation and without insulation, and with Bighorn sandy loam and with Yolo light clay. The geometries and the meshes used for the slab-on-grade and basement problems are shown in Figures 6.6 and 6.7. Both meshes consist of three-node triangles.

The boundary conditions along the sides were zero heat and moisture fluxes. The bottom boundary was maintained at $\psi=0.0 \mathrm{~m}$ (i.e. saturated) and $\mathrm{T}=10^{\circ} \mathrm{C}$. The air temperature above the floor was $20^{\circ} \mathrm{C}$ with the convective heat-transfer coefficient for the floor equal to 6.0 $\mathrm{W} / \mathrm{m}^{2} \cdot \mathrm{K}$ and $8.3 \mathrm{~W} / \mathrm{m}^{2} \cdot \mathrm{K}$ for the basement wall. The ground surface boundary was assumed to have had 10-cm-high vegetation, a long-wave emittance of 0.9 , and a reflectance of 0.23 .

The material properties used in the simulations are shown in Table 6.1. The insulated cases included $5 \mathrm{~cm}$ of insulation under the entire floor and along the outside of the foundation wall and $2 \mathrm{~cm}$ of insulation separating the floor from the foundation or basement wall. Gravel under the slab was simulated as a heat conduction only material, which will introduce a small error, but gravel drains very well and contains very little moisture.

Table 6.1. Material Properties Used for Ground-Heat-Transfer Simulations.

\begin{tabular}{|l|l|l|l|l|}
\hline \multicolumn{1}{|c|}{ Material } & \multicolumn{1}{c|}{$\begin{array}{c}\text { Thickness } \\
(\mathbf{c m})\end{array}$} & $\begin{array}{c}\boldsymbol{\rho} \\
\left(\mathbf{k g} / \mathbf{m}^{\mathbf{3}}\right)\end{array}$ & \multicolumn{1}{c|}{$\begin{array}{c}\mathbf{k} \\
(\mathbf{W} / \mathbf{m} \cdot \mathbf{K})\end{array}$} & \multicolumn{1}{c|}{$\begin{array}{c}\mathbf{C}_{\mathbf{p}} \\
(\mathbf{J} / \mathbf{k g} \cdot \mathbf{K})\end{array}$} \\
\hline concrete floor $^{1}$ & 10 & 2,400 & 1.5 & 1,000 \\
\hline concrete wall $^{1}$ & 20 & 2,400 & 1.5 & 1,000 \\
\hline gravel $^{2}$ & 15 & 2,000 & 2.0 & 812 \\
\hline insulation $^{1}$ & 5 & 40 & 0.029 & 1.21 \\
\hline
\end{tabular}

${ }^{1}$ ASHRAE Handbook of Fundamentals (1997)

${ }^{2}$ Kersten (1949)

The initial conditions for the summer simulations were obtained by starting with linear temperature and moisture distributions in depth and running the program for a 3-year period with sinusoidal varying weather conditions and $25 \mathrm{~mm}$ of rain added once a week to keep the surface from becoming completely dry. It is worth noting that both the temperature and moisture fields took 2 to 3 years to reach a quasi-steady-state distribution, which agrees with the predictions by Lachenbruch (1957) and the measurements by Trethowen and Delsante (1998). The initial conditions for the winter simulations started with the results at the end of the 3-year summer run and ran for one more year with the winter 1 conditions from Table 6.2. 


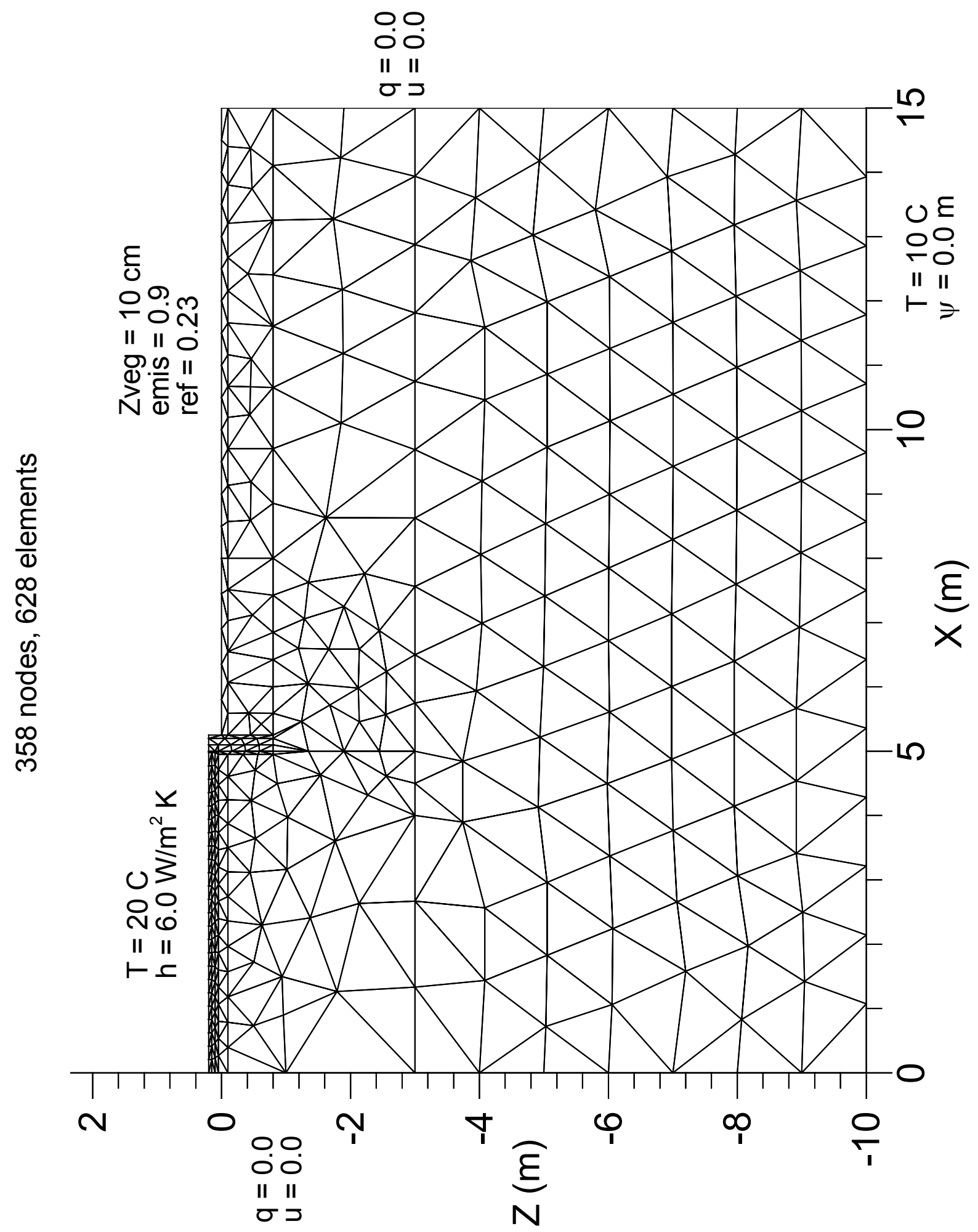

Figure 6.6. Mesh and boundary conditions used for the slab-on-grade simulations. 


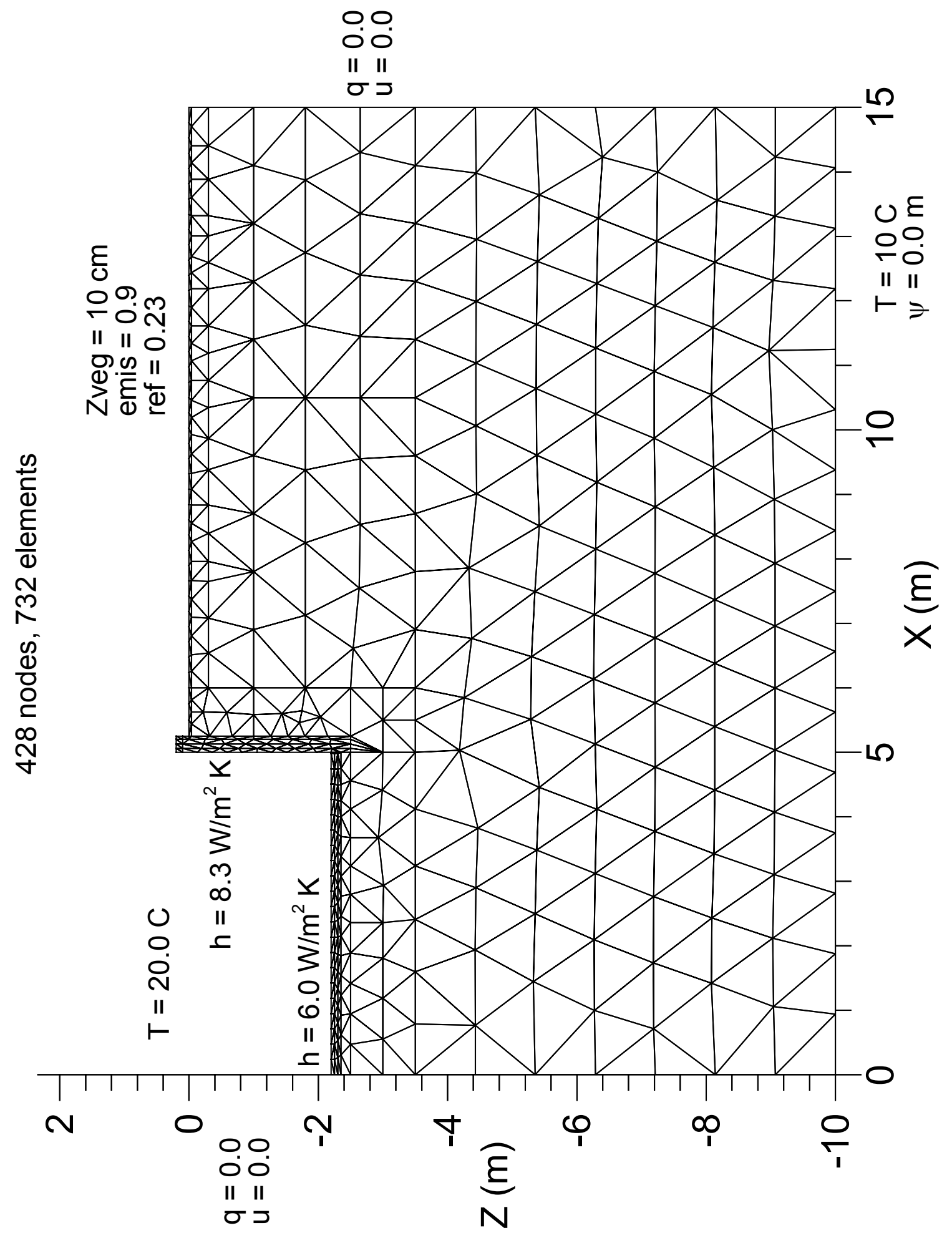

Figure 6.7. Mesh and boundary conditions used for the basement simulations. 
The daily weather conditions were simulated using Eqs. (6.5) to (6.7) and the data in Table 6.2 for solar radiation, temperature, and wind speed. The solar radiation was set to zero when the values from Eq. (6.5) were negative.

$$
\begin{aligned}
& \mathrm{G}=\mathrm{G}_{\mathrm{m}}+\mathrm{G}_{\mathrm{a}} \sin (\pi(2 \mathrm{t} / 24-1 / 2)) \\
& \mathrm{T}=\mathrm{T}_{\mathrm{m}}+\mathrm{T}_{\mathrm{a}} \sin (\pi(2 \mathrm{t} / 24-2 / 3)) \\
& \mathrm{u}=\mathrm{u}_{\mathrm{m}}+\mathrm{u}_{\mathrm{a}} \sin (\pi(6 \mathrm{t} / 24-1 / 2))
\end{aligned}
$$

Table 6.2.Weather Parameters Used for Ground Heat Transfer Simulations.

\begin{tabular}{|l|l|r|r|r|}
\hline \multicolumn{1}{|c|}{ Variable } & \multicolumn{1}{c|}{ Units } & Summer & Winter 1 & Winter 2 \\
\hline \hline $\mathrm{G}_{\mathrm{m}}$ & $\mathrm{Wh} / \mathrm{m}^{2}$ & 0.0 & 0.0 & 0.0 \\
\hline $\mathrm{G}_{\mathrm{a}}$ & $\mathrm{Wh} / \mathrm{m}^{2}$ & 900.0 & 450.0 & 200.0 \\
\hline $\mathrm{T}_{\text {dry bulb-m }}$ & ${ }^{\circ} \mathrm{C}$ & 15 & 0.0 & -10.0 \\
\hline $\mathrm{T}_{\text {dry bulb-a }}$ & ${ }^{\circ} \mathrm{C}$ & 10 & 5.0 & 5.0 \\
\hline $\mathrm{T}_{\text {dewpoint-m }}$ & ${ }^{\circ} \mathrm{C}$ & 7.5 & -1.0 & -12.0 \\
\hline $\mathrm{T}_{\text {dewpoint-a }}$ & ${ }^{\circ} \mathrm{C}$ & 5.0 & 4.0 & 4.0 \\
\hline $\mathrm{u}_{\mathrm{m}}$ & $\mathrm{m} / \mathrm{s}$ & 4.0 & 4.0 & 4.0 \\
\hline $\mathrm{u}_{\mathrm{a}}$ & $\mathrm{m} / \mathrm{s}$ & 2.0 & 2.0 & 2.0 \\
\hline precip-slab & $\mathrm{mm}$ & 25.0 & 25.0 & 25.0 \\
precip-basement & & 50.0 & 25.0 & 50.0 \\
\hline
\end{tabular}

The winter 1 weather parameters in Table 6.2 were used during the 1-year setup run for the initial conditions, and the winter 2 values were used with the slab-on-grade and basement simulations. All of the summer simulations were 16 weeks (112 days), and the winter simulations were 8 weeks (56 days).

\subsection{Effect of Surface Moisture on Slab-on-Grade Heat Transfer}

The slab-on-grade simulation cases are listed in Table 6.3. Twenty-five mm of rain was added on days 7 and 14 between 6 and 7 a.m. for the rainy cases. The heat flux from the slab-on-grade floor was first calculated at the element centroids and then at the nodal points by an areaweighted average.

Figure 6.8 shows the heat flux variation across the floor at 12:00 p.m. on day 14 with the sandy loam soil for the uninsulated-dry, uninsulated-rain, and insulated-rain cases. Adding rain has only a small effect on the uninsulated floor, and then only near the perimeter. The effect of the insulation is substantial for the first $2 \mathrm{~m}$ in from the outside edge and then diminishes towards the center of the floor. However, at the center of the floor, the insulation still reduces the heat loss by one-third, which may be significant depending on the building, the location, and the heating fuel costs.

For the summer cases (1-8), Figures 6.9 and 6.10 show the hourly total heat loss across the slab floor per unit of depth. Adding rain on days 7 and 14 has an obvious effect on the heat transfer from the floor for all cases. The average magnitude of the heat transfer from the uninsulated floors is about twice the value from that of the insulated floors, and the daily variation is about 
100 times larger. The general downward slope of the graphs is due to the surface soil slowly drying out, which lowers the thermal conductivity. For each case, the increase in heat loss over the 112 days caused by adding rain is: $1.2 \%$ for the insulated sandy loam, $3.1 \%$ for the uninsulated sandy loam, $0.4 \%$ for the insulated Yolo light clay, and $1.2 \%$ for the uninsulated Yolo light clay.

Table 6.3 Cases to Show the Effects of Surface Moisture on Ground-Coupled Heat Transfer from a Slab-on-Grade.

\begin{tabular}{|r|l|l|}
\hline Case & Code & \multicolumn{1}{c|}{ Description } \\
\hline 1 & ssrfs & slab, summer, rain, full insulation, sandy loam \\
\hline 2 & ssdfs & slab, summer, dry, full insulation, sandy loam \\
\hline 3 & ssrns & slab, summer, rain, no insulation, sandy loam \\
\hline 4 & ssdns & slab, summer, dry, no insulation, sandy loam \\
\hline 5 & ssrfc & slab, summer, rain, full insulation, Yolo light clay \\
\hline 6 & ssdfc & slab, summer, dry, full insulation, Yolo light clay \\
\hline 7 & ssrnc & slab, summer, rain, no insulation, Yolo light clay \\
\hline 8 & ssdnc & slab, summer, dry, no insulation, Yolo light clay \\
\hline 9 & swrfs & slab, winter 2, rain, full insulation, sandy loam \\
\hline 10 & swdfs & slab, winter 2, dry, full insulation, sandy loam \\
\hline 11 & swrns & slab, winter 2, rain, no insulation, sandy loam \\
\hline 12 & swdns & slab, winter 2, dry, no insulation, sandy loam \\
\hline 13 & swrnc & slab, winter 2, rain, no insulation, Yolo light clay \\
\hline 14 & swdnc & slab, winter 2, dry, no insulation, Yolo light clay \\
\hline
\end{tabular}

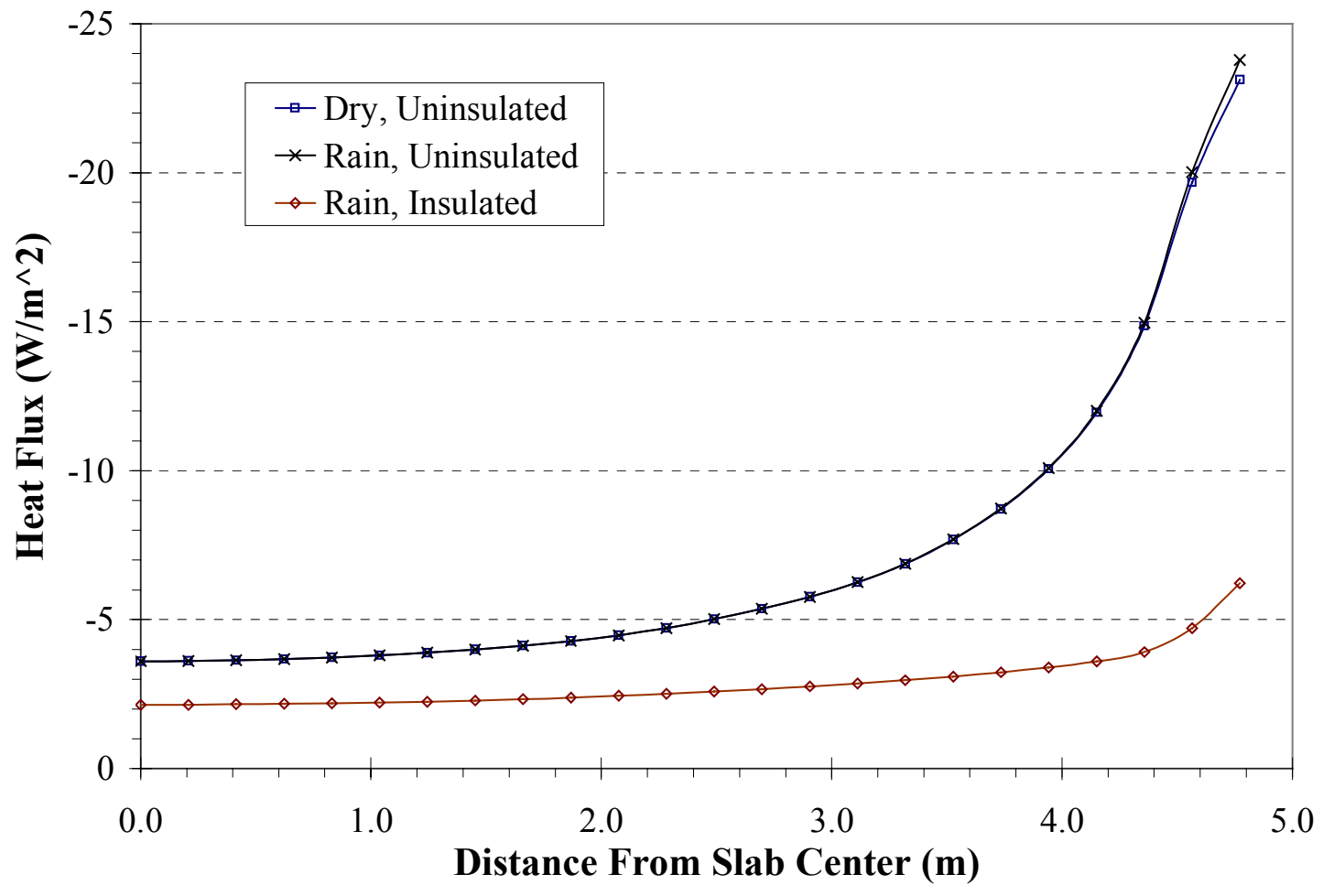

Figure 6.8. Heat flux across the slab-on-grade floor at 12:00 on day 14 for the sandy loam soil and winter conditions. 


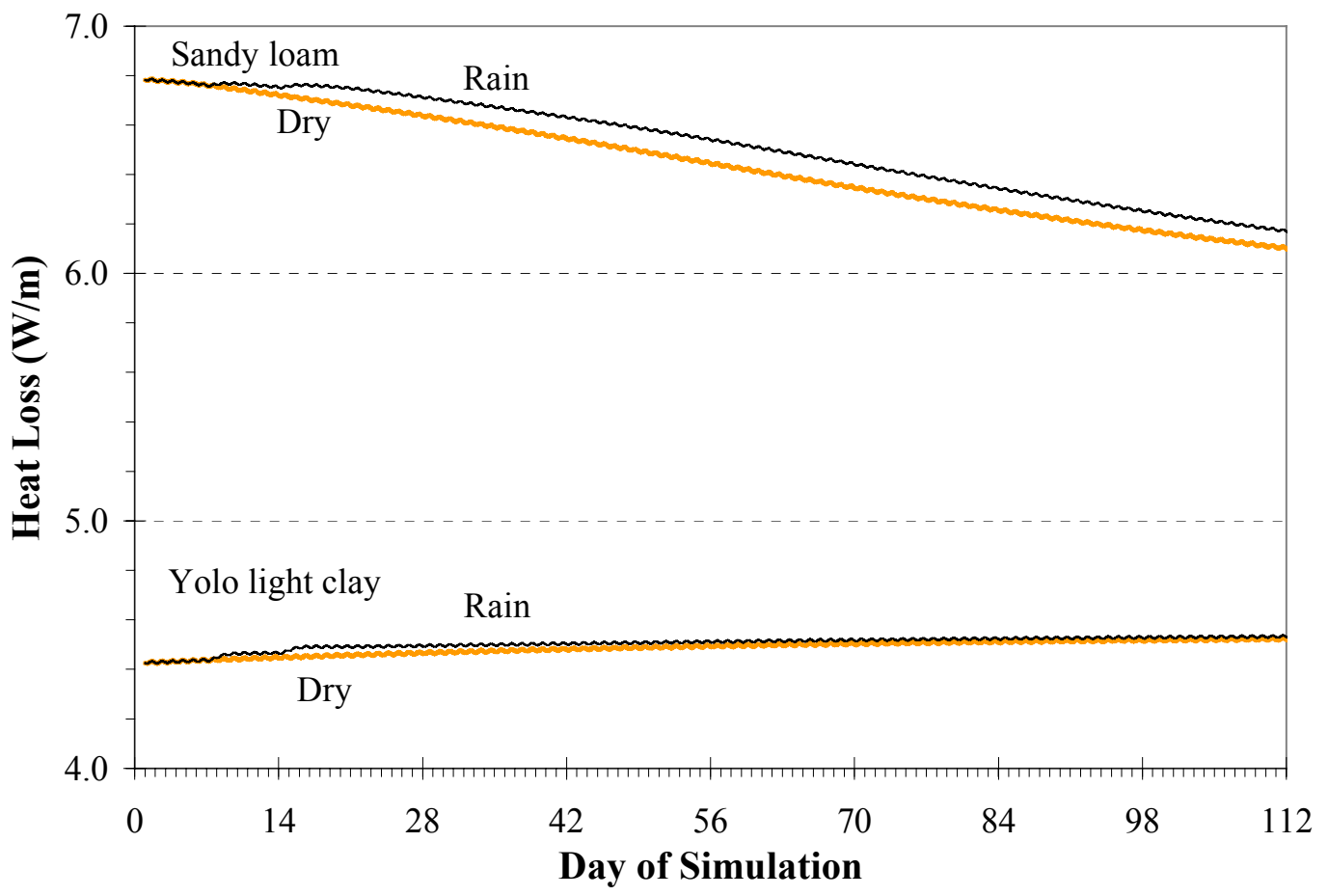

Figure 6.9. Hourly total heat loss for summer conditions from the insulated slab-on-grade for a sandy loam and a Yolo light clay for dry conditions and with $25 \mathrm{~mm}$ of rain added on days 7 and 14 .

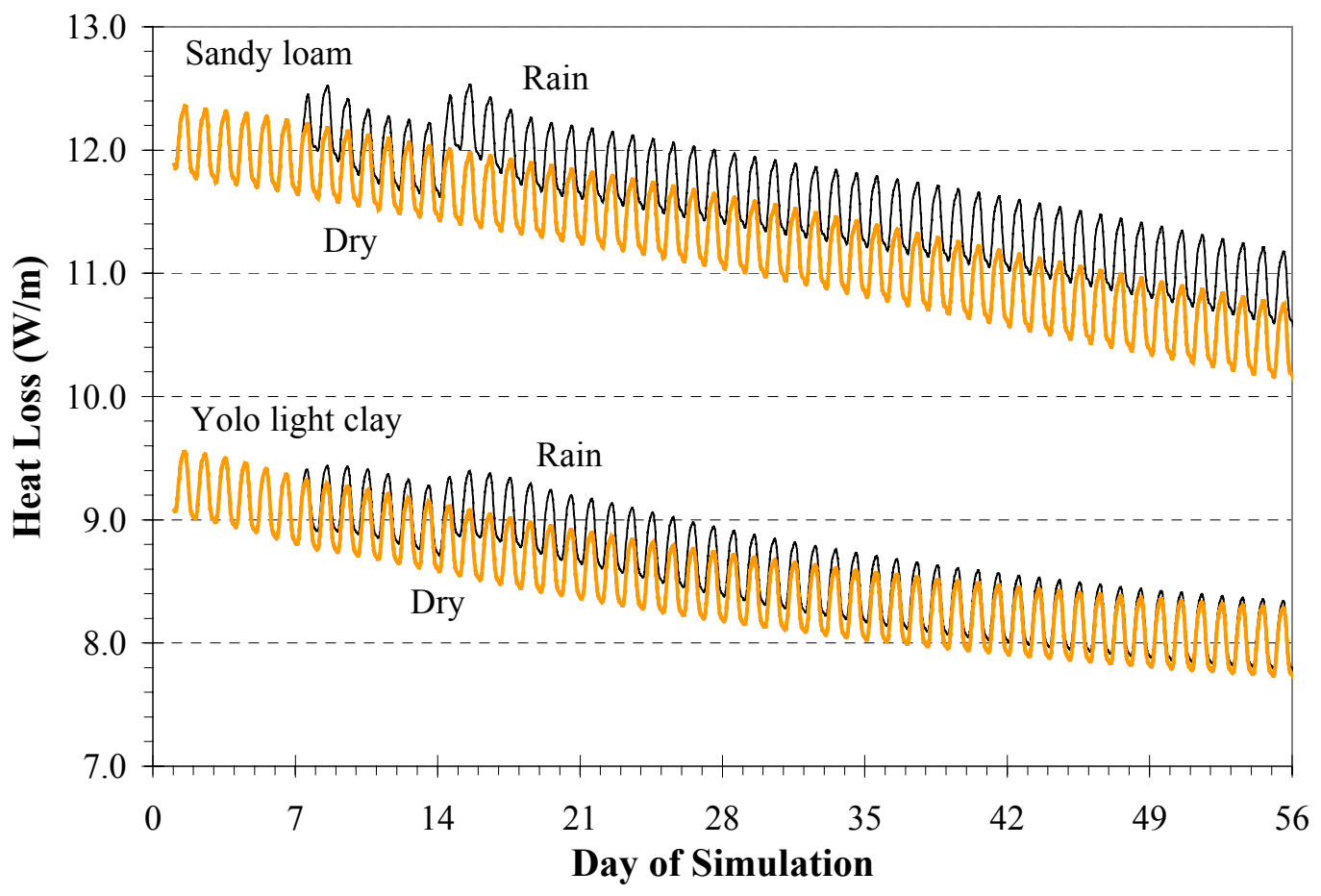

Figure 6.10. Hourly heat loss for summer conditions from the uninsulated slab-on-grade for a sandy loam and a Yolo light clay for dry conditions and with $25 \mathrm{~mm}$ of rain added on days 7 and 14 . 
A comparison of the heat loss for the rainy and dry cases for the uninsulated winter run with sandy loam soil is shown in Figure 6.11. The effect of the moisture addition is again obvious, but it is short-lived, and the two solutions converge. The percentage of change from the dry to the rainy cases is much smaller for the winter weather than for the summer weather. It is only $0.1 \%$ for the insulated sandy loam and $0.2 \%$ for the uninsulated sandy loam.

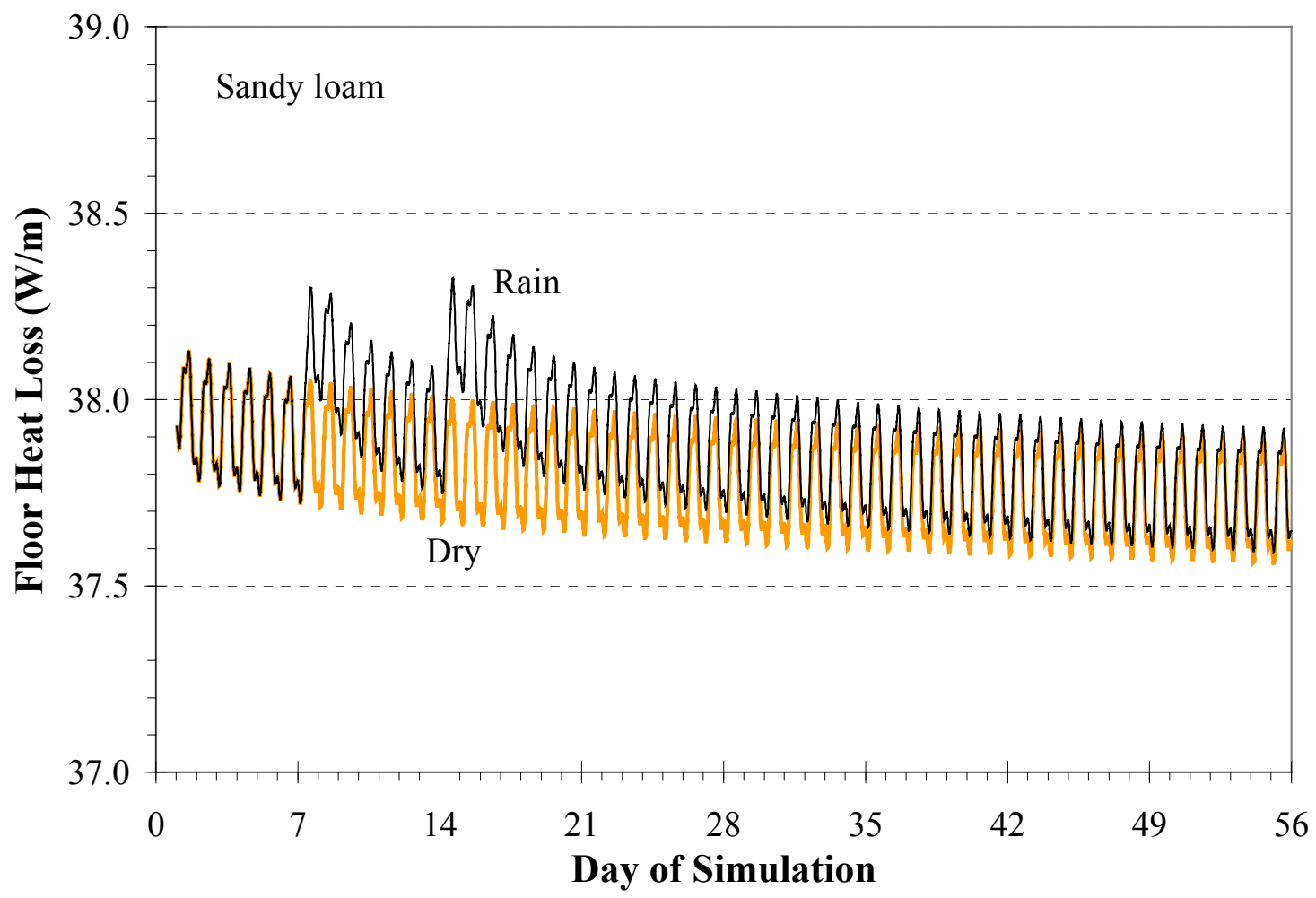

Figure 6.11. Hourly total heat loss for winter conditions from the uninsulated slab-on-grade with a sandy loam for the dry case and the case with $25 \mathrm{~mm}$ of rain added on days 7 and 14 .

\subsection{Effects of Surface Moisture on Basement Heat Transfer}

Basement walls are closely tied to the surface conditions and are therefore sensitive to additions of moisture at the surface. The heat transfer from basement floors is unaffected by short-term surface conditions, but is closely coupled to conditions in the deep ground below the building. The cases in Table 6.4 were used to study the effects of additional surface moisture on basement heat transfer. For the rainy cases, $50 \mathrm{~mm}$ of rain was added on day 7 of the simulations. 


\section{Table 6.4 Cases to Show Effects of Surface Moisture on Ground-Coupled Heat}

Transfer from Basements.

\begin{tabular}{|r|l|l|}
\hline \multicolumn{1}{|c|}{ Case } & \multicolumn{1}{|c|}{ Code } & \multicolumn{1}{c|}{ Description } \\
\hline \hline 15 & bsrfs & basement, summer, rain, full insulation, sandy loam \\
\hline 16 & bsdfs & basement, summer, dry, full insulation, sandy loam \\
\hline 17 & bsrns & basement, summer, rain, no insulation, sandy loam \\
\hline 18 & bsdns & basement, summer, dry, no insulation, sandy loam \\
\hline 19 & bwrfs & basement, winter, rain, full insulation, sandy loam \\
\hline 20 & bwdfs & basement, winter, dry, full insulation, sandy loam \\
\hline 21 & bwrns & basement, winter, rain, no insulation, sandy loam \\
\hline 22 & bwdns & basement, winter, dry, no insulation, sandy loam \\
\hline
\end{tabular}

For the summer conditions, the rain's effect on heat loss from the floor was small: the heat loss increased by less than $0.4 \%$ for the insulated and uninsulated configurations. The heat loss from the basement wall increased by $5.7 \%$ and $6.4 \%$ for the insulated and uninsulated cases, respectively. Figure 6.12 shows the daily wall heat loss for the four summer cases. Both the uninsulated and insulated walls show a jump in heat loss when rain is added and a slow convergence with the dry case. The gradual decrease in heat loss is caused by the soil drying out, which lowers the thermal conductivity. The insulation has a large effect on the overall results. The heat losses for the insulated basements for both the rainy and dry simulations were reduced by $50 \%$ for the floor, $66 \%$ for the wall, and $55 \%$ for the total. The wall insulation is slightly more effective for summer conditions and a 10-m water table depth.

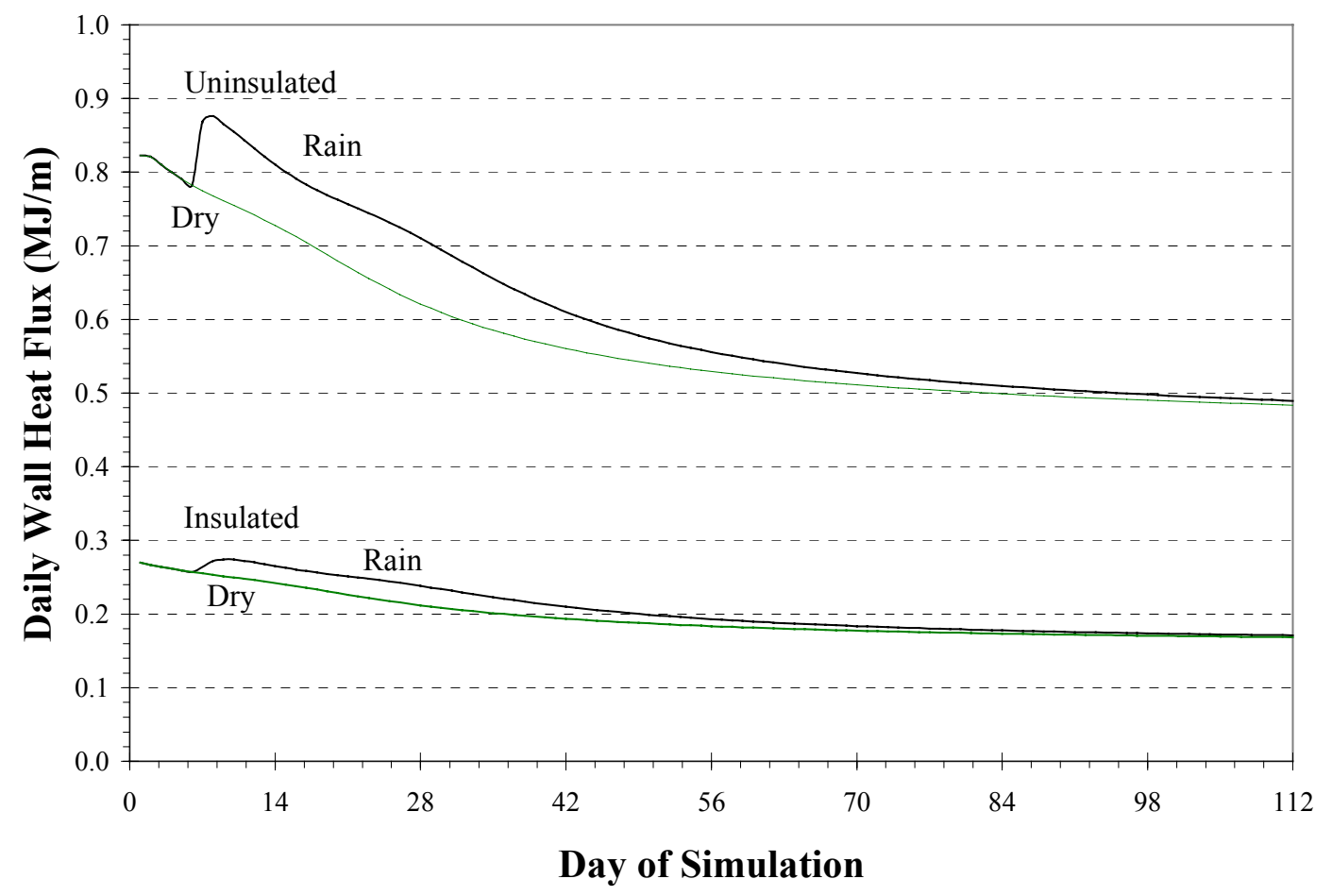

Figure 6.12. Daily basement wall heat losses for summer conditions over 112 days. 
The winter cases exhibited very little change when rain was added to the surface. In both the insulated and uninsulated cases, there was less than a $0.1 \%$ increase in the heat loss when rain was added. However, two results should be pointed out. First, the insulation on the basement wall is very effective in the winter cases, reducing the wall heat loss by over $73 \%$ and the total heat loss by $66 \%$. Second, the ratio of heat loss from the floor and the walls changes with the seasons. In the summer, approximately $70 \%$ of the heat loss is from the floor, but in the winter, it is only about $30 \%$ of the total.

The insulation configuration has a significant influence on the behavior of the heat transfer inside the basement wall. Figures 6.13 and 6.14 show the heat flux calculated at the wall surface nodes in the $\mathrm{x}$-direction for the rainy and dry cases and for the insulated and uninsulated cases. The heat loss for the uninsulated case is, of course, greater, and there is actually some heat gain late in the day around 6 p.m. There is very little variation in heat loss in both cases from the walls between the floor and $0.7 \mathrm{~m}$ below the ground surface.

Figures 6.15 and 6.16 show a similar set of graphs for the heat flux in the z-direction. The rain and dry results are nearly identical for the insulated case, so only the rainy case is shown in Figure 6.16. Two interesting points here are the large variation in the uninsulated case over the day near the top of the wall and the large heat flow in the negative z-direction in the insulated wall case. For the insulated wall and floor, there is a thermal bridge down the wall through the footing to the ground. Because the footing must support the weight of the building, it is difficult to insulate against this loss. The vertical heat loss from the bottom of the wall also causes a larger temperature gradient in the $\mathrm{x}$-direction around $0.4 \mathrm{~m}$ above the floor, as seen by the knee in Figure 6.14. 


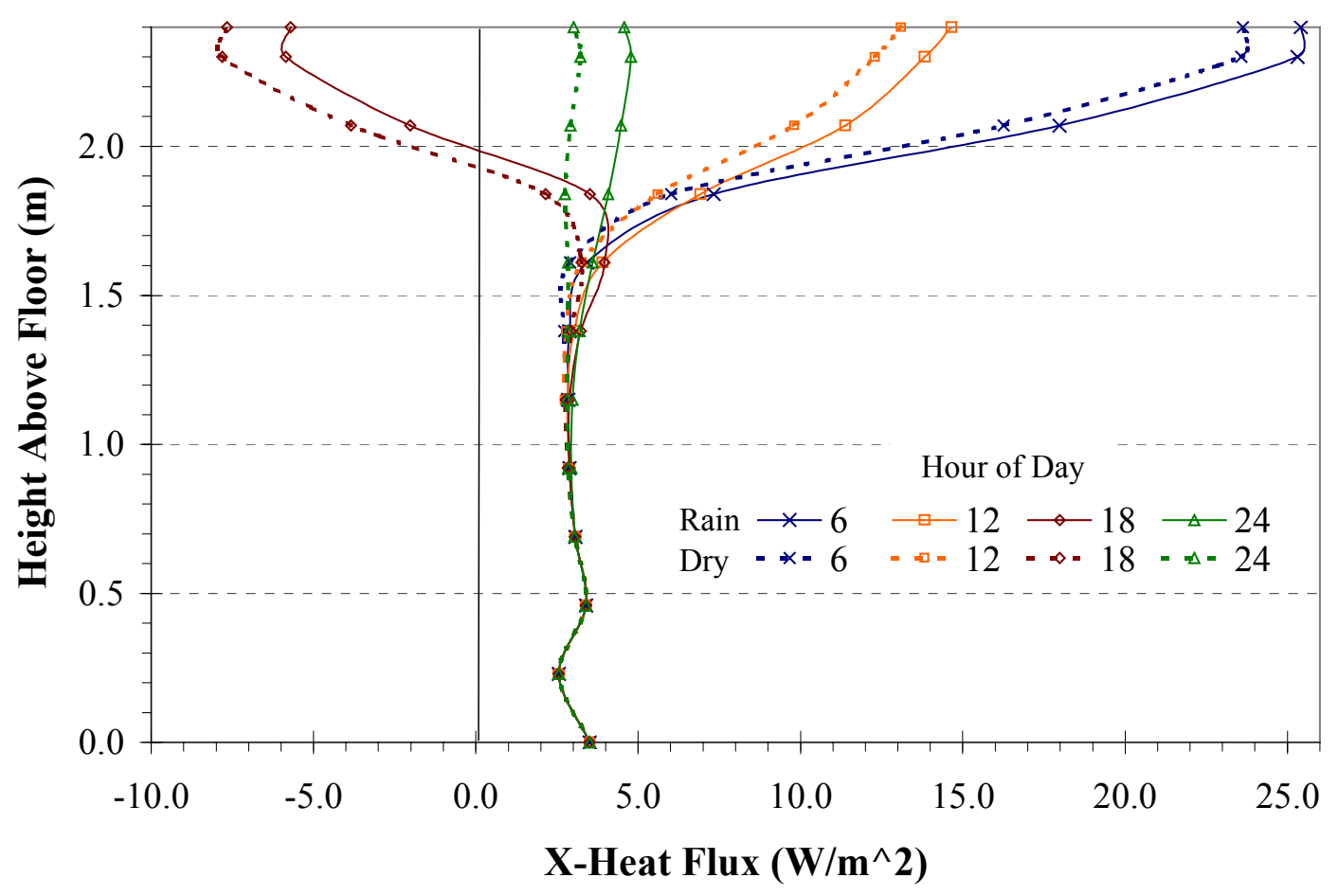

Figure 6.13. Basement wall heat flux in the x-direction for the uninsulated wall and summer conditions on day 8 of the simulation.

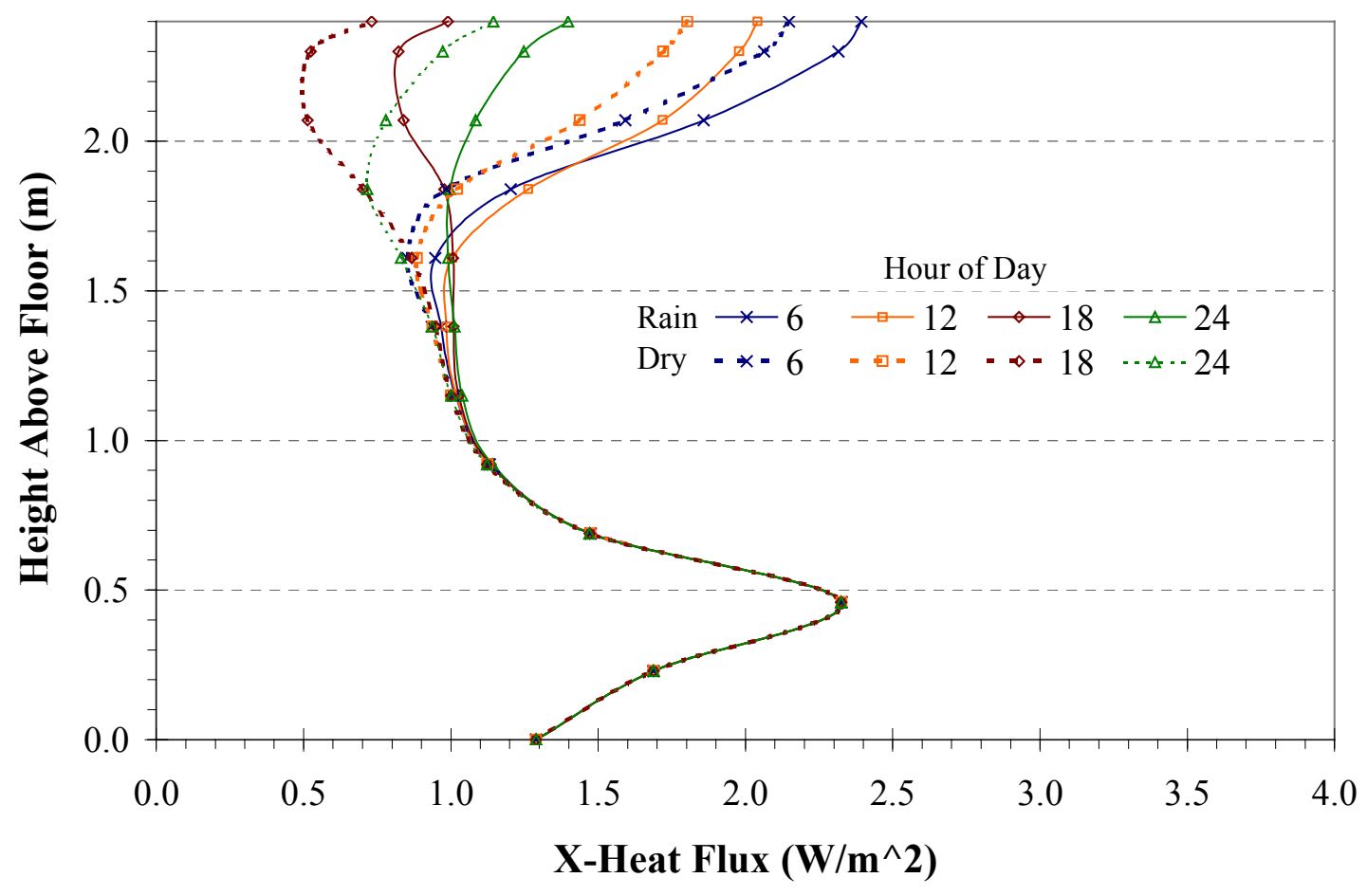

Figure 6.14. Basement wall heat flux in the $x$-direction for the insulated wall and summer conditions on day 8 of the simulation. 


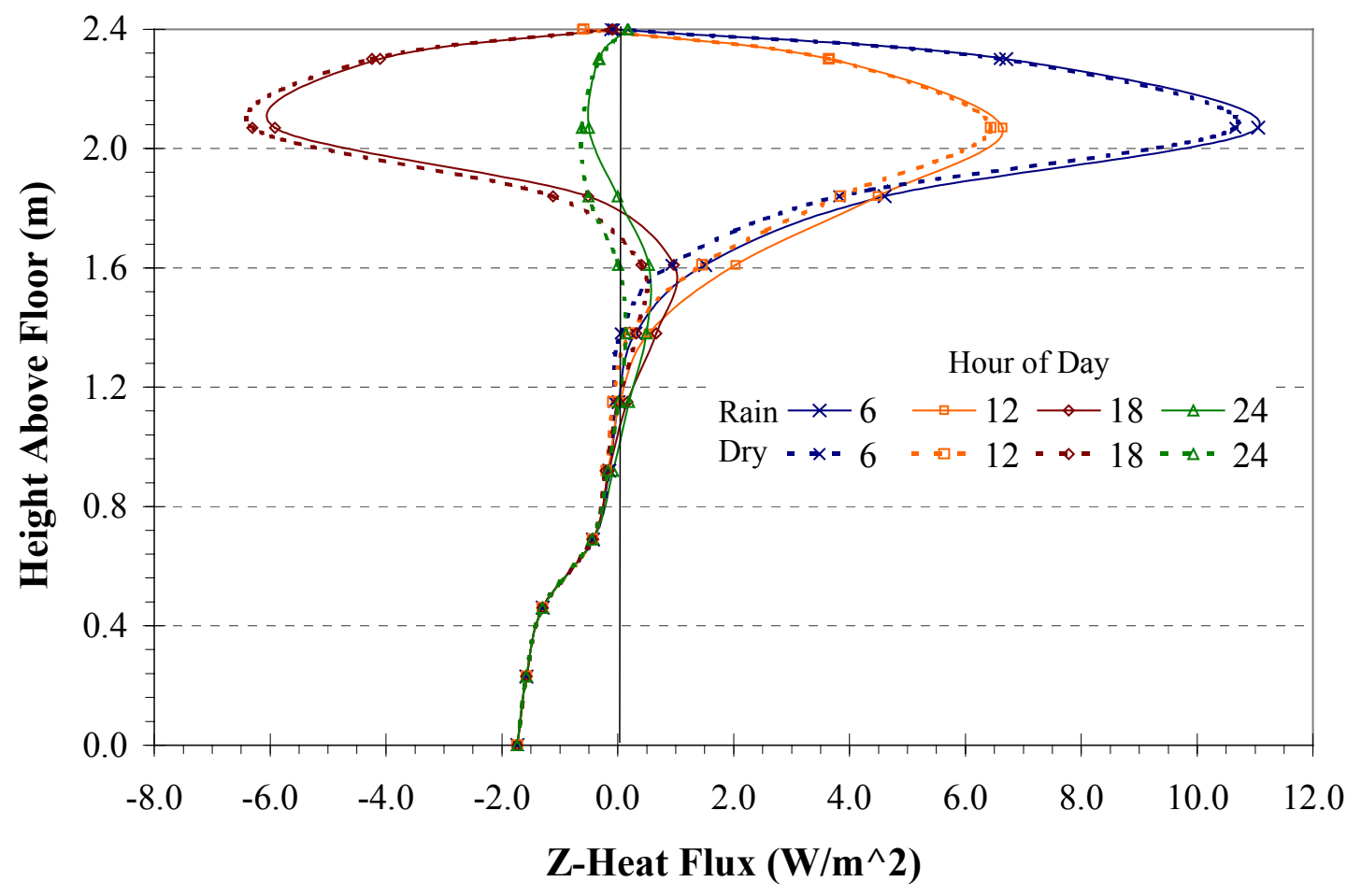

Figure 6.15. Basement wall heat flux in the z-direction for the uninsulated wall and summer conditions on day 8 of the simulation.

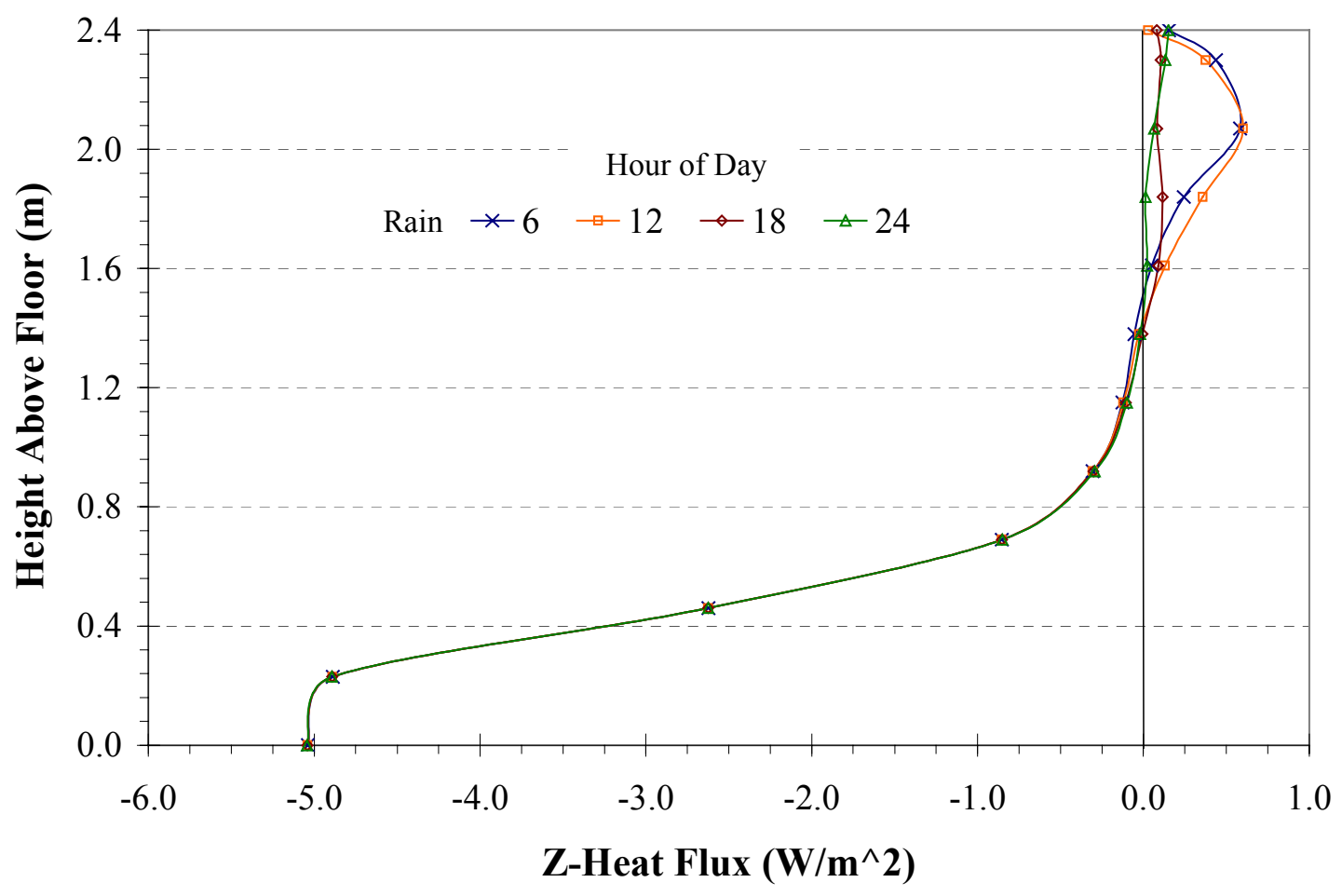

Figure 6.16. Basement wall heat flux in the z-direction for the insulated wall and summer conditions on day 8 of the simulation. 


\subsection{Effect of Groundwater Depth on Heat Transfer From a Basement}

Groundwater depth can have a large influence on the heat transfer from buildings, especially those with basements. Groundwater is usually modeled as a constant temperature boundary, which neglects the effect of the moisture. With a heat-and-moisture-transfer model, the groundwater can be modeled as a saturated boundary, which provides a source of moisture for the soil to draw from. To show the effects of groundwater depth on the heat transfer from a basement, the cases listed in Table 6.4 with no rain added were run with water-table depths of 5 $\mathrm{m}$ and $3 \mathrm{~m}$. The simulations from Section 6.5 assumed a water-table depth of $10 \mathrm{~m}$ at a temperature of $10^{\circ} \mathrm{C}$. For the case with a water table at $5 \mathrm{~m}$, the summer and winter temperatures of this boundary were $10^{\circ} \mathrm{C}$ and $7^{\circ} \mathrm{C}$. For the case with a water table at $3 \mathrm{~m}$, the summer and winter temperatures were $10^{\circ} \mathrm{C}$ and $5^{\circ} \mathrm{C}$, respectively.

The average daily wall heat loss, as a function of the groundwater depth below the basement floor, is shown in Figure 6.17. The water depth only has a small effect on the heat loss from the wall since it is more closely tied to the surface conditions. The most significant feature of this graph is the increase in the heat loss from the uninsulated wall in the winter, demonstrating the importance of insulating basement walls in cold climates.

Figure 6.18 shows the average daily heat loss from the basement floor with the depth of the water below the floor. The heat loss increases dramatically for the uninsulated cases as the groundwater nears the floor, regardless of the season. The affect on the insulated floors is very small. For uninsulated basement floors, uncertainty in the groundwater depth appears to be more important than the temperature of the groundwater when the water table is close to the floor. 


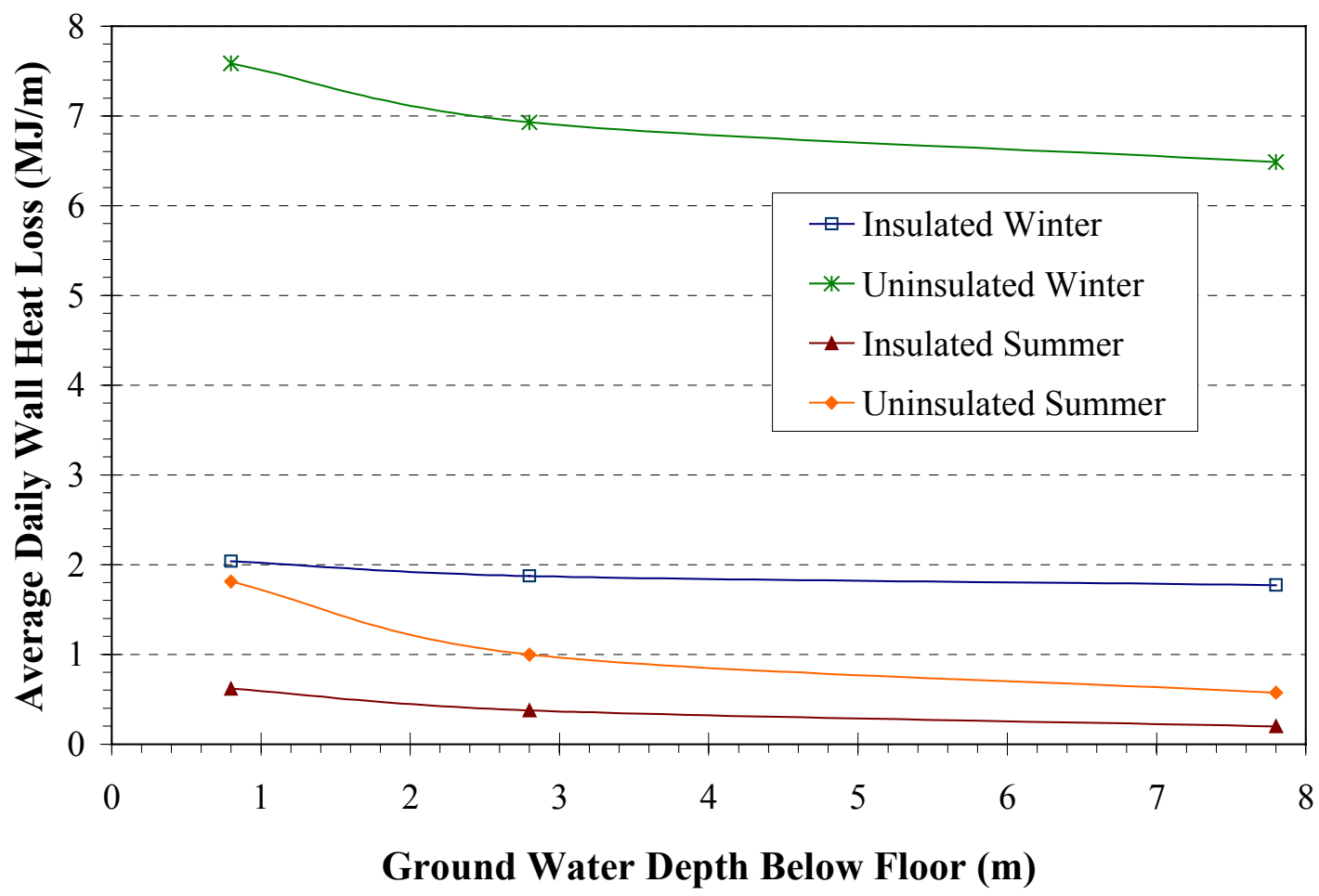

Figure 6.17. Average daily basement wall heat loss as a function of groundwater depth below the basement floor.

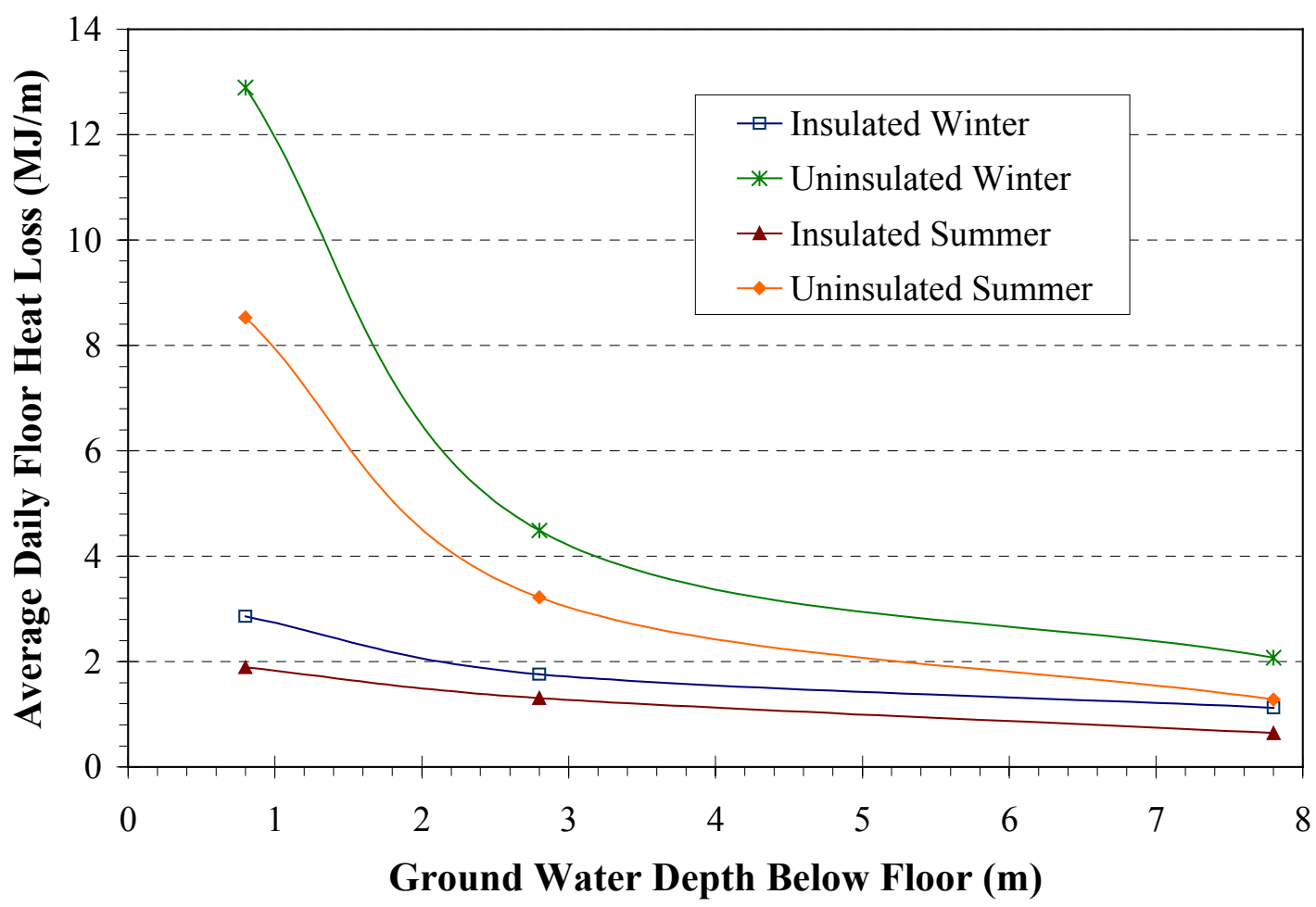

Figure 6.18. Average daily basement floor heat loss as a function of groundwater depth below the basement floor. 
Figure 6.19 shows the temperature contours for the three groundwater depths on day 46 of the winter cases. The contour plots of the effective soil thermal conductivity, as calculated by the de Vries method (1966) (see Chapter 3), are shown in Figure 6.20. From these contour plots, it is easy to see why the groundwater depth can have a large impact on basement floor heat losses. The temperature gradient immediately beneath the basement floor for the $3-\mathrm{m}$ case is roughly 8 times the value of the 10-m case, and the effective thermal conductivity of the soil is approximately 1.3 times larger due to the higher soil moisture content. The combination of these two effects produces the dramatic increase in the heat loss from the basement floor. The effect on the heat loss from the basement wall is much smaller, because the basement wall heat loss is driven more by the surface conditions than by the deep ground conditions.

\subsection{Effect of Buildings on the Soil Moisture Field}

A contour plot of the soil volumetric moisture content surrounding an uninsulated basement for the summer case with ground water at $10 \mathrm{~m}$ is presented in Figure 6.21 . This plot shows that the presence of the basement has little affect on the moisture distribution in the soil. All of the cases simulated in this work exhibited a similar behavior, demonstrating that a change in soil moisture content, and thus a change in thermal conductivity with depth around a building, may be approximated by a one-dimensional column of soil, which is much easier to simulate. The variation in thermal conductivity with depth can be used in a heat-transfer-only program, which is much faster, to approximate the ground-coupled heat transfer for complicated geometries. 

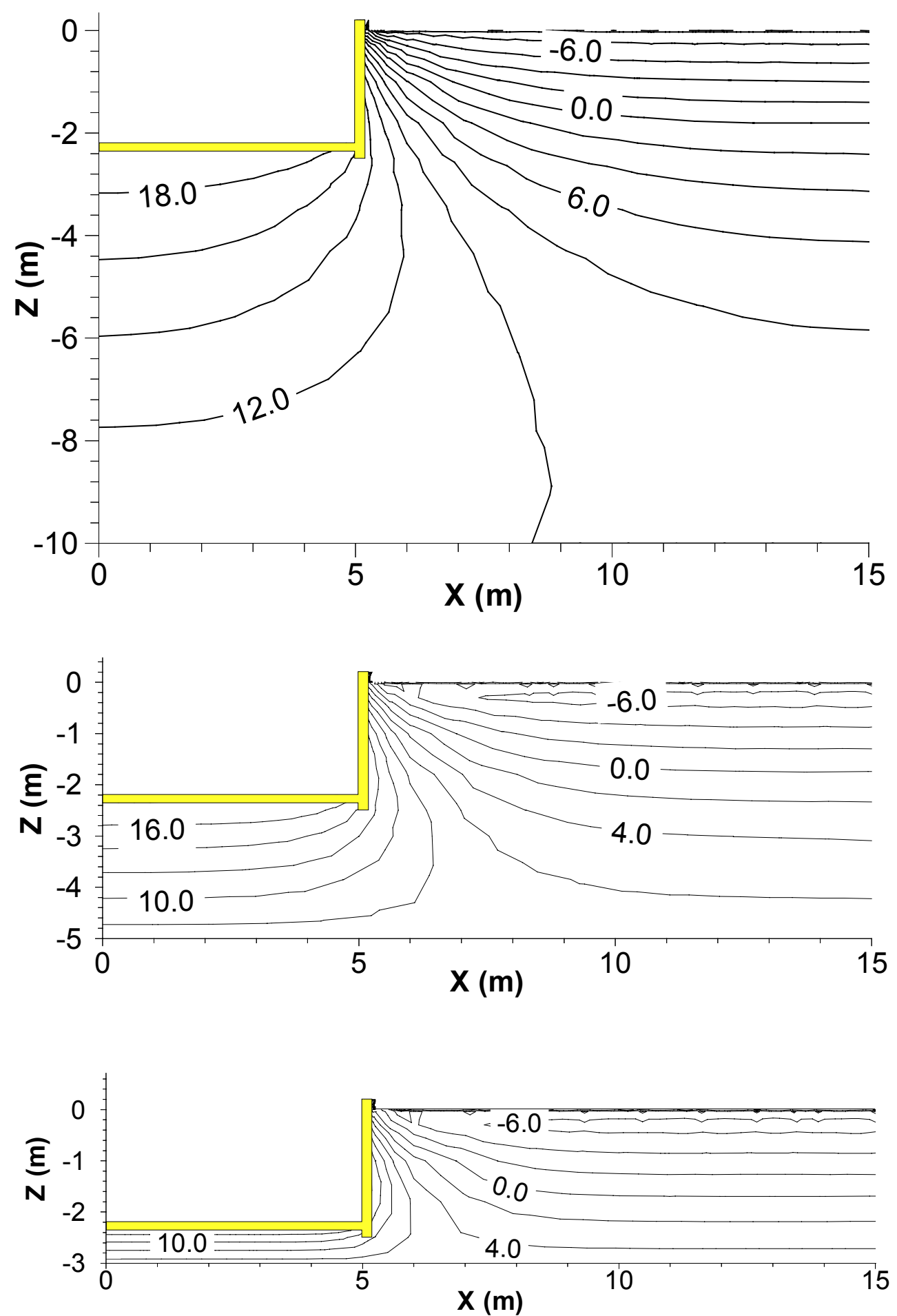

Figure 6.19. Temperature contours $\left({ }^{\circ} \mathrm{C}\right)$ for uninsulated basements on day 46 of simulations with winter conditions, sandy loam soil, and ground water depths of $-10 \mathrm{~m},-5 \mathrm{~m}$, and $-3 \mathrm{~m}$. 

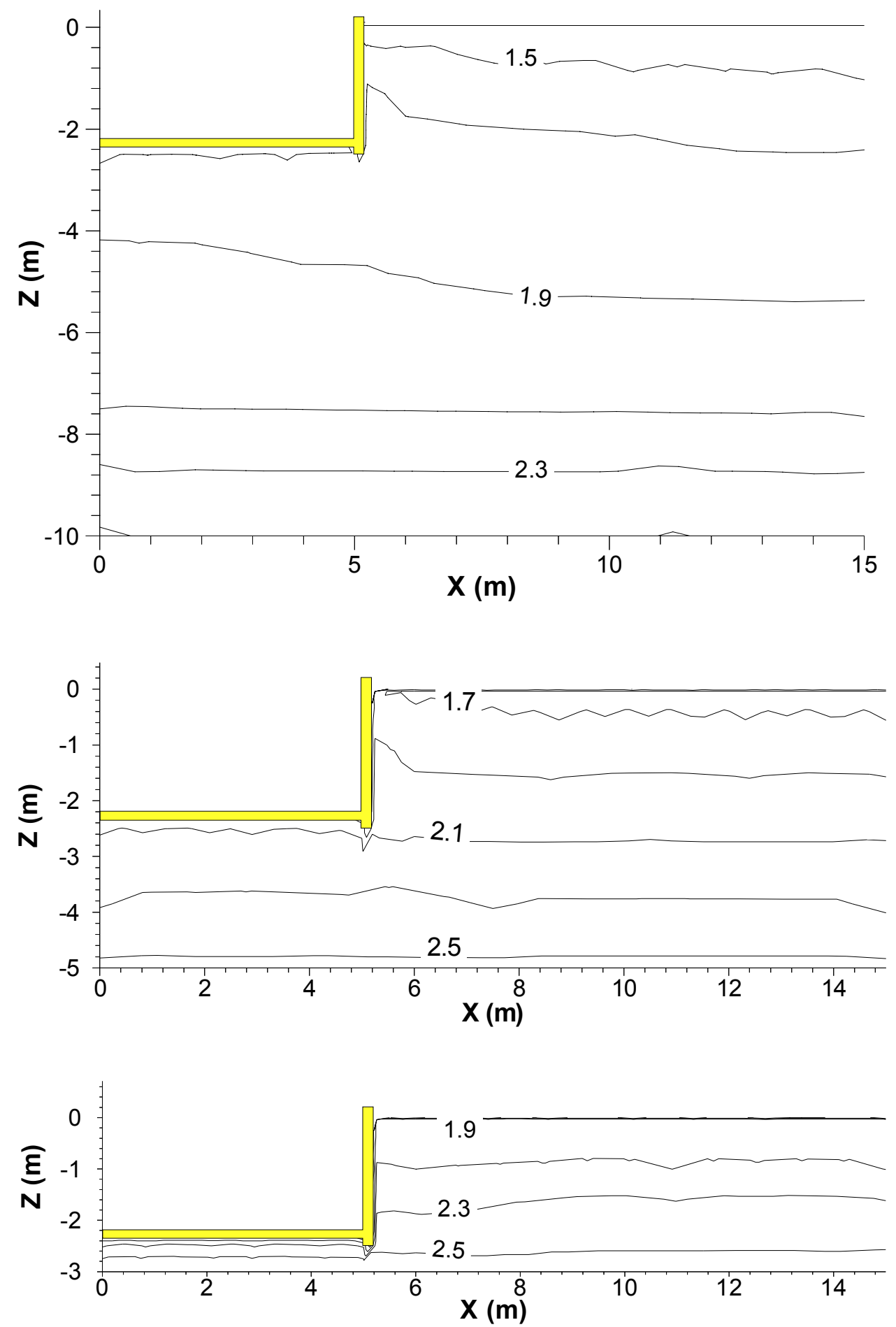

Figure 6.20. Contours of the effective thermal conductivity $(\mathrm{W} / \mathrm{m} \cdot \mathrm{K})$ for an uninsulated basement on day 46 of simulations with winter conditions, sandy loam soil, and ground water depths of $-10 \mathrm{~m},-5$ $\mathrm{m}$, and $-3 \mathrm{~m}$. 


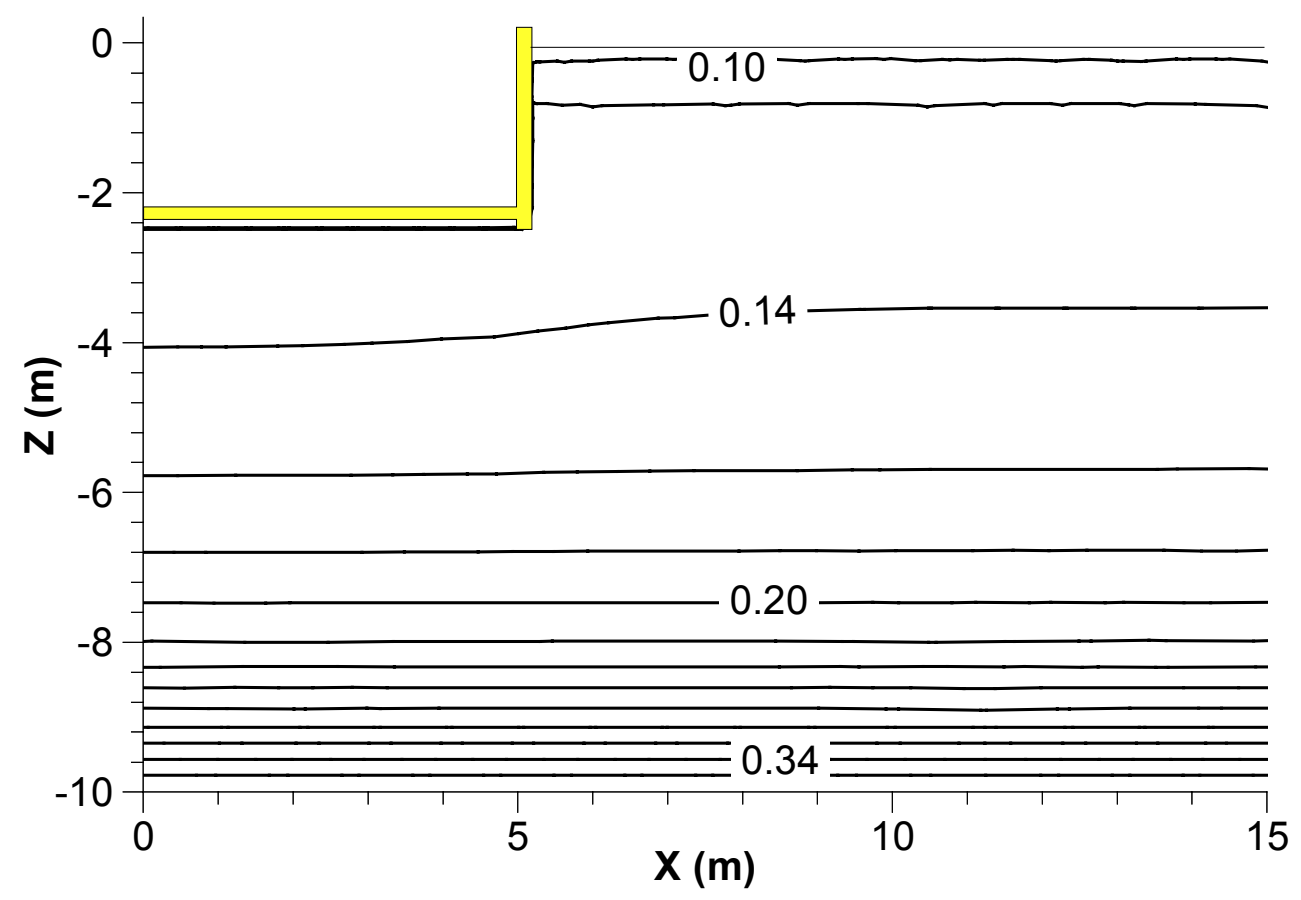

Figure 6.21. Contours of the soil volumetric moisture content for an uninsulated basement.

\subsection{Effect of Freezing on Heat Transfer From a Basement}

To determine the effect of the freezing phase change on the heat transfer from a basement, the winter case - with no insulation and a 5-m water-table depth - was run with the freezing model turned off in GHAMT. There was no change in the heat loss from the floor and only a $2.8 \%$ increase in the heat loss from the wall over the 56 days of the simulation. This result suggests that the effect of soil freezing is small and a simple freezing model can be used without a large penalty.

\subsection{Comparison of the Heat and Moisture Transfer Model with a Heat Transfer Model}

The results from the heat-and-moisture transfer program GHAMT were compared with the results from the heat-transfer program GHT2D. The objective was to study how soil conditions and daily heat transfers vary with annual weather patterns and to determine if a heat-conduction model can account for these variations. Annual simulations were completed with River Rock sandy clay loam and the basement geometry shown in Figure 6.7, with the lower boundary set at $\mathrm{z}=-5.0 \mathrm{~m}$. Insulation with $\mathrm{R}=1.7 \mathrm{~m}^{2} \cdot \mathrm{K} / \mathrm{W}$ was added to the outside of the basement wall extending $1.2 \mathrm{~m}$ down from the top of the wall. The boundary conditions for the bottom boundary were a constant temperature, $\mathrm{T}=10^{\circ} \mathrm{C}$, and saturated soil, $\psi=0.0 \mathrm{~m}$. The indoor conditions were a constant temperature, $\mathrm{T}=20^{\circ} \mathrm{C}$, with a convective heat transfer coefficient of $\mathrm{h}=6.0 \mathrm{~W} / \mathrm{m}^{2} \cdot \mathrm{K}$ for the floor and $\mathrm{h}=8.3 \mathrm{~W} / \mathrm{m}^{2} \cdot \mathrm{K}$ for the wall. The boundaries along the sides of 
the domain were modeled as impermeable adiabatic surfaces. The ground surface had a vegetation height of $\mathrm{z}_{\mathrm{veg}}=10 \mathrm{~cm}$, an infrared emissivity of $\varepsilon=0.9$, and a reflectivity of $\rho=0.23$. The weather data was measured in 1999 in Fort Collins, Colorado. Cloud cover information was not included in this data set; therefore, opaque cloud cover was only modeled during hours with precipitation, then tapered off for 2 hours following the rain. The weather data set used here includes the data set used in Section 5.5 for the model validation. To obtain the initial conditions, the models were run for 1 year starting with the temperature and moisture distributions from the winter cases run in Section 6.6. For both models, the time step was 30 minutes, except during periods of rain, where GHAMT used a time step of 1 minute to avoid instabilities. The runtimes for annual simulations on a Pentium III, $600 \mathrm{Mhz}$ computer were 3.5 hours for GHAMT and 10 minutes for GHT2D. Both models could be faster with some code optimization, but the heat-andmoisture transfer model is obviously much more computationally intensive.

The annual results from the two models are listed in Table 6.5. Seven simulations were completed with the heat-conduction model using various soil thermal conductivity values and evapotranspiration levels. The evapotranspiration level is determined by the ratio of the actual evapotranspiration and the potential evapotranspiration, $K_{\text {evap. }}$. Potential evapotranspiration is the maximum value, which occurs when the surface remains saturated and the vapor pressure is at saturation. This situation only occurs when the surface is near saturation.

The first case uses the soil thermal conductivity at the critical moisture content $\theta_{\mathrm{k}}=0.09$, which is approximately the wilting point of this soil and is the value at the knee in the thermal conductivity curve shown in Figure C.4. The total heat transfer was $13.7 \%$ below the results from the heat-and-moisture transfer model. To improve these results, a second thermal conductivity value was estimated by comparing the total heat transfer from the first heat transfer case with the results from the heat-and-moisture transfer model. Assuming the heat-and-moisture transfer model provides the benchmark value, a rough estimate of the thermal conductivity can be calculated from:

$$
\begin{aligned}
\mathrm{k}_{2} & =\frac{\mathrm{Q}_{2}}{\mathrm{Q}_{1}} \mathrm{k}_{1} \\
& =\frac{1730}{1493} 1.75 \\
& =2.03
\end{aligned}
$$

The results from the second case were much better. However, most of the improvement was in predicting the floor heat loss; the wall heat loss did not improve as much.

A common practice is to use seasonal soil thermal conductivity values to represent the seasonal change in soil moisture content. The third case does this with a summer value of $\mathrm{k}_{\text {sum }}=2.2$ $\mathrm{W} / \mathrm{m} \cdot \mathrm{K}$ and a winter value of $\mathrm{k}_{\mathrm{win}}=2.03 \mathrm{~W} / \mathrm{m} \cdot \mathrm{K}$. Again, this improved the results for the floor heat loss but not for the wall value. Another frequently used technique is to vary the soil thermal conductivity with soil depth. The fourth case used a thermal conductivity value of $\mathrm{k}_{\text {top }}=2.03$ $\mathrm{W} / \mathrm{m} \cdot \mathrm{K}$ for the soil above the basement floor and $\mathrm{k}_{\text {deep }}=2.1 \mathrm{~W} / \mathrm{m} \cdot \mathrm{K}$ for the soil below the basement floor level. This improves the prediction of the floor heat loss but, again, does not improve the wall heat-loss prediction. The value of the soil thermal conductivity does not have a 
strong effect on the heat loss predictions from the basement wall. One cause for this is the effect of evapotranspiration on the surface temperature.

The last three cases investigate the effect of evapotranspiration. The fifth and sixth cases use a soil thermal conductivity of $\mathrm{k}=1.75 \mathrm{~W} / \mathrm{m} \cdot \mathrm{K}$ and evapotranspiration ratios of 1.0 and 0.5 . The wall heat loss with potential evapotranspiration is greater than the value from the heat-andmoisture transfer model by $11.2 \%$, and the floor heat loss is only slightly improved over the previous cases. When the evapotranspiration is half the potential value, the wall heat loss is only $1 \%$ more than the heat-and-moisture transfer model value. The last case attempts to model the physical effects occurring at the wall and the floor by varying the thermal conductivity with depth and using an evapotranspiration ratio of 0.5 . The two soil thermal conductivity values were chosen from the results of the heat-and-moisture transfer model as the approximate average of the effective soil thermal conductivity in the regions near the wall and the floor. This combination produced results that agree with the heat-and-moisture transfer model very well, differing by only $1.2 \%$ for the floor, $2.4 \%$ for the wall, and $1.6 \%$ overall.

\section{Table 6.5.Annual Heat Loss for a Half-Width Basement from GHAMT and GHT2D per Unit Length of Perimeter.}

\begin{tabular}{|c|c|c|c|c|c|c|c|}
\hline \multirow{3}{*}{$\begin{array}{c}\begin{array}{c}\text { Soil Thermal } \\
\text { Conductivity }\end{array} \\
\mathrm{W} / \mathrm{m} \cdot \mathrm{K}\end{array}$} & \multirow{3}{*}{$K_{\text {evap }}$} & \multicolumn{6}{|c|}{ Annual Heat Loss } \\
\hline & & \multicolumn{2}{|c|}{ Floor } & \multicolumn{2}{|c|}{ Wall } & \multicolumn{2}{|c|}{ Total } \\
\hline & & $\mathbf{M J} / \mathbf{m}$ & $\begin{array}{c}\% \\
\text { diff }\end{array}$ & $\mathbf{M J} / \mathbf{m}$ & $\%$ diff & $\mathbf{M J} / \mathbf{m}$ & $\%$ diff \\
\hline Heat \& moisture model & $\mathrm{n} / \mathrm{a}$ & $1,203.4$ & $\mathrm{n} / \mathrm{a}$ & 526.7 & $\mathrm{n} / \mathrm{a}$ & $1,730.0$ & $\mathrm{n} / \mathrm{a}$ \\
\hline $\mathrm{k}=1.75$ & 0.0 & $1,045.1$ & -13.2 & 448.2 & -14.9 & $1,493.3$ & -13.7 \\
\hline $\mathrm{k}=2.03$ & 0.0 & $1,171.1$ & -2.7 & 480.7 & -8.7 & $1,651.8$ & -4.5 \\
\hline $\mathrm{k}_{\mathrm{sum}}=2.2, \mathrm{k}_{\mathrm{win}}=2.03$ & 0.0 & $1,196.4$ & -0.6 & 487.1 & -7.5 & $1,683.5$ & -2.7 \\
\hline $\mathrm{k}_{\mathrm{top}}=2.03, \mathrm{k}_{\text {deep }}=2.1$ & 0.0 & $1,200.8$ & -0.2 & 481.3 & -8.6 & $1,682.1$ & -2.8 \\
\hline $\mathrm{k}=1.75$ & 1.0 & $1,075.3$ & -10.6 & 585.9 & 11.2 & $1,661.2$ & -4.0 \\
\hline $\mathrm{k}=1.75$ & 0.5 & $1,064.3$ & -11.6 & 532.0 & 1.0 & $1,596.3$ & -7.7 \\
\hline $\mathrm{k}_{\mathrm{top}}=1.75, \mathrm{k}_{\text {deep }}=2.1$ & 0.5 & $1,218.4$ & 1.2 & 539.3 & 2.4 & $1,757.7$ & 1.6 \\
\hline
\end{tabular}

To examine the seasonal variations, the daily heat loss for each case is graphed in Figures 6.22 to 6.24. The graph of wall heat loss in Figure 6.22 illustrates the effect of evapotranspiration, which peaks in the summer as expected. The first case, with no evapotranspiration, predicts a small heat gain in the summer and closely models the winter heat loss; the case with $\mathrm{K}_{\text {evap }}=1.0$ overpredicts the heat loss; and the case with $\mathrm{K}_{\text {evap }}=0.5$ correctly predicts the heat loss in the summer, but slightly over-predicts the heat loss in the winter. Notice that the case with the increased soil thermal conductivity and $\mathrm{K}_{\text {evap }}=0.0$ exhibits similar behavior in the summer as the case with $\mathrm{k}_{\text {soil }}$ $=1.75 \mathrm{~W} / \mathrm{m} \cdot \mathrm{K}$, showing the importance of modeling the evapotranspiration effects.

The heat loss from the floor is shown in Figure 6.23. The case with seasonal thermal conductivities matched the annual floor heat loss predicted by the heat-and-moisture transfer model very closely, but did not match the daily variations well. The step changes in the soil thermal conductivity produced corresponding step changes in the daily heat loss. A much better result was obtained by increasing the thermal conductivity of the soil beneath the basement floor. The soil properties at this depth do not change appreciably with the seasonal changes at the 
surface. A large influx of water can penetrate to this depth, but the effect is small, as can be seen by the small bump in the heat-and-moisture transfer model results around day 125 in Figure 6.23.

The total heat loss in Figure 6.24 shows that accurate results can be obtained with the heat transfer model by using a soil thermal conductivity that varies with depth and by estimating the correct amount of evapotranspiration. Estimating the amount of evapotranspiration can be difficult. The amount of evapotranspiration will be close to the potential value if the ground is kept moist all of the time. If the soil is bare and dry, then there will be very little evapotranspiration. Selecting a value halfway between is a compromise that works very well for the situations studied in this report. If there is a large change in the evapotranspiration between summer and winter, it may be better to use a seasonal value of $\mathrm{K}_{\text {evap}}$; however, the winter evapotranspiration is small due to the colder temperatures and lower solar radiation, so the error of using a constant $\mathrm{K}_{\text {evap }}$ is small.

This comparison shows that the heat-conduction model can perform very well if the correct soil thermal conductivity value is known and if the effects of evapotranspiration are included. Classifying the soil and its properties is a weakness in both models; however, the heat-andmoisture transfer model can provide more insight into the effects of temperature and moisture content. With a rough knowledge of the soil composition, a user could select one of the five soil types in GHAMT and determine an effective soil thermal conductivity to use with a heat-transfer model. This thermal conductivity value can then be used with more confidence on complicated geometries with the heat-transfer program. Another approach would be to use GHAMT to develop guidelines for selecting a thermal conductivity for various soils and locations.

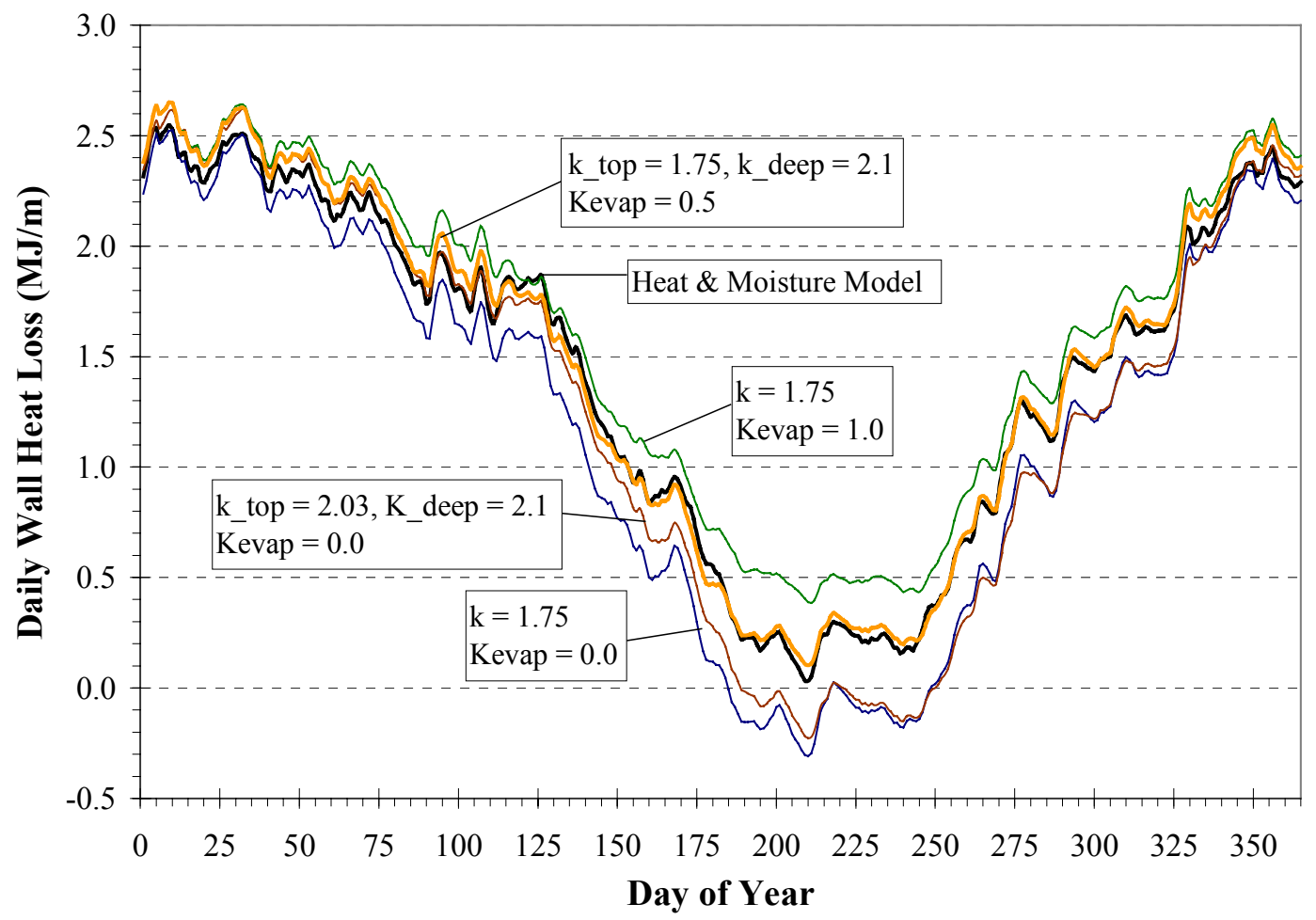

Figure 6.22. Daily basement-wall heat loss predicted by GHAMT and GHT2D. 


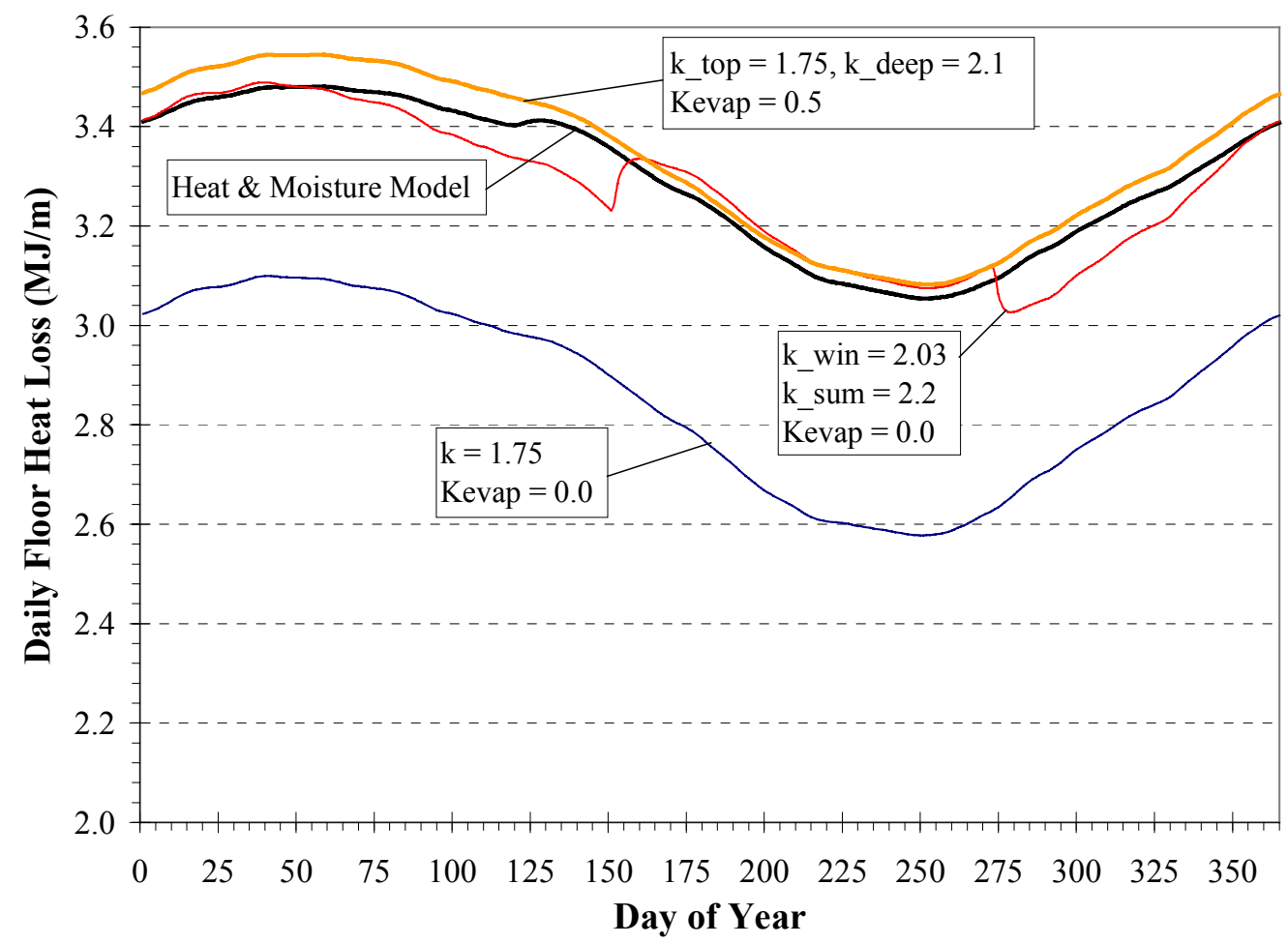

Figure 6.23. Daily basement-floor heat loss predicted by GHAMT and GHT2D.

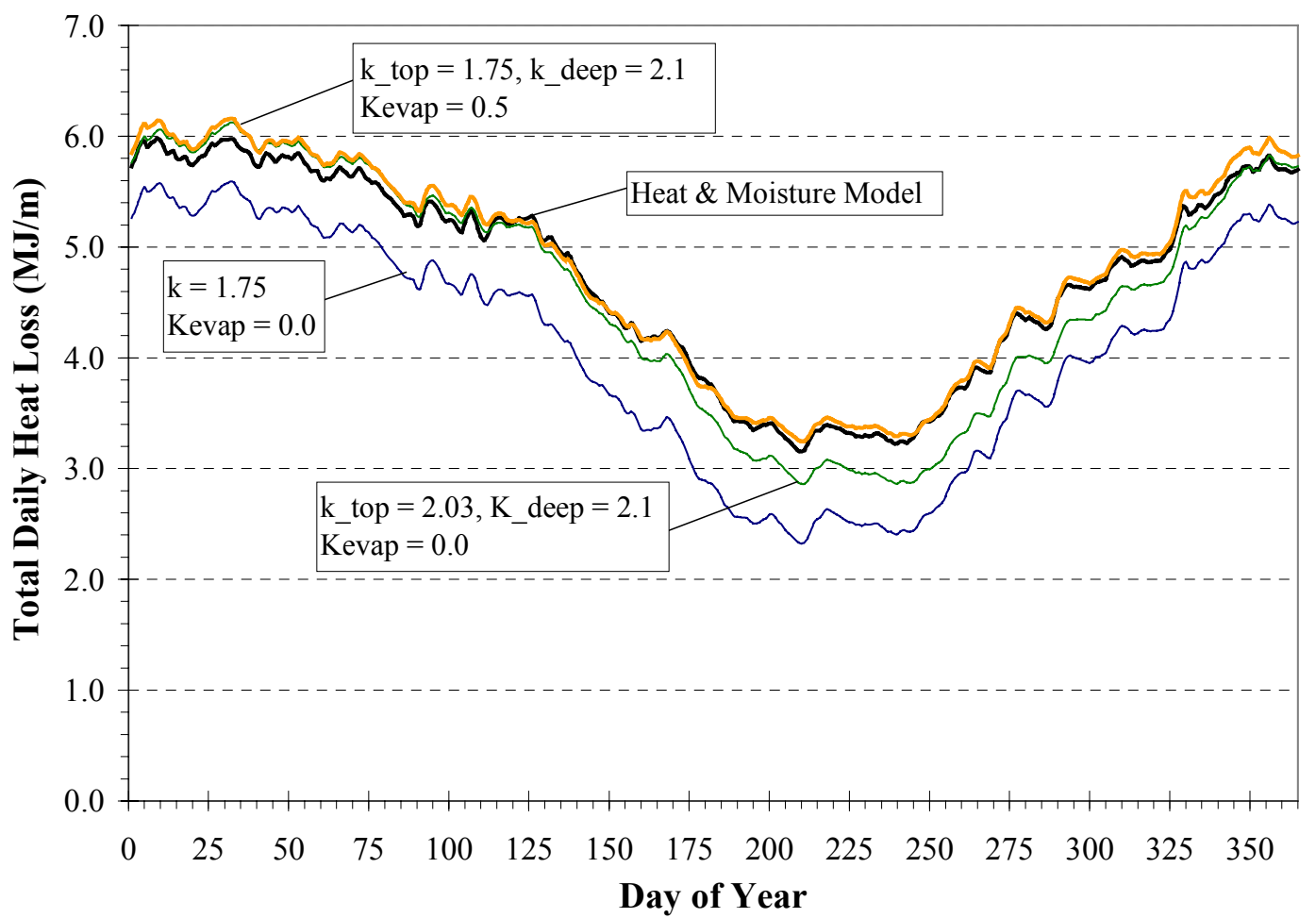

Figure 6.24. Daily total basement heat loss predicted by GHAMT and GHT2D. 


\subsection{Comparison of the Heat Transfer Model with the Mitalas Method}

The monthly heat loss values calculated by the Mitalas method (1982 and 1987) were compared to the heat loss from the two-dimensional heat transfer model, GHT2D, for the basement geometry shown in Figure 6.7. Simulations were completed for a basement with no insulation and with $\mathrm{R}=1.74 \mathrm{~m}^{2} \cdot \mathrm{K} / \mathrm{W}$ insulation over the entire height of the wall. The soil thermal conductivity was $1.8 \mathrm{~W} / \mathrm{m} \cdot \mathrm{K}$ for the portion above the basement floor and $2.0 \mathrm{~W} / \mathrm{m} \cdot \mathrm{K}$ below the basement floor. Calculations were completed with evapotranspiration ratios of $\mathrm{K}_{\text {evap }}=0.5$ and $\mathrm{K}_{\text {evap }}=1.0$. The weather data for Fort Collins used in the previous section was used again for this simulation. The basement air temperature was held constant at $20^{\circ} \mathrm{C}$.

Mitalas developed a series of shape factors called Basement Heat Loss Factors for various geometries and soil conditions based on hundreds of two- and three-dimensional simulations. There are two types of shape factors: one for the annual mean value of the heat loss, and one for the periodic component of the heat loss. The mean value of the heat loss is related to the mean indoor and outdoor air-temperature difference, and the periodic value is related to the amplitude of the first harmonic of the annual outdoor air temperature. These temperatures were determined with GHT2D to be $10^{\circ} \mathrm{C}$ and $12^{\circ} \mathrm{C}$, respectively. The Mitalas method uses corner correction factors to adjust the two-dimensional calculated values for the three-dimensional effects of heat transfer from a real basement. These correction factors were not used for this comparison, and the heat transfer values were calculated per meter of perimeter.

The annual heat-loss predictions for each case are shown in Table 6.6. The values differ by up to $32 \%$, with the largest difference in the wall heat loss. The difference in the total heat-loss prediction varies from $11.4 \%$ to $18.0 \%$. It is difficult to determine the source of the disagreements, because Mitalas does not give many details on the numerical model and the assumptions used to develop the basement heat loss factors. We assume that some of the differences arise from the treatment of the ground surface boundary condition since this is the most complicated and was probably greatly simplified in the Mitalas models.

Table 6.6. Annual Heat Loss for a Half-Width Basement from the Mitalas Method and GHT2D per Unit Length of Perimeter.

\begin{tabular}{|c|c|c|c|c|c|c|c|}
\hline \multirow{3}{*}{ Model } & \multirow{3}{*}{$\mathbf{K}_{\text {evap }}$} & \multicolumn{6}{|c|}{ Annual Heat Loss } \\
\hline & & \multicolumn{2}{|c|}{ Floor } & \multicolumn{2}{|c|}{ Wall } & \multicolumn{2}{|c|}{ Total } \\
\hline & & $\mathbf{M J} / \mathbf{m}$ & $\%$ diff & $\mathbf{M J} / \mathbf{m}$ & $\%$ diff & $\mathbf{M J} / \mathbf{m}$ & $\%$ diff \\
\hline Mitalas (uninsulated) & $\mathrm{n} / \mathrm{a}$ & 750 & $\mathrm{n} / \mathrm{a}$ & 1,122 & $\mathrm{n} / \mathrm{a}$ & 1,875 & $\mathrm{n} / \mathrm{a}$ \\
\hline GHT2D (uninsulated) & 0.5 & 649 & -13.5 & 889 & -20.8 & 1,538 & -18. \\
\hline GHT2D (uninsulated) & 1.0 & 673 & -10.3 & 989 & -11.9 & 1,662 & -11.4 \\
\hline Mitalas (insulated) & $\mathrm{n} / \mathrm{a}$ & 765 & $\mathrm{n} / \mathrm{a}$ & 4407 & $\mathrm{n} / \mathrm{a}$ & 1,172 & $\mathrm{n} / \mathrm{a}$ \\
\hline GHT2D (insulated) & 0.5 & 687 & -10.2 & 278 & -31.7 & 966 & -17.6 \\
\hline GHT2D (insulated) & 1.0 & 713 & -6.8 & 309 & -24.1 & 1,022 & -12.8 \\
\hline
\end{tabular}

The average daily heat loss on a monthly basis for the insulated case and $\mathrm{K}_{\text {evap }}=1.0$ are shown in Figures 6.25 to 6.27 . Both methods agree very well on the floor heat loss. The Mitalas model shows a higher wall heat loss in the winter and very similar values for the summer. The evapotranspiration in GHT2D is much smaller in the winter, which limits the heat transfer at the 
surface and reduces the heat transfer from the basement wall. The details of the ground surface energy balance are not given in the Mitalas model, so it is impossible to know what assumptions were made at this boundary. The two methods do exhibit very similar seasonal behavior.

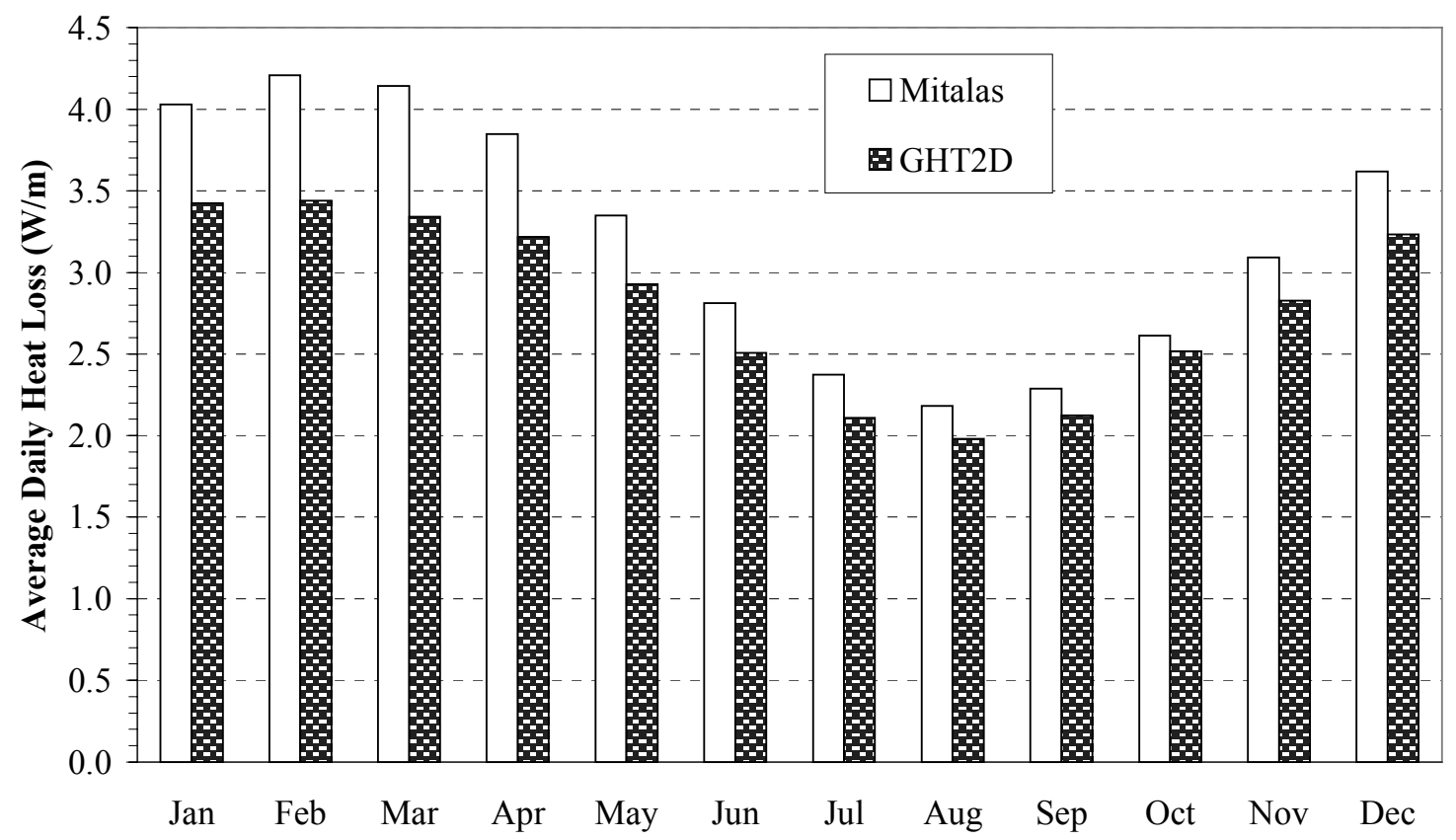

Figure 6.25. Daily average floor heat loss for a basement with an insulated wall from the Mitalas method and GHT2D.

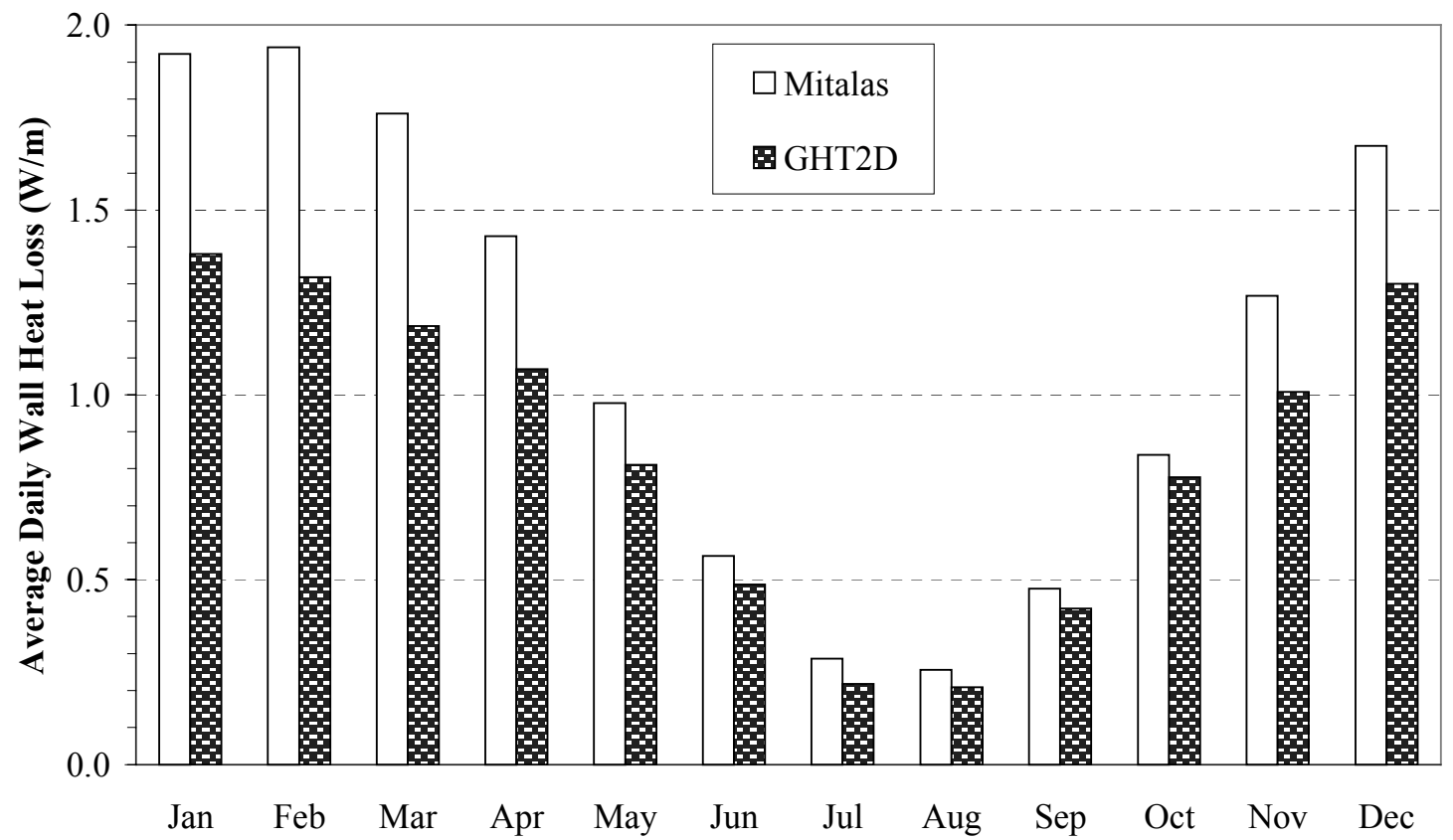

Figure 6.26. Daily average wall heat loss for a basement with an insulated wall from the Mitalas method and GHT2D. 


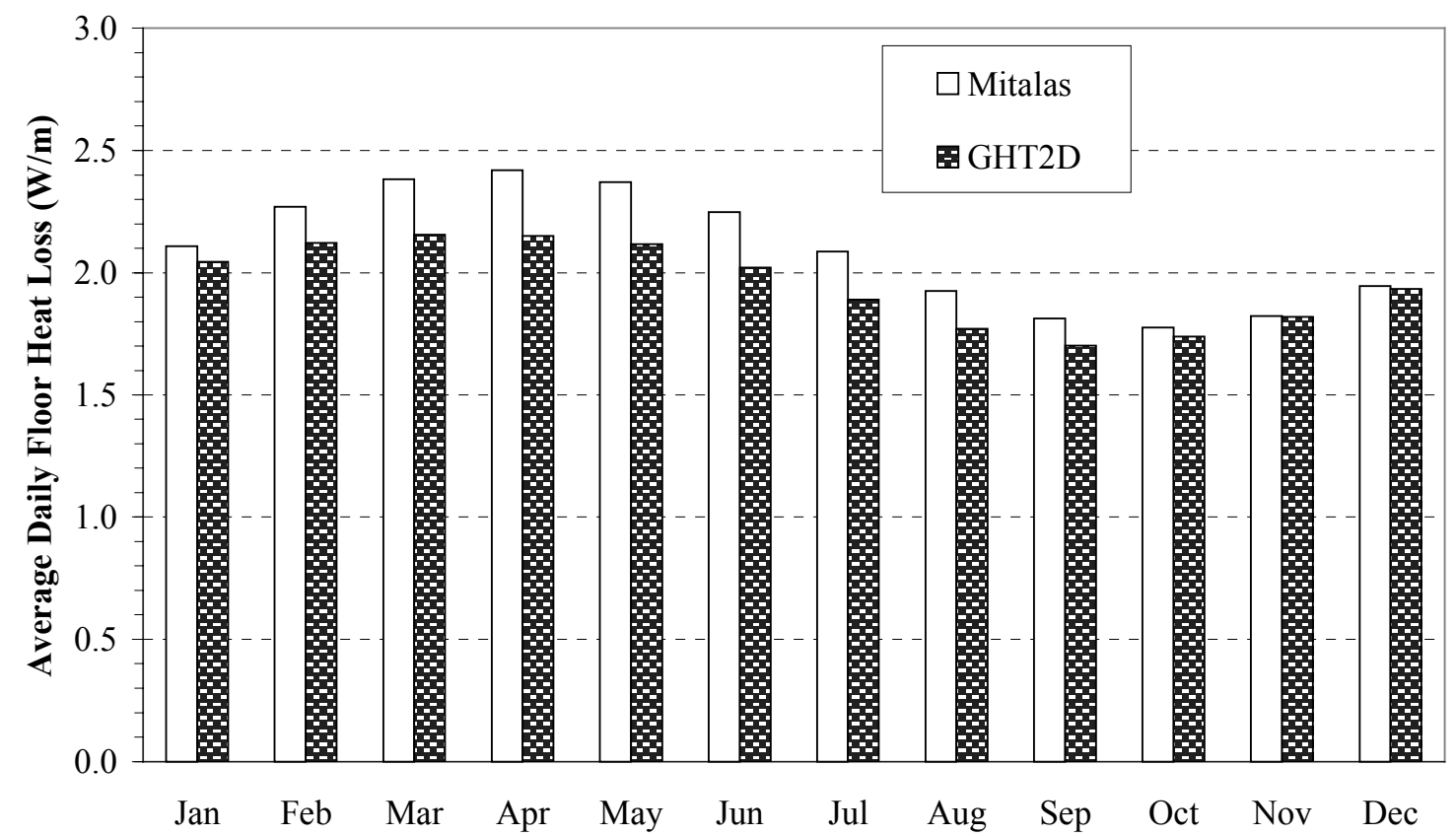

Figure 6.27. Daily average total heat loss for a basement with an insulated wall from the Mitalas method and GHT2D.

\subsection{Comparison of the Heat Transfer Model with the ASHRAE Method}

The predicted heat loss for a basement using the method in the ASHRAE Handbook of Fundamentals (1997) was compared with predictions using GHT2D. The purpose of this comparison was to test the monthly heat-loss values predicted by the ASHRAE method with the results from a numerical simulation. The ASHRAE method is limited to a soil thermal conductivity of $\mathrm{k}=1.38 \mathrm{~W} / \mathrm{m} \cdot \mathrm{K}$; therefore, the previous results cannot be directly compared. The basement geometry in Figure 6.7 was used with wall insulation $\left(\mathrm{R}=1.47 \mathrm{~m}^{2} \cdot \mathrm{K} / \mathrm{W}\right)$ extending 1.2 $\mathrm{m}$ down from the top. GHT2D was run with the Fort Collins weather data used in Section 6.9, a soil thermal conductivity of $\mathrm{k}=1.38 \mathrm{~W} / \mathrm{m} \cdot \mathrm{K}$, and an evaporation ratio of $\mathrm{K}_{\text {evap }}=0.5$.

The total monthly heat losses predicted by each case are shown in Figure 6.28, which shows that the two models agree fairly well in the spring and summer, but not very well in the fall and winter. The total heat loss for the year from the ASHRAE method is $22 \%$ lower than the prediction from GHT2D. A comparison of the predicted wall and floor heat losses is shown in Figures 6.29 and 6.30. The ASHRAE method predicts 68\% higher wall heat losses and 20\% lower floor heat losses. This confirms claims by other researchers that the ASHRAE method does not properly account for heat losses to the deep ground and shows that the method overpredicts the heat loss to the ground surface.

The ASHRAE method is based on the work of Latta and Boileau (1969), which is a rough approximation based on steady-state calculations. They assumed that the heat loss from a basement wall could be approximated by the heat conduction calculated along a circular path from the wall to the ground surface. They further assumed that "the average rate of heat loss through the floor may be taken as equal to that from a point located one quarter of the basement width from the side wall" to the ground surface. The mean ground-surface design temperature is 
estimated by subtracting the appropriate amplitude for the location from the mean air temperature. This approximation depends only on the mean ambient temperature, wall insulation levels, and basement depth. Variations in the surface conditions such as solar gain, wind, and moisture are not accounted for, which explains why the predicted wall heat losses are much higher in this case. In addition, vertical heat transfer in the basement wall can be significant, as shown in Figures 6.15 and 6.16. Floor heat losses for a full basement are more closely tied with the deep-ground conditions than the surface conditions, as was shown in Sections 6.5 and 6.6. From this comparison, the ASHRAE method should be used with caution.

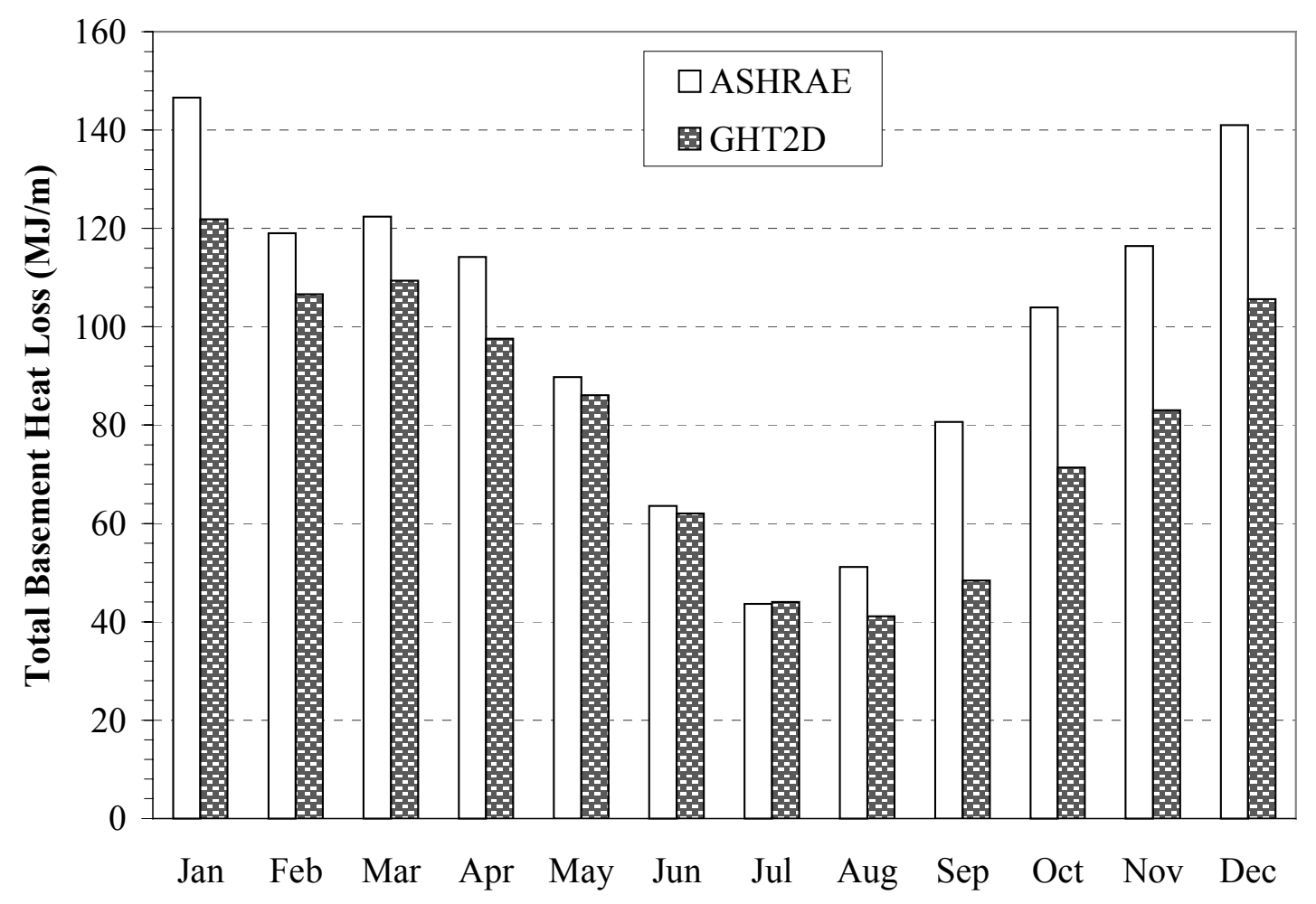

Figure 6.28. Monthly basement heat loss predicted by the ASHRAE method and by GHT2D for Fort Collins weather data. 


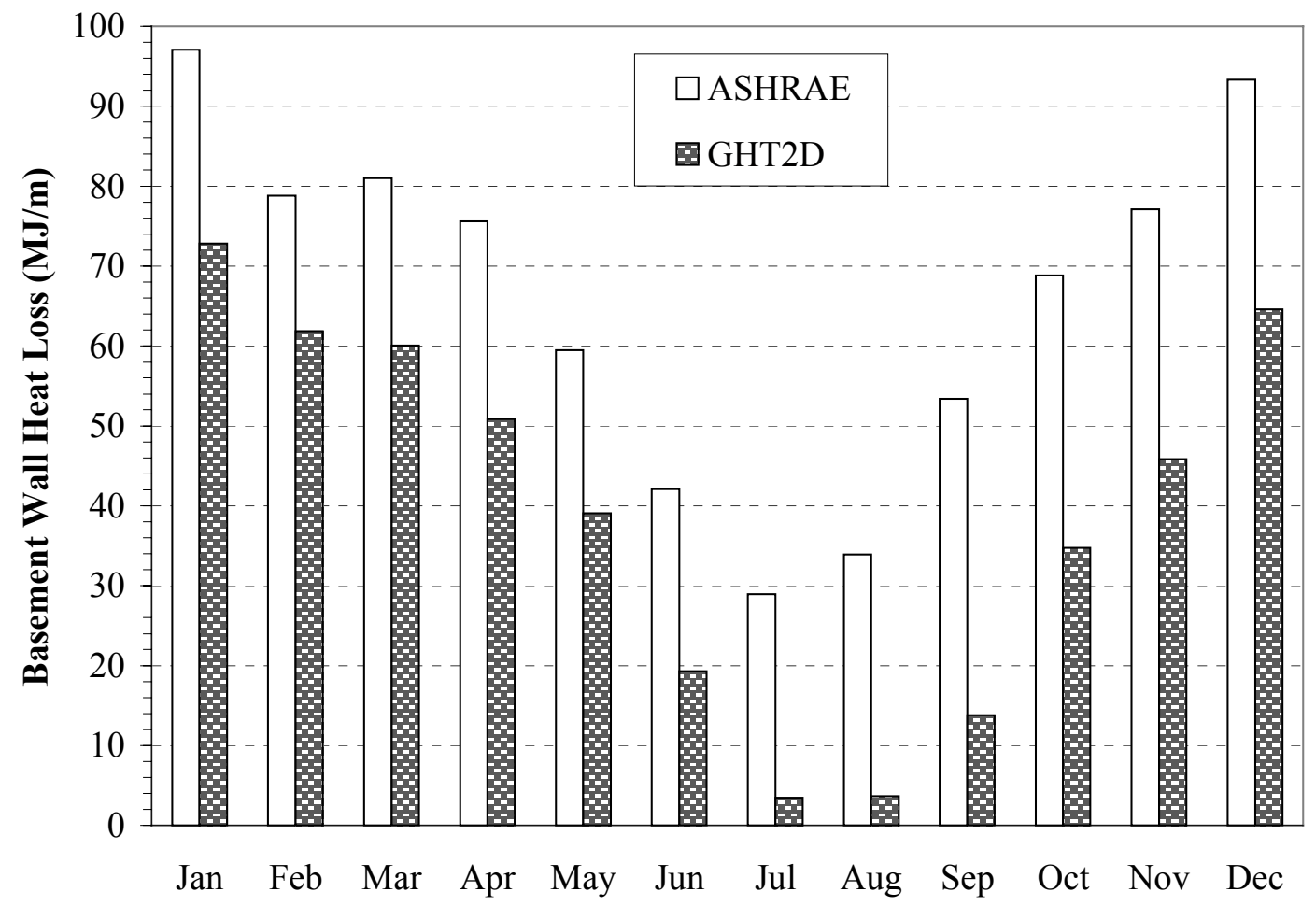

Figure 6.29. Monthly basement-wall heat loss predicted by the ASHRAE method and by GHT2D for Fort Collins weather data.

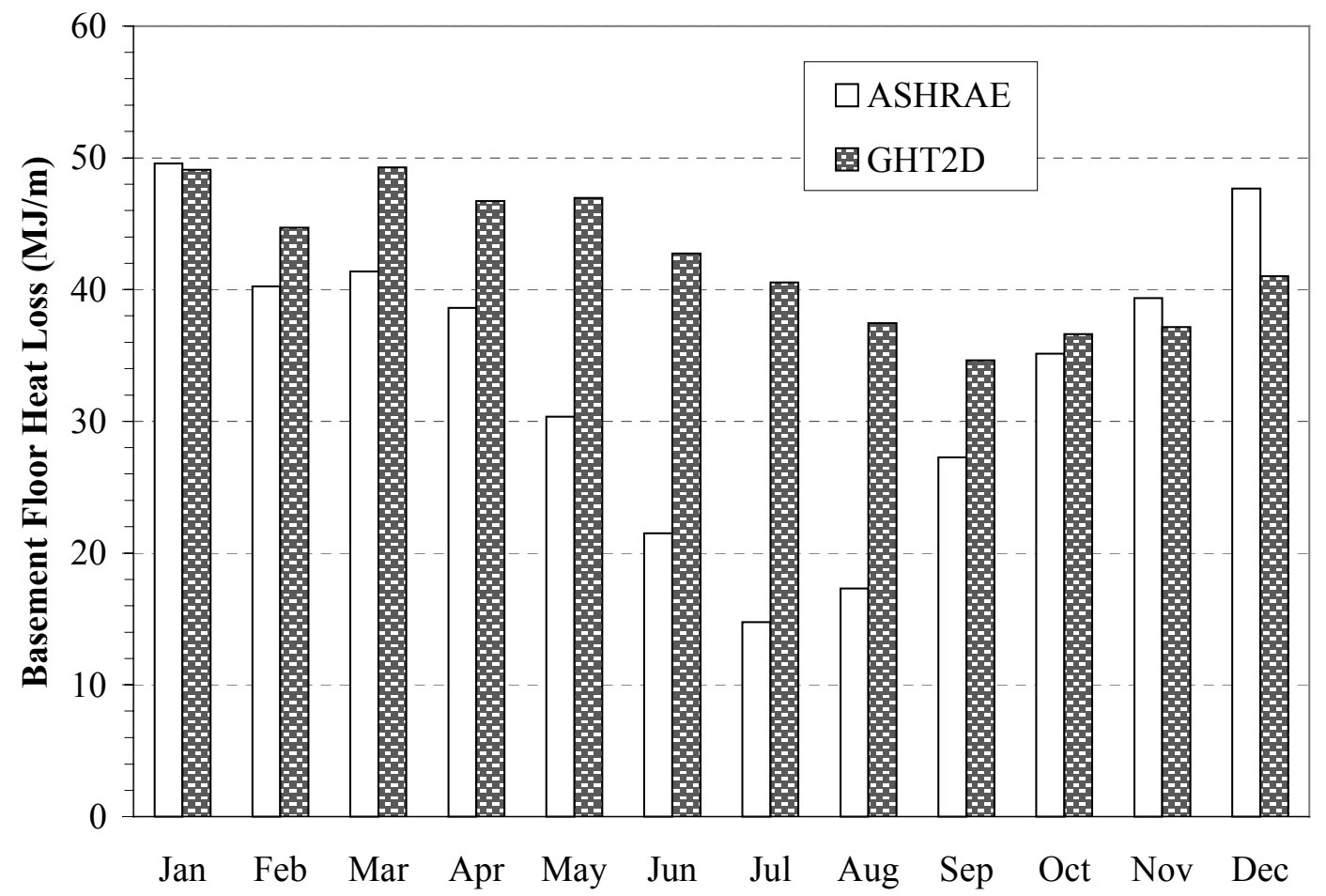

Figure 6.30. Monthly basement-floor heat loss predicted by the ASHRAE method and by GHT2D for Fort Collins weather data. 


\section{Chapter 7: Conclusions and Recommendations}

\subsection{Conclusions from Research}

A two-dimensional heat-and-moisture transfer program, GHAMT, and a two-dimensional heatconduction program, GHT2D, were developed to study the ground-coupled heat transfer from buildings. They were created to address the following issues: (1) study the effects of soil moisture content on the thermal properties and what effect this has on the heat transfer from ground-coupled buildings; (2) accurately model the surface energy and moisture balances; (3) study the effects of water table depths on ground-coupled heat transfer; and (4) determine if the heat-transfer model can simulate the effects of moisture predicted by the heat-and-moisture transfer model.

Many insights were gained from the research performed during this project. Soil thermal and moisture properties are strongly dependent on the type of soil and the moisture content. Soil thermal conductivity is the most important parameter in determining the ground-coupled heat transfer and can change by a factor of ten with moisture content; however, the soil moisture content around buildings varies slightly except at the surface, where the soil can change from saturated to dry on a regular basis. The equations for soil thermal conductivity developed by de Vries (1966) can account for the changes in moisture content and the heat transfer associated with the evaporation-condensation cycles within the soil pores. The dominant term in the heattransfer equation is the conduction term, except when there is bulk liquid flow in the soil, such as ground water flow, or for a brief period following a large influx of moisture at the surface, in which case the convective term can be the largest.

Freezing can have a significant impact on the soil thermal conductivity and the soil moisture behavior. In the case where the soil freezes and stays frozen, the simple freezing model used in this work is adequate and predicts a small effect due to freezing. The case of cyclic freezing and thawing is more difficult because of the various types of ice formation and the complex soil moisture behavior at the freezing front. A more detailed model is required to accurately simulate these physical processes.

The GHAMT program was used to investigate the effects of moisture added to the ground surface on the heat transfer from a slab-on-grade and from a basement. For an uninsulated slabon-grade with summer weather conditions, the heat loss increased $3.1 \%$ with a sandy loam and $1.2 \%$ with Yolo light clay when moisture was added. For the insulated slab-on-grade cases, the effect of the added moisture was less than $1 \%$. For the basement floor, the effect of surface moisture on the heat loss was negligible; however, it increased the heat loss from the basement wall by around $6 \%$ for the insulated and uninsulated cases for summer conditions and sandy loam soil. The changes for the winter cases were very small for all configurations.

The effect of the groundwater depth on heat loss from a basement was shown to be significant for uninsulated basement floors. The heat loss from the uninsulated floor increased by approximately six times when the water-table depth was changed from $10 \mathrm{~m}$ to $3 \mathrm{~m}$, regardless of the season. The heat loss for the insulated floors was roughly double when changing from the 10-m depth to the 3-m depth. The larger heat-transfer rates are caused by increases in the temperature gradient and thermal conductivity in the soil adjacent to the floor. Uncertainty in the 
depth of the groundwater can have a large impact on predicted heat losses from the floor when the groundwater is within $2 \mathrm{~m}$ of the basement floor.

Results from GHAMT were compared with GHT2D for an annual simulation of a partially insulated basement using hourly weather data. It was determined that the heat-transfer model should take into account the variation of the soil thermal conductivity with depth and accurately model the ground-surface boundary condition, including the effects of evapotranspiration. A simple method of modeling the variation in the soil thermal conductivity with depth is to use at least two values: one value for the soil below the basement floor, or about 1.5-m depth, and another value that is $10-20 \%$ lower for the soil above this depth. This accounts for the higher soil moisture content below the top 1-2 m of soil. The level of evapotranspiration modeled can have a large impact on the calculated heat transfer from basement walls. Unless there is knowledge of the exact level of evapotranspiration, the results should be bracketed between the potential value and zero. Using seasonal values of thermal conductivity (slightly higher in the summer) produced reasonable annual heat-loss values, but caused a jump in the floor heat loss corresponding to the change in thermal conductivity and so is not recommended.

Two analytic methods for calculating the heat loss from a basement, the Mitalas method (1987) and the ASHRAE method (1997), were compared with GHT2D. Both methods predicted higher heat loss from the wall than GHT2D: Mitalas by $13-45 \%$ and ASHRAE by $68 \%$. The Mitalas method predicted higher floor heat loss by 6-15\%, and the ASHRAE method predicted $20 \%$ lower floor heat loss. The seasonal variability of the Mitalas method agreed very well with GHT2D, but the ASHRAE method did not match the seasonal variability. Both methods were derived with simplified ground-surface boundary conditions, and information on the assumptions used in the models is not stated in the literature. The Mitalas method differed from the measured data by $1-42 \%$ (Mitalas 1982). Applying any mathematical approximation should be done with caution and with an awareness of the possible errors in the answers.

Although the soil thermal conductivity is important, its value is usually chosen with very little knowledge or account of the soil type and moisture content. One of the most important results from this research is using the heat-and-moisture transfer model to determine an effective soil thermal conductivity to use with heat-transfer models. With a rough estimate of the soil type, GHAMT may be used for a simple case to estimate an effective thermal conductivity to use with a heat-conduction program. This thermal conductivity value can then be used with a higher level of confidence for more complex geometries with a much faster heat-conduction code.

Although the optimal use of insulation was not the subject of this research, some suggestions can be inferred from the results. Under most circumstances, ground-coupled buildings steadily lose heat to the ground; therefore, insulation levels should be carefully considered. This steady heat loss is desired in some cases to cool buildings, but in cold climates, it can account for a large portion of a building's energy budget. To control heat loss to the atmosphere, insulation should be used around the perimeter for slabs-on-grade and basement walls. To control heat loss to the deep ground, slab-on-grade and basement floors should be insulated if the ground water is within 1-2 $\mathrm{m}$ of the floor. Further economic analysis should be conducted concerning the building size, construction, location, soil conditions, and heating fuel costs. Good resources for guidelines on insulation are the Building Foundation Design Handbook (Labs et al. 1988) and the Builder's Foundation Handbook (Carmody et al. 1991) from the Oak Ridge National Laboratory. 


\subsection{Recommendations for Further Work}

There are two general areas for continuing this work: use the models to further analyze groundcoupled heat-and-moisture transfer, and work on improving the models. Research areas for improving the models include the following:

1. Validate the model against measured temperature and moisture contents similar to what was done in Chapter 5 with temperature data.

2. Develop a surface-cover algorithm that can model vegetation cover in the summer and snow cover in the winter. This can be done in a crude way with the present model, but should be improved.

3. Automate the mesh-generation process.

4. Extend the programs to three dimensions.

5. Integrate the programs with a building energy simulation program.

6. Investigate the freezing model and the determination of the frozen soil thermal conductivity.

Combining the heat-and-moisture transfer model with the heat-transfer model forms a great asset for researchers. The programs use the same input files and share many of the same program modules, which makes them easy to use and modify. The models could be used to further investigate the effects of moisture and location on ground-coupled heat transfer and to develop guidelines for better use of simple models as suggested above. In addition, the programs are not limited to analyzing buildings; they could be used for other heat and mass transfer problems in porous media. 


\section{References}

Adjali, M.H., Davies, M., and Littler, J. (1998a). "Earth-Contact Heat Flows: Review and Application of Design Guidance Predictions." Proceedings CIBSE A: Building Services Engineering Technology, Vol. 19(3); pp. 111-121.

Adjali, M.H., Davies, M., and Littler, J. (1998b). "Three-Dimensional Earth-Contact Heat Flows: A Comparison of Simulated and Measured Data for a Buried Structure." Renewable Energy, Vol. 15; pp.356-359.

Arfken, G.B. and Weber, H.J. (1995). Mathematical Methods for Physicists, $4^{\text {th }}$ Ed., New York: Academic Press.

ASHRAE Handbook of Fundamentals. (1997). American Society of Heating Refrigeration and Air Conditioning Engineers, Atlanta, GA.

Bahnfleth, W.P., Cogil, C.A., and Yuill, G.K. (1998). "Three-Dimensional Modeling of Conditioned and Unconditioned Basement Thermal Performance." Proceedings of Thermal Performance of the Exterior Envelopes of Buildings VII, Clear Water, FL, USA; pp. 501-522.

Bahnfleth, W.P. (1989). "Three-Dimensional Modeling of Heat Transfer From Slab Floors." National Technical Information Service, Springfield, VA, ADA210826.

Bahnfleth, W.P. and Pedersen, C.O. (1990). "A Three-Dimensional Numerical Study of SlabOn-Grade Heat Transfer." ASHRAE Transactions, Vol. 96(2); pp. 61-72.

Bareither, H.D., Fleming, A.N. and Alberty, B.E. (1948). Temperature and Heat Loss Characteristics of Concrete Floor Laid on the Ground, University of Illinois Small Homes Council Technical Report.

Beausoleil-Morrison, I., Mitalas, G., and Chin, H. (1995). "Estimating Three-Dimensional Below-Grade Heat Losses from Houses Using Two-Dimensional Calculations." Proceedings of Thermal Performance of the Exterior Envelopes of Buildings VI, Clear Water, FL, USA; pp. 95-99.

Bligh, T.P. and Knoth, B.H. (1983). "Data From One-, Two-, and Three-Dimensional Temperature Fields in the Soil Surrounding an Earth-Sheltered House." ASHRAE Transactions, Vol. 89(1B); pp. 395-404.

Bligh, T.P., Knoth, B.H., Smith, E.A., and Apthorp, D.M. (1982). "Earth Contact Systems: Soil Temperature and Thermal Conductivity Data, Heat Flux Data and Meter Calibration." Proceedings of the Passive and Hybrid Solar Energy Update Conference, Washington, D.C. DE83007242; pp. 73-86. 
Bligh, T.P. and Willard, T.E. (1985). "Modeling the Thermal Performance of Earth-Contact Buildings, Including the Effect of Phase Change due to Soil Freezing." Computers and Structures, Vol. 21, n. 1/2; pp. 291-318.

Burmeister, L.C. (1993). Convective Heat Transfer, $2^{\text {nd }}$ Ed. New York: John Wiley \& Sons, Inc.

Businger, J.A. (1975). "Aerodynamics of Vegetated Surfaces." Heat and Mass Transfer in the Biosphere, Part 1 Transfer Processes in the Plant Environment. de Vries, D.A. and Afgan, N.H. Eds. New York: John Wiley \& Sons; pp. 139-165.

Camillo, P.J., and Gurney, R.J. (1986). “A Resistance Parameter for Bare-Soil Evaporation Models." Soil Science, Vol. 141, No. 2; pp. 95-105.

Carmody, J., Christian, J., and Labs, K., (1991). Builder's Foundation Handbook, Oak Ridge National Laboratory. ORNL/CON-295.

Cary, J.W. and Taylor, S.A. (1962a). "The Interaction of the Simultaneous Diffusions of Heat and Water Vapor.”S Soil Science Society Am. Proc., Vol. 26; pp. 413-416.

Cary, J.W. and Taylor, S.A. (1962b). “Thermally Driven Liquid and Vapor Phase Transfer of Water and Energy in Soil." Soil Science Society Am. Proc., Vol. 26; pp. 417-420.

Case, C.M. (1994). Physical Principles of Flow in Unsaturated Porous Media. Oxford Monographs on Geology and Geophysics No. 26. New York: Oxford University Press.

Celia, M.A., Bouloutas, E.T., and Zarba, R.L. (1990). “A General Mass-Conservative Numerical Solution for the Unsaturated Flow Equation." Water Resources Research, Vol. 26, No. 7; pp. 1483-1496.

CIBSE Guide, Vol. A. (1986). London: The Chartered Institution of Building Services Engineers.

Claesson, J. and Hagentoft, C-E. (1991a). "Heat Loss to the Ground From a Building - I. General Theory." Building and Environment, Vol. 26, No. 2; pp. 195-208.

Claesson, J. and Hagentoft, C-E. (1991b). "Heat Loss to the Ground from a Building - II. Slab on the Ground." Building and Environment, Vol. 26, No. 4; pp. 395-403.

Claridge, D.E. (1988). "Design Methods for Earth-Contact Heat Transfer." Advances in Solar Energy, Vol. 4. Boer, K.W., Ed. Boulder, CO: American Solar Energy Society; pp. $305-351$.

Cole, R. (1981). "Underground Dwellings in Southern Tunisia." Passive Cooling, International Passive and Hybrid Cooling Conference. Bowen, A., Clark, E., and Labs, K., Eds. American Section of the International Solar Energy Society; pp. 176-178. 
Davies, M.G. (1993). "Heat Loss From a Solid Ground Floor." Building and Environment, Vol. 28, No. 3;.pp. 347-359.

Delsante, A.E. and Stokes, A.N. (1983). "Application of Fourier Transforms to Periodic Heat Flow into the Ground Under the Building." Int. J. Heat Mass Transfer, Vol. 26, No. 1; pp. 121-132.

Delsante, A.E. (1988). "Theoretical Calculations of the Steady-State Heat Losses Through a Slab-on-Ground Floor." Building and Environment, Vol. 26, No. 4; pp. 11-17.

Delsante, A.E. (1989). "Steady-State Heat Losses from the Core and Perimeter Regions of a Slab-on-Grade Floor." Building and Environment, Vol. 24, No. 3; pp. 253-257.

Delsante, A.E. (1990). "A Comparison Between Measured and Calculated Heat Losses Through a Slab-on-Ground Floor." Building and Environment, Vol. 25, No. 1; pp. 25-31.

de Vries, D.A. (1958). "Simultaneous Transfer of Heat and Moisture in Porous Media." Trans. American Geophysical Union, Vol. 39, n. 5; pp. 909-915.

de Vries, D.A. (1966). “Thermal Properties of Soils.” Physics of Plant Environment. Van Wijk W.R. Ed. Amsterdam: North-Holland Publishing Company.

de Vries, D.A. (1975). "Heat Transfer in Soils." Heat and Mass Transfer in the Biosphere, Part 1 Transfer Processes in the Plant Environment. de Vries, D.A. and Afgan, N.H. Eds. New York: John Wiley \& Sons; pp. 5-28.

Eagleson, P.S. (1970). Dynamic Hydrology. New York: McGraw-Hill.

Edlefsen, N.E. and Anderson, A.B.C. (1943). "Thermodynamics of Soil Moisture.” Hilgardia, Vol. 15; pp. 31-298.

Ewen, J. and Thomas, H.R. (1989). "Heating Unsaturated Medium Sand.” Geotechnique, Vol. 39, No. 3; pp. 455-470.

Fanchiotti, A. and Scudo, G. (1981). "Large Scale Underground Cooling System in Italian $16^{\text {th }}$ Century Palladian Villas." Passive Cooling, International Passive and Hybrid Cooling Conference. Bowen, A., Clark, E., and Labs, K., Eds. American Section of the International Solar Energy Society; pp. 179-182.

Farouki, O.T. (1981). “Thermal Properties of Soils.” CRREL Monograph 81-1. U.S. Army Cold Regions Research and Engineering Laboratory, Hanover, NH.

Flint, B. (1981). "Troglodytic and Semi-Troglodytic Dwellings of the Goreme Valley, Anatolia, Turkey." Passive Cooling, International Passive and Hybrid Cooling Conference. Bowen, A., Clark, E., and Labs, K., Eds. American Section of the International Solar Energy Society; pp. 183-187. 
Geiger, R., Aron, R.H., and Todhunter, P. (1995). The Climate Near the Ground. $5^{\text {th }}$ Ed. Vieweg, Braunschweig, Germany.

Giakoumakis, S.G. and Tsakiris, G.P. (1991). "Eliminating the Effect of Temperature From Unsaturated Soil Hydraulic Functions.” Journal of Hydrology, Vol. 129; pp. 109-125.

Gilpin, R.R. and Wong, B.K. (1976). "Heat-Valve Effects in the Ground Thermal Regime." ASME Journal of Heat Transfer, Vol. 98; pp. 537-542.

Gold, L.W. (1967). "Influence of Surface Conditions on Ground Temperature." Canadian J. Earth Sciences, Vol. 4; pp. 199-208.

Hagentoft, C-E. (1996a). "Heat Losses and Temperature in the Ground Water Under a Building With and Without Ground Water Flow - I. Infinite Ground Water Flow Rate.” Building and Environment, Vol. 31, No. 1; pp. 3-11.

Hagentoft, C-E. (1996b). "Heat Losses and Temperature in the Ground Water Under a Building With and Without Ground Water Flow - II. Finite Ground Water Flow Rate.” Building and Environment, Vol. 31, No. 1; pp. 13-19.

Hampton, D. (1989). Coupled Heat and Fluid Flow in Saturated-Unsaturated Compressible Porous Media. PhD Dissertation, Colorado State University, Fort Collins, CO.

Harlan, R.L. (1973). “Analysis of Coupled Hot-Fluid Transport in Partially Frozen Soil." Water Resources Research, Vol. 9, No. 5; pp.1314-1323.

Haverkamp, R., Vauclin, M., Touma, J., Wierenga, P. J., and Vachaud, G. (1977). “A Comparison of Numerical Simulation Models For One-Dimensional Infiltration." Soil Science Society, American Journal, Vol. 41; pp. 285-294.

Hillel, D. (1998). Environmental Soil Physics. San Diego, CA: Academic Press.

Hoekstra, P. (1966). "Moisture Movement in Soils Under Temperature Gradients with the Cold-Side Temperature Below Freezing." Water Resources Research, Vol. 2, No. 2; pp. $241-250$.

Horiguchi, K. and Miller, R.D. (1983). "Hydraulic Conductivity Functions of Frozen Materials." Permafrost: Fourth International Conference Proceedings. Washington, D.C.: National Academy Press; pp.504-508.

Houghten, F.C., Taimuty, S. I., Gutberlet, C., and Brown, C. J. (1942). "Heat Loss Through Basement Walls and Floors.” ASHVE Transactions, Vol. 48; pp. 369-384.

Huang Y.J., Shen, L.S., Bull, J.C., and Goldberg, L.F., (1988). "Whole House Simulation of Foundation Heat Flows Using the DOE-2.1C Program.” ASHRAE Transactions, Vol. 94(2); pp. 936-958. 
Incropera, F.P. and De Witt, D.P. (1985). Fundamentals of Heat and Mass Transfer, $2^{\text {nd }}$ Ed. New York: John Wiley and Sons.

Istok, J. (1989). Groundwater Modeling by the Finite Element Method. Water Resources Monograph 13, American Geophysical Union, Washington, D.C.

Jensen, M.E., Ed. (1973). Consumptive Use of Water and Irrigation Water Requirement. New York: American Society of Civil Engineers.

Judkoff, R. and Neymark, J. (1995). Building Energy Simulation Test (BESTEST) and Diagnostic Method, International Energy Association, NREL/TP-472-6231, National Renewable Energy Laboratory, Golden, CO.

Jury, W.A. (1973). Simultaneous Transport of Heat and Moisture Through a Medium Sand. Ph.D. Thesis, University of Wisconsin, Madison, WI.

Kay, B.D. and Perfect, E. (1988). "State of the Art: Heat and Mass Transfer in Freezing Soils." $5^{\text {th }}$ International Symposium on Ground Freezing. Jones and Holden, Eds.; pp. 3-21.

Kersten, M.S. (June 1949). Thermal Properties of Soils. University of Minnesota Institute of Technology, Bulletin 28, Vol. LII, N. 21, Minneapolis, MN.

Kimball, B.A., Jackson, R.D., Reginato, R.J., Nakayama, F.S., and Idso, S.B. (1976). "Comparison of Field-Measured and Calculated Soil-Heat Fluxes." Soil Science Society of America Journal, Vol. 40; pp.18-25.

Krarti, M., Claridge, D.E., and Kreider, J.F. (1988a). "The ITPE Technique Applied to SteadyState Ground-Coupling Problems." International Journal of Heat Mass Transfer, Vol. 31, No. 9; pp. 1885-1898.

Krarti, M., Claridge, D.E., and Kreider, J.F. (1988b). "ITPE Technique Applications to TimeVarying Two-Dimensional Ground-Coupling Problems." International Journal of Heat Mass Transfer, Vol. 31, No. 9; pp. 1899-1911.

Krarti, M., Claridge, D.E., and Kreider, J.F. (November 1990). "ITPE Technique Applications to Time-Varying Three-Dimensional Ground-Coupling Problems." Journal of Heat Transfer, ASME, Vol. 112; pp. 849-856.

Krarti, M., Claridge, D.E., and Kreider, J.F. (1994). "A Foundation Heat Transfer Algorithm for Detailed Building Energy Programs.” ASHRAE Transactions, Vol. 100(2); pp. 843-850.

Krarti, M., Claridge, D.E., and Kreider, J.F. (1995a). "Frequency Response Analysis of Ground-Coupled Building Envelope Surfaces." ASHRAE Transactions, Vol. 101(1); pp. $355-367$.

Krarti, M., Claridge, D.E., Nicoulin, C.V., and Kreider, J.F. (1995b). “Comparison of Energy Prediction of Three Ground-Coupled Heat Transfer Calculation Methods." ASHRAE Transactions, Vol. 101(1); pp. 158-172. 
Krarti, M. and Choi, S. (1996). "Simplified Method for Foundation Heat Loss Calculation." ASHRAE Transactions, Vol. 102(1); pp. 140-152.

Krarti, M. (1999). "Building Foundation Heat Transfer.” Advances in Solar Energy, Vol. 13. Boer, K.W., Ed. Boulder, CO: American Solar Energy Society; pp. 241-315.

Kusuda, T. and Achenbach, P.R. (1963). "Numerical Analyses of the Thermal Environment of Occupied Underground Spaces With Finite Cover Using a Digital Computer." ASHRAE Transactions, Vol. 69; pp. 439-447.

Kusuda, T. (1975). "The Effect of Ground Cover on Earth Temperature." Proceedings Alternatives in Energy Conservation: The Use of Earth-Covered Buildings. Fort Worth, TX, July 9-12, 1975; pp. 279-303.

Kusuda, T., Mizuno, M., and Bean, J.W. (1982). "Seasonal Heat Loss Calculation for Slab-onGrade Floors." U.S. Department of Commerce, National Bureau of Standards, Center for Building Technology, NBSIR 81-2420.

Kusuda, T. and Bean, J.W. (1984). "Simplified Methods for Determining Seasonal Heat Loss From Uninsulated Slab-on-Grade Floors.” AHSRAE Transactions, Vol. 90(1B); pp. 611632.

Labs, K., Carmody, J., Sterling, R., Shen, L., Huang, Y., and Parker, D. (1988). Building Foundation Design Handbook. ORNL Report Sub/86-72143/1, Oak Ridge National Laboratory.

Labs, K. (1989) “Earth Coupling.” Passive Cooling, Solar Heat Technologies: Fundamentals and Applications. Cook, J., Ed. Cambridge, MA: MIT Press; pp. 197-346.

Lachenbruch, A.H. (1957). "Three-Dimensional Heat Conduction in Permafrost Beneath Heated Buildings.” Geological Survey Bulletin 1052-B.

Latta, J.K. and Boileau, G.G. (1969). "Heat Loss from House Basements." Canadian Building, Vol. 19, No. 10; pp. 39-42.

MacDonald, G.R., Claridge, D.E., and Oatman, P.A. (1985). “A Comparison of Seven Basement Heat Loss Calculation Methods Suitable for Variable-Base Degree-Day Calculations." ASHRAE Transactions, Vol. 91(1B); pp. 916-933.

Macey, H.H. (1949). "Heat Loss Through a Solid Floor.” Journal of the Institute of Fuel, Vol. 22; pp. 369-371.

Martin, M. and Berdahl, P. (1984). "Characteristics of Infrared Sky Radiation in the United States." Solar Energy, Vol. 33, No. 3/4; pp. 321-336.

Martin, M. (1989). "Radiative Cooling.” Passive Cooling, Solar Heat Technologies: Fundamentals and Applications. Cook, J., Ed. Cambridge, MA: MIT Press; pp. 138196. 
McAdams, W.H. (1954). Heat Transmission, $3^{\text {rd }}$ Ed. New York: McGraw-Hill.

McBride, M.F., Blancett, R. S., Sepsy, C. F., and Jones, C. D. (1979). "Measurement of Subgrade Temperatures For Prediction of Heat Loss in Basements." ASHRAE Transactions, Vol. 85(1); pp. 642-655.

McConnell, S. (1993). Code Complete: A Practical Handbook of Software Construction. Redmond, WA: Microsoft Press.

Miller, E.E. and Miller, R.D. (1956). "Physical Theory for Capillary Flow Phenomena." Journal of Applied Physics, Vol. 27; pp. 324-332.

Milly, P.C.D. and Eagleson, P.S. (1980). "The Coupled Transport of Water and Heat in a Vertical Soil Column Under Atmospheric Excitation." Technical Report 279. R.M. Parsons Lab., Department of Civil Engineering, MIT, Cambridge, MA.

Milly, P.C.D. (1982). "A Simulation Analysis of Thermal Effects on Evaporation From Soil." Water Resources Research, Vol. 20, No. 8; pp. 1087-1098.

Milly, P.C.D. (1984). "Moisture and Heat Transport in Hysteretic, Inhomogeneous Porous Media: A Matric Head-Based Formulation and a Numerical Model." Water Resources Research, Vol. 18, No. 3; pp. 489-498.

Milly, P.C.D. (1985). “A Mass-Conservative Procedure for Time-Stepping in Models of Unsaturated Flow." Advances in Water Resources, Vol. 8; pp. 32-36.

Mitalas, G.P. (1982). "Basement Heat Loss Studies at DBR/NRC.” National Research Council of Canada Division of Building Research, DBR Paper No. 1045.

Mitalas, G.P. (1987). "Calculation of Below-Grade Residential Heat Loss: Low-Rise Residential Building." ASHRAE Transactions, Vol. 93(1); pp. 743-784.

Moore, R.E. (1939). "Water Conduction From Shallow Water Tables." Hilgardi, Vol. 12, No. 6; pp. 383-426.

Muncey, R.W.R. and Spencer, J.W. (1978). "Heat Flow into the Ground Under a House." Energy Conservation in Heating, Cooling, and Ventilating Buildings, Vol. 2. Hoogendoorn, C.J. and Afgan, N.H., Eds. Washington, DC: Hemisphere Publishing Corporation; pp. 649-660.

Nakano, M. and Miyazaki, T. (1979). "The Diffusion and Nonequilibrium Thermodynamic Equations of Water Vapor in Soils Under Temperature Gradients.” Soil Science, Vol. 128, No. 3; pp. 184-188.

Nimmo, JR. and Miller, E.E. (1986). "The Temperature Dependence of Isothermal Moisture vs. Potential Characteristics of Soils." Soil Science Society of America Journal, Vol. 50; pp. $1105-1113$. 
Noborio, K., McInnes, K.J., and Heilman, J.L. (1996). “Two-Dimensional Model for Water, Heat, and Solute Transport in Furrow-Irrigated Soil: II. Field Evaluation." Soil Science Society of America Journal, Vol. 60; pp. 1001-1009.

NREL, 2003. User's Manual for TMY2s (Typical Meteorological Years). Resource Data Center. National Renewable Energy Laboratory. http://rredc.nrel.gov/solar/pubs/tmy2/

Paulson, C.A. (1970). "The Mathematical Representation of Wind Speed and Temperature Profiles in the Unstable Atmospheric Surface Layer." Journal of Applied Meteorology, Vol. 9; pp. 851-861.

Penman, H.L. (1948). "Natural Evaporation From Open Water, Bare Soil, and Grass." Procedings of the Royal Society of London, Ser. A; pp. 120-145.

Philip, J.R. (1957). "The Theory of Infiltration: 1. The Infiltration Equation and Its Solution." Soil Science, Vol. 83; pp. 435-448.

Philip, J.R. and de Vries, D.A. (1957) "Moisture Movement in Porous Materials Under Temperature Gradients." Transactions American Geophysical Union, Vol. 38(2); pp. $222-232$.

Plate, E.J. (1971). Aerodynamic Characteristics of Atmospheric Boundary Layers. U.S. Atomic Energy Commission Office of Information Services.

Rees, S.W., Lloyd, R.M., and Thomas, H.R. (1995) “A Numerical Simulation of Measured Transient Heat Transfer Through a Concrete Ground Floor Slab and Underlying Substrata." International Journal for Numerical Methods in Heat and Fluid Flow, Vol. 5; pp. 669-683.

Rees, S.W. and Thomas, H.R. (1997). "Two-Dimensional Heat Transfer Beneath a Modern Commercial Building: Comparison of Numerical Prediction With Field Measurement." Proceedings of CIBSE A: Building Services Engineers, Vol. 18(3); pp. 169-174.

Salomone, L.A. and Marlowe, J.I. (1989). "Soil and Rock Classification According to Thermal Conductivity, Design of Ground-Coupled Heat Pump Systems." EPRI CU-6482, Electric Power Research Institute.

Sellers, W.D. (1965). Physical Climatology. Chicago, IL: University of Chicago Press.

Shen, L.S. and Ramsey, J.W. (1983). "A Simplified Thermal Analysis of Earth-Sheltered Buildings Using a Fourier-Series Boundary Method." ASHRAE Transactions, Vol. 89(1B); pp. 438-448.

Shen, L.S. (1986). "An Investigation of Transient, Two-Dimensional Coupled Heat and Moisture Flow in Soils.” Ph.D. Thesis, University of Minnesota, Minneapolis, MN. 
Shen, L.S. and Ramsey, J.W. (1988). "An Investigation of Transient, Two-Dimensional Coupled Heat and Moisture Flow in the Soil Surrounding a Basement Wall." International Journal of Heat and Mass Transfer, Vol. 31, No. 7; pp.1517-1527.

Shen, L.S., Poliakova, J., and Huang, Y.J. (1988). "Calculation of Building Foundation Heat Loss Using Superposition and Numerical Scaling." ASHRAE Transactions Vol. 94(2); pp. 917-935.

Sherman, M.H. and Grimsrud, D.T. (1980). "Infiltration-Pressurization Correlations: Simplified Physical Modeling.” ASHRAE Transactions, Vol. 86(2); pp.778-803.

Shipp, P.H. (1979). “The Thermal Characteristics of Large Earth-Sheltered Structures.” Ph.D. Thesis, University of Minnesota, Minneapolis, MN.

Shuttleworth, W.J. (1993). "Evaporation.” Handbook of Hydrology. Maidment, D.R., Ed. New York: McGraw-Hill Inc.

Sommerville, I. (1995). Software Engineering. Fifth Edition. Harlow, England: AddisonWesley.

Speltz, J. (1980). "A Numerical Simulation of Transient Heat Flow in Earth Sheltered Buildings for Seven Selected U.S. Cities." MS Thesis, Trinity University, San Antonio, TX.

Thomas, H.R. and Rees, S.W. (1999). "The Thermal Performance of Ground Floor Slabs - a Full Scale in-situ Experiment.” Building and Environment, Vol. 34; pp. 139-164.

Thompson, E. (1999). The Finite Element Method. Class notes, Colorado State University, Fort Collins, CO.

Trethowen, H.A. and Delsante, A.E. (1998). "Four-Year On-Site Measurement of Heat Flow in Slab-on-Ground Floors with Wet Soils." Proceedings of Thermal Performance of the Exterior Envelopes of Buildings VII, Clear Water, FL; pp. 487-499.

van Bavel, C.H.M. and Hillel, D.I. (1976). "Calculating Potential and Actual Evaporation From a Bare Soil Surface by Simulation of Concurrent Flow of Water and Heat." Agricultural Meteorology, Vol. 17; pp. 453-476.

van Genuchten, M.Th., (1980). "A Closed-Form Equation for Predicting the Hydraulic Conductivity of Unsaturated Soils." Soil Science Society American Journal, Vol. 44; pp. 892-898.

van Wijk, W.R. and de Vries, D.A. (1966). "Periodic Temperature Variations in a Homogeneous Soil.” Physics of Plant Environment. Van Wijk, W.R., Ed. Amsterdam: North-Holland Publishing Company.

Walton, G.N. (1987) "Estimating 3-D Heat Loss From Rectangular Basements and Slabs Using 2-D Calculations.” ASHRAE Transactions, Vol. 93(1); pp. 791-797. 
Wang, F.S. (1979) "Mathematical Modeling and Computer Simulation of Insulation Systems in Belos Grade Applications." Proceedings of ASHRAE/DOE-ORNL Conference on Thermal Performance of the Exterior Envelopes of Buildings, Kissimmee, FL.

Winkelmann, F. (1998) "Underground Surfaces: How to Get a Better Underground Surface Heat Transfer Calculation in DOE-2.1E.” User News, Vol. 19, No. 1; pp. 6-13.

Yard, D.C., Morton-Gibson, M., and Mitchell, J.W. (1984). "Simplified Dimensionless Relations for Heat Loss From Basements.," ASHRAE Transactions, Vol. 90(1B); pp. 633-643.

Yoshino, H., Matsumoto, S., Nagatomo, M., and Sakanishi, T. (1992). "Five-Year Measurements of Thermal Performance for a Semi-Underground Test House," Tunneling and Underground Space Technology, Vol. 7(4); pp. 339-346.

Zienkiewicz, O.C. and Taylor, R.L. (1989). The Finite Element Method. Fourth Edition. London: McGraw-Hill Book Company. 


\section{APPENDIX A: Derivation of the Heat-and-Moisture Transfer Equations}

\section{A.1. Liquid Transfer}

The flow of water through saturated soil can be approximated by Darcy's law relating the flow $\mathbf{u}_{\ell}$ to the gradient of the hydraulic head. Richards extended Darcy's law to unsaturated soil by using the gradient of the total potential $\Phi$ and defining the hydraulic conductivity $\mathrm{K}$ as a function of the soil water matric potential $\psi$ (Hillel 1998).

$$
\mathbf{u}_{\ell}=-\mathrm{K}(\psi) \nabla \Phi
$$

This equation applies to low flow situations where the inertia forces are negligible, i.e., for a Reynolds number based on effective pore diameter of less than one (Hillel 1998).

The total potential energy of the soil moisture is taken as the sum of the matric and gravitational potentials as presented in Eq. (A.2), where $\mathrm{z}$ is positive upwards.

$$
\Phi=\psi+\mathrm{z}
$$

Substituting Eq. (A.2) into Eq. (A.1) yields:

$$
\mathbf{u}_{\ell}=-\mathrm{K} \nabla \psi-\mathrm{K} \hat{\mathrm{k}}
$$

Consider a control volume of soil as shown in Figure A.1, the mass balance on the liquid water is governed by the simple equation

$$
\Delta \dot{\mathrm{m}}_{\text {stored }}=\sum \mathrm{m}_{\text {in }}-\sum \mathrm{m}_{\text {out }}+\mathrm{S}
$$

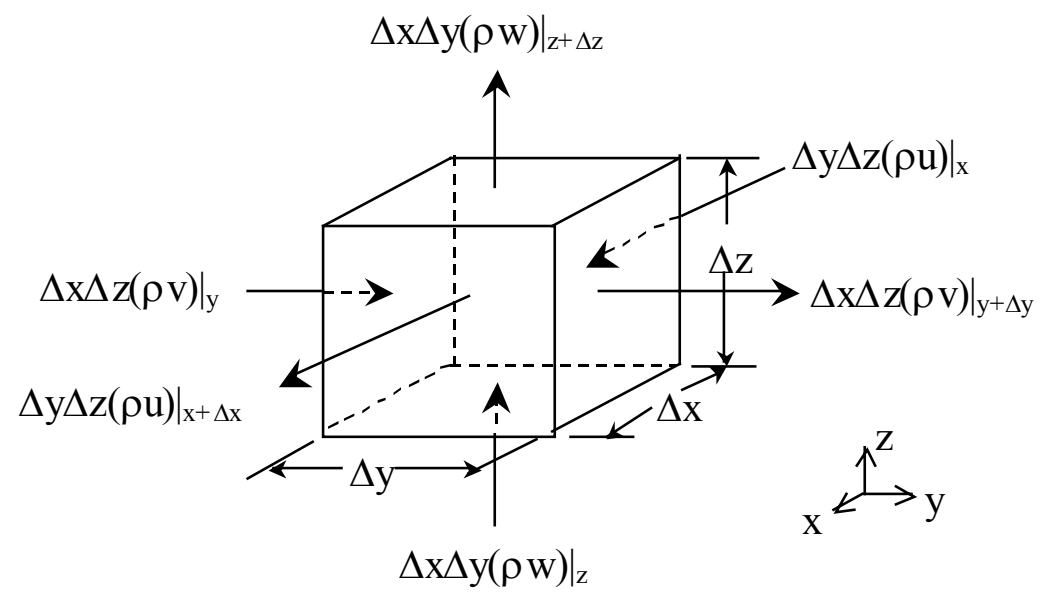

Figure A.1. Fixed control volume of soil used for the liquid moisture balance.

Equation (A.4) can be written as 


$$
\frac{\partial\left(\rho_{\ell} \mathrm{Vol}_{\ell}\right)}{\partial \mathrm{t}}=-\left(\frac{\partial\left(\rho_{\ell} \mathrm{u}\right)}{\partial \mathrm{x}}+\frac{\partial\left(\rho_{\ell} \mathrm{v}\right)}{\partial \mathrm{y}}+\frac{\partial\left(\rho_{\ell} \mathrm{w}\right)}{\partial \mathrm{z}}\right) \Delta \mathrm{x} \Delta \mathrm{y} \Delta \mathrm{z}+\mathrm{S}
$$

where S represents a source term. Assuming a constant density, dividing through by the density and the total volume results in

$$
\frac{\partial \theta_{\ell}}{\partial \mathrm{t}}=-\nabla \cdot \mathbf{u}_{\ell}-\mathrm{E}
$$

The volumetric liquid moisture content is $\theta_{\ell}\left(\mathrm{m}^{3} / \mathrm{m}^{3}\right)$ and the evaporation from the liquid to the vapor phase in the soil pores is $\mathrm{E}\left(\mathrm{s}^{-1}\right)$. The liquid content is a function of the matric potential and temperature; therefore, the time derivative of the liquid content can be expanded by the chain rule to give

$$
\frac{\partial \theta_{\ell}}{\partial \mathrm{t}}=\left(\frac{\partial \theta_{\ell}}{\partial \psi}\right)_{\mathrm{T}} \frac{\partial \psi}{\partial \mathrm{t}}+\left(\frac{\partial \theta_{\ell}}{\partial \mathrm{T}}\right)_{\psi} \frac{\partial \mathrm{T}}{\partial \mathrm{t}}
$$

Substituting Eqs. (A.3) and (A.7) into (A.6) results in the governing equation for liquid transfer.

$$
\mathrm{C}_{\psi \ell} \frac{\partial \psi}{\partial \mathrm{t}}+\mathrm{C}_{\mathrm{T} \ell} \frac{\partial \mathrm{T}}{\partial \mathrm{t}}=\nabla \cdot[\mathrm{K} \nabla \psi]+\frac{\partial \mathrm{K}}{\partial \mathrm{z}}-\mathrm{E}
$$

where the matric and thermal liquid capacitances are defined as

$$
\begin{aligned}
& \mathrm{C}_{\psi \ell}=\left(\frac{\partial \theta_{\ell}}{\partial \psi}\right)_{\mathrm{T}} \\
& \mathrm{C}_{\mathrm{T} \ell}=\left(\frac{\partial \theta_{\ell}}{\partial \mathrm{T}}\right)_{\psi}
\end{aligned}
$$

\section{A.2. Vapor Transfer}

Assuming a uniform and constant total pressure, $\mathrm{P}(\mathrm{Pa})$, vapor mass diffusion in a single gasfilled pore can be approximated as a modification of Fick's law of diffusion (de Vries 1975 and Nakano and Miyazaki 1979):

$$
\dot{\mathbf{m}}_{\mathrm{v}}=-\frac{\mathrm{D}_{\mathrm{a}}}{\mathrm{R}_{\mathrm{w}} \mathrm{T}} \frac{\mathrm{P}}{\mathrm{P}-\mathrm{P}_{\mathrm{v}}} \nabla \mathrm{P}_{\mathrm{v}}
$$

The molecular diffusivity of water vapor in air is $\mathrm{D}_{\mathrm{a}}\left(\mathrm{m}^{2} / \mathrm{s}\right), \mathrm{R}_{\mathrm{w}}(461.5 \mathrm{~J} / \mathrm{kg} \mathrm{K})$ is the gas constant for water vapor, $T(K)$ is the absolute temperature, and $P_{v}$ is the partial pressure of the vapor. The molecular diffusivity of water vapor in air can be determined by (deVries 1975):

$$
\mathrm{D}_{\mathrm{a}}=\mathrm{c}\left(\frac{\mathrm{P}_{\mathrm{o}}}{\mathrm{P}}\right)\left(\frac{\mathrm{T}}{\mathrm{T}_{\mathrm{o}}}\right)^{\mathrm{n}}
$$


The reference pressure is $\mathrm{P}_{\mathrm{o}}=1.01325 \times 10^{5} \mathrm{~Pa}$, the reference temperature is $\mathrm{T}_{\mathrm{o}}=273.15 \mathrm{~K}, \mathrm{c}=$ $2.17 \times 10^{-5} \mathrm{~m}^{2} / \mathrm{s}$, and $\mathrm{n}=1.88$. The mass-flow factor as calculated by Eq. (A.13) is unity for all situations found around buildings and is therefore dropped from further equations.

$$
v=\frac{\mathrm{P}}{\mathrm{P}-\mathrm{P}_{\mathrm{v}}}
$$

Assuming the vapor behaves as an ideal gas, the vapor pressure can be written as

$$
\mathrm{P}_{\mathrm{v}}=\mathrm{R}_{\mathrm{w}} \mathrm{T} \rho_{\mathrm{v}}
$$

Now the vapor diffusion equation can be written in terms of the vapor density as

$$
\dot{\mathbf{m}}_{\mathrm{v}}=-\mathrm{D}_{\mathrm{a}}\left(\nabla \rho_{\mathrm{v}}+\frac{\rho_{\mathrm{v}}}{\mathrm{T}}(\nabla \mathrm{T})_{\mathrm{p}}\right)
$$

The term $(\nabla \mathrm{T})_{\mathrm{p}}$ is the temperature gradient across a single gas-filled pore. The vapor density in the pores can be expressed as the product of the relative humidity $\varphi$ and the saturated vapor density $\rho_{\mathrm{vs}}$ (Edlefsen and Anderson 1943).

$$
\rho_{\mathrm{v}}=\rho_{\mathrm{vs}} \varphi
$$

An expression for the relative humidity in the gas-filled pores can be found by assuming that the soil liquid and vapor are in thermodynamic equilibrium. In the absence of solutes, the free energy of the liquid phase and the vapor phase are equal (Edlefsen and Anderson 1943 and Hillel 1998). The free energy of the liquid and vapor phases is

$$
\begin{aligned}
& \Delta \mathrm{f}_{\ell}=\psi \mathrm{g} \\
& \Delta \mathrm{f}_{\mathrm{v}}=\mathrm{R}_{\mathrm{w}} \mathrm{T} \ln \left(\frac{\mathrm{P}_{\mathrm{v}}}{\mathrm{P}_{\mathrm{vs}}}\right)=\mathrm{R}_{\mathrm{w}} \mathrm{T} \ln (\varphi)
\end{aligned}
$$

The acceleration of gravity is represented by $g$, and $\mathrm{P}_{\mathrm{vs}}$ is the saturated vapor pressure at temperature T. Setting these two equations equal to each other gives an expression for the relative humidity.

$$
\varphi=\exp \left(\frac{\psi g}{\mathrm{R}_{\mathrm{w}} \mathrm{T}}\right)
$$

From Eqs. (A.16) and (A.19), the vapor density gradient can be expressed in terms of temperature and matric potential gradients, and the vapor diffusion equation can be written as

$$
\dot{\mathbf{m}}_{\mathrm{v}}=-\mathrm{D}_{\mathrm{a}}\left[\left.\rho_{\mathrm{vs}} \frac{\partial \varphi}{\partial \psi}\right|_{\mathrm{T}} \nabla \psi+\left(\varphi \frac{\partial \rho_{\mathrm{vs}}}{\partial \mathrm{T}}+\left.\rho_{\mathrm{vs}} \frac{\partial \varphi}{\partial \mathrm{T}}\right|_{\psi}+\frac{\varphi \rho_{\mathrm{vs}}}{\mathrm{T}}\right)(\nabla \mathrm{T})_{\mathrm{p}}\right]
$$

From equation (A.19), the derivatives of the relative humidity with temperature and matric potential are 


$$
\begin{aligned}
& \frac{\partial \varphi}{\partial \mathrm{T}}=\varphi\left[\left.\frac{\mathrm{g}}{\mathrm{R}_{\mathrm{w}} \mathrm{T}} \frac{\partial \psi}{\partial \mathrm{T}}\right|_{\theta}-\frac{\psi \mathrm{g}}{\mathrm{R}_{\mathrm{w}} \mathrm{T}^{2}}\right] \\
& \frac{\partial \varphi}{\partial \psi}=\frac{\varphi \mathrm{g}}{\mathrm{R}_{\mathrm{w}} \mathrm{T}}
\end{aligned}
$$

Substituting Eqs. (A.21) and (A.22) into Eq. (A.20) results in

$$
\dot{\mathbf{m}}_{\mathrm{v}}=-\mathrm{D}_{\mathrm{a}} \varphi \rho_{\mathrm{vs}}\left[\frac{\mathrm{g}}{\mathrm{R}_{\mathrm{w}} \mathrm{T}} \nabla \psi+\left(\frac{1}{\rho_{\mathrm{vs}}} \frac{\partial \rho_{\mathrm{vs}}}{\partial \mathrm{T}}+\frac{1}{\mathrm{~T}}-\frac{\psi \mathrm{g}}{\mathrm{R}_{\mathrm{w}} \mathrm{T}^{2}}+\left.\frac{\mathrm{g}}{\mathrm{R}_{\mathrm{w}} \mathrm{T}} \frac{\partial \psi}{\partial \mathrm{T}}\right|_{\theta}\right)(\nabla \mathrm{T})_{\mathrm{p}}\right]
$$

A closer look at the temperature gradient coefficient is needed at this point. De Vries (1958 and 1975) only includes the first term in the parentheses. Nakano and Miyazaki (1979) graphed the first three terms as a function of temperature for values of the matric potential of $-10^{4}$ and $-10^{5}$ $\mathrm{m}$ and presented a logical argument concerning the fourth term. They concluded that $(1 / \mathrm{T})$ is negligible, the term $\left(\psi \mathrm{g} / \mathrm{R}_{\mathrm{w}} \mathrm{T}^{2}\right)$ is only significant for $\psi<-10^{4} \mathrm{~m}$, and the term $\left(\mathrm{g} / \mathrm{R}_{\mathrm{w}} \mathrm{T}^{2}(\partial \psi / \partial \mathrm{T})\right)$ is only significant for $\psi<-10^{5} \mathrm{~m}$. The four terms are plotted as a function of the matric potential in Figure A.2 assuming that the surface tension ratio is a valid temperature correction for the matric potential. From this graph, it is easy to see that the second and third terms are negligible for $\psi>-10^{4} \mathrm{~m}$ and quickly become the dominant terms below this point. Only in extremely dry conditions is the matric potential less than $-10^{4} \mathrm{~m}$. However, since these terms become large very quickly, they are included for $\psi<-10^{4} \mathrm{~m}$. The term $(1 / \mathrm{T})$ is considered negligible and is dropped from the calculations. 


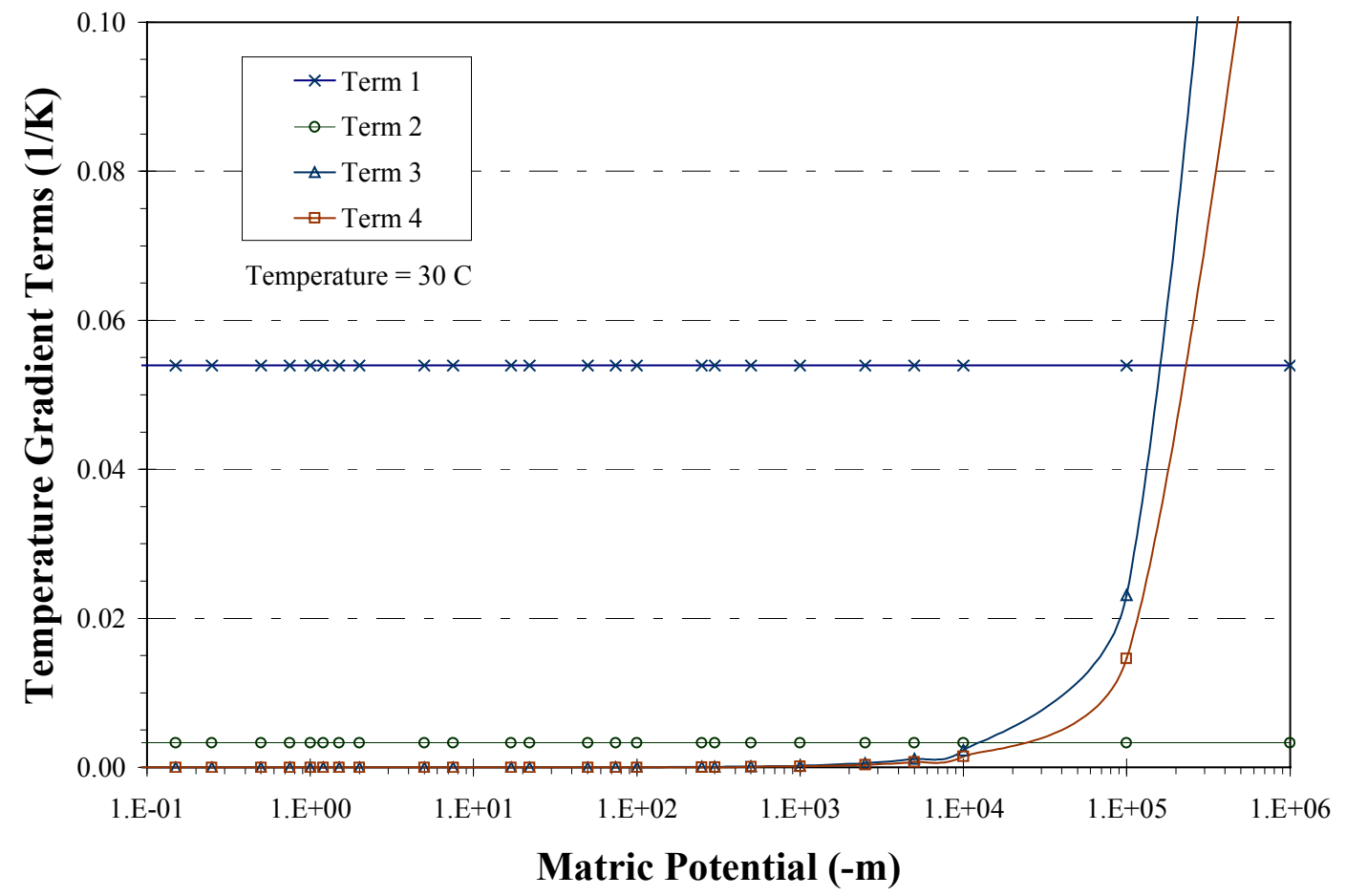

Figure A.2. Temperature gradient coefficient terms for the vapor diffusion equation (Eq. (A.23)) at $30.0^{\circ} \mathrm{C}$.

The vapor mass flux presented Eq. (A.23) is for a single pore and must be altered to include the effects of the porous matrix found in soil. The usual method of doing this is to introduce a term for the cross-section available for diffusion and a tortuosity factor. Philip and de Vries (1957) point out that the vapor and liquid phases interact under the influence of a temperature gradient and describe the process as a "series-parallel" transfer. This interaction increases both the available cross-section for diffusion and the tortuosity factor. A vapor-diffusion correction factor $\mathrm{f}\left(\theta_{\ell}\right)$ is added to account for these interactions. The vapor-diffusion correction factor is defined by de Vries (1958) as

$$
\begin{array}{ll}
\mathrm{f}\left(\theta_{\ell}\right)=\eta, & \text { for } \theta_{\ell} \leq \theta_{\mathrm{k}} \\
\mathrm{f}\left(\theta_{\ell}\right)=\left(\eta-\theta_{\ell}\right)+\theta_{\ell}\left(\eta-\theta_{\ell}\right) /\left(\eta-\theta_{\mathrm{k}}\right), & \text { for } \theta_{\ell}>\theta_{\mathrm{k}}
\end{array}
$$

The soil porosity is $\eta$, and $\theta_{\mathrm{k}}$ is a critical moisture content below which the hydraulic conductivity falls to a value much lower than its value at saturation (Philip and de Vries 1957). This critical moisture content value is not exactly the same as the value defined in Chapter 3 in the thermal conductivity discussion, but it is taken as the same value in this work.

Another correction for applying Eq. (A.23) to a soil matrix is required because the temperature gradients across the gas-filled pores are higher than that across the system due to the lower thermal conductivity of the gas-filled pores. The temperature gradient term is multiplied by the ratio of the average temperature gradient across the pores and the temperature gradient across the system. 
The vapor mass flux of Eq. (A.23) can now be written for the soil system as

$$
\frac{\dot{\mathbf{m}}_{\mathrm{v}}}{\rho_{\ell}}=-\mathrm{D}_{\psi \mathrm{v}} \nabla \psi-\mathrm{D}_{\mathrm{Tv}} \nabla \mathrm{T}
$$

The equation is divided by the liquid density for consistency with the liquid transfer equation. The matric and thermal vapor diffusivities are

$$
\begin{aligned}
& \mathrm{D}_{\psi \mathrm{v}}=\mathrm{f}\left(\theta_{\ell}\right) \mathrm{D}_{\mathrm{a}} \frac{\rho_{\mathrm{vs}}}{\rho_{\ell}} \frac{\varphi \mathrm{g}}{\mathrm{R}_{\mathrm{w}} \mathrm{T}} \\
& \mathrm{D}_{\mathrm{Tv}}=\mathrm{f}\left(\theta_{\ell}\right) \mathrm{D}_{\mathrm{a}} \varphi \frac{\rho_{\mathrm{vs}}}{\rho_{\ell}}\left(\frac{1}{\rho_{\mathrm{vs}}} \frac{\partial \rho_{\mathrm{vs}}}{\partial \mathrm{T}}-\frac{\psi \mathrm{g}}{\mathrm{R}_{\mathrm{w}} \mathrm{T}^{2}}+\left.\frac{\mathrm{g}}{\mathrm{R}_{\mathrm{w}} \mathrm{T}} \frac{\partial \psi}{\partial \mathrm{T}}\right|_{\theta}\right) \frac{(\nabla \mathrm{T})_{\mathrm{p}}}{(\nabla \mathrm{T})}
\end{aligned}
$$

As discussed above, the last two terms in the parentheses of Eq. (A.27) are only included for $\psi<$ $-10^{4} \mathrm{~m}$. The term $(\nabla \mathrm{T})_{\mathrm{p}}$ now represents the average temperature gradient across the gas-filled pores and not a single pore as used in Eq. (A.23). An expression for the ratio of the temperature gradients follows from the de Vries method of approximating the thermal conductivity (Chapter 3 and Appendix C) and can be calculated as

$$
\frac{(\nabla T)_{p}}{(\nabla T)}=\frac{\xi_{p}}{x_{w}+\xi_{p} x_{p}+\sum_{i=1}^{n} \xi_{i} x_{i}}
$$

The vapor content is expressed as an equivalent liquid content; therefore, assuming thermodynamic equilibrium between the liquid and vapor, we can write

$$
\theta_{\mathrm{v}}=\frac{\left(\eta-\theta_{\ell}\right) \rho_{\mathrm{v}}}{\rho_{\ell}}
$$

Expansion of $\left(\partial \theta_{v} / \partial t\right)$ from Eq. (A.29) yields

$$
\frac{\partial \theta_{\mathrm{v}}}{\partial \mathrm{t}}=-\frac{\varphi \rho_{\mathrm{vs}}}{\rho_{\mathrm{v}}} \frac{\partial \theta_{\ell}}{\partial \mathrm{t}}+\frac{\varphi\left(\eta-\theta_{\ell}\right)}{\rho_{\mathrm{v}}} \frac{\partial \rho_{\mathrm{vs}}}{\partial \mathrm{t}}+\frac{\left(\eta-\theta_{\ell}\right) \rho_{\mathrm{vs}}}{\rho_{\mathrm{v}}} \frac{\partial \varphi}{\partial \mathrm{t}}
$$

Substituting Eq. (A.7) into Eq. (A.30) and expanding the other time derivatives in terms of $\psi$ and $\mathrm{T}$ yields

$$
\frac{\partial \theta_{\mathrm{v}}}{\partial \mathrm{t}}=\mathrm{C}_{\psi \mathrm{v}} \frac{\partial \psi}{\partial \mathrm{t}}+\mathrm{C}_{\mathrm{Tv}} \frac{\partial \mathrm{T}}{\partial \mathrm{t}}
$$

where the matric and thermal vapor capacitances are

$$
\mathrm{C}_{\psi \mathrm{v}}=\frac{\rho_{\mathrm{vs}} \varphi}{\rho_{\ell}}\left[\frac{\left(\eta-\theta_{\ell}\right) \mathrm{g}}{\mathrm{R}_{\mathrm{w}} \mathrm{T}}-\left(\frac{\partial \theta_{\ell}}{\partial \psi}\right)_{\mathrm{T}}\right]
$$




$$
\mathrm{C}_{\mathrm{Tv}}=\frac{\rho_{\mathrm{vs}} \varphi}{\rho_{\ell}}\left[\frac{\left(\eta-\theta_{\ell}\right)}{\rho_{\mathrm{vs}}}\left(\frac{\partial \rho_{\mathrm{vs}}}{\partial \mathrm{T}}\right)-\left(\frac{\partial \theta_{\ell}}{\partial \mathrm{T}}\right)_{\psi}\right]
$$

By applying the conservation of mass to the vapor content in a similar manner as done earlier for the liquid moisture content, the following equation can be written.

$$
\frac{\partial \theta_{\mathrm{v}}}{\partial \mathrm{t}}=-\nabla \cdot\left(\dot{\mathbf{m}}_{\mathrm{v}} / \rho_{\ell}\right)+\mathrm{E}
$$

The governing equation for vapor transfer can now be derived by substituting Eqs. (A.25) and (A. 31) into (A.34).

$$
\mathrm{C}_{\psi \mathrm{v}} \frac{\partial \psi}{\partial \mathrm{t}}+\mathrm{C}_{\mathrm{Tv}} \frac{\partial \mathrm{T}}{\partial \mathrm{t}}=\nabla \cdot\left[\mathrm{D}_{\psi \mathrm{v}} \nabla \psi\right]+\nabla \cdot\left[\mathrm{D}_{\mathrm{Tv}} \nabla \mathrm{T}\right]+\mathrm{E}
$$

\section{A.3. Total Moisture Transfer}

The total moisture transfer equation is found by combining the equations for liquid and vapor transport, Eqs. (A.8) and (A.35).

$$
\mathrm{C}_{\psi \mathrm{m}} \frac{\partial \psi}{\partial \mathrm{t}}+\mathrm{C}_{\mathrm{Tm}} \frac{\partial \mathrm{T}}{\partial \mathrm{t}}=\nabla \cdot\left[\mathrm{D}_{\psi \mathrm{m}} \nabla \psi\right]+\nabla \cdot\left[\mathrm{D}_{\mathrm{Tm}} \nabla \mathrm{T}\right]+\frac{\partial \mathrm{K}}{\partial \mathrm{z}}
$$

where the matric and thermal moisture capacitances are

$$
\begin{aligned}
& \mathrm{C}_{\psi \mathrm{m}}=\mathrm{C}_{\psi \ell}+\mathrm{C}_{\psi \mathrm{v}} \quad[\mathrm{m}] \\
& \mathrm{C}_{\mathrm{Tm}}=\mathrm{C}_{\mathrm{T} \ell}+\mathrm{C}_{\mathrm{Tv}}[\mathrm{K}]
\end{aligned}
$$

and the matric and thermal moisture diffusivities are

$$
\begin{aligned}
& \mathrm{D}_{\psi \mathrm{m}}=\mathrm{K}+\mathrm{D}_{\psi \mathrm{v}}[\mathrm{m} / \mathrm{s}] \\
& \mathrm{D}_{\mathrm{Tm}}=\mathrm{D}_{\mathrm{Tv}}\left[\mathrm{m}^{2} / \mathrm{s} \mathrm{K}\right]
\end{aligned}
$$

\section{A.4. Heat Transfer}

Heat transfer in soil occurs by conduction, convection, latent heat transfer by vapor distillation cycles, sensible heat transfer by vapor and liquid movement, and radiation. Consider an energy balance on the control volume in Cartesian coordinates in Figure A.3. The energy balance is governed by the first law of thermodynamics.

$$
\mathrm{Q}_{\text {in }}=\Delta \mathrm{E}+\mathrm{W}_{\text {out }}
$$


The thermal energy transfer from the surroundings to the control volume is $\mathrm{Q}_{\mathrm{in}}$, the change in the internally stored energy of the system is $\Delta \mathrm{E}$, and the work done by the control volume on the surroundings is $\mathrm{W}_{\text {out }}$. The internal energy of the system consists of (Burmeister 1993)

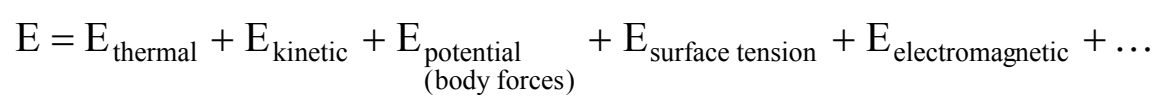

For the soil system, the changes in energy due to surface tension and electromagnetic forces are assumed to be negligible. The soil matrix is assumed to be fixed and, therefore, there is no change in potential energy. The change in the liquid's potential energy is taken into account through the connection to the moisture transfer equation. The fluid is assumed to move very slowly; therefore, changes in the system's kinetic energy are also negligible. This leaves only the thermal energy. If the first law of thermodynamics is taken as a rate equation, then it can be written as

$$
\dot{\mathrm{E}}_{\text {stored }}=\dot{\mathrm{E}}_{\text {in }}-\dot{\mathrm{E}}_{\text {out }}+\dot{\mathrm{Q}}_{\text {in }}-\mathrm{W}_{\text {out }}
$$

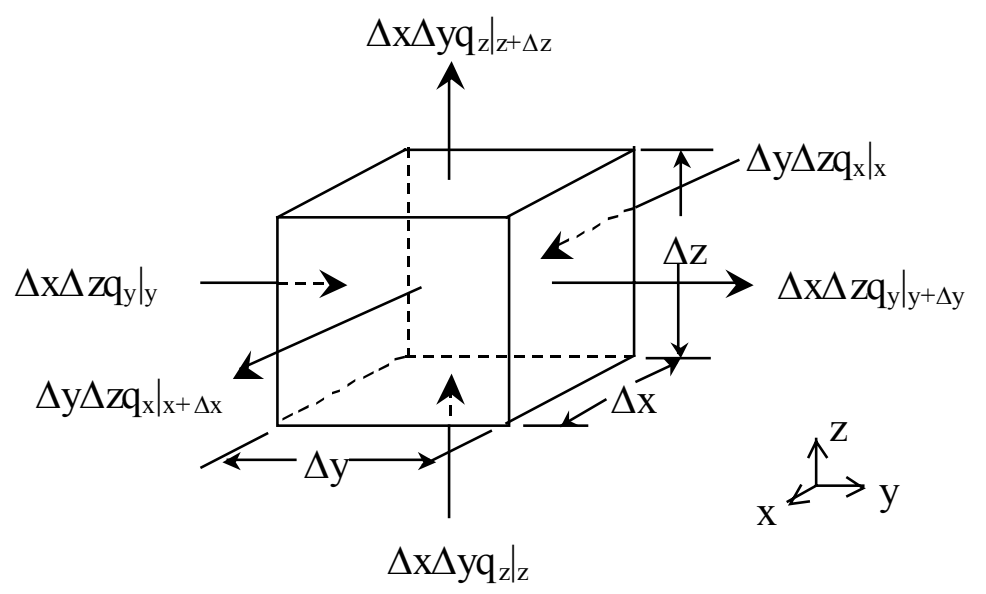

Figure A.3. Fixed-shape control volume and energy transfers.

The energy balance as a rate equation on the control volume in Figure A.3 is

$$
\begin{aligned}
\frac{\left(e \rho_{\mathrm{t}+\Delta \mathrm{t}}-\mathrm{e} \rho_{\mathrm{t}}\right)}{\Delta \mathrm{t}} \Delta \mathrm{x} \Delta \mathrm{y} \Delta \mathrm{z} & =-\left[\left(\mathrm{q}_{\mathrm{x}}\right)_{\mathrm{x}+\Delta \mathrm{x}}-\left(\mathrm{q}_{\mathrm{x}}\right)_{\mathrm{x}}\right] \Delta \mathrm{y} \Delta \mathrm{z} \\
& -\left[\left(\mathrm{q}_{\mathrm{y}}\right)_{\mathrm{y}+\Delta \mathrm{y}}-\left(\mathrm{q}_{\mathrm{y}}\right)_{\mathrm{y}}\right] \Delta \mathrm{x} \Delta \mathrm{z} \\
& -\left[\left(\mathrm{q}_{\mathrm{z}}\right)_{\mathrm{z}+\Delta \mathrm{z}}-\left(\mathrm{q}_{\mathrm{z}}\right)_{\mathrm{z}}\right] \Delta \mathrm{x} \Delta \mathrm{y} \\
& +\mathrm{q}^{\prime \prime \prime} \Delta \mathrm{x} \Delta \mathrm{y} \Delta \mathrm{z}-\mathrm{W}_{\text {out }}
\end{aligned}
$$

The internal energy per unit mass is e $\left(\mathrm{J} / \mathrm{m}^{3}\right)$, the flux crossing the boundary is $\mathrm{q}\left(\mathrm{W} / \mathrm{m}^{2}\right)$ and defined in Eq. (A.49), and $\mathrm{q}^{\prime \prime \prime}\left(\mathrm{W} / \mathrm{m}^{3}\right)$ is a heat-source term. Dividing both sides of the above equation by the volume and taking the limit as the differential quantities go to zero gives 


$$
\frac{\partial(\rho e)}{\partial t}=-\frac{\partial \mathrm{q}_{\mathrm{x}}}{\partial \mathrm{x}}-\frac{\partial \mathrm{q}_{\mathrm{y}}}{\partial \mathrm{y}}-\frac{\partial \mathrm{q}_{\mathrm{z}}}{\partial \mathrm{z}}+\mathrm{q}^{\prime \prime \prime}-\frac{\dot{\mathrm{W}}_{\text {out }}}{\Delta \mathrm{Vol}}
$$

The system volume is fixed and the fluid velocities are very small; therefore, the work done by the control volume is negligible.

As stated above, only changes in the thermal internal energy are considered, which can be approximated by

$$
\Delta \mathrm{e}=\Delta u=\mathrm{C}_{\mathrm{v}} \Delta \mathrm{T}
$$

For an incompressible media, the specific heat at constant volume is approximately equal to the specific heat at constant pressure.

$$
\mathrm{C}_{\mathrm{v}} \approx \mathrm{C}_{\mathrm{p}}
$$

The soil system is considered to be composed of solid soil grains (s), liquid water $(\ell)$, water vapor (v), and air (with other gasses). Neglecting the heat capacity of the air and the heat of wetting, the soil system's thermal energy relative to a reference temperature $T_{0}$ can be written as (Jury 1973)

$$
\begin{aligned}
\rho e & =(1-\eta) \rho_{\mathrm{s}} \mathrm{C}_{\mathrm{p}, \mathrm{s}}\left(\mathrm{T}-\mathrm{T}_{\mathrm{o}}\right)+\rho_{\ell} \theta_{\ell} \mathrm{C}_{\mathrm{p}, \ell}\left(\mathrm{T}-\mathrm{T}_{\mathrm{o}}\right) \\
& +\rho_{\ell} \theta_{\mathrm{v}} \mathrm{C}_{\mathrm{p}, \mathrm{v}}\left(\mathrm{T}-\mathrm{T}_{\mathrm{o}}\right)+\mathrm{h}_{\mathrm{fg}}\left(\mathrm{T}_{0}\right) \rho_{\ell} \theta_{\mathrm{v}}
\end{aligned}
$$

The specific heat capacities are denoted by $\mathrm{C}_{\mathrm{p}}(\mathrm{J} / \mathrm{kg} \mathrm{K})$, the latent heat (enthalpy) of vaporization is $h_{\mathrm{fg}}(\mathrm{J} / \mathrm{kg})$, and $\theta_{\mathrm{v}}$ is the volumetric vapor content and calculated as an effective volumetric liquid content. This equation assumes that the thermal sources and sinks are uniformly distributed throughout the soil system.

The heat flux in the soil consists of conduction, convection, and radiation. The conduction term is dominant, and the radiation term is negligible. With this in mind, the heat flux across a surface in the soil can be represented by the following equation

$$
\mathbf{q}=-\mathrm{k}^{*} \nabla \mathrm{T}+\mathrm{h}_{\mathrm{fg}}\left(\mathrm{T}_{\mathrm{o}}\right) \dot{\mathbf{m}}_{\mathrm{v}}+\mathrm{C}_{\mathrm{p}, \ell}\left(\mathrm{T}-\mathrm{T}_{\mathrm{o}}\right) \dot{\mathbf{m}}_{\ell}+\mathrm{C}_{\mathrm{p}, \mathrm{v}}\left(\mathrm{T}-\mathrm{T}_{\mathrm{o}}\right) \dot{\mathbf{m}}_{\mathrm{v}}
$$

The thermal conductivity $\mathrm{k}^{*}$ represents the pure heat conduction through the soil system with no moisture movement. Note that this is different than the thermal conductivity k calculated by the de Vries method (Chapter 3 and Appendix C), which includes the effect of temperature-driven latent heat transfer by vapor distillation. Substituting Eqs. (A.48) and (A.49) into Eq. (A.45) yields 


$$
\begin{aligned}
(1-\eta) \rho_{\mathrm{s}} \mathrm{C}_{\mathrm{p}, \mathrm{s}} \frac{\partial \mathrm{T}}{\partial \mathrm{t}}+\rho_{\ell} \theta_{\ell} \mathrm{C}_{\mathrm{p}, \ell} \frac{\partial \mathrm{T}}{\partial \mathrm{t}}+\rho_{\ell} \mathrm{C}_{\mathrm{p}, \ell}\left(\mathrm{T}-\mathrm{T}_{\mathrm{o}}\right) \frac{\partial \theta_{\ell}}{\partial \mathrm{t}}+\mathrm{h}_{\mathrm{fg}}\left(\mathrm{T}_{0}\right) \rho_{\ell} \frac{\partial \theta_{\mathrm{v}}}{\partial \mathrm{t}} \\
+\rho_{\ell} \theta_{\mathrm{v}} \mathrm{C}_{\mathrm{p}, \mathrm{v}} \frac{\partial \mathrm{T}}{\partial \mathrm{t}}+\rho_{\ell} \mathrm{C}_{\mathrm{p}, \mathrm{v}}\left(\mathrm{T}-\mathrm{T}_{\mathrm{o}}\right) \frac{\partial \theta_{\mathrm{v}}}{\partial \mathrm{t}} \\
=\nabla \cdot\left(\mathrm{k}^{*} \nabla \mathrm{T}\right)-\mathrm{h}_{\mathrm{fg}}\left(\mathrm{T}_{0}\right) \nabla \cdot \dot{\mathbf{m}}_{\mathrm{v}}-\mathrm{C}_{\mathrm{p}, \ell}\left(\mathrm{T}-\mathrm{T}_{\mathrm{o}}\right) \nabla \cdot \dot{\mathbf{m}}_{\ell}-\mathrm{C}_{\mathrm{p}, \ell} \dot{\mathbf{m}}_{\ell} \cdot \nabla \mathrm{T} \\
\quad-\mathrm{C}_{\mathrm{p}, \mathrm{v}}\left(\mathrm{T}-\mathrm{T}_{\mathrm{o}}\right) \nabla \cdot \dot{\mathbf{m}}_{\mathrm{v}}-\mathrm{C}_{\mathrm{p}, \mathrm{v}} \dot{\mathbf{m}}_{\mathrm{v}} \cdot \nabla \mathrm{T}+\mathrm{q}^{\prime \prime \prime}
\end{aligned}
$$

The total heat capacity of the soil system and the latent heat of vaporization at temperature $\mathrm{T}$ can be defined as

$$
\begin{aligned}
& \mathrm{C}=(1-\eta) \rho_{\mathrm{s}} \mathrm{C}_{\mathrm{p}, \mathrm{s}}+\theta_{\ell} \rho_{\ell} \mathrm{C}_{\mathrm{p}, \ell}+\theta_{\mathrm{v}} \rho_{\ell} \mathrm{C}_{\mathrm{p}, \mathrm{v}} \\
& \mathrm{h}_{\mathrm{fg}}(\mathrm{T})=\mathrm{h}_{\mathrm{fg}}\left(\mathrm{T}_{\mathrm{o}}\right)-\mathrm{C}_{\mathrm{p} \ell}\left(\mathrm{T}-\mathrm{T}_{\mathrm{o}}\right)+\mathrm{C}_{\mathrm{pv}}\left(\mathrm{T}-\mathrm{T}_{\mathrm{o}}\right)
\end{aligned}
$$

With these substitutions, Eq. (A.50) becomes

$$
\begin{aligned}
\mathrm{C} & \frac{\partial \mathrm{T}}{\partial \mathrm{t}}+\rho_{\ell} \mathrm{h}_{\mathrm{fg}} \frac{\partial \theta_{\mathrm{v}}}{\partial \mathrm{t}}+\rho_{\ell} \mathrm{C}_{\mathrm{p}, \ell}\left(\mathrm{T}-\mathrm{T}_{\mathrm{o}}\right) \frac{\partial \theta_{\ell}}{\partial \mathrm{t}}+\rho_{\ell} \mathrm{C}_{\mathrm{p}, \ell}\left(\mathrm{T}-\mathrm{T}_{\mathrm{o}}\right) \frac{\partial \theta_{\mathrm{v}}}{\partial \mathrm{t}} \\
= & \nabla \cdot\left(\mathrm{k}^{*} \nabla \mathrm{T}\right)-\mathrm{h}_{\mathrm{fg}} \nabla \cdot \dot{\mathbf{m}}_{\mathrm{v}}-\mathrm{C}_{\mathrm{p}, \ell}\left(\mathrm{T}-\mathrm{T}_{\mathrm{o}}\right) \nabla \cdot \dot{\mathbf{m}}_{\mathrm{v}}-\mathrm{C}_{\mathrm{p}, \ell}\left(\mathrm{T}-\mathrm{T}_{\mathrm{o}}\right) \nabla \cdot \dot{\mathbf{m}}_{\ell} \\
& \quad-\mathrm{C}_{\mathrm{p}, \ell} \dot{\mathbf{m}}_{\ell} \cdot \nabla \mathrm{T}-\mathrm{C}_{\mathrm{p}, \mathrm{v}} \dot{\mathbf{m}}_{\mathrm{v}} \cdot \nabla \mathrm{T}+\mathrm{q}^{\prime \prime \prime}
\end{aligned}
$$

The conservation of total moisture in the system can be expressed as

$$
\rho_{\mathrm{m}} \frac{\partial \theta_{\mathrm{m}}}{\partial \mathrm{t}}+\nabla \cdot \dot{\mathbf{m}}_{\mathrm{m}}=0
$$

By combining the like vapor and liquid terms in Eq. (A.53) to form moisture transfer terms similar to that of Eq. (A.54) and neglecting the sensible heat transfer of vapor flux, the soil heat transfer equation becomes

$$
\mathrm{C} \frac{\partial \mathrm{T}}{\partial \mathrm{t}}+\rho_{\ell} \mathrm{h}_{\mathrm{fg}} \frac{\partial \theta_{\mathrm{v}}}{\partial \mathrm{t}}=\nabla \cdot\left(\mathrm{k}^{*} \nabla \mathrm{T}\right)-\mathrm{h}_{\mathrm{fg}} \nabla \cdot \dot{\mathbf{m}}_{\mathrm{v}}-\mathrm{C}_{\mathrm{p}, \ell} \dot{\mathbf{m}}_{\ell} \cdot \nabla \mathrm{T}+\mathrm{q}^{\prime \prime \prime}
$$

From the derivations of the liquid and vapor transfer equations, we can substitute for the time rate of change of vapor (Eq. (A.31)) and the vapor flux (Eq. (A.25)) to get

$$
\begin{aligned}
& \mathrm{C} \frac{\partial \mathrm{T}}{\partial \mathrm{t}}+\rho_{\ell} \mathrm{h}_{\mathrm{fg}} \mathrm{C}_{\mathrm{Tv}} \frac{\partial \mathrm{T}}{\partial \mathrm{t}}+\rho_{\ell} \mathrm{h}_{\mathrm{fg}} \mathrm{C}_{\psi \mathrm{v}} \frac{\partial \psi}{\partial \mathrm{t}} \\
& =\nabla \cdot\left(\mathrm{k}^{*} \nabla \mathrm{T}\right)+\rho_{\ell} \mathrm{h}_{\mathrm{fg}} \nabla \cdot\left(\mathrm{D}_{\mathrm{Tv}} \nabla \mathrm{T}\right)+\rho_{\ell} \mathrm{h}_{\mathrm{fg}} \nabla \cdot\left(\mathrm{D}_{\psi \mathrm{v}} \nabla \psi\right) \\
& \quad+\mathrm{C}_{\mathrm{p}, \ell} \dot{\mathbf{m}}_{\ell} \cdot \nabla \mathrm{T}+\mathrm{q}^{\prime \prime \prime}
\end{aligned}
$$

finally

$$
\mathrm{C}_{\mathrm{TT}} \frac{\partial \mathrm{T}}{\partial \mathrm{t}}+\mathrm{C}_{\psi \mathrm{T}} \frac{\partial \psi}{\partial \mathrm{t}}=\nabla \cdot(\mathrm{k} \nabla \mathrm{T})+\nabla \cdot\left(\mathrm{D}_{\psi \mathrm{T}} \nabla \psi\right)+\mathrm{C}_{\mathrm{p}, \ell} \dot{\mathbf{m}}_{\ell} \cdot \nabla \mathrm{T}+\mathrm{q}^{\prime \prime \prime}
$$


The first term on the right hand side of Eq. (A.57) combines the first two terms on the right hand side of Eq. (A.56). This combination of the Fourier heat conduction and the temperature-driven latent heat transfer by the vapor distillation cycles is a result of using the de Vries method of calculating the effective thermal conductivity $\mathrm{k}$ of the soil system. The matric diffusivity is

$$
\mathrm{D}_{\psi \mathrm{T}}=\rho_{\ell} \mathrm{h}_{\mathrm{fg}} \mathrm{D}_{\psi \mathrm{v}} \quad\left[\mathrm{W} / \mathrm{m}^{2}\right]
$$

and the matric and thermal heat capacitances are

$$
\begin{aligned}
& \mathrm{C}_{\mathrm{TT}}=\mathrm{C}+\rho_{\ell} \mathrm{h}_{\mathrm{fg}} \mathrm{C}_{\mathrm{Tv}} \quad\left[\mathrm{J} \mathrm{s} / \mathrm{m}^{4}\right] \\
& \mathrm{C}_{\psi \mathrm{T}}=\rho_{\ell} \mathrm{h}_{\mathrm{fg}} \mathrm{C}_{\psi \mathrm{v}} \quad\left[\mathrm{J} / \mathrm{m}^{3} \mathrm{~K}\right]
\end{aligned}
$$

\section{A.5. Freezing Model}

The purpose of this model is to capture the effects of freezing on the heat transfer process while avoiding complications that increase computation time drastically. Freezing affects the heat transfer mainly through the heat that is released or absorbed during the phase-change process and through the changes in thermal and hydraulic properties.

The phase change associated with freezing water in soil is not isothermal; in fact, a small amount of liquid water remains even at temperatures near liquid nitrogen (Harlan 1973). The unfrozen water content at temperatures below the freezing point of water exists in thin films adsorbed on the soil grains. The freezing process is often modeled as starting at the $0.0^{\circ} \mathrm{C}$ isotherm and extending through a frozen fringe to a solid ice layer (called an ice lens). In a dynamic situation, the properties of the frozen fringe are typically unknown and must be approximated (Nakano 1999). To simplify the model due to the lack of knowledge of the physical process, the freezing process was assumed to be isothermal as shown in Figure A.4.

If only pore ice exists in the partially frozen soil, the movement of the unfrozen water content can be approximated by a Darcy's Law approach similar to that used in unfrozen soil (Kay and Perfect 1988). The correlations used for the hydraulic conductivity and other properties for frozen soil are given in Appendix C. The soil matrix is assumed to be nondeformable; therefore, frost heaving is not modeled. The effects of solutes are also neglected. 


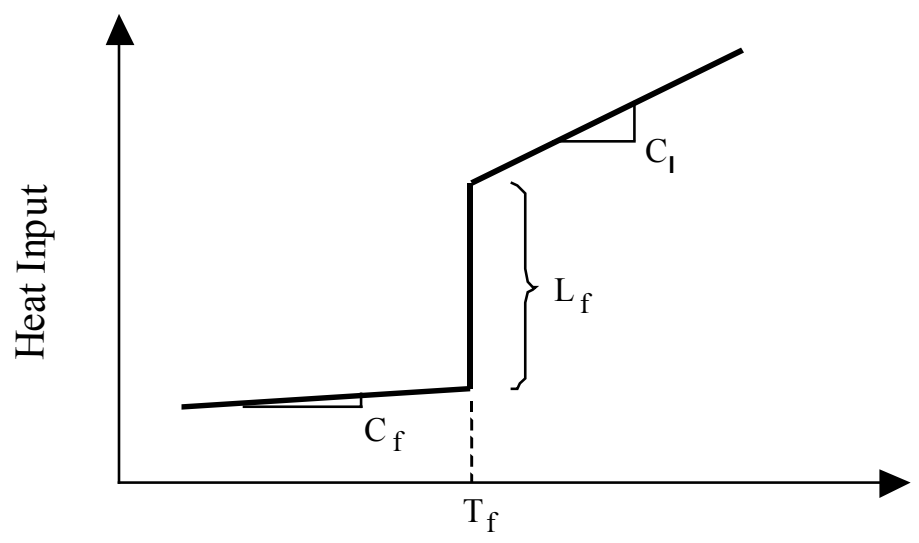

Temperature

Figure A.4. Model of the isothermal soil-freezing process.

The freezing and thawing processes are modeled as shown in Figure A.5. It is assumed that the heat capacity of each node can be calculated by Eq. (A.61) for the initial estimate of the temperature $\mathrm{T}_{1}$. After the temperature and matric potential equations are solved, the nodes are checked for a solid-liquid phase change and new temperatures $\mathrm{T}_{2}^{\prime}$ and moisture and ice contents $\theta_{\ell, 2}^{\prime}$ and $\theta_{i, 2}^{\prime}$ are calculated accounting for the effects of the latent heat of fusion according to the cases outlined below.

$$
\mathrm{C}=\rho_{\mathrm{s}} \mathrm{C}_{\mathrm{P}, \mathrm{s}}+\theta_{\ell} \rho_{\ell} \mathrm{C}_{\mathrm{P}, \ell}+\theta_{\mathrm{i}} \rho_{\mathrm{i}} \mathrm{C}_{\mathrm{P}, \mathrm{i}}
$$

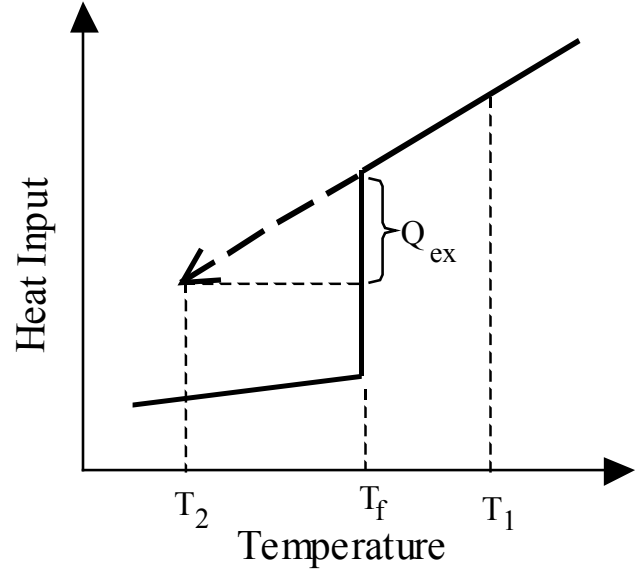

(a) Freezing

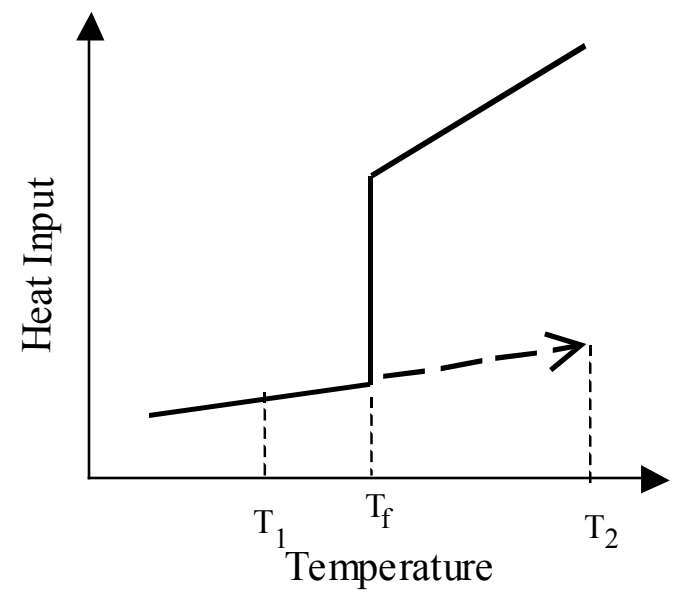

(b) Thawing

Figure A.5. Model approximation of isothermal (a) freezing and (b) thawing of soil.

CASE 1: Freezing starting at $\mathrm{T}_{1}$ in Figure A.5a

The excess heat removed beyond cooling the system from $T_{1}$ to $T_{f}$, is given by: 


$$
\mathrm{Q}_{\mathrm{ex}}=\mathrm{CV}_{\mathrm{n}}\left(\mathrm{T}_{2}-\mathrm{T}_{\mathrm{f}}\right)=\mathrm{C}_{\mathrm{TT}}\left(\mathrm{T}_{2}-\mathrm{T}_{\mathrm{f}}\right)
$$

The volume associated with the node is $\mathrm{V}_{\mathrm{n}}, \mathrm{C}$ is the volumetric heat capacity, and $\mathrm{C}_{\mathrm{TT}}$ is the heat capacity of the node as defined by Eq. (A.59) and calculated in the finite element formulation of the problem.

The heat removal required for a complete phase change with $\mathrm{L}_{\mathrm{f}}(\mathrm{J} / \mathrm{kg})$ as the latent heat of fusion is

$$
\mathrm{Q}_{\mathrm{pc}}=-\theta_{\ell} \rho_{\ell} \mathrm{L}_{\mathrm{f}} \mathrm{V}_{\mathrm{n}}
$$

If $\left|Q_{e x}\right| \leq\left|Q_{p c}\right|$, then the system is partially frozen, and the following applies

$$
\begin{aligned}
& \mathrm{T}_{2}^{\prime}=\mathrm{T}_{\mathrm{f}} \\
& \theta_{\ell, 2}^{\prime}=\theta_{\ell, 1}\left(1-\mathrm{Q}_{\mathrm{ex}} / \mathrm{Q}_{\mathrm{pc}}\right) \\
& \theta_{\mathrm{i}, 2}^{\prime}=\theta_{\mathrm{i}, 1}+\left(\theta_{\ell, 1}-\theta_{\ell, 2}^{\prime}\right) \rho_{\ell} / \rho_{\mathrm{i}}
\end{aligned}
$$

If $\left|Q_{e x}\right|>\left|Q_{p c}\right|$, then the system is completely frozen, and the following equations apply. Note that the new temperature is just an approximation since the heat capacity was originally calculated with a liquid content and the final state is frozen. A more accurate temperature will be calculated on the next iteration, which will use the correct heat capacities.

$$
\begin{aligned}
& \mathrm{T}_{2}^{\prime}=\mathrm{T}_{\mathrm{f}}+\frac{\mathrm{Q}_{\mathrm{ex}}-\mathrm{Q}_{\mathrm{pc}}}{\mathrm{C}_{\mathrm{TT}}} \\
& \theta_{\ell, 2}^{\prime}=0 \\
& \theta_{\mathrm{i}, 2}^{\prime}=\theta_{\mathrm{i}, 1}+\left(\theta_{\ell, 1}-\theta_{\ell, 2}\right) \rho_{\ell} / \rho_{\mathrm{i}}
\end{aligned}
$$

This case also applies for an initial temperature of $\mathrm{T}_{\mathrm{f}}$ and freezing.

CASE 2: Thawing starting at $\mathrm{T}_{1}$ in Figure A.5b.

The excess heat added beyond heating the system from $T_{1}$ to $T_{f}$, is given by

$$
\mathrm{Q}_{\mathrm{ex}}=\mathrm{CV}_{\mathrm{n}}\left(\mathrm{T}_{2}-\mathrm{T}_{\mathrm{f}}\right)=\mathrm{C}_{\mathrm{TT}}\left(\mathrm{T}_{2}-\mathrm{T}_{\mathrm{f}}\right)
$$

The heat addition required for a complete phase change is

$$
\mathrm{Q}_{\mathrm{pc}}=\theta_{\mathrm{i}} \rho_{\mathrm{i}} \mathrm{L}_{\mathrm{f}} \mathrm{V}_{\mathrm{n}}
$$

If $\left|Q_{e x}\right| \leq\left|Q_{p c}\right|$, then the system is partially frozen, and the following applies

$$
\begin{aligned}
& \mathrm{T}_{2}^{\prime}=\mathrm{T}_{\mathrm{f}} \\
& \theta_{\mathrm{i}, 2}^{\prime}=\theta_{\mathrm{i}, 1}\left(1-\mathrm{Q}_{\mathrm{ex}} / \mathrm{Q}_{\mathrm{pc}}\right) \\
& \theta_{\ell, 2}^{\prime}=\theta_{\ell, 1}+\left(\theta_{\mathrm{i}, 1}-\theta_{\mathrm{i}, 2}^{\prime}\right) \rho_{\mathrm{i}} / \rho_{\ell}
\end{aligned}
$$


If $\left|Q_{\mathrm{ex}}\right|>\left|\mathrm{Q}_{\mathrm{pc}}\right|$, then the system is completely thawed, and the following equations apply. Note that the new temperature is just an approximation since the heat capacity was originally calculated with an ice content and the final state has no ice. A more accurate temperature is calculated on the next iteration, which will use the correct heat capacities.

$$
\begin{aligned}
& \mathrm{T}_{2}^{\prime}=\mathrm{T}_{\mathrm{f}}+\frac{\mathrm{Q}_{\mathrm{ex}}-\mathrm{Q}_{\mathrm{pc}}}{\mathrm{C}_{\mathrm{TT}}} \\
& \theta_{\mathrm{i}, 2}^{\prime}=0 \\
& \theta_{\ell, 2}^{\prime}=\theta_{\ell, 1}+\left(\theta_{\mathrm{i}, 1}-\theta_{\mathrm{i}, 2}\right) \rho_{\mathrm{i}} / \rho_{\ell}
\end{aligned}
$$

This case also applies for an initial temperature of $\mathrm{T}_{\mathrm{f}}$ and thawing. 


\section{APPENDIX B: Finite Element Formulation}

\section{B.1. Introduction}

When using the FEM, the problem domain is divided into elements with three or more nodes for two dimensions and four or more nodes for three dimensions. The dependent variables, in this case $\mathrm{T}$ and $\psi$, are approximated with piecewise continuous functions over the elements. The approximations are denoted by $\hat{\mathrm{T}}$ and $\hat{\psi}$ and are calculated over each element by (Zienkiewicz and Taylor 1989)

$$
\begin{aligned}
& \mathrm{T}(\mathrm{x}, \mathrm{y}, \mathrm{z}) \approx \hat{\mathrm{T}}(\mathrm{x}, \mathrm{y}, \mathrm{z})=\sum_{\mathrm{i}=1}^{\mathrm{n}} \mathrm{N}_{\mathrm{i}}(\mathrm{x}, \mathrm{y}, \mathrm{z}) \mathrm{T}_{\mathrm{i}} \\
& \psi(\mathrm{x}, \mathrm{y}, \mathrm{z}) \approx \hat{\psi}(\mathrm{x}, \mathrm{y}, \mathrm{z})=\sum_{\mathrm{i}=1}^{\mathrm{n}} \mathrm{N}_{\mathrm{i}}(\mathrm{x}, \mathrm{y}, \mathrm{z}) \psi_{\mathrm{i}}
\end{aligned}
$$

In Eq. (B.1), the $\mathrm{N}_{\mathrm{i}}$ are shape functions (or interpolation functions), $\mathrm{T}_{\mathrm{i}}$ and $\psi_{\mathrm{i}}$ are the nodal point values, and $\mathrm{n}$ is the number of nodes per element. The form of the shape functions determines the "shape" of the approximation over the elements. For two-dimensional problems, three- and fournode elements use linear approximations, and elements with more nodes use higher order approximations. The programs for this research were written to accept only three-node triangles and four-node quadrilaterals.

In the FEM, the elements in the problem domain are mapped to a parent element using the shape functions. The most common parent elements are isoperimetric elements, which means that the order of the interpolation functions used to map the dependent variables and the shape functions used to describe the shape of the elements are the same (Istok 1989). The parent isoperimetric elements used and the shape functions are shown in Figure B.1.

\section{B.2. Application to the Heat-and-Moisture Transfer Equations}

The governing differential equations for the heat and moisture transfer in soil can be written as

$$
\begin{aligned}
& \nabla \cdot(\mathrm{k} \nabla \mathrm{T})+\nabla \cdot\left(\mathrm{D}_{\psi \mathrm{T}} \nabla \psi\right)+\mathrm{C}_{\mathrm{p}, \ell} \dot{\mathbf{m}}_{\ell} \cdot \nabla \mathrm{T}+\mathrm{Q}-\mathrm{C}_{\mathrm{TT}} \frac{\partial \mathrm{T}}{\partial \mathrm{t}}-\mathrm{C}_{\psi \mathrm{T}} \frac{\partial \psi}{\partial \mathrm{t}}=0 \\
& \nabla \cdot\left(\mathrm{D}_{\mathrm{Tm}} \nabla \mathrm{T}\right)+\nabla \cdot\left(\mathrm{D}_{\psi \mathrm{m}} \nabla \psi\right)+\frac{\partial \mathrm{K}}{\partial \mathrm{z}}-\mathrm{C}_{\mathrm{Tm}} \frac{\partial \mathrm{T}}{\partial \mathrm{t}}-\mathrm{C}_{\psi \mathrm{m}} \frac{\partial \psi}{\partial \mathrm{t}}=0
\end{aligned}
$$



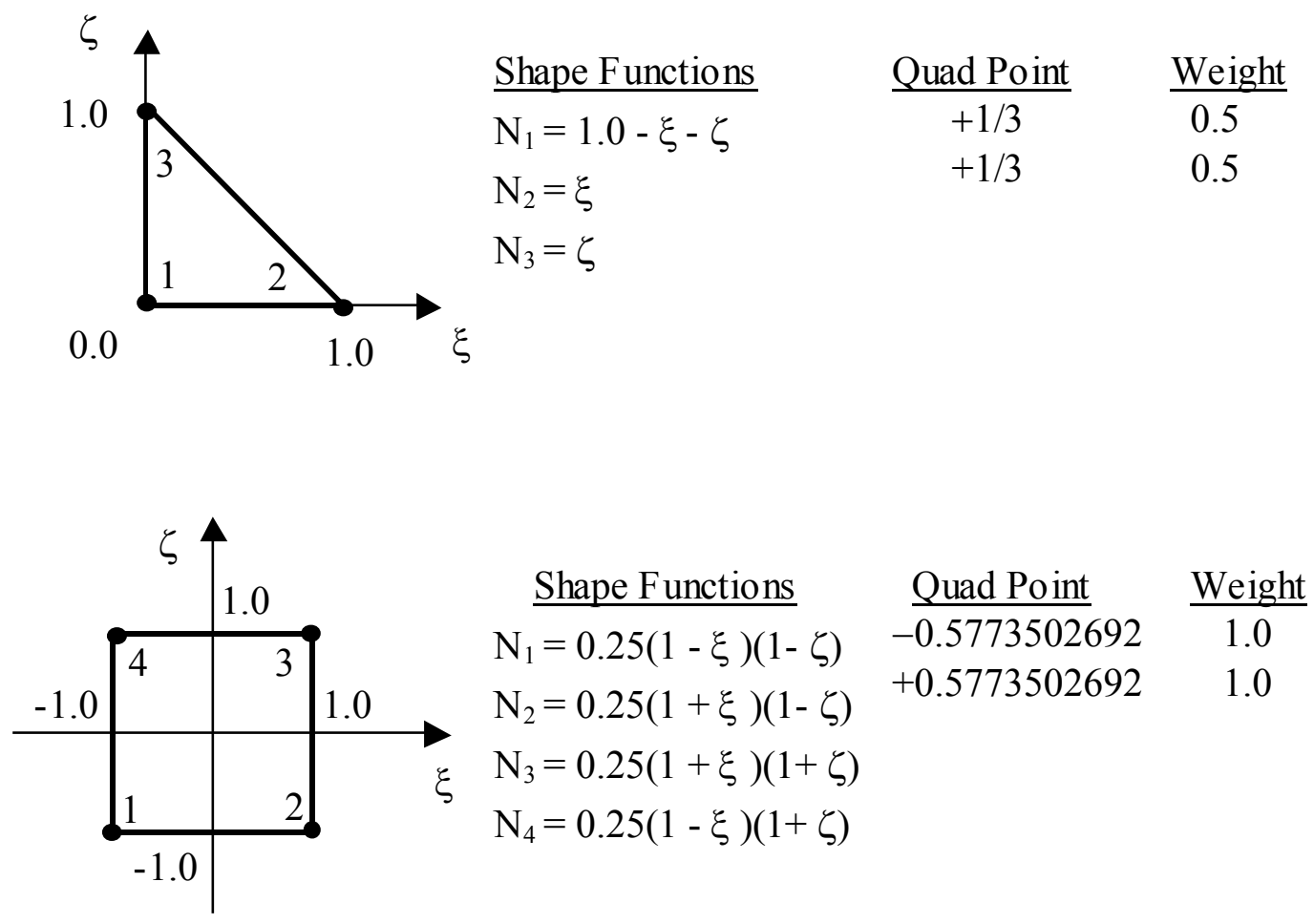

Figure B.1. Three- and four-node isoperimetric parent elements, shape functions, and points and weights used for Gaussian quadrature (Zienkiewicz and Taylor 1989).

When approximate solutions are used in Eqs. (B.2) and (B.3), the equations are not satisfied and there is a residual. The residual varies across the domain, and it is not possible to make the residual zero for every node. In the method of weighted residuals, the weighted average of the residuals is forced to zero. In Galerkin's method of weighted residuals, the weighting functions are the original shape functions. Applying Galerkin's method to the governing differential equations consists of multiplying the residual by the shape factors and setting the integral over the domain equal to zero.

$$
\begin{gathered}
\int_{\Omega} \mathbf{N}\left[\begin{array}{c}
\nabla \cdot(\mathrm{k} \nabla \hat{\mathrm{T}})+\nabla \cdot\left(\mathbf{D}_{\psi \mathrm{T}} \nabla \hat{\psi}\right)+\mathrm{C}_{\mathrm{p}, \ell} \dot{\mathbf{m}}_{\ell} \cdot \nabla \hat{\mathrm{T}} \\
\left.+\mathbf{Q}-\mathbf{C}_{\mathrm{TT}} \frac{\partial \hat{\mathrm{T}}}{\partial \mathrm{t}}-\mathbf{C}_{\psi \mathrm{T}} \frac{\partial \hat{\psi}}{\partial \mathrm{t}}\right] \mathrm{d} \Omega=0 \\
\int_{\Omega} \mathbf{N}\left[\nabla \cdot\left(\mathbf{D}_{\mathrm{Tm}} \nabla \hat{\mathrm{T}}\right)+\nabla \cdot\left(\mathbf{D}_{\psi \mathrm{m}} \nabla \hat{\psi}\right)+\frac{\partial \mathrm{K}}{\partial \mathrm{z}}-\mathbf{C}_{\mathrm{Tm}} \frac{\partial \hat{\mathrm{T}}}{\partial \mathrm{t}}-\mathbf{C}_{\psi \mathrm{m}} \frac{\partial \hat{\psi}}{\partial \mathrm{t}}\right] \mathrm{d} \Omega=0
\end{array}\right.
\end{gathered}
$$

The double derivatives in the above equations can be expanded by the chain rule to get 


$$
\begin{aligned}
& \int_{\Omega}\left[\begin{array}{r}
\nabla \cdot\left(\mathbf{N}^{\mathrm{T}} \mathrm{k} \nabla \hat{\mathrm{T}}\right)-\mathbf{D}_{\mathrm{TT}} \nabla^{\mathrm{T}} \mathbf{N} \nabla \hat{\mathrm{T}}+\nabla \cdot\left(\mathbf{N}^{\mathrm{T}} \mathbf{D}_{\psi \mathrm{T}} \nabla \hat{\psi}\right)-\mathbf{D}_{\psi \mathrm{T}} \nabla^{\mathrm{T}} \mathbf{N} \nabla \hat{\psi} \\
+\mathrm{C}_{\mathrm{p}, \ell} \dot{\mathbf{m}}_{\ell} \cdot \nabla \hat{\mathrm{T}}+\mathbf{N} \mathbf{Q}-\mathbf{N} \mathbf{C}_{\mathrm{TT}} \frac{\partial \hat{\mathrm{T}}}{\partial \mathrm{t}}-\mathbf{N} \mathbf{C}_{\psi \mathrm{T}} \frac{\partial \hat{\psi}}{\partial \mathrm{t}}
\end{array}\right] \mathrm{d} \Omega=0 \\
& \int_{\Omega}\left[\begin{array}{l}
\nabla \cdot\left(\mathbf{N}^{\mathrm{T}} \mathbf{D}_{\mathrm{Tm}} \nabla \hat{\mathrm{T}}\right)-\mathbf{D}_{\mathrm{Tm}} \nabla^{\mathrm{T}} \mathbf{N} \nabla \hat{\mathrm{T}}+\nabla \cdot\left(\mathbf{N}^{\mathrm{T}} \mathbf{D}_{\psi \mathrm{m}} \nabla \hat{\psi}\right)- \\
\left.\mathbf{D}_{\psi \mathrm{m}} \nabla^{\mathrm{T}} \mathbf{N} \nabla \hat{\psi}+\mathbf{N} \frac{\partial \mathrm{K}}{\partial \mathrm{z}}-\mathbf{N} \mathbf{C}_{\mathrm{Tm}} \frac{\partial \hat{\mathrm{T}}}{\partial \mathrm{t}}-\mathbf{N} \mathbf{C}_{\psi \mathrm{m}} \frac{\partial \hat{\psi}}{\partial \mathrm{t}}\right] \mathrm{d} \Omega=0
\end{array}\right]
\end{aligned}
$$

Equation (B.7) can be rewritten to eliminate the derivative of the hydraulic conductivity with respect to $\mathrm{z}$ with the following identities from Eqs (A.39) and (A.2).

$$
\begin{aligned}
& \mathrm{D}_{\psi \mathrm{m}}=\mathrm{K}+\mathrm{D}_{\psi \mathrm{v}} \\
& \psi=\Phi-\mathrm{z} \\
& \mathrm{K} \nabla \psi=\mathrm{K} \nabla \Phi-\mathrm{K} \hat{\mathrm{k}}
\end{aligned}
$$

The third and fifth terms from Eq. (B.7) can be rewritten using the identities in Eqs. (B.8) and (B.10) to get

$$
\nabla \cdot\left(\mathbf{N}^{\mathrm{T}} \mathbf{D}_{\psi \mathrm{m}} \nabla \hat{\psi}\right)+\mathbf{N} \frac{\partial \mathrm{K}}{\partial \mathbf{z}}=\nabla \cdot\left(\mathbf{N}^{\mathrm{T}} \mathbf{D}_{\psi \mathrm{v}} \nabla \hat{\psi}\right)+\nabla \cdot\left(\mathbf{N}^{\mathrm{T}} \mathrm{K} \nabla \hat{\Phi}\right)+\mathrm{K} \frac{\partial \mathbf{N}_{\mathrm{j}}}{\partial \mathrm{z}}
$$

Substituting these new terms back into Eq. (B.7) gives

$$
\int_{\Omega}\left[\begin{array}{l}
\nabla \cdot\left(\mathbf{N}^{\mathrm{T}} \mathbf{D}_{\mathrm{Tm}} \nabla \hat{\mathrm{T}}\right)-\mathbf{D}_{\mathrm{Tm}} \nabla^{\mathrm{T}} \mathbf{N} \nabla \hat{\mathrm{T}}+\nabla \cdot\left(\mathbf{N}^{\mathrm{T}} \mathbf{D}_{\psi \mathrm{v}} \nabla \hat{\psi}\right)+\nabla \cdot\left(\mathbf{N}^{\mathrm{T}} \mathrm{K} \nabla \hat{\Phi}\right)- \\
\mathbf{D}_{\psi \mathrm{m}} \nabla^{\mathrm{T}} \mathbf{N} \nabla \hat{\psi}+\mathrm{K} \frac{\partial \mathbf{N}}{\partial \mathrm{z}}-\mathbf{N} \mathbf{C}_{\mathrm{Tm}} \frac{\partial \hat{\mathrm{T}}}{\partial \mathrm{t}}-\mathbf{N} \mathbf{C}_{\psi \mathrm{m}} \frac{\partial \hat{\psi}}{\partial \mathrm{t}}
\end{array}\right] \mathrm{d} \Omega=0
$$

The double derivative terms in Eqs. (B.6) and (B.12) can be transformed by applying Gauss's Theorem, which may be stated as (Arfken and Weber 1995)

$$
\int_{\Omega} \nabla \cdot \mathbf{V} \mathrm{d} \Omega \equiv \int_{\Gamma} \mathbf{V} \cdot \mathrm{d} \Gamma
$$

The volume integral $\Omega$ is transformed into a surface integral $\Gamma$. With this transformation, the governing equations are now in the weak form.

$$
\begin{aligned}
& \int_{\Omega}\left[\mathbf{k} \nabla^{\mathrm{T}} \mathbf{N} \nabla \hat{\mathrm{T}}+\mathbf{D}_{\psi \mathrm{T}} \nabla^{\mathrm{T}} \mathbf{N} \nabla \hat{\psi}+\mathbf{N C}_{\mathrm{TT}} \frac{\partial \hat{\mathrm{T}}}{\partial \mathrm{t}}+\mathbf{N} \mathbf{C}_{\psi \mathrm{T}} \frac{\partial \hat{\psi}}{\partial \mathrm{t}}\right] \mathrm{d} \Omega \\
& +\int_{\Omega} \mathrm{C}_{\mathrm{p}, \ell} \mathbf{N} \dot{\mathbf{m}}_{\ell} \cdot \nabla \hat{\mathrm{T}} \mathrm{d} \Omega-\int_{\Omega} \mathbf{N Q} \mathrm{d} \Omega-\int_{\Gamma}\left[\mathbf{N D}_{\mathrm{TT}} \frac{\partial \hat{\mathrm{T}}}{\partial \mathrm{n}}\right] \mathrm{d} \Gamma-\int_{\Gamma}\left[\mathbf{N D}_{\psi \mathrm{T}} \frac{\partial \hat{\psi}}{\partial \mathrm{n}}\right] \mathrm{d} \Gamma=0
\end{aligned}
$$




$$
\begin{aligned}
& \int_{\Omega}\left[\mathbf{D}_{\mathrm{Tm}} \nabla^{\mathrm{T}} \mathbf{N} \nabla \hat{\mathrm{T}}+\mathbf{D}_{\psi \mathrm{m}} \nabla^{\mathrm{T}} \mathbf{N} \nabla \hat{\psi}+\mathbf{N} \mathbf{C}_{\mathrm{Tm}} \frac{\partial \hat{\mathrm{T}}}{\partial \mathrm{t}}+\mathbf{N} \mathbf{C}_{\psi \mathrm{m}} \frac{\partial \hat{\psi}}{\partial \mathrm{t}}\right] \mathrm{d} \Omega \\
& +\int_{\Omega} \mathbf{K} \frac{\partial \mathbf{N}}{\partial \mathrm{z}} \mathrm{d} \Omega-\int_{\Gamma}\left[\mathbf{N D}_{\mathrm{Tm}} \frac{\partial \hat{\mathrm{T}}}{\partial \mathrm{n}}\right] \mathrm{d} \Gamma-\int_{\Gamma}\left[\mathbf{N D}_{\psi \mathrm{v}} \frac{\partial \hat{\psi}}{\partial \mathrm{n}}\right] \mathrm{d} \Gamma-\int_{\Gamma}\left[\mathbf{N K} \frac{\partial \hat{\Phi}}{\partial \mathrm{n}}\right] \mathrm{d} \Gamma=0
\end{aligned}
$$

Notice that only the first derivative of the dependent variables appears in the equations; therefore, the requirements on the solutions have been weakened. Now the FEM approximations from Eq. (B.1) are inserted for the approximations of the dependent variables to get

$$
\begin{aligned}
& \int_{\Omega} \mathbf{N}^{\prime \mathrm{T}} \mathrm{k} \mathbf{N}^{\prime} \mathbf{T} \mathrm{d} \Omega+\int_{\Omega} \mathbf{N}^{\prime \mathrm{T}} \mathbf{D}_{\psi \mathrm{T}} \mathbf{N}^{\prime} \boldsymbol{\psi} \mathrm{d} \Omega+\int_{\Omega} \mathbf{N} \mathbf{C}_{\mathrm{TT}} \mathbf{N}^{\mathrm{T}} \frac{\partial \mathbf{T}}{\partial \mathrm{t}} \mathrm{d} \Omega+ \\
& \int_{\Omega} \mathbf{N C}_{\psi \mathrm{T}} \mathbf{N}^{\mathrm{T}} \frac{\partial \psi}{\partial \mathrm{t}} \mathrm{d} \Omega+\int_{\Omega} \mathrm{C}_{\mathrm{p}, \ell} \mathbf{N} \dot{m}_{\ell} \cdot \mathbf{N}^{\prime} \mathbf{T} \mathrm{d} \Omega \\
& -\int_{\Omega} \mathbf{N} \mathbf{d} \Omega-\int_{\Gamma} \mathbf{N}_{\mathrm{s}} \mathbf{D}_{\mathrm{TT}} \mathbf{N}_{\mathrm{s}}^{\mathrm{T}} \frac{\partial \mathbf{T}}{\partial \mathrm{n}} \mathrm{d} \Gamma-\int_{\Gamma} \mathbf{N}_{\mathrm{s}} \mathbf{D}_{\psi \mathrm{T}} \mathbf{N}_{\mathrm{s}}^{\mathrm{T}} \frac{\partial \boldsymbol{\psi}}{\partial \mathrm{n}} \mathrm{d} \Gamma=0 \\
& \int_{\Omega} \mathbf{N}^{\prime \mathrm{T}} \mathbf{D}_{\mathrm{Tm}} \mathbf{N}^{\prime} \mathbf{T} \mathrm{d} \Omega+\int_{\Omega} \mathbf{N}^{\prime \mathrm{T}} \mathbf{D}_{\psi \mathrm{m}} \mathbf{N}^{\prime} \boldsymbol{\psi} \mathrm{d} \Omega+\int_{\Omega} \mathbf{N} \mathbf{C}_{\mathrm{Tm}} \mathbf{N}^{\mathrm{T}} \frac{\partial \mathbf{T}}{\partial \mathrm{t}} \mathrm{d} \Omega+ \\
& \int_{\Omega} \mathbf{N C}_{\psi \mathrm{m}} \mathbf{N}^{\mathrm{T}} \frac{\partial \boldsymbol{\psi}}{\partial \mathrm{t}} \mathrm{d} \Omega-\int_{\Omega} \mathbf{K} \frac{\partial \mathbf{N}}{\partial \mathrm{z}} \mathrm{d} \Omega-\int_{\Gamma} \mathbf{N}_{\mathrm{s}} \mathbf{D}_{\mathrm{Tm}} \mathbf{N}_{\mathrm{s}}^{\mathrm{T}} \frac{\partial \mathbf{T}}{\partial \mathrm{n}} \mathrm{d} \Gamma- \\
& \int_{\Gamma} \mathbf{N}_{\mathrm{s}} \mathbf{D}_{\psi \mathrm{v}} \mathbf{N}_{\mathrm{s}}^{\mathrm{T}} \frac{\partial \psi}{\partial \mathrm{n}} \mathrm{d} \Gamma-\int_{\Gamma} \mathbf{N}_{\mathrm{s}} \mathbf{K} \mathbf{N}_{\mathrm{s}}^{\mathrm{T}} \frac{\partial \boldsymbol{\Phi}}{\partial \mathrm{n}} \mathrm{d} \Gamma=0
\end{aligned}
$$

where $\mathbf{N}^{\prime}=\nabla \mathbf{N}$ and $\mathbf{N}^{\prime T}=\nabla^{\mathrm{T}} \mathbf{N}$. The temperatures, matric potentials, and total potentials are now vectors of the nodal point values for the element. Equations (B.16) and (B.17) are applied to one element at a time. The flux boundary conditions are defined in Eqs. (4.46) and (4.75) and repeated here for convenience.

$$
\begin{aligned}
& \mathrm{q}_{\mathrm{g}}=-\mathrm{D}_{\mathrm{TT}} \frac{\partial \mathrm{T}}{\partial \mathrm{n}}-\mathrm{D}_{\psi \mathrm{T}} \frac{\partial \psi}{\partial \mathrm{n}} \\
& \frac{\dot{\mathrm{m}}_{\mathrm{m}, \mathrm{g}}}{\rho_{\ell}}=-\mathrm{K} \frac{\partial \Phi}{\partial \mathrm{n}}-\mathrm{D}_{\psi \mathrm{v}} \frac{\partial \psi}{\partial \mathrm{n}}-\mathrm{D}_{\mathrm{Tm}} \frac{\partial \mathrm{T}}{\partial \mathrm{n}}
\end{aligned}
$$

With the substitution of the flux boundary conditions, and extending the elemental equations to a system of equations for each node, the FEM equations can be written as

$$
\begin{aligned}
& \mathbf{D}_{\mathrm{TT}} \mathbf{T}+\mathbf{D}_{\psi \mathrm{T}} \boldsymbol{\psi}+\mathbf{C}_{\mathrm{TT}} \dot{\mathbf{T}}+\mathbf{C}_{\psi \mathrm{T}} \dot{\boldsymbol{\psi}}+\mathbf{f}_{\mathrm{T}}=0 \\
& \mathbf{D}_{\mathrm{Tm}} \mathbf{T}+\mathbf{D}_{\psi \mathrm{m}} \boldsymbol{\psi}+\mathbf{C}_{\mathrm{Tm}} \dot{\mathbf{T}}+\mathbf{C}_{\psi \mathrm{m}} \dot{\boldsymbol{\psi}}+\mathbf{f}_{\psi}=0
\end{aligned}
$$

The conductance matrices, D, and capacitance matrices, C, follow the pattern of Eqs. (B.22) and (B.23). Note that only the $\mathbf{D}_{\mathrm{TT}}$ matrix contains the last two terms in Eq. (B.22). The second term of Eq. (B.22) contains the liquid mass flux calculated using the previous value of the matric 
potential. The last term in Eq. (B.22) occurs only at the surface nodes with a convective boundary condition. The presence of the second term in Eq. (B.22) makes the conductance matrix nonsymetric, which increases the storage requirements. The forcing vectors are defined in Eqs. (B.24) and (B.25). All of the integrations are performed using Gaussian quadrature for volumes, areas, and lines where appropriate.

$$
\begin{aligned}
& \mathbf{D}_{\mathrm{TT}}=\int_{\Omega} \mathbf{N}^{\prime \mathrm{T}} \mathrm{k} \mathbf{N}^{\prime} \mathrm{d} \Omega+\int_{\Omega} \mathrm{C}_{\mathrm{p}, \ell} \mathbf{N} \dot{\mathbf{m}}_{\ell} \cdot \mathbf{N}^{\prime} \mathrm{d} \Omega+\int_{\Omega} \mathbf{N}_{\mathrm{s}} \mathbf{N}_{\mathrm{s}}^{\mathrm{T}} \mathbf{h} \mathrm{d} \Gamma \\
& \mathbf{C}_{\mathrm{TT}}=\int_{\Omega} \mathbf{N C}_{\mathrm{TT}} \mathbf{N}^{\mathrm{T}} \mathrm{d} \Omega \\
& \mathbf{f}_{\mathrm{T}}=-\int_{\Omega} \mathbf{N} \mathbf{Q} \mathrm{d} \Omega-\int_{\Gamma} \mathbf{N}_{\mathrm{s}} \mathbf{N}_{\mathrm{s}}^{\mathrm{T}} \mathbf{q}_{\mathrm{g}} \mathrm{d} \Gamma-\int_{\Gamma} \mathbf{N}_{\mathrm{s}} \mathbf{h} \mathrm{T}_{\mathrm{amb}} \mathrm{d} \Gamma \\
& \mathbf{f}_{\psi}=-\int_{\Omega} \mathbf{K} \frac{\partial \mathbf{N}}{\partial \mathrm{z}} \mathrm{d} \Omega-\int_{\Gamma} \mathbf{N}_{\mathrm{s}} \mathbf{N}_{\mathrm{s}}^{\mathrm{T}} \dot{\mathbf{m}}_{\mathrm{m}, \mathrm{g}} / \rho_{\ell} \mathrm{d} \Gamma
\end{aligned}
$$

The two sets of equations for the heat-and-moisture transfer can be combined into one set and written as shown in Eq. (B.26). They are combined with alternating equations for temperature and matric potential at each node. This is done to promote symmetry and reduce the bandwidth of the conductance and capacitance matrices, which reduces storage requirements and solution time.

$$
\mathbf{D U}+\mathbf{C} \dot{\mathbf{U}}+\mathbf{f}=0
$$

A single-step algorithm for the transient analysis is presented in Eq. (B.27), where $\mathrm{k}$ is the timestep number and $\beta$ is a time-weighting function, which determines whether the method is explicit $(\beta=0)$ or implicit $(0<\beta<=1)$ (Zienkiewicz and Taylor 1989). All of the analysis done in this report applied a time-weighting function of 0.5 , which is analogous to the Crank-Nicolson implicit routine used in finite differences. The forcing function is averaged assuming a linear variation in time as in Eq. (B.29).

$$
\begin{aligned}
& {[\mathbf{C}+\beta \Delta \mathrm{t} \mathbf{D}] \mathbf{U}_{\mathrm{k}+1}=[\mathbf{C}-(1-\beta) \Delta \mathrm{t} \mathbf{D}] \mathbf{U}_{\mathrm{k}}-\Delta \mathrm{t} \overline{\mathbf{f}}} \\
& {[\mathbf{C P D}] \mathbf{U}_{\mathrm{k}+1}=[\mathbf{C M D}] \mathbf{U}_{\mathrm{k}}-\Delta \mathrm{t} \overline{\mathbf{f}}} \\
& \overline{\mathbf{f}}=\mathbf{f}_{\mathrm{k}}+\beta\left(\mathbf{f}_{\mathrm{k}+1}-\mathbf{f}_{\mathrm{k}}\right)
\end{aligned}
$$

The coefficient matrices are calculated using values of $\mathrm{T}$ and $\psi$ averaged between the value from the previous time step $\mathrm{k}$ and the value from the previous iteration of the current time step i-1.

$$
\overline{\mathrm{T}}_{\mathrm{k}}^{\mathrm{i}}=(1-\alpha) \mathrm{T}_{\mathrm{k}-1}+\alpha \mathrm{T}_{\mathrm{k}}^{\mathrm{i}-1}
$$

Equation (B.28) is nonlinear since the coefficient matrices are functions of the dependent variables. The solution of the moisture-transfer equation is also subject to mass balance errors due to the highly nonlinear relationship between the moisture content and the matric potential (Milly 1985 and Celia et al. 1990). This is especially a problem with the infiltration into an initially dry soil. According to Celia et al, diagonalizing or lumping the capacitance matrix is necessary to ensure a nonoscillatory and mass conservative solution, and it has been shown to 
reduce the number of iterations to convergence. Diagonalization is accomplished by summing the total capacitance for the element and using a scaled distribution to each of the nodes.

The nonlinear equations are solved using a modified Picard iteration method (Istok 1989). In this method a residual vector is calculated as

$$
\mathbf{R}_{\mathrm{k}}^{\mathrm{i}-1}=[\mathbf{C M D}] \mathbf{U}_{\mathrm{k}}^{\mathrm{i}-1}-\Delta \mathrm{t} \overline{\mathbf{f}}-[\mathbf{C P D}] \mathbf{U}_{\mathrm{k}}^{\mathrm{i}-1}
$$

Then the following system of equations is solved for $\Delta \mathbf{U}_{\mathrm{k}}^{\mathrm{i}}$.

$$
[\mathbf{C P D}] \Delta \mathbf{U}_{\mathrm{k}}^{\mathrm{i}}=\mathbf{R}_{\mathrm{k}}^{\mathrm{i}-1}
$$

The new values of $U$ for time step $k$ and iteration $i$ are then calculated as

$$
\mathbf{U}_{\mathrm{k}}^{\mathrm{i}}=\mathbf{U}_{\mathrm{k}}^{\mathrm{i}-1}+\varpi \Delta \mathbf{U}_{\mathrm{k}}^{\mathrm{i}}
$$

The value of the relaxation factor $\varpi$ is determined by experience. For this work, it was found that a relaxation factor of $\varpi=1.0$ works best. For the first iteration at time step $k$, the values for $\mathbf{U}_{\mathrm{k}}^{\mathrm{i}-1}$ are taken from the previous time step. Convergence is defined as

$$
\operatorname{MAX}\left|\frac{\Delta \mathbf{U}}{\mathbf{U}}\right|<\varepsilon
$$

The convergence criterion $\varepsilon$ is typically set at 0.001 . If convergence is not reached, new coefficient matrices are assembled and a new residual is determined by Eq. (B.31), and the process is repeated. 


\section{APPENDIX C: Material Properties}

\section{C.1. Properties for Air, Water, and Ice}

The thermal conductivity $k$, density $\rho$, specific heat capacity $\mathrm{C}_{\mathrm{P}}$, surface tension $\sigma$, and kinematic viscosity $v$, for air, water, and ice are listed in Table C.1. All temperatures used in Eqs. (C.1) to (C.5) are in degrees C.

Table C.1. Physical and thermal properties of air, water, and ice.

\begin{tabular}{|c|c|c|c|c|c|}
\hline & $\begin{array}{c}k \\
(W / \mathbf{m} \cdot K)\end{array}$ & $\begin{array}{c}\rho \\
\left(\mathrm{kg} / \mathrm{m}^{3}\right)\end{array}$ & $\begin{array}{c}C_{p} \\
(J / k g \cdot K)\end{array}$ & $\begin{array}{c}\sigma \\
\left(J / \mathbf{m}^{2}\right)\end{array}$ & $\begin{array}{c}v \\
\left(s / m^{2}\right)\end{array}$ \\
\hline Air & Eq. $(\text { C.1 })^{(1)}$ & $1.2^{(2)}$ & $1,007.0^{(2)}$ & & \\
\hline Water & Eq. (C.2) ${ }^{(1)}$ & Eq. $(\text { C.3 })^{(1)}$ & $4,180.0^{(2)}$ & Eq. (C.1) ${ }^{(4)}$ & Eq. $(\text { C.11) })^{(1)}$ \\
\hline Ice & $2.2^{(3)}$ & $921.0^{(3)}$ & $2,040.0^{(3)}$ & & \\
\hline
\end{tabular}

$$
\begin{aligned}
& \mathrm{k}_{\mathrm{a}}=0.02417+7.596 \times 10^{-5} \mathrm{~T} \\
& \mathrm{k}_{\mathrm{w}}=0.5694+1.847 \times 10^{-3} \mathrm{~T}-7.394 \times 10^{-6} \mathrm{~T}^{2} \\
& \rho_{\mathrm{w}}=1000-0.0477 \mathrm{~T}-0.0038 \mathrm{~T}^{2} \\
& \sigma=0.1171-0.0001516(\mathrm{~T}+273.15) \\
& v=1.71806 \times 10^{-6}-4.46108 \times 10^{-8} \mathrm{~T} \\
& \quad+5.36977 \times 10^{-10} \mathrm{~T}^{2}-2.35693 \times 10^{-12} \mathrm{~T}^{3}
\end{aligned}
$$

The latent heats of fusion $\mathrm{L}_{\mathrm{f}}$ and vaporization $\mathrm{h}_{\mathrm{fg}}$ of water are given in Eqs. (C.6) and (C.7) (ASHRAE, 1977). The equation for the latent heat of vaporization is a fit to data from the ASHRAE Handbook of Fundamentals where the temperature is in degrees C.

$$
\begin{aligned}
& \mathrm{L}_{\mathrm{f}}=3.338 \times 10^{5} \quad[\mathrm{~J} / \mathrm{kg}] \\
& \mathrm{h}_{\mathrm{fg}}=2.501 \times 10^{6}-2405 \mathrm{~T}[\mathrm{~J} / \mathrm{kg}]
\end{aligned}
$$

The density of saturated water vapor is given in Eqs. (C.8) and (C.9), where the temperature is in $\mathrm{K}$. The first expression is from Ewen and Thomas (1989), and the second expression is taken from the ASHRAE Handbook of Fundamentals (1997).

$$
\rho_{\mathrm{vs}}=\frac{1}{194.4} \exp \left[\begin{array}{l}
0.06374(\mathrm{~T}-273.15)- \\
1.634 \times 10^{-4}(\mathrm{~T}-273.15)^{2}
\end{array}\right] \quad \text { for } \mathrm{T}>273.15 \mathrm{~K}
$$




$$
\rho_{\mathrm{vs}}=\frac{1000}{\mathrm{R}_{\mathrm{w}} \mathrm{T}} \exp \left[\begin{array}{l}
\mathrm{C}_{1} \mathrm{~T}^{-1}+\mathrm{C}_{2}+\mathrm{C}_{3} \mathrm{~T}+\mathrm{C}_{4} \mathrm{~T}^{2}+ \\
\mathrm{C}_{5} \mathrm{~T}^{3}+\mathrm{C}_{6} \mathrm{~T}^{4}+\mathrm{C}_{7} \ln (\mathrm{T})
\end{array}\right] \quad \text { for } \mathrm{T} \leq 273.15 \mathrm{~K}
$$

The coefficients in Eq. (C.9) are

$$
\begin{aligned}
& \mathrm{C}_{1}=-5674.5359 \\
& \mathrm{C}_{2}=-0.51523058 \\
& \mathrm{C}_{3}=-9.677843 \mathrm{E}-3 \\
& \mathrm{C}_{4}=6.2215701 \mathrm{E}-7 \\
& \mathrm{C}_{5}=2.0747825 \mathrm{E}-9 \\
& \mathrm{C}_{6}=-9.484024 \mathrm{E}-13 \\
& \mathrm{C}_{7}=4.1635019
\end{aligned}
$$

\section{C.2. Properties of Soils}

Five soils that represent the range of soils often found around building foundations and basements were selected to be included in this work. This section includes the soil classifications and the equations used to calculate the hydraulic and thermal properties.

\section{C.2.3. Soil Classifications}

The properties of five different soils listed in Table C.2 are included in this work and with the program GHAMT. These represent the range of soils often found around building foundations and basements. The information on three of the soils was taken from literature. For the other two soils, samples were collected by the author and tested by the Soil, Water, and Plant Testing Laboratory at Colorado State University, Fort Collins, Colorado. The River Rock sandy clay loam was taken from the River Rock co-housing development in Fort Collins, Colorado, and the Bighorn sandy loam was taken from the Bighorn commercial center in Silverthorne, Colorado.

Table C.2. Classification and properties of soils included in this work.

\begin{tabular}{|l|l|l|l|l|l|l|c|}
\hline \multicolumn{1}{|c|}{ Name } & Classification & \multicolumn{3}{|c|}{$\begin{array}{c}\text { Particle Volumetric } \\
\text { Content }\end{array}$} & Porosity & $\begin{array}{c}\text { Bulk } \\
\text { Density }\end{array}$ & $\begin{array}{c}\text { Sat. } \\
\text { Hydraulic } \\
\text { Conductivity }\end{array}$ \\
\hline & & Sand & \multicolumn{1}{|c|}{ Silt } & \multicolumn{1}{|c|}{ Clay } & & $\mathbf{( k g / \mathbf { m } ^ { 3 } )}$ & $\mathbf{( m / s )}$ \\
\hline $\begin{array}{l}\text { Solar Village Clay } \\
\text { (Hampton 1989) }\end{array}$ & bentonitic clay & 0.158 & 0.40 & 0.442 & 0.550 & 1,260 & $1.5 \mathrm{E}-6$ \\
\hline $\begin{array}{l}\text { Yolo Light Clay } \\
\text { (Moore 1939) }\end{array}$ & clay loam & 0.238 & 0.45 & 0.312 & 0.495 & 1,320 & $1.23 \mathrm{E}-7$ \\
\hline $\begin{array}{l}\text { River Rock Sandy } \\
\text { Clay Loam }\end{array}$ & sandy clay loam & 0.56 & 0.16 & 0.28 & 0.381 & 1,420 & $5.7 \mathrm{E}-5$ \\
\hline Bighorn Sandy Loam & sandy loam & 0.77 & 0.10 & 0.13 & 0.381 & 1,400 & $5.0 \mathrm{E}-5 *$ \\
\hline $\begin{array}{l}\text { Loamy Sand } \\
\text { (Noborio et al. 1996) }\end{array}$ & loamy sand & 0.835 & 0.07 & 0.09 & 0.396 & 1,602 & $4.455 \mathrm{E}-5$ \\
\hline
\end{tabular}

${ }^{*}$ Estimated value of saturated hydraulic conductivity 


\section{C.2.4. Soil Moisture Retention}

For the all of the soils except the loamy sand, the soil moisture retention (or soil water characteristic) curve is estimated by the method presented by van Genuchten (1980). The form of the correlation is

$$
\begin{aligned}
& \Theta=\left(\frac{1}{1+(\alpha \psi)^{\mathrm{n}}}\right)^{\mathrm{m}} \\
& \Theta \equiv \frac{\theta-\theta_{\mathrm{r}}}{\theta_{\mathrm{s}}-\theta_{\mathrm{r}}}
\end{aligned}
$$

where $\Theta$ is the degree of saturation; $\theta_{\mathrm{r}}$ and $\theta_{\mathrm{s}}$ are the residual and saturated water contents; and $\alpha, \mathrm{m}$, and $\mathrm{n}$ are parameters set to fit the measured data. Van Genuchten gives a graphical method of determining these parameters to fit the measured data. The approximation curves along with the measured data for Solar Village clay and Yolo light clay are shown in Figure C.1. Because the measured data for the Solar Village clay exhibits two knees, the approximation had to be divided into two sections. The parameters for the van Genuchten method and the reference temperature at which the measured data were taken are shown in Table C.3.

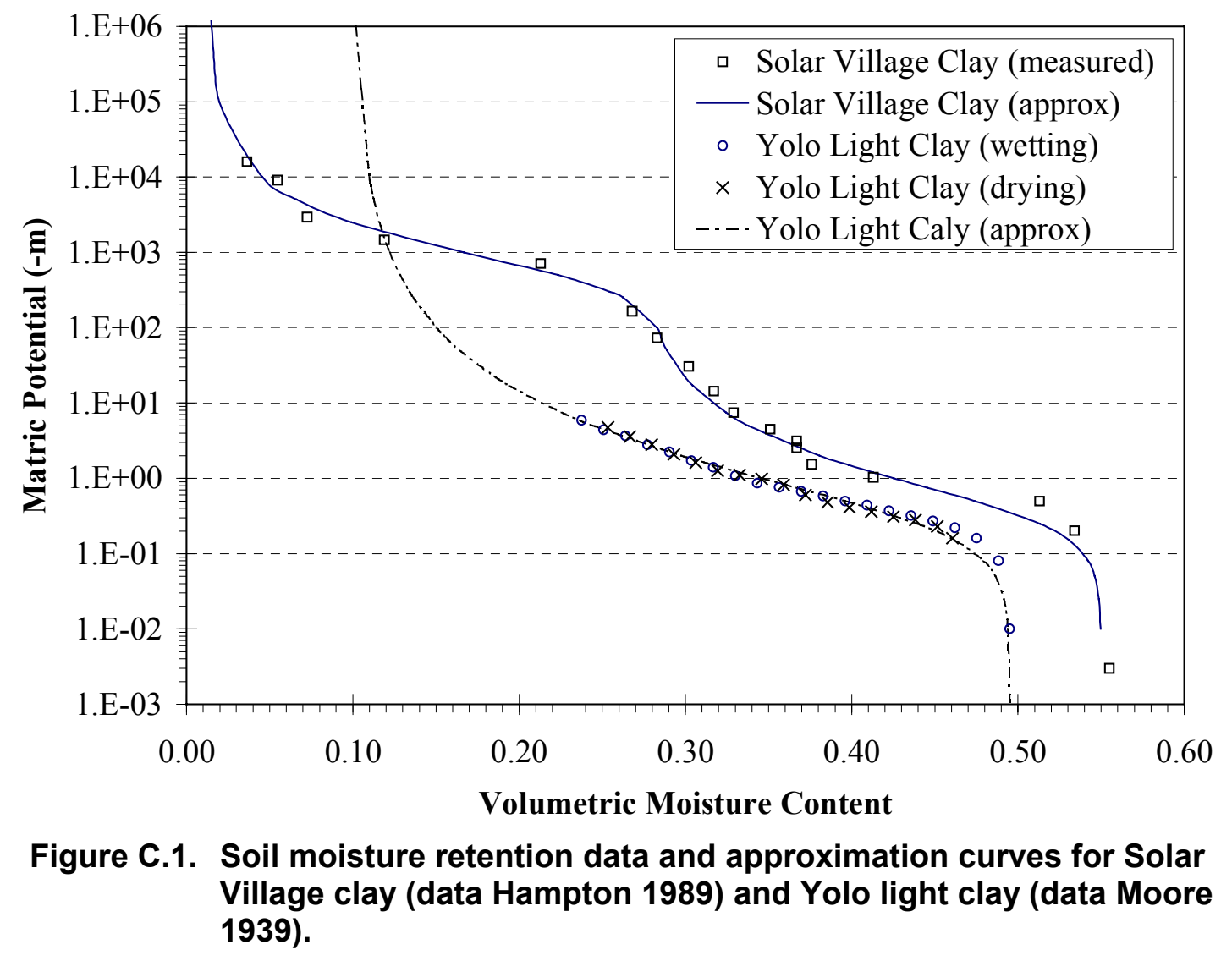


Table C.3. Parameters from the van Genuchten Method for the Matric Potential and Hydraulic Conductivity Correlations.

\begin{tabular}{|l|l|l|l|l|l|l|}
\hline \multicolumn{1}{|c|}{ Soil } & \multicolumn{1}{|c|}{$\boldsymbol{\theta}_{\mathbf{r}}$} & \multicolumn{1}{c|}{$\boldsymbol{\theta}_{\mathbf{s}}$} & \multicolumn{1}{c|}{$\boldsymbol{\alpha}$} & \multicolumn{1}{c|}{$\mathbf{m}$} & \multicolumn{1}{c|}{$\mathbf{n}$} & $\mathbf{T}_{\text {ref }}(\mathbf{C})$ \\
\hline \hline Solar Village clay (1)* & 0.014 & 0.289 & 0.00188 & 0.4246 & 1.738 & 25.0 \\
\hline Solar Village clay (2)* & 0.27 & 0.55 & 2.5119 & 0.3578 & 1.5572 & 25.0 \\
\hline Yolo light clay & 0.1 & 0.495 & 3.337 & 0.262 & 1.355 & 30.0 \\
\hline River Rock sandy clay loam & 0.079 & 0.381 & 1.1714 & 0.44166 & 1.791 & 20.0 \\
\hline Bighorn sandy loam & 0.074 & 0.381 & 1.2708 & 0.42145 & 1.7285 & 20.0 \\
\hline
\end{tabular}

* The curve for Solar Village clay is divided into the following regions:

$\begin{array}{ll}\text { Region (1) } & 0.0 \leq \theta<0.285 \\ \text { Region (2) } & 0.285 \leq \theta \leq 0.495\end{array}$

The soil moisture retention curve correlation for the loamy sand was published by Noborio et al. (1996) with a reference temperature of $25.0^{\circ} \mathrm{C}$ and shown in Eq. (C.12). The curves used in GHAMT to approximate the soil moisture retention are shown in Figure (C.2)

$$
\begin{array}{ll}
\psi=\frac{1}{\mathrm{~g}}\left(\frac{1-\Theta}{0.01223}\right)^{0.5}, & \Theta \geq 0.56362 \\
\psi=\frac{1}{\mathrm{~g}}\left(0.551 \Theta^{-2.1}+4.136488\right), & \Theta<0.56362
\end{array}
$$

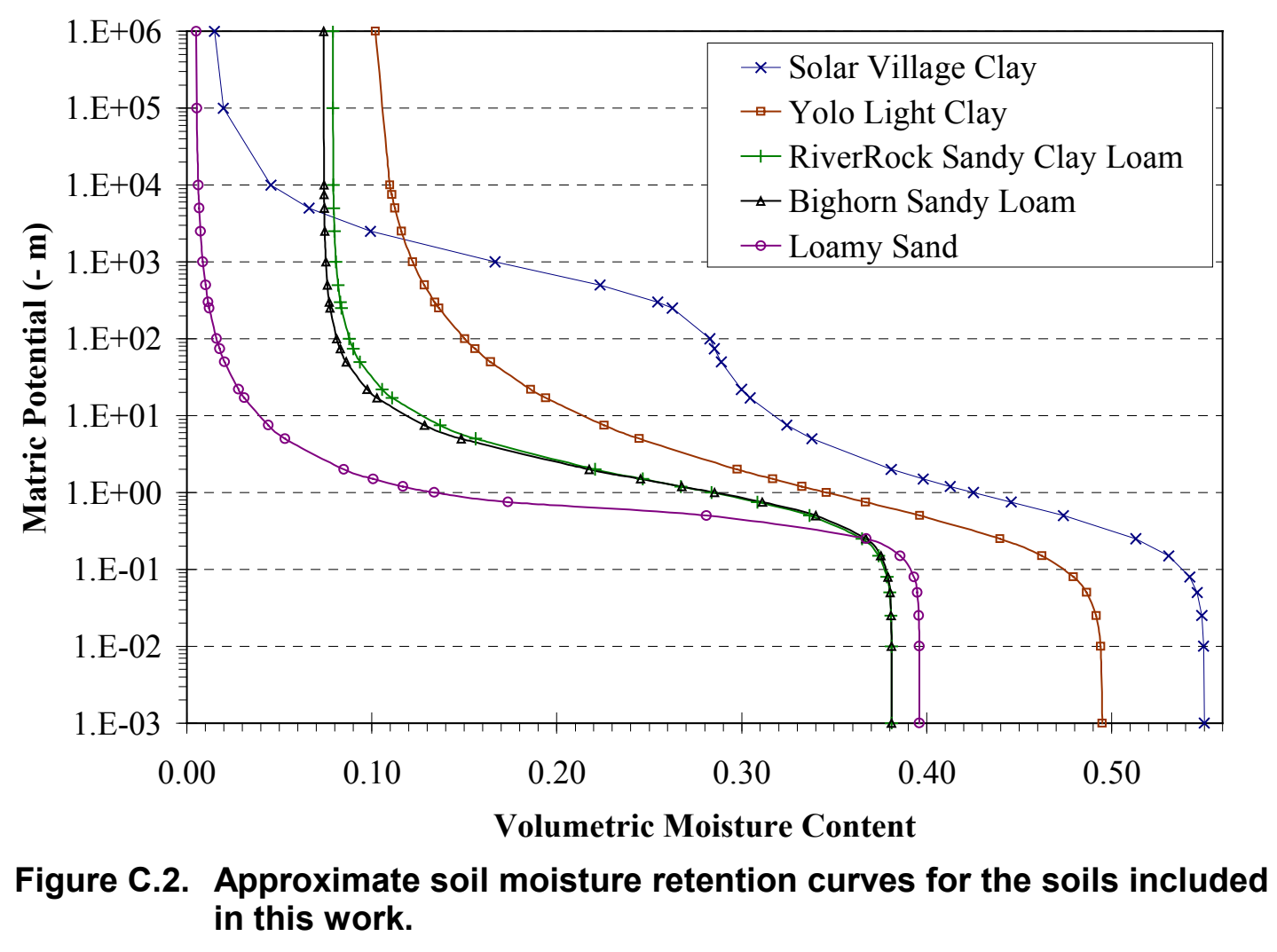


It is difficult to model the behavior of soil moisture for very low moisture contents. This region is difficult and time consuming to measure in the lab, and the mathematical form of the van Genuchten model does not allow it to be modeled well. The correlation of van Genuchten goes to infinity at the residual moisture content, and the value of the residual moisture content is limited in the process of fitting the measured data. Unless measured data at very low moisture contents is known, the van Genuchten method is the best available solution.

Hysteresis is not included in this model due to the added complexities and the uncertainties in the effectiveness of the hysteresis models. However, ignoring the hysteresis in the soil moisture retention curve can lead to substantial errors in certain cases (Miller and Miller, 1956). This is one area of this model that may need to be improved if further research shows that a hysteresis model is necessary.

\section{C.2.5. Hydraulic Conductivity}

If measured data is known for the range of moisture contents, a good approximation can be found by fitting the data with a least squares technique (Haverkamp et al. 1977). If values of hydraulic conductivity are not known over the range of moisture contents, a fairly good approximation from van Genuchten (1980) uses the hydraulic conductivity at saturation (Table C.2) and the parameters determined from the soil moisture retention curve (Table C.3).

$$
\mathrm{K}(\Theta)=\mathrm{K}_{\mathrm{sat}} \Theta^{1 / 2}\left[1-\left(1-\Theta^{1 / \mathrm{m}}\right)^{\mathrm{m}}\right]^{2}
$$

or in terms of the matric potential

$$
\mathrm{K}(\psi)=\mathrm{K}_{\mathrm{sat}} \frac{\left\{1-|\alpha \psi|^{\mathrm{n}-1}\left[1+|\alpha \psi|^{\mathrm{n}}\right]^{-\mathrm{m}}\right\}^{2}}{\left[1+|\alpha \psi|^{\mathrm{n}}\right]^{\mathrm{m} / 2}}
$$

This method is used for all of the soils except the loamy sand from Noborio et al. (1996). They used the following correlation with $\mathrm{K}$ and $\mathrm{K}_{\mathrm{sat}}$ in $(\mathrm{m} / \mathrm{s})$

$$
\begin{array}{ll}
\mathrm{K}=\mathrm{K}_{\text {sat }} \Theta^{11.39}, & 0.375<\theta \leq \theta_{\text {s }} \\
\mathrm{K}=\mathrm{K}_{\text {sat }} 0.71356 \Theta^{5.3817}, & 0.239<\theta \leq 0.375 \\
\mathrm{~K}=\mathrm{K}_{\text {sat }} 4.5444 \Theta^{8.9775}, & 0.0<\theta \leq 0.239
\end{array}
$$

The approximations used for the hydraulic conductivity of the five soils are shown in Figure C.3. 


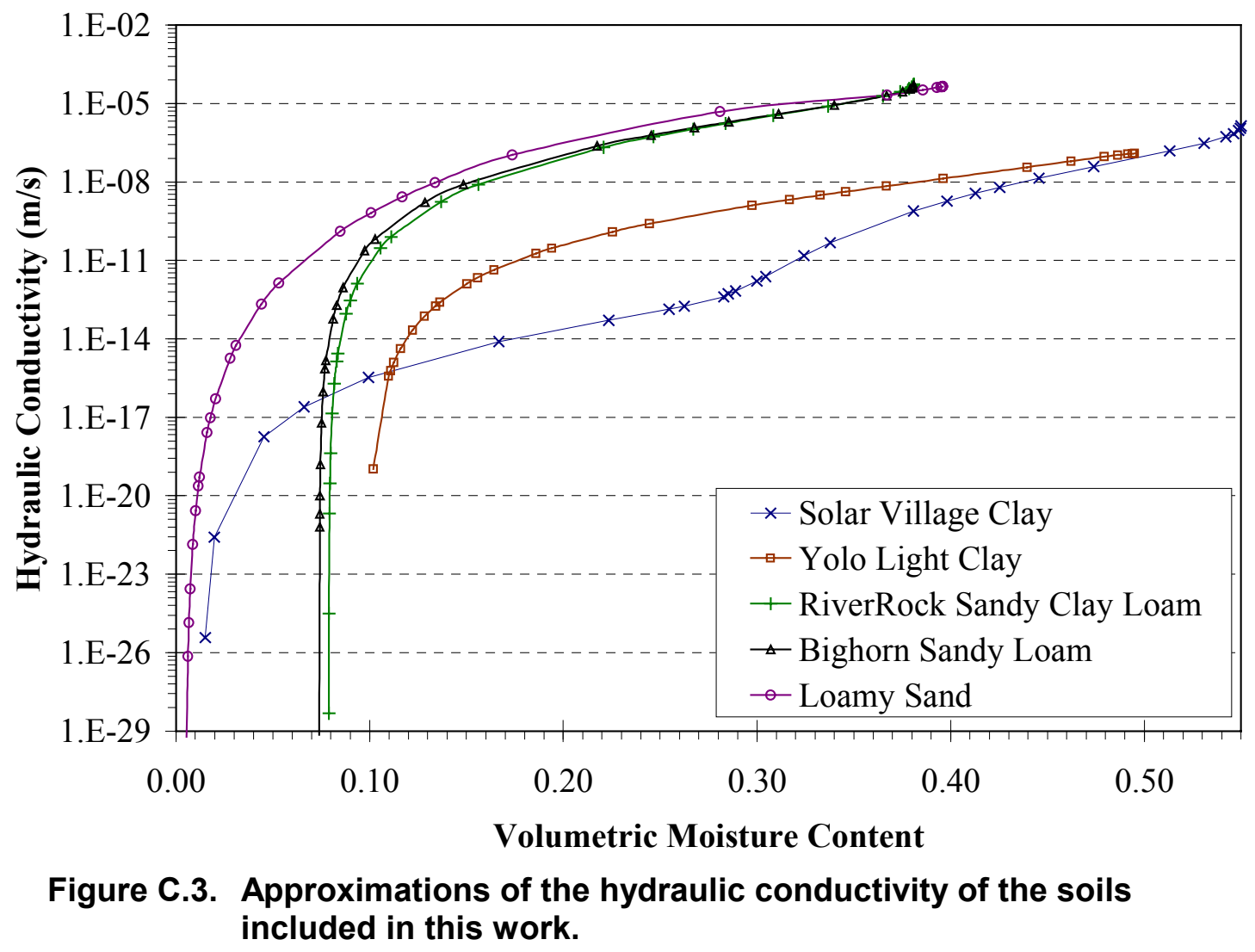

\section{C.2.6. Hydraulic Conductivity of Frozen Soil}

The hydraulic conductivity reduces drastically as the liquid water content of the soil freezes (Horiguchi and Miller 1983). The hydraulic conductivity of partially frozen soil is a function of the unfrozen water content, which is a function of the temperature (Hoekstra 1966 and Harlan 1973). Because no correlations for the hydraulic conductivity of frozen soil were found, it is assumed to follow the unfrozen relation using the unfrozen water content and corresponding matric potential.

\section{C.2.7. Temperature Dependency}

The method used to account for the temperature effects is the STVF approach. This method uses the ratio of the surface tensions and kinematic viscosities at a reference temperature and the temperature of interest to adjust the matric potential and the hydraulic conductivity.

$$
\begin{aligned}
& \psi\left(T, \theta_{\ell}\right)=\frac{\sigma(\mathrm{T})}{\sigma\left(\mathrm{T}_{\mathrm{r}}\right)} \psi\left(\mathrm{T}_{\mathrm{r}}, \theta_{\ell}\right) \\
& \mathrm{K}\left(\mathrm{T}, \theta_{\ell}\right)=\frac{v\left(\mathrm{~T}_{\mathrm{r}}\right)}{v(\mathrm{~T})} \mathrm{K}\left(\mathrm{T}_{\mathrm{r}}, \theta_{\ell}\right)
\end{aligned}
$$




\section{C.2.8. Thermal Conductivity}

The model for the soil thermal conductivity is taken from de Vries (1966). This method assumes that the soil consists of a continuous medium (usually water or air for dry soil) with evenly distributed ellipsoidal-shaped grains. The thermal conductivity is then given by Eq. (C.18). Air is considered the continuous medium at moisture contents below 0.05 , and the thermal conductivity from this equation is multiplied by a correction factor of 1.25 .

$$
\mathrm{k}=\frac{\mathrm{x}_{\mathrm{w}} \mathrm{k}_{\mathrm{w}}+\xi_{\mathrm{p}} \mathrm{x}_{\mathrm{p}} \mathrm{k}_{\mathrm{p}}+\sum_{\mathrm{i}=1}^{\mathrm{n}} \xi_{\mathrm{i}} \mathrm{x}_{\mathrm{i}} \mathrm{k}_{\mathrm{i}}}{\mathrm{x}_{\mathrm{w}}+\xi_{\mathrm{p}} \mathrm{x}_{\mathrm{p}}+\sum_{\mathrm{i}=1}^{\mathrm{n}} \xi_{\mathrm{i}} \mathrm{x}_{\mathrm{i}}}
$$

The number of grain types of the same shape and thermal conductivity is $\mathrm{n}, \mathrm{x}$ is the volumetric content, and $\xi$ is the ratio of the average temperature gradient in the constituent and the average temperature gradient of the medium and is approximated by

$$
\xi_{\mathrm{i}}=\frac{1}{3} \sum_{\mathrm{a}, \mathrm{b}, \mathrm{c}}\left[1+\left(\frac{\mathrm{k}_{\mathrm{i}}}{\mathrm{k}_{\mathrm{w}}}-1\right) \mathrm{g}_{\mathrm{a}}\right]^{-1}
$$

The values of $g_{a}, g_{b}$, and $g_{c}$ depend on the ratios of the axes of the grains, and they sum to unity. For a sphere they are equal to $1 / 3$. See Table C.4 for the values used in this work.

The effective thermal conductivity of the gas filled pores is calculated as

$$
\begin{aligned}
& \mathrm{k}_{\mathrm{p}}=\mathrm{k}_{\mathrm{a}}+\mathrm{k}_{\mathrm{v}} \\
& \mathrm{k}_{\mathrm{v}}=\mathrm{h}_{\mathrm{fg}} \mathrm{D}_{\mathrm{a}} \varphi \frac{\mathrm{d} \rho_{\mathrm{vs}}}{\mathrm{dT}}
\end{aligned}
$$

\begin{tabular}{|c|c|c|c|c|}
\hline Soil Constituent & $\begin{array}{c}\mathbf{k} \\
(W / \mathbf{m} \cdot K)\end{array}$ & $\begin{array}{c}\rho \\
(\mathrm{kg} / \mathrm{m} 3)\end{array}$ & $\begin{array}{c}\text { Cp } \\
(\mathrm{J} / \mathrm{kg} \cdot \mathrm{K})\end{array}$ & ga \\
\hline$\overline{\text { Quartz }}$ & Eq. $\left(\right.$ C.22) ${ }^{(1)}$ & $2,650.0^{(3)}$ & $731.5^{(3)}$ & $0.144^{(2)}$ \\
\hline Other minerals & $2.93^{(3)}$ & $2,650.0^{(3)}$ & $731.5^{(3)}$ & $0.144^{(2)}$ \\
\hline Organic material & $0.25^{(3)}$ & $1,300.0^{(3)}$ & $1,923.0^{(3)}$ & $0.5^{(2)}$ \\
\hline Water & Eq. $(C .2)^{(4)}$ & Eq. $(\text { C.3 })^{(4)}$ & $4,180.0^{(5)}$ & $\mathrm{n} / \mathrm{a}$ \\
\hline Ice & $2.2^{(6)}$ & $921.0^{(6)}$ & $2,040.0^{(6)}$ & $0.144^{(2)}$ \\
\hline Air & Eq. $(\text { C.1 })^{(4)}$ & $1.2^{(5)}$ & $1,007.0^{(5)}$ & $\mathrm{n} / \mathrm{a}$ \\
\hline
\end{tabular}

Table C.4. Physical and thermal properties of soil constituents

${ }^{1}$ Equation fit to data from de Vries (1966)

2 de Vries (1966)

${ }^{3}$ van Wijk and de Vries (1966)

${ }^{4}$ Equation fit to data from Incropera and DeWitt (1985)

${ }^{5}$ Incropera and DeWitt (1985)

${ }^{6}$ ASHRAE (1997)

$$
\mathrm{k}_{\mathrm{qtz}}=9.051-0.02659 \mathrm{~T}
$$




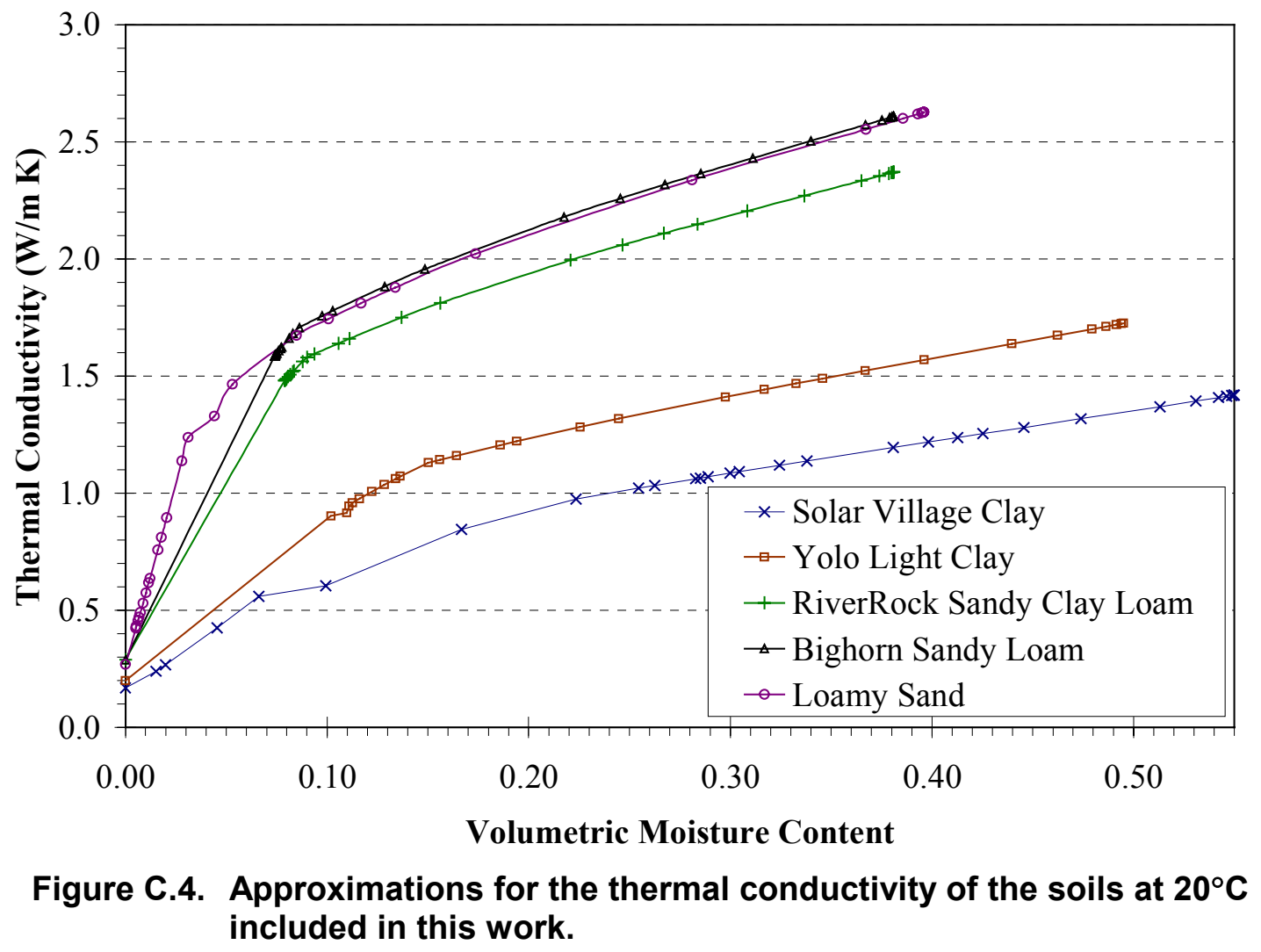

\section{C.2.9. Thermal Conductivity of Frozen Soil}

The thermal conductivity of frozen soil is approximated using the de Vries method, treating the ice as another soil constituent. The value of $g_{a}$ is assumed the same as that for quartz grains, which may not always be a good approximation because ice takes different forms depending on conditions. This report assumes that water is the continuous medium for $\theta_{\ell} \geq 0.05$, and air is the continuous medium for moisture contents below this.

\section{C.2.10.Soil Heat Capacity}

The volumetric heat capacity $\mathrm{C}\left(\mathrm{J} / \mathrm{m}^{3} \cdot \mathrm{K}\right)$ is calculated as a weighted average of the specific heat capacities $C_{P}(\mathrm{~J} / \mathrm{kg} \cdot \mathrm{K})$ of the soil constituents as shown in Eq. (C.23). The heat capacity of the gases is neglected.

$$
\mathrm{C}=\mathrm{x}_{\mathrm{w}} \rho_{\mathrm{w}} \mathrm{C}_{\mathrm{P}_{\mathrm{w}}}+\mathrm{x}_{\text {ice }} \rho_{\text {ice }} \mathrm{C}_{\mathrm{P}_{\text {ice }}}+\sum_{\mathrm{i}=1}^{\mathrm{n}} \mathrm{x}_{\mathrm{i}} \rho_{\mathrm{i}} \mathrm{C}_{\mathrm{Pi}_{\mathrm{i}}}
$$




\section{APPENDIX D: Analysis of the Convective Heat Transfer Coefficient}

\section{D.1. Introduction}

This appendix examines several eddy diffusivity models used to estimate the convective heat transfer coefficient and evaporation transfer coefficient.

\section{D.2. Models for the Convective Heat Transfer Coefficient}

The basic equations for convective heat and vapor transfer are

$$
\begin{aligned}
\mathrm{q}_{\text {conv }} & =\mathrm{h}\left(\mathrm{T}_{\mathrm{amb}}-\mathrm{T}_{\mathrm{s}}\right) \\
& =\rho_{\mathrm{a}} \mathrm{C}_{\mathrm{P}, \mathrm{a}} \mathrm{D}_{\mathrm{h}}\left(\mathrm{T}_{\mathrm{amb}}-\mathrm{T}_{\mathrm{s}}\right) \\
\mathrm{q}_{\mathrm{v}}= & \mathrm{h}_{\mathrm{fg}} \mathrm{D}_{\mathrm{v}}\left(\rho_{\mathrm{v}, \mathrm{amb}}-\rho_{\mathrm{v}, \mathrm{s}}\right)
\end{aligned}
$$

The convection heat transfer coefficient is $\mathrm{h}\left(\mathrm{W} / \mathrm{m}^{2} \cdot \mathrm{K}\right)$, the latent heat of vaporization is $\mathrm{h}_{\mathrm{fg}}$ $(\mathrm{J} / \mathrm{kg})$, the heat and mass diffusivities in air are $\mathrm{D}_{\mathrm{h}}(\mathrm{m} / \mathrm{s})$ and $\mathrm{D}_{\mathrm{v}}(\mathrm{m} / \mathrm{s})$, and the vapor densities at the ambient and surface conditions are $\rho_{\mathrm{v}, \text { amb }}$ and $\rho_{\mathrm{v}, \mathrm{s}}\left(\mathrm{kg} / \mathrm{m}^{3}\right)$.

The stability of the air mass above the ground can be estimated by the Richardson number, which relates the buoyancy and frictional forces. The relationship used in this research for the Richardson number is (Businger 1975)

$$
\mathrm{Ri} \approx \frac{\mathrm{g}\left(\mathrm{T}_{\mathrm{amb}}-\mathrm{T}_{\mathrm{s}}\right)}{\mathrm{u}_{\mathrm{w}}^{2}} \frac{\left(\mathrm{z}_{\mathrm{o}} \mathrm{z}\right)^{1 / 2}}{\ln \left(\mathrm{z} / \mathrm{z}_{\mathrm{o}}\right)}
$$

Notice that this definition of the Richardson number goes to infinity as the wind speed goes to zero; therefore, this relationship is not valid for small wind speed values.

The four eddy diffusivity models examined in this research are from Jensen (1973), van Bavel and Hillel (1976), Sellers (1965), and Camillo and Gurney (1986). The first three models calculate a neutral stability momentum transfer coefficient by Eq. (D.4), and then adjust for air mass stability.

$$
\mathrm{D}_{\mathrm{m}}=\frac{\kappa^{2} \mathrm{u}_{\mathrm{w}}}{\left[\ln \left(\mathrm{z}_{\mathrm{w}} / \mathrm{z}_{\mathrm{o}}\right)\right]^{2}}[\mathrm{~m} / \mathrm{s}]
$$

Here, $\kappa$ is the von Karman constant, $u_{w}(m / s)$ is the local wind speed, $z_{w}(m)$ is the height of the wind speed measurement, and $\mathrm{z}_{\mathrm{o}}(\mathrm{m})$ is the roughness height of the ground surface.

The stability correction relationships reported by Jensen, which follow the work by Businger (1975) are

$$
\begin{array}{ll}
D_{h}=D_{m}(1-16 R i)^{0.75} & , \text { for Ri } \leq 0 \\
D_{h}=D_{m}(1+10 R i)^{-1} & , \text { for Ri }>0
\end{array}
$$


The relationships presented by Sellers (1965) are

$$
\begin{array}{ll}
\mathrm{D}_{\mathrm{h}}=\mathrm{D}_{\mathrm{m}}\left[1+14\left(\frac{\mathrm{T}_{\mathrm{s}}-\mathrm{T}_{\mathrm{amb}}}{\mathrm{u}_{2 \mathrm{~m}}^{2}}\right)\right]^{1 / 3}, & \text { for } \mathrm{T}_{\mathrm{s}} \geq \mathrm{T}_{\mathrm{amb}} \\
\mathrm{D}_{\mathrm{h}}=\mathrm{D}_{\mathrm{m}}\left[1-14\left(\frac{\mathrm{T}_{\mathrm{s}}-\mathrm{T}_{\mathrm{amb}}}{\mathrm{u}_{2 \mathrm{~m}}^{2}}\right)\right]^{-1 / 3}, & \text { for } \mathrm{T}_{\mathrm{s}}<\mathrm{T}_{\mathrm{amb}}
\end{array}
$$

The equation used by van Bavel and Hillel (1976) is

$$
\mathrm{D}_{\mathrm{h}}=\mathrm{D}_{\mathrm{m}}(1-10 \mathrm{Ri})
$$

The fourth method used by Camillo and Gurney (1986) (following the work by Paulson (1970)) is more rigorous. The turbulent heat transfer coefficient is calculated as

$$
\mathrm{D}_{\mathrm{h}}=\frac{\mathrm{\kappa}^{2} \mathrm{u}_{\mathrm{w}}}{\left[\ln \left(\mathrm{z}_{\mathrm{w}} / \mathrm{z}_{\mathrm{o}}\right)-\mathrm{P}_{1}\right]\left[\ln \left(\mathrm{z}_{\mathrm{w}} / \mathrm{z}_{\mathrm{o}}\right)-\mathrm{P}_{2}\right]}
$$

where $\mathrm{P}_{1}$ and $\mathrm{P}_{2}$ are stability correction factors. The stability is determined by the MoninObukhov length, which can be represented as

$$
M O=\frac{T_{a m b} u_{w}^{2}}{g\left(T_{a m b}-T_{s}\right) \ln \left(\frac{z_{w}}{z_{o}}\right)} \frac{1-P_{2} / \ln \left(\frac{z_{w}}{z_{o}}\right)}{\left[1-P_{1} / \ln \left(\frac{z_{w}}{z_{o}}\right)\right]^{2}}
$$

The method of calculating $\mathrm{P}_{1}$ and $\mathrm{P}_{2}$ depends on the atmospheric stability determined by the airto-surface temperature difference. For a neutral atmosphere, defined by Camillo and Gurney as $\left|\mathrm{T}_{\mathrm{amb}}-\mathrm{T}_{\mathrm{s}}\right| \leq 0.1 \mathrm{~K}$, both $\mathrm{P}_{1}$ and $\mathrm{P}_{2}$ are 0 .

For an unstable atmosphere, $\left(\mathrm{T}_{\mathrm{amb}}-\mathrm{T}_{\mathrm{s}}\right)<-0.1 \mathrm{~K}, \mathrm{P}_{1}$ and $\mathrm{P}_{2}$ are calculated as

$$
\begin{aligned}
& \mathrm{P}_{1}=2 \ln \left(\frac{1+\mathrm{X}}{2}\right)+\ln \left(\frac{1+\mathrm{X}^{2}}{2}\right)-\tan ^{-1}(\mathrm{X})+\frac{\pi}{2} \\
& \mathrm{P}_{2}=2 \ln \left(\frac{1+\mathrm{X}^{2}}{2}\right) \\
& \mathrm{X}=\left(1-\frac{16 \mathrm{z}_{\mathrm{w}}}{\mathrm{MO}}\right)^{0.25}
\end{aligned}
$$

For a stable atmosphere, $\left(\mathrm{T}_{\mathrm{amb}}-\mathrm{T}_{\mathrm{s}}\right)>0.1 \mathrm{~K}$, the following expressions are used 


$$
\begin{array}{ll}
\mathrm{P}_{1}=\mathrm{P}_{2}=-5\left(\mathrm{z}_{\mathrm{w}}-\mathrm{z}_{\mathrm{o}}\right) / \mathrm{MO}, & \text { for } \mathrm{z}_{\mathrm{w}} / \mathrm{MO} \leq 1 \\
\mathrm{P}_{1}=\mathrm{P}_{2}=-5 \ln \left(\mathrm{z}_{\mathrm{w}} / \mathrm{z}_{\mathrm{o}}\right) \quad, \text { for } \mathrm{z}_{\mathrm{w}} / \mathrm{MO}>1
\end{array}
$$

These relationships cannot be solved explicitly for MO; therefore, they must be solved iteratively. For their cases, Camillo and Gurney found that the second term in Eq. (D.10) was always between 0.97 and 1.0 and was therefore set to 1.0. However, for the cases run in this work, this was not always true and the equations had to be solved iteratively.

Finally, a very simple method of calculating the convective heat transfer coefficient is presented here for comparison (McAdams 1954).

$$
\mathrm{h}=5.7+3.8 \mathrm{u}_{\mathrm{w}}
$$

Comparisons of the convective heat transfer coefficient $h$ from each of these methods, along with the Richardson number, are shown in Figures D.1-D.4. Figure D.1 presents the effect of the temperature difference between the ground surface and the air on the heat transfer coefficient with a wind speed of $5.0 \mathrm{~m} / \mathrm{s}$. The Jensen, van Bavel-Hillel, and the Camillo-Gurney models behave similarly, but the Sellers model predicts very large values for the heat transfer coefficient. The effect of the surface roughness on the heat transfer is shown in Figure D.2. Again, the model from Sellers predicts much higher values of the heat transfer coefficient.

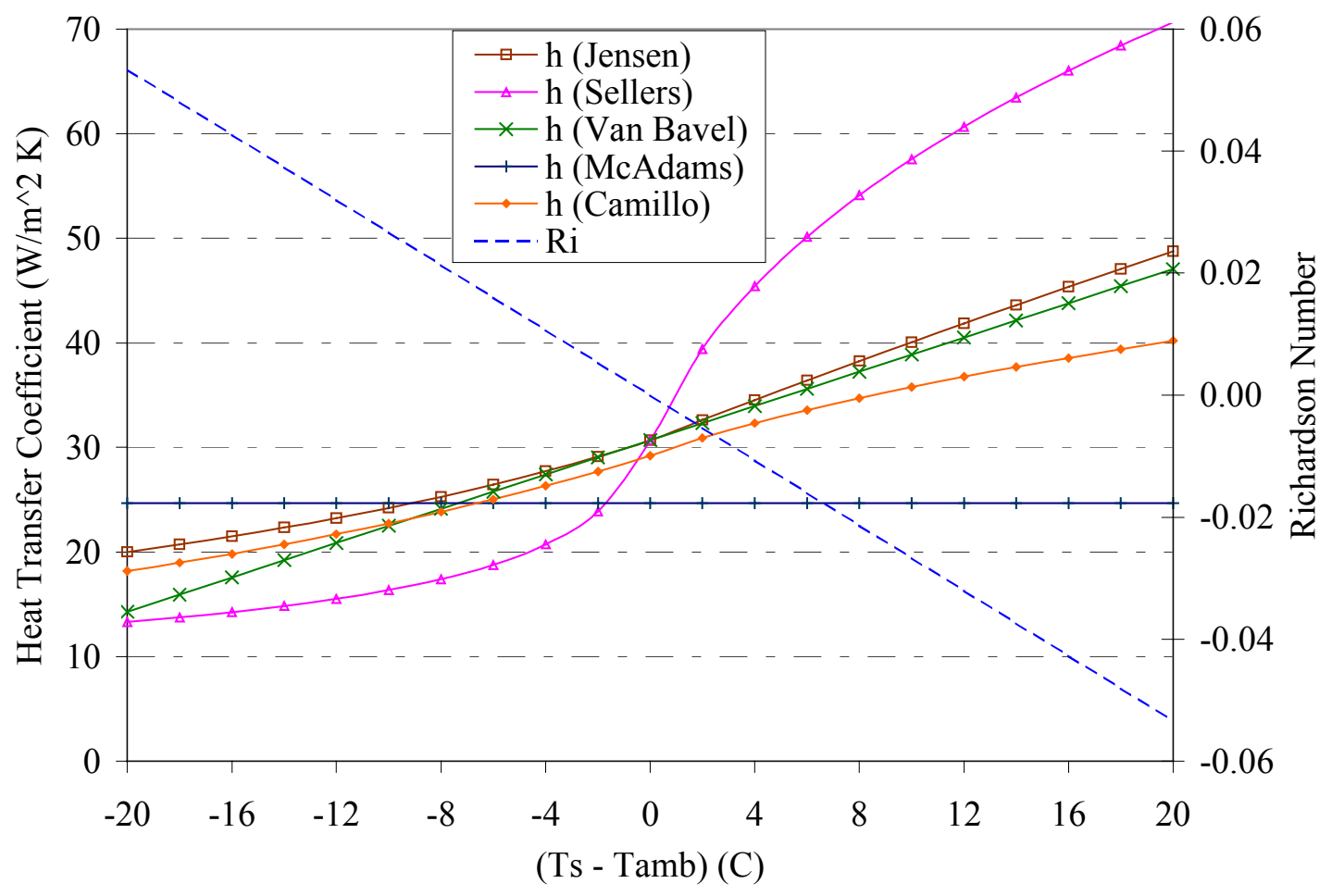

Figure D.1. Effect of ground surface/ambient air temperature difference on the convective heat transfer coefficient $u_{w}=5.0 \mathrm{~m} / \mathrm{s}, z_{v e g}=0.05 \mathrm{~m}$. 


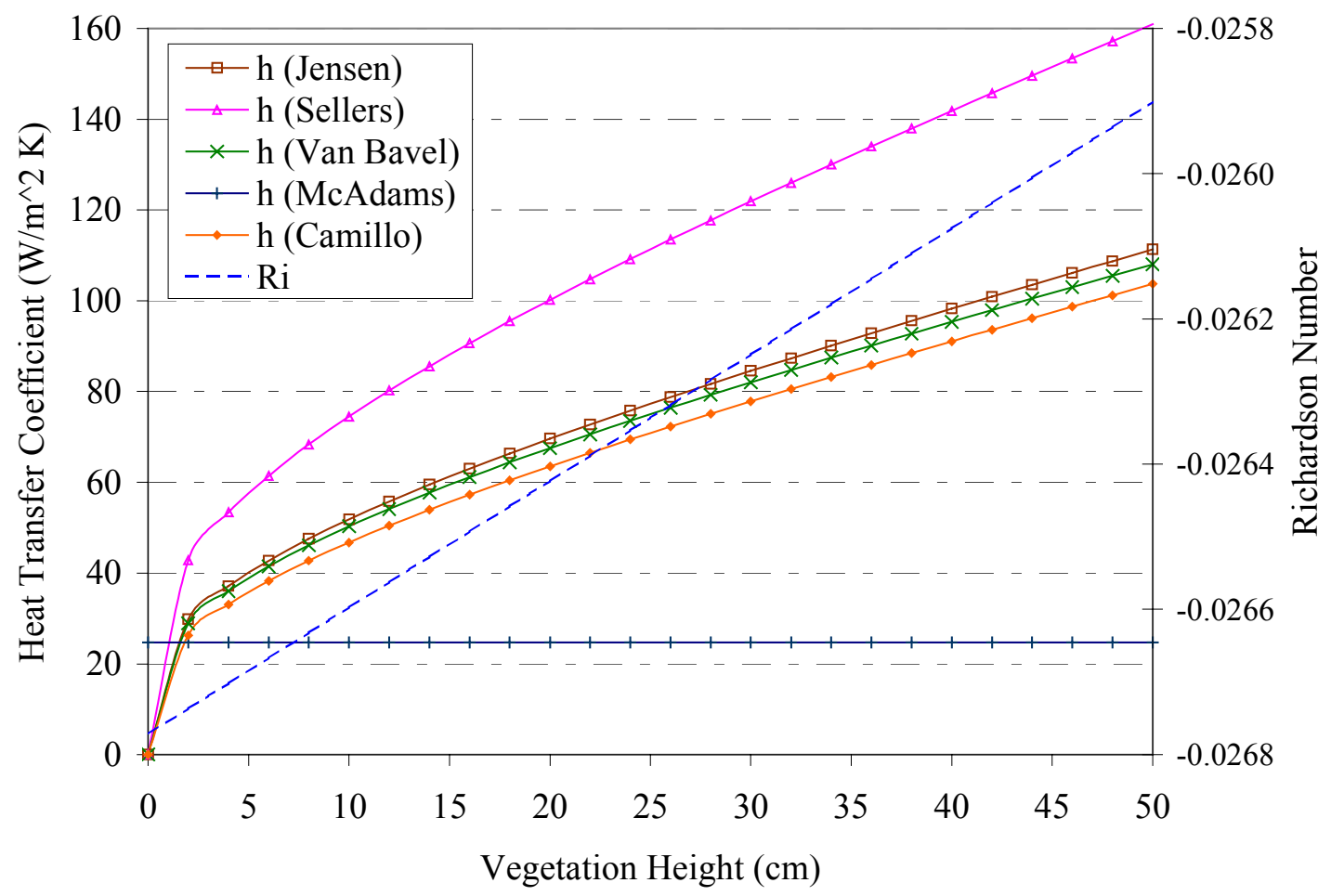

Figure D.2. Effect of surface roughness height on the convective heat transfer coefficient for a stable temperature gradient $\left(T_{a m b}-T_{s}\right)=$ $+10.0 \mathrm{C}, \mathrm{u}_{\mathrm{w}}=5.0 \mathrm{~m} / \mathrm{s}$.

Figures D. 3 and D. 4 show the effect of wind speed for stable and unstable temperature stratification. For the stable condition, all five correlations behave similarly with one exception: at low wind speeds, the van Bavel-Hillel model diverges and becomes negative. For the unstable condition, note how Ri has a large negative value for low wind speeds. This causes the Jensen and van Bavel models to show a slight increase at low wind speeds. The Camillo-Gurney method predicts a large negative number, which is also incorrect. Seller's model predicts values that are much higher than the other models and was therefore not selected. Physically, with low wind speed and unstable temperature stratification, large turbulent plums of air rise from the warm ground.

This instability in the air is difficult to model as demonstrated by three of the models. In this region, natural convection takes over, and the forced convection models fail. This is handled by introducing a natural convection coefficient and blending it with the forced convection value. Natural convection from a horizontal flat plate can be estimated by (Incropera and DeWitt 1985)

$$
\begin{array}{ll}
\bar{N} u_{L}=0.54 R a_{L}^{1 / 4}, & \text { for } 10^{4} \leq \mathrm{Ra}_{\mathrm{L}} \leq 10^{7} \\
\bar{N} \mathrm{u}_{\mathrm{L}}=0.15 \mathrm{Ra}_{\mathrm{L}}^{1 / 3}, & \text { for } 10^{7} \leq \mathrm{Ra}_{\mathrm{L}} \leq 10^{11}
\end{array}
$$

The Rayleigh number $\mathrm{Ra}_{\mathrm{L}}$ is proportional to the cube of the characteristic length, usually the length of the plate. It can be easily shown that, for the conditions encountered for natural convection from the ground surface, that $\mathrm{Ra}_{\mathrm{L}}>10^{7}$; therefore, the second relation is used and the natural convection heat transfer coefficient can be approximated by 


$$
\overline{\mathrm{h}}_{\mathrm{n}}=0.15 \mathrm{k}\left(\frac{\mathrm{g}\left(\mathrm{T}_{\mathrm{s}}-\mathrm{T}_{\mathrm{amb})}\right.}{\mathrm{T}_{\mathrm{f}} v \alpha}\right)^{1 / 3}
$$

The film temperature $\mathrm{T}_{\mathrm{f}}$ is the average of the ambient and surface temperatures. For transverse flows over a horizontal plate, the forced and natural convection terms can be combined by Eq. (D.17) (Incropera and DeWitt 1985). Note that the length scales are slightly different in the forced and natural convection values of $\mathrm{Nu}_{\mathrm{L}}$; therefore, the equation for $\mathrm{h}_{\mathrm{c}}$ does not derive exactly from the $\mathrm{Nu}$ correlation. The combined forced convection coefficient (from the Jensen model) and natural convection coefficient are shown in Figure D.5.

$$
\begin{aligned}
& \mathrm{Nu}^{4}=\mathrm{Nu}_{\mathrm{f}}^{4}+\mathrm{Nu}_{\mathrm{n}}^{4} \\
& \mathrm{~h}^{4}=\mathrm{h}_{\mathrm{f}}^{4}+\mathrm{h}_{\mathrm{n}}^{4}
\end{aligned}
$$

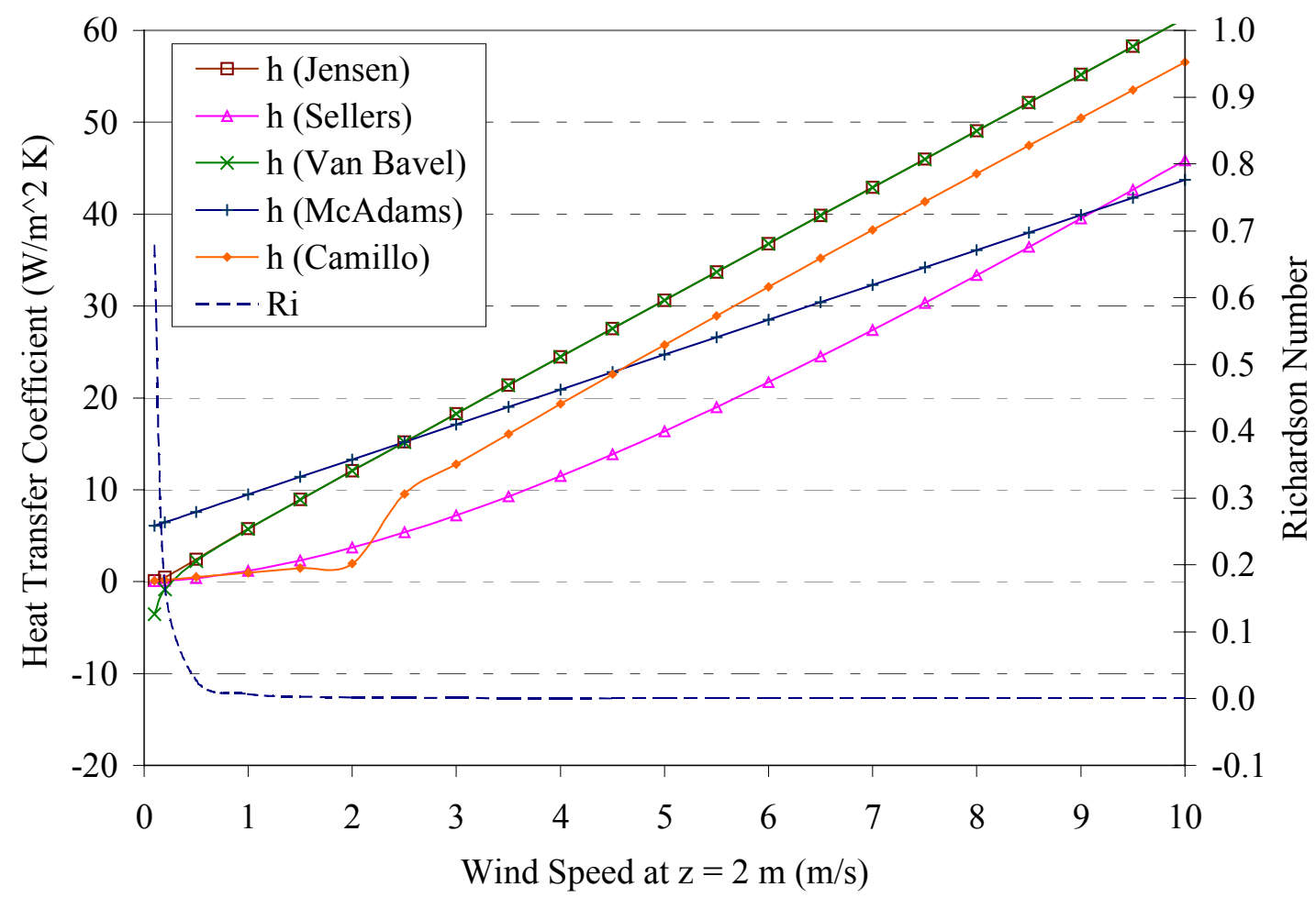

Figure D.3. Effect of wind speed on the convective heat transfer coefficient for a stable temperature gradient $\left(T_{\text {amb }}-T_{s}\right)=+10.0^{\circ} \mathrm{C}, \mathrm{z}_{\mathrm{veg}}=0.05 \mathrm{~m}$. 


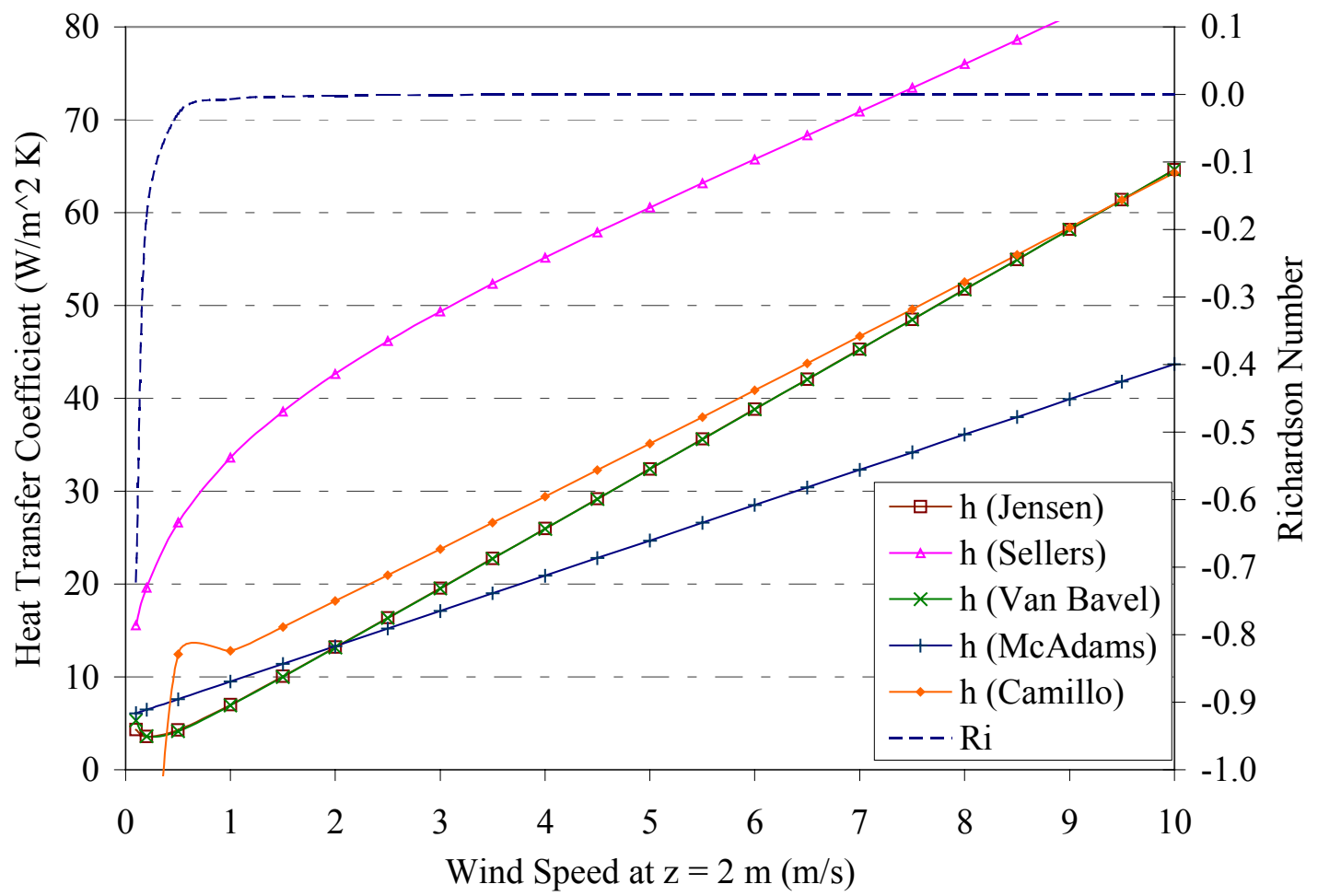

Figure D.4. Effect of wind speed on the convective heat transfer coefficient for an unstable temperature gradient $\left(T_{\mathrm{amb}}-\mathrm{T}_{\mathrm{s}}\right)=-10.0^{\circ} \mathrm{C}, \mathrm{z}_{\mathrm{veg}}=0.05 \mathrm{~m}$.

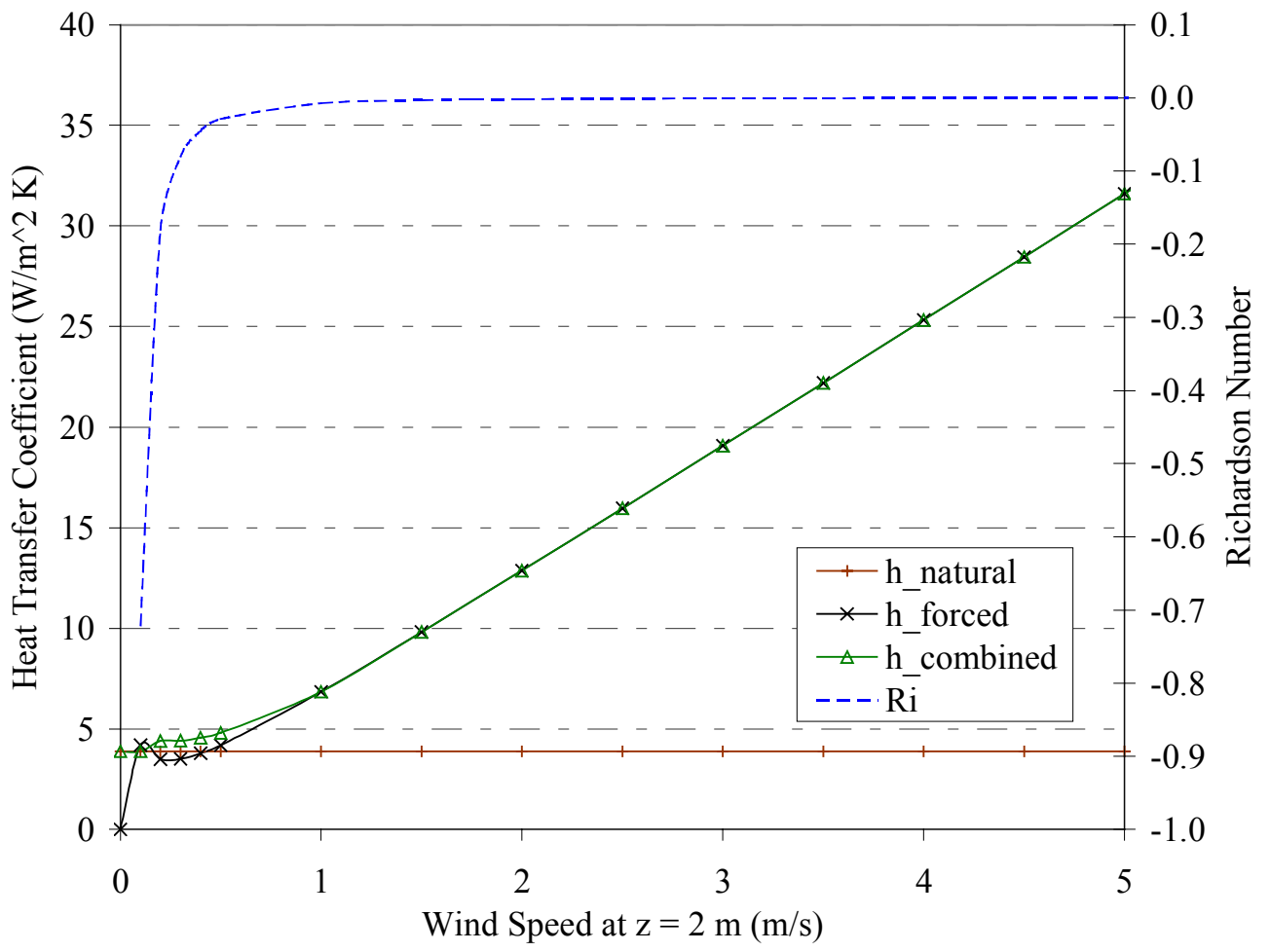

Figure D.5. Combined forced and natural convective heat transfer coefficients. The forced convection coefficient is calculated using the Jensen model. 


\section{REPORT DOCUMENTATION PAGE}

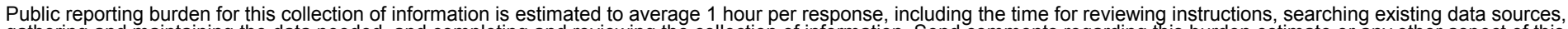

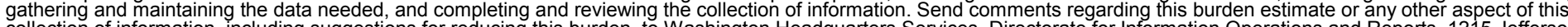

Davis Highway, Suite 1204, Arlington, VA 22202-4302, and to the Office of Management and Budget, Paperwork Reduction Project (0704-0188), Washington, DC 20503.
1. AGENCY USE ONLY (Leave blank)
2. REPORT DATE June 2003
3. REPORT TYPE AND DATES COVERED
Technical report

4. TITLE AND SUBTITLE
A Model for Ground-Coupled Heat and Moisture Trans
6. AUTHOR(S)
M. Deru, Ph.D.
7. PERFORMING ORGANIZATION NAME(S) AND ADDRESS(ES)
National Renewable Energy Laboratory
1617 Cole Blvd.
Golden, CO $80401-3393$

9. SPONSORING/MONITORING AGENCY NAME(S) AND ADDRESS(ES)

5. FUNDING NUMBERS

BEC3.4005

8. PERFORMING ORGANIZATION REPORT NUMBER NREL/TP-550-33954

10. SPONSORING/MONITORING AGENCY REPORT NUMBER

\section{SUPPLEMENTARY NOTES}

12a. DISTRIBUTION/AVAILABILITY STATEMENT

National Technical Information Service

12b. DISTRIBUTION CODE

U.S. Department of Commerce

5285 Port Royal Road

Springfield, VA 22161

13. ABSTRACT (Maximum 200 words) An important factor in soil heat transfer that is often over looked is the effect of moisture, which can vary the effective thermal conductivity by a factor of ten. The objective of this research was to investigate the groundcoupled heat and moisture transfer from buildings, and to develop results and tools to improve energy simulation of groundcoupled heat transfer.

14. SUBJECT TERMS

15. NUMBER OF PAGES

ground-coupled heat transfer; heat transfer; buildings; thermal conductivity; moisture transfer.

16. PRICE CODE

17. SECURITY CLASSIFICATION OF REPORT Unclassified
18. SECURITY CLASSIFICATION OF THIS PAGE Unclassified
19. SECURITY CLASSIFICATION OF ABSTRACT

Unclassified
20. LIMITATION OF ABSTRACT

UL 